Ana Paula Morais Krelling

\title{
The Potiguar Eddy: a subsurface anticyclone associated with the North Brazil Undercurrent at $4^{\circ} \mathrm{S}$
}

Thesis presented to the Oceanographic Institute of the University of São Paulo and the School for Marine Science and Technology of the University of Massachusetts as part of the requirements for the title of Doctor of Science, program of Oceanography, Physical Oceanography area.

USP Advisor: Prof. Dr. Ilson Carlos Almeida da Silveira UMASS Advisor: Prof. Dr. Avijit Gangopadhyay

São Paulo 


\author{
Universidade de São Paulo \\ Instituto Oceanográfico \\ University of Masachussetts \\ School for Marine Science and Technology
}

The Potiguar Eddy: a subsurface anticyclone associated with the North Brazil

Undercurrent at $4^{\circ} \mathrm{S}$

Ana Paula Morais Krelling

Thesis presented to the Oceanographic Institute of the University of São Paulo and the School for Marine Science and Technology of the University of Massachusetts as part of the requirements for the title of Doctor of Science, program of Oceanography, Physical Oceanography area.

Evaluated on __ I _ I

Prof. Dr.

Grade

Prof. Dr.

Grade

Prof. Dr.

Grade

Prof. Dr.

Grade

Prof. Dr.

Grade 


\section{Contents}

$\operatorname{Resumo} \ldots \ldots \ldots \ldots \ldots \ldots \ldots \ldots \ldots \ldots \ldots \ldots$. . . . . . . . . . . . . . .

Abstract . . . . . . . . . . . . . . . xix

$\begin{array}{lll}1 & \text { Introduction } & 1\end{array}$

1.1 Equatorial Current System $\ldots \ldots \ldots \ldots$

1.2 The Origins of the North Brazil Undercurrent $\ldots \ldots \ldots \ldots$

1.3 NBUC Characterization . . . . . . . . . . . . . . . . . . . . . . 4

1.4 The cSEC and its Influence on the NBUC $\ldots \ldots \ldots \ldots \ldots$

1.5 The NBUC North of $5^{\circ} \mathrm{S} \ldots \ldots \ldots \ldots$

1.6 Dissertation Hypothesis $\ldots \ldots \ldots \ldots$

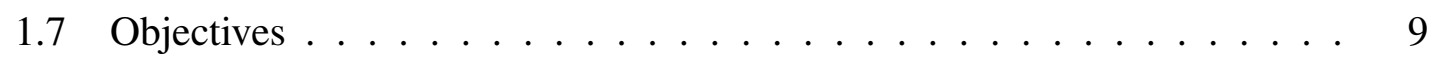

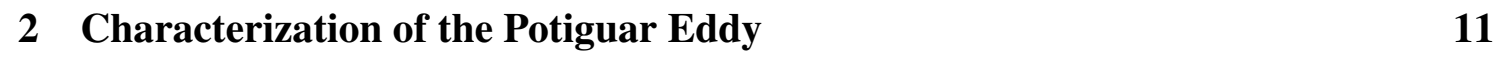

2.1 Data set . . . . . . . . . . . . . . . . . 11

2.2 Results . . . . . . . . . . . . . . . . . . . . . . . 15

2.2 .1 VMADCP Vertical Sections . . . . . . . . . . . . . . . 21

2.2 .2 The Rossby and Burger Numbers $\ldots \ldots \ldots \ldots \ldots$

2.2 .3 Geostrophic Fields in the PE Region . . . . . . . . . . . . 32

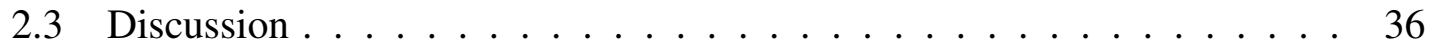

\begin{tabular}{|lll}
\hline 3 & Temporal Variability & 41
\end{tabular}

3.1 Data sets . . . . . . . . . . . . . . . . . . . . 41

$3.1 .1 \quad$ Mooring Data $\ldots \ldots \ldots \ldots \ldots \ldots \ldots$

3.1 .2 Numerical Model Outputs . . . . . . . . . . . . . . . . . 43

3.1 .3 Altimetry Data . . . . . . . . . . . . . . . . . 43 
3.2 Observed Intraseasonal Variability $\ldots \ldots \ldots$. . . . . . . . . . . . . 44

3.2.1 Current meter mooring mean patterns . . . . . . . . . . . 44

3.2.2 Current Meter Mooring Time Series Analysis . . . . . . . . . . . 45

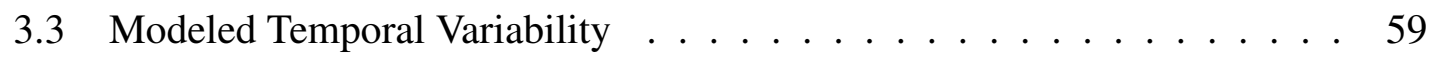

3.3 .1 Model Validation . . . . . . . . . . . . . . . . . . . . 59

3.3.2 Analysis of the HYCOM Model Time Series . . . . . . . . . . 62

3.4 Discussion . . . . . . . . . . . . . . . . . . 70

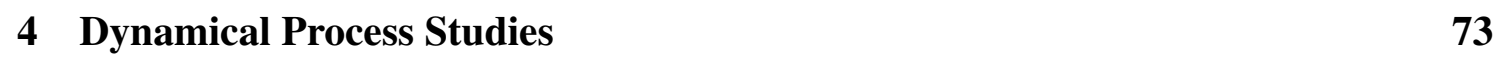

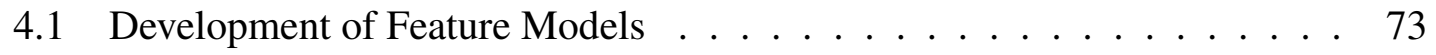

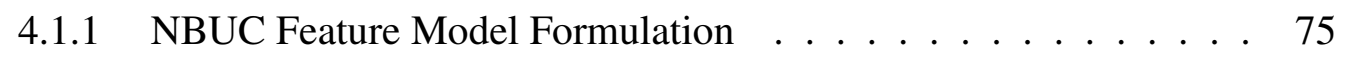

4.1 .2 DWBC Feature Model Formulation . . . . . . . . . . . . . . 83

4.2 Numerical experiments set-up . . . . . . . . . . . . . . . . . 91

$4.3 \quad$ Calibration of Numerical Model and Sensitivity

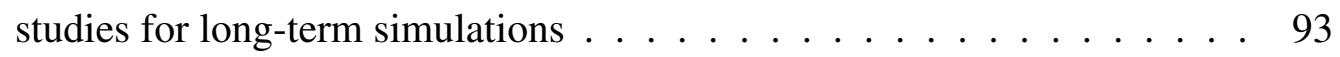

4.4 Model results . . . . . . . . . . . . . . . . . . . . . . . 96

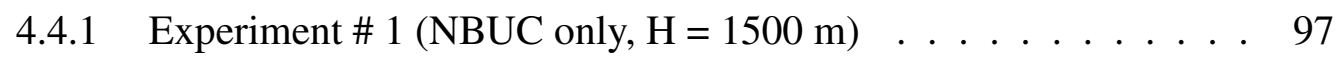

4.4 .2 Experiment \# 2 (NBUC + DWBC, $\mathrm{H}=5500 \mathrm{~m})$. . . . . . . 108

4.5 Discussion . . . . . . . . . . . . . . . . . . . . . . . 119

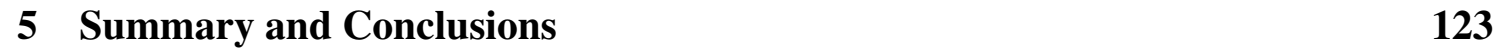

References. . . . . . . . . . . . . . . . . . . . 127 


\section{List of Figures}

$1.1 \quad$ Schematic map of the currents in the upper Western Equatorial Atlantic

\begin{tabular}{|c|}
\hline Ocean. Solid lines represent surface-intensified currents, and dashed lines, \\
\hline
\end{tabular} subsurface currents. Shown are the South Equatorial Countercurrent (SECC), central, equatorial and north branches of the South Equatorial Current (cSEC, eSEC and nSEC, respectively), South Equatorial Undercurrent (SEUC), Equatorial Undercurrent (EUC), North Equatorial Undercurrent (NEUC), North Equatorial Countercurrent (NECC), and North Brazil Current (NBC). Based on Goes et al (2005), Stramma and Schott (1999) and Schott et al (1998). . . . . . . . . . . . . . . . . 2

1.2 Mean $35^{\circ} \mathrm{W}$ velocity section from Schott et al (2003) (from 13 sections). Shown are the North Brazil Current (NBC), South Equatorial Current (SEC), South Equatorial Undercurrent (SEUC), South Intermediate Countercurrent (SICC), Equatorial Undercurrent (EUC), Equatorial intermediate Current (EIC), North Intermediate Countercurrent (NICC), upper, middle and lower North Atlantic Deep Water (uNADW, mNADW and INADW, respectively), and Antarctic Bottom Water (AABW). Positive values indicate eastward flow . . . . . . . . . . . . . . . 7

2.1 Trajectory of the vessel while acquiring ADCP data and location of CTD stations during ONEI (February $26^{\text {th }}$ - March $21^{\text {st }}$ 2002, left panel) and ONEII (October $26^{\text {th }}$ - December $20^{\text {th }} 2004$, right panel) cruises. Light gray areas indicate regions shallower than $60 \mathrm{~m}$. 
2.2 Temperature and ADCP velocity vectors at $32 \mathrm{~m}$ (left panel) and $144 \mathrm{~m}$ (right panel) during ONEI. Light gray areas indicate regions shallower than $60 \mathrm{~m} . \ldots \ldots \ldots \ldots$

2.3 Temperature and ADCP velocity vectors at $32 \mathrm{~m}$ (left panel) and $144 \mathrm{~m}$ (right panel) during ONEII. Light gray areas indicate regions shallower than $60 \mathrm{~m} . \ldots \ldots \ldots \ldots$

2.4 Salinity and ADCP velocity vectors at $32 \mathrm{~m}$ (left panel) and $144 \mathrm{~m}$ (right panel) during ONEI. Light gray areas indicate regions shallower than $60 \mathrm{~m} .17$

2.5 Salinity and ADCP velocity vectors at $32 \mathrm{~m}$ (left panel) and $144 \mathrm{~m}$ (right \begin{tabular}{|c|c|}
\hline panel) during ONEII. Light gray areas indicate regions shallower than 60 \\
\hline
\end{tabular} m. ............................ 17

2.6 Potential density and ADCP velocity vectors at $32 \mathrm{~m}$ (left panel) and 144 m (right panel) during ONEI. Light gray areas indicate regions shallower than $60 \mathrm{~m} . \ldots \ldots \ldots \ldots$

$2.7 \quad$ Potential density and ADCP velocity vectors at $32 \mathrm{~m}$ (left panel) and 144 $\mathrm{m}$ (right panel) during ONEII. Light gray areas indicate regions shallower than $60 \mathrm{~m} . \ldots \ldots \ldots \ldots$

2.8 ADCP-derived streamfunction distribution during ONEI (February - March $2002)$ at $32 \mathrm{~m}(\approx$ surface, upper panel) and $144 \mathrm{~m}(\approx$ depth of the PE core, lower panel) depth. . . . . . . . . . . . . . . . . 20

2.9 ADCP-derived streamfunction distribution during ONEII (October - December 2004) at $32 \mathrm{~m}(\approx$ surface, upper panel) and $144 \mathrm{~m}(\approx$ depth of the PE core, lower panel) depth. . . . . . . . . . . . . . . . . . 20

2.10 ADCP velocity sections 1 (top panel), 2 (middle panel) and 3 (bottom panel) from ONEI cruise (February - March 2002). Values are in $\mathrm{m} . \mathrm{s}^{-1}$. Dashed velocities are northward. The $\sigma_{0}=24.5 \mathrm{~kg} . \mathrm{m}^{-3}$ and $\sigma_{0}=26.8$ $\mathrm{kg} \cdot \mathrm{m}^{-3}$ isopycnals are plotted. Shaded areas indicate regions where the percent good from the ADCP data was lower than 50. . . . . . . . . . . 22 
2.11 ADCP velocity sections 4 (top panel), 5 (second panel), 6 (third panel) and 7 (bottom panel) from ONEI cruise (February - March 2002). Values are in $\mathrm{m} . \mathrm{s}^{-1}$. Dashed velocities are northward. The $\sigma_{0}=24.5 \mathrm{~kg} . \mathrm{m}^{-3}$ and $\sigma_{0}=26.8 \mathrm{~kg} \cdot \mathrm{m}^{-3}$ isopycnals are plotted. Shaded areas indicate regions where the percent good from the ADCP data was lower than 50. . . . . . 23

2.12 ADCP velocity section 8 from ONEI cruise (February - March 2002).

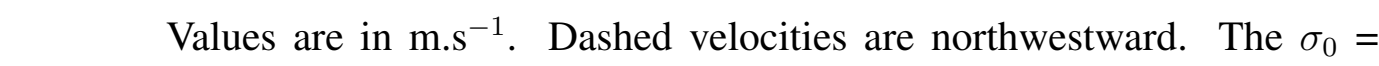
$24.5 \mathrm{~kg} . \mathrm{m}^{-3}$ and $\sigma_{0}=26.8 \mathrm{~kg} \cdot \mathrm{m}^{-3}$ isopycnals are plotted. Shaded areas indicate regions where the percent good from the ADCP data was lower

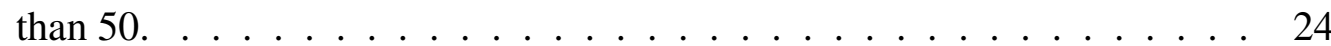

2.13 ADCP velocity sections 1 (top panel) and 2 (bottom panel) from ONEII

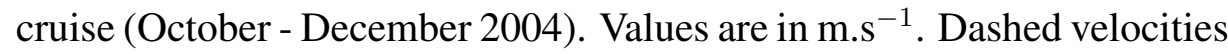
are northward. The $\sigma_{0}=24.5 \mathrm{~kg} \cdot \mathrm{m}^{-3}$ and $\sigma_{0}=26.8 \mathrm{~kg} \cdot \mathrm{m}^{-3}$ isopycnals are plotted. Shaded areas indicate regions where the percent good from the ADCP data was lower than $50 . \ldots \ldots$. . . . . . . . . . . . 24

2.14 ADCP velocity sections 3 (top panel) and 4 (bottom panel) from ONEII cruise (October - December 2004). Values are in ${\mathrm{m} . \mathrm{s}^{-1}}^{-}$. Dashed velocities are northward. The $\sigma_{0}=24.5 \mathrm{~kg} \cdot \mathrm{m}^{-3}$ and $\sigma_{0}=26.8 \mathrm{~kg} \cdot \mathrm{m}^{-3}$ isopycnals are plotted. Shaded areas indicate regions where the percent good from the ADCP data was lower than $50 . \ldots \ldots$. . . . . . . . . . . . 26

2.15 ADCP velocity sections 5 (top panel), 6 (second panel), 7 (third panel), and 8 (bottom panel) from ONEII cruise (October - December 2004). Values are in ${\mathrm{m} . \mathrm{s}^{-1}}$. Dashed velocities are northward. The $\sigma_{0}=24.5 \mathrm{~kg} . \mathrm{m}^{-3}$ and $\sigma_{0}=26.8 \mathrm{~kg} \cdot \mathrm{m}^{-3}$ isopycnals are plotted. Shaded areas indicate regions where the percent good from the ADCP data was lower than 50. . . 27

2.16 ADCP velocity section 9 from ONEII cruise (October - December 2004). Values are in $\mathrm{m} \cdot \mathrm{s}^{-1}$. Dashed velocities are northwestward. The $\sigma_{0}=$ $24.5 \mathrm{~kg} \cdot \mathrm{m}^{-3}$ and $\sigma_{0}=26.8 \mathrm{~kg} \cdot \mathrm{m}^{-3}$ isopycnals are plotted. Shaded areas indicate regions where the percent good from the ADCP data was lower than $50 . \ldots \ldots \ldots \ldots \ldots$ 
2.17 ADCP velocity sections 10 (top panel), 11 (second panel), 12 (third panel), and 13 (bottom panel) from ONEII cruise (October - December 2004). Values are in $\mathrm{m} . \mathrm{s}^{-1}$. Dashed velocities are northwestward. The $\sigma_{0}=24.5$ kg.m ${ }^{-3}$ and $\sigma_{0}=26.8 \mathrm{~kg} . \mathrm{m}^{-3}$ isopycnals are plotted. Shaded areas indicate regions where the percent good from the ADCP data was lower than

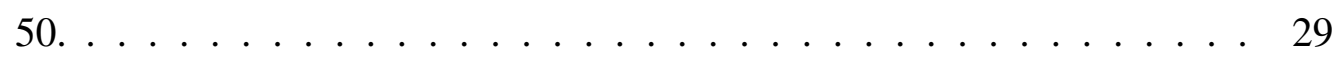

2.18 Map with the ADCP-derived velocity vectors at $150 \mathrm{~m}$ for ONEII cruise (October - December 2004). The area used for the Rossby number calculation is in blue. . . . . . . . . . . . . . . . . . . . 31

2.19 Comparison between the geostrophic velocity referenced to the $\sigma_{1}=32.15$ kg.m ${ }^{-3}$ isopycnal (middle and bottom panels) and ADCP velocity (top

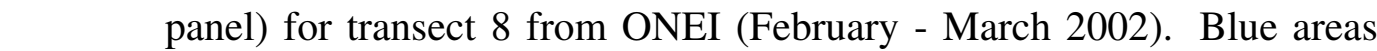
indicate west/northwestward velocities, red areas indicate east/southeast velocities. The shaded area on the top panel indicates areas with percent good lower than 50. The shaded area on the middle and bottom panels indicates the portion of the plot which is generated by extrapolation. Inverted triangles indicate the location of oceanographic stations. The isopycnals $\sigma_{\theta}=24.5 \mathrm{~kg} \cdot \mathrm{m}^{-3}$ and $\sigma_{\theta}=26.8 \mathrm{~kg} \cdot \mathrm{m}^{-3}$ are also shown. . . . . . 33

2.20 Comparison between the geostrophic velocity referenced to the $\sigma_{1}=32.15$ kg.m ${ }^{-3}$ isopycnal (middle and bottom panels) and ADCP velocity (top panel) for transect 9 from ONEII (October - December 2004). Blue areas indicate west/northwestward velocities, red areas indicate east/southeast velocities. The shaded area on the top panel indicates areas with percent good lower than 50. The shaded area on the middle and bottom panels indicates the portion of the plot which is generated by extrapolation. Inverted triangles indicate the location of oceanographic stations. The isopycnals $\sigma_{\theta}=24.5 \mathrm{~kg} \cdot \mathrm{m}^{-3}$ and $\sigma_{\theta}=26.8 \mathrm{~kg} \cdot \mathrm{m}^{-3}$ are also shown. . . . . . 34

3.1 Location of the PBM1 and PBM2 moorings, with the mean velocity vectors for $44 \mathrm{~m}$ (blue) and $144 \mathrm{~m}$ (red). . . . . . . . . . . . . . . . . 42 
3.2 Mean cross-shore (left) and alongshore (right) profiles for mooring PBM1. Pos-

itive values of cross-shore (alongshore) velocity indicate northeastward (southeastward) flow . . . . . . . . . . . . . . . . . . . . . . 44 4

3.3 Mean cross-shore (left) and alongshore (right) profiles for mooring PBM2.

Positive values of cross-shore (alongshore) velocity indicate northeastward (southeastward) flow . . . . . . . . . . . . . . . . . 45

3.4 Explained variance of each statistical mode calculated from the observed PBM1 data and from a random time-series. The thick black line represents the explained variance for each statistical mode for the observed mooring; the thin black line represents the mean explained variance for the statistical modes of a random time-series (Montecarlo simulations). The dashed lines represent the interval of two standard deviations about the mean . . . . . . . . . . . . . . . . . . . 46

3.5 Explained variance of each statistical mode calculated from the observed PBM2 data and from a random time-series. The thick black line represents the explained variance for each statistical mode for the observed mooring; the thin black line represents the mean explained variance for the statistical modes of a random time-series (Montecarlo simulations). The dashed lines represent the interval of two standard deviations about the mean . . . . . . . . . . . . . . . . . . . . 47

3.6 Vertical structure of the first EOF for mooring PBM1 (top panel) and amplitude time series for the first EOF mode for PBM1 (bottom panel). . 48

$3.7 \quad$ Vertical structure of the first EOF for mooring PBM2 (top panel) and amplitude time series for the first EOF mode for PBM2 (bottom panel). . 49

3.8 Vertical structure of the second EOF for mooring PBM1 (top panel) and amplitude time series for the second EOF mode for PBM1 (bottom panel). 50

3.9 Vertical structure of the second EOF for mooring PBM2 (top panel) and amplitude time series for the second EOF mode for PBM2 (bottom panel). 51

3.10 Wavelet analysis of the amplitude time-series for the first EOF for the alongshore velocity data for PBM1. . . . . . . . . . . . . . 52 
3.11 Wavelet analysis of the amplitude time-series for the first EOF for the alongshore velocity data for PBM2. . . . . . . . . . . . 53

3.12 Vertical structure of the barotropic and first three baroclinic modes for mooring PBM1. . . . . . . . . . . . . . . . 53

3.13 Vertical structure of the barotropic and first three baroclinic modes for mooring PBM2. . . . . . . . . . . . . . . . . . . . . . 54

3.14 Projection of the dynamical modes onto the first EOF for mooring PBM1. 55

3.15 Projection of the dynamical modes onto the first EOF for mooring PBM2. 56

3.16 Dispersion relation for second-mode baroclinic Rossby Waves. The black bar denotes the frequency corresponding to the period of 35 days, as estimated from the currentmeter mooring time series. The black cross denotes the period of 33.8 days depicted from the altimeter data analysis.

3.17 Time-Longitude diagram 33-day waves along $4^{\circ} \mathrm{S}$ from AVISO altimetric Sea Surface Height data (in meters). . . . . . . . . . . . . . . . 58

3.18 Mean (2003-2011) streamfunction map from HYCOM results at $150 \mathrm{~m}$ depth. . . . . . . . . . . . . . . . 60

3.19 Map with the mean (2003-2011) velocity vectors at $150 \mathrm{~m}$ for HYCOM results. The area used on the calculation of the Rossby number is in blue. 61

3.20 Mean (2003-2011) cross-eddy velocity section from HYCOM results. Dashed velocities are northwestward. The $\sigma_{0}=24.5 \mathrm{~kg} . \mathrm{m}^{[\text {Pleaseinsertintopreamble }] 3}$ and $\sigma_{0}=26.8 \mathrm{~kg} \cdot \mathrm{m}^{[\text {Pleaseinsertintopreamble }]} 3$ isopycnals are plotted. $\ldots . . . . . .662$

3.21 Mean cross-shore (left) and alongshore (right) profiles for PBM1 synthetic mooring. Positive values of cross-shore (alongshore) velocity indicate northeastward (southeastward) flow. . . . . . . . . . . . . . . . 63

3.22 Mean cross-shore (left) and alongshore (right) profiles for PBM2 synthetic mooring. Positive values of cross-shore (alongshore) velocity indicate northeastward (southeastward) flow. . . . . . . . . . . . . . . . 63 
3.23 Explained variance of each statistical mode calculated from the synthetic PBM1 and from a random time-series. The thick black line represents the explained variance for each statistical mode for the observed mooring; the thin black line represents the mean explained variance for the statistical modes of a random time-series (Montecarlo simulations). The dashed lines represent the interval of two standard deviations about the mean. . . 64

3.24 Explained variance of each statistical mode calculated from the synthetic PBM2 and from a random time-series. The thick black line represents the explained variance for each statistical mode for the observed mooring; the thin black line represents the mean explained variance for the statistical modes of a random time-series (Montecarlo simulations). The dashed lines represent the interval of two standard deviations about the mean. . . 65

3.25 Vertical structure of the first EOF for synthetic mooring PBM1. . . . . . . 66

3.26 Vertical structure of the first EOF for synthetic mooring PBM2. . . . . . . 67

3.27 Vertical structure of the second EOF for synthetic mooring PBM1. . . . . . 67

3.28 Vertical structure of the second EOF for synthetic mooring PBM2. . . . . 68

3.29 Fit of annual and semi-annual signals on the amplitude time series for the first (top panel) and second (bottom panel) EOF for synthetic mooring PBM1. . . . . . . . . . . . . . . . . . . . 69

4.1 Feature Model Characteristics based on ONEI measurements. Upper panel: cross section velocity at section 6 of ONEI (Feb-Mar, 2002). Middle panel: observed (solid line) and FM (dashed line) velocity profile at the location indicated by the vertical black line on the upper panel. Lower panel: observed (solid line) and FM (dashed line) horizontal velocity distribution at the depth indicated by the horizontal black line on the upper panel. Positive velocities indicate northward flow. . . . . . . . . . . . 78 
4.2 Feature Model Characteristics based on ONEII measurements. Upper panel: cross section velocity at section 5 of ONEII (Oct-Dec, 2004). Mid-

dle panel: observed (blue line) and FM (red line) velocity profile at the location indicated by the vertical black line on the upper panel. Lower panel: observed (solid line) and FM (dashed line) horizontal velocity distribution at the depth indicated by the horizontal black line on the upper panel. Positive velocities indicate northward flow. . . . . . . . . . . . 79

4.3 Sections in which the NBUC FM was calculated. . . . . . . . . . . . 80

4.4 Velocity section 1 (southernmost) of the NBUC FM. . . . . . . . . 81

4.5 Velocity section 44 (northernmost) of the NBUC FM. . . . . . . . . . . . 82

4.6 FM-derived potential temperature field of the NBUC FM for the entire domain at the surface (top panel) and $200 \mathrm{~m}$ (bottom panel). Superimposed are the FM-derived velocity vectors for NBUC. $\ldots \ldots \ldots$

4.7 Salinity field of the NBUC FM for the entire domain at the surface (top panel) and $200 \mathrm{~m}$ (bottom) panel) (from WOA (2013)). . . . . . . . . . . 87

4.8 Velocity section 1 (southernmost) of the NBUC + DWBC FMs. . . . . . . 88

4.9 Velocity section 44 (northernmost) of the NBUC + DWBC FMs. . . . . . 89

4.10 Upper panel: mean of 5 sections at $5^{\circ} \mathrm{S}$. Lower panel: mean of 9 sections at $11^{\circ}$ S. Image from Schott et al. (2005). . . . . . . . . . . . . . 90

4.11 Transport values imposed on the edges of the domain for Experiment \# 1.91

4.12 Transport values imposed on the edges of the domain for Experiment \# 2. 92

4.13 Time evolution of domain-averaged kinetic energy for Experiment \# 1 . Note that the dynamical equilibrium of the simulation is reached after about 100 days. . . . . . . . . . . . . . . . 97

4.14 Velocity and temperature fields on day 101 at the surface for Experiment

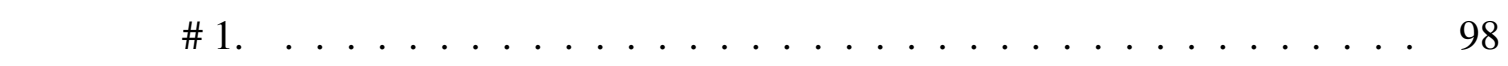

4.15 Evolution of the temperature and velocity fields at $200 \mathrm{~m}$ during Experi-

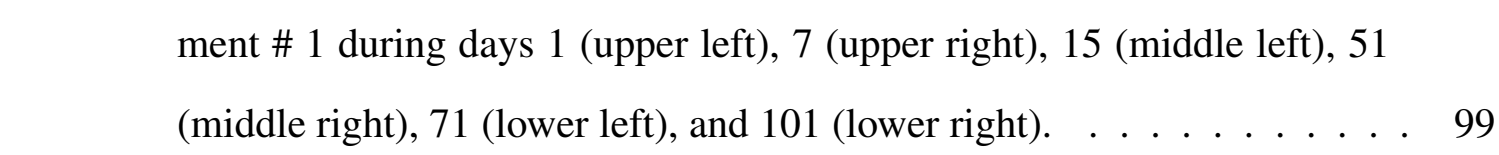


4.16 Evolution of the velocity field over a cross-eddy section during Experiment \# 1 during days 1 (upper left), 7 (upper right), 15 (middle left), 51 (middle right), 71 (lower left), and 101 (lower right). . . . . . . . . . . 100

4.17 Evolution of the temperature field over a cross-eddy section during Experiment \# 1 during days 1 (upper left), 7 (upper right), 15 (middle left), 51 (middle right), 71 (lower left), and 101 (lower right). . . . . . . . . 101

4.18 Mean cros-section for Experiment \# 1, over days 201-360. . . . . . . . . 102

4.19 Velocity and temperature fields on day 101 at $500 \mathrm{~m}$ for Experiment \# 1. 103

4.20 Velocity and temperature fields on day 101 at $900 \mathrm{~m}$ for Experiment \# 1. . 104

4.21 Velocity and temperature fields on day 101 at $1000 \mathrm{~m}$ for Experiment \# 1.105

4.22 Evolution of the relative vorticity field at $200 \mathrm{~m}$ during Experiment \# 1 \begin{tabular}{|c|}
\hline during days 1 (upper left), 7 (upper right), 15 (middle left), 51 (middle \\
\hline
\end{tabular} right), 71 (lower left), and 101 (lower right). . . . . . . . . . . . . . 106

4.23 Evolution of the relative vorticity field at $200 \mathrm{~m}$ during Experiment \# 1 during days 1 (upper left), 7 (upper right), 15 (middle left), 51 (middle right), 71 (lower left), and 101 (lower right). . . . . . . . . . . . . . . 107

4.24 Time evolution of domain-averaged eddy kinetic energy for Experiment

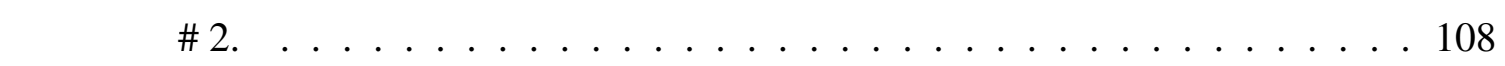

4.25 Evolution of the temperature and velocity fields at $200 \mathrm{~m}$ during Experi-

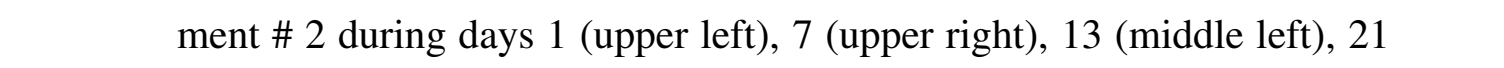
(middle right), 25 (lower left), and 121 (lower right). . . . . . . . . . . 109

4.26 Evolution of the velocity field over a cross-eddy section during Experiment \# 2 during days 1 (upper left), 7 (upper right), 13 (middle left), 21 (middle right), 25 (lower left), and 121 (lower right). . . . . . . . 110

4.27 Evolution of the temperature field over a cross-eddy section during Experiment \# 2 during days 1 (upper left), 7 (upper right), 13 ( middle left), 21 (middle right), 25 (lower left), and 121 (lower right). . . . . . . . . . . 112

4.28 Mean cros-section for Experiment \# 2, over days 101-361. . . . . . . . . 113

4.29 Mean cros-section for Experiment \# 2, over days 101-361 (Same as Figure

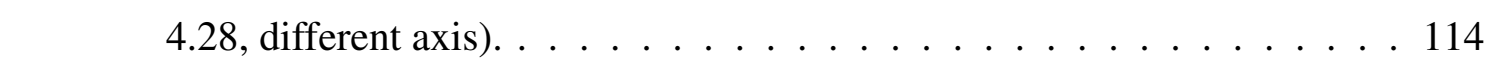


4.30 Velocity and temperature fields on day 121 at $1 \mathrm{~m}$ (top panel) and $500 \mathrm{~m}$ (bottom panel) for Experiment \# 2. . . . . . . . . . . . . . . . 115

4.31 Velocity and temperature fields on day 121 at $1000 \mathrm{~m}$ (top panel) and $2000 \mathrm{~m}$ (bottom panel) for Experiment \# 2. . . . . . . . . . . . . . 116

4.32 Evolution of the relative vorticity field at $200 \mathrm{~m}$ during Experiment \# 2 during days 1 (upper left), 7 (upper right), 13 (middle left), 21 (middle right), 25 (lower left), and 121 (lower right). . . . . . . . . . . . . 117

4.33 Evolution of the relative vorticity field at $200 \mathrm{~m}$ during Experiment \# 2 during days 1 (upper left), 7 (upper right), 13 (middle left), 21 (middle right), 25 (lower left), and 121 (lower right). . . . . . . . . . . . . . 118 


\section{List of Tables}

$2.1 \quad$ Scales used for the estimation of the Rossby and Burger numbers. . . . . 25

$2.2 \quad$ Scales used for the estimation of the Rossby and Burger numbers. . . . . 32

$3.1 \quad$ Properties of the 35-day linear free second-mode Rossby waves in the Tropical Atlantic . . . . . . . . . . . . . . . . . . . . 55

4.1 Information from the data and literature for the NBUC FM formulation. . 76

4.2 Information from the literature for the DWBC FM formulation. . . . . . . 83

$4.3 \quad$ Simulations for Experiment \# 1. M3: 3D momentum; M2: 2D momentum; T: tracers (temperature and salinity). . . . . . . . . . . . . . . . . . . . . . . 94

4.4 Simulations for Experiment \# 2. M3: 3D momentum; M2: 2D momentum; T: tracers (temperature and salinity). . . . . . . . . . . . . . 95 


\section{List of Abbreviations}

\begin{tabular}{|c|c|}
\hline SEC & South Equatorial Current \\
\hline sSEC & South South Equatorial Current \\
\hline SECC & South Equatorial Countercurrent \\
\hline cSEC & Central South Equatorial Current \\
\hline SEUC & South Equatorial Undercurrent \\
\hline eSEC & Equatorial South Equatorial Current \\
\hline EUC & Equatorial Undercurrent \\
\hline nSEC & North South Equatorial Current \\
\hline NEUC & North Equatorial Undercurrent \\
\hline $\mathrm{BC}$ & Brazil Current \\
\hline NBUC & North Brazil Undercurrent \\
\hline $\mathrm{PE}$ & Potiguar Eddy \\
\hline DWBC & Deep Western Boundary Current \\
\hline ITCZ & Intertropical Convergence Zone \\
\hline CTD & Conductivity-Temperature-Depth \\
\hline $\mathrm{ADCP}$ & Acoustic Doppler Current Profiler \\
\hline VMADCP & Vessel-Mounted Acoustic Doppler Current Profiler \\
\hline SACW & South Atlantic Central Water \\
\hline $\mathrm{TW}$ & Tropical Water \\
\hline SUW & Subtropical Underwater \\
\hline AIW & Antarctic Intermediate Water \\
\hline NBC & North Brazil Current \\
\hline NADW & North Atlantic Deep Water \\
\hline CODAS & Common Ocean Data Access System \\
\hline HYCOM & Hybrid Coordinate Ocean Model \\
\hline
\end{tabular}


ROMS

FM

WOA
Regional Ocean Modelling System

Feature Model

World Ocean Atlas 


\section{Acknowledgments}

I thank both my advisors for being so kind as to share their expertise with me, for all their patience, and mostly for never giving up on me - I am quite sure they have considered it once or twice. I would also like to thank CNPq for funding my research for the last four years, and PETRÓLEO BRASILEIRO S.A., specially Renato Parkinson and José Antônio Lima, for kindly allowing me to analyze their data for this dissertation.

I thank the awesome people from PuBBoston, IEAPM, and SMAST for the very warm welcome, great moments spent together and all the help received. I specially thank Rafael Soutelino for the huge help while I was in Arraial do Cabo.

I thank the academic 'Moms' and 'Dads' that I was fortunate enough to acquire during my undergraduate as well as graduate school, for always being so kindly concerned with my personal as well as professional well-being, following up and giving me so much incentive and inspiration. Really, thank you. I thank specially Odete Silveira (In Memoriam) for being one of the people who inspired me the most to pursue my professional dreams. Odete, you will be greatly missed.

I thank the professors from IOUSP and SMAST for the great lectures, courses and conversation, specially Dr. Paulo Polito.

I thank all UMASS and IOUSP staff. The absence of your help would have made my job much harder.

The continuous support from my unbelievably awesome friends from Belém, Rio de Janeiro and São Paulo was also very important for this accomplishment. Aditionally, there are some few very inspiring people with whom I had only a brief contact but truly inspired me very much, such as Trenton, Isabela and Hafizh. I thank you very, very much for your inspiration in times during which I really, really needed.

Last but definitely not least, I thank the most wonderful, loving and supporting parents of the entire universe: mine. I'm sorry about the bad moments during these four years and I'm very, very grateful for your unconditional support. There is no way this work could be dedicated to anyone but you. 
xvii

"But [life] ain't about how hard you hit, it's about how hard you can get hit and keep moving forward."

\section{Rocky Balboa}

"The greater our knowledge increases, the more our ignorance unfolds."

John F. Kennedy 


\section{Resumo}

Nesta tese descrevemos o Vórtice Potiguar (VP): um meandro frontal da Subcorrente Norte do Brasil (SNB) recentendemente identificado na costa nordeste brasileira, com núcleo em aproximadamente $4^{\circ} \mathrm{S}$ e $36,5^{\circ} \mathrm{W}$. O VP tem formato elíptico com maior e menor eixos medindo 330 e $130 \mathrm{~km}$, aproximadamente, intensificado em subsuperfície. O vórtice se estende verticalmente de 100 a 400 metros, com velocidades máximas de $0,6 \mathrm{~m} \cdot \mathrm{s}^{-1}$, recirculando cerca de $2 \mathrm{~Sv}$ das águas da SNB. Apesar da presença do vórtice na termoclina, o fluxo em superfície é para noroeste durante todo o ano. A análise da variabilidade da velocidade coletada em fundeio na Bacia Potiguar revela dois principais modos estatísticos de variabilidade; um com maiores amplitudes na porção da coluna dágua correspondente ao VP, e um outro modo, que explica menor porcentagem da variância da série de dados original, associado a processos ligados à camada de superfície. O primeiro EOF é associado a oscilações baroclínicas com períodos de 25 a 35 dias. Este sinal também é identificado em altimetria no Atlântico. Nós caracterizamos esses sinais como expressão de ondas de Rossby, e especulamos que o gatilho para a geração das mesmas seria instabilidade barotrópica gerada pelo cisalhamento de correntes no Atlântico Tropical.

Adicionalmente, com o intuito de analisar o processos de geração do VP, nós desenvolvemos modelos de feição da SBN e Corrente Profunda de Contorno Oeste (CCP), para serem usados como base para o deselvolvimento do campo inicial para simulações de modelagem numérica em uma abordagem de estudo de processo dinâmico. Os Modelos de Feição, desenvolvidos a partir de dados de velocidade, com densidade e temperatura calculados a partir da relação do vento térmico e salinidade da climatologia WOA (2013), capturam os principais atributos das feições de interesse com sucesso, sendo adequados para a investigação das principais características do campo de correntes na Bacia Potiguar.

Dois numéricos experimentos foram realizados: (i) Somente SNB, com profundidade máxima de 1500 m, e (ii) SNB + CCP, com profundidade máxima de $5500 \mathrm{~m}$. O VP foi gerado em ambos os experimentos, com velocidade máxima, profundidade do núcleo e tamanho consistentes com observações sinóticas. Assim, temos que o VP pode ser gerado em um campo de velocidades contendo somente a SNB, e que o cisalhamento vertical induzido pela presença da CCP parece ter um papel importante nas características do mesmo (extensão vertical, velocidades máximas, etc, etc), uma vez que o VP teve um processo de formação diferente em cada experimento.

Palavras Chave: Mesoescala, Vórtice, Subcorrente Norte do Brasil. 


\section{Abstract}

In this dissertation we describe a newly discovered subsurface frontal meander of the North Brazil Undercurrent (NBUC), centered at about $4{ }^{\circ} \mathrm{S}, 36.5^{\circ} \mathrm{W}$, hereafter Potiguar Eddy (PE). The Potiguar Eddy is an elliptically-shaped eddy, with major and minor axes of approximately 330 and $130 \mathrm{~km}$, with a subsurface signature. It extends vertically from $100 \mathrm{~m}$ to $400 \mathrm{~m}$, with maximum velocities of $0.6 \mathrm{~m} . \mathrm{s}^{-1}$ and recirculates about $2 \mathrm{~Sv}$ of waters from the NBUC. Despite the presence of the PE in subtermocline waters, the surface flow is northwestward throughout the year. The analysis of variability of mooring velocity data in the Potiguar Bight revealed two most important statistical modes of variability (EOFs); one with high amplitudes over most of the portion of the water column which corresponds to the PE, and another one, explaining a lower percentage of the variance, associated with upper-layer processes. The first EOF mode is found to be associated with baroclinic oscillations with periods of about 25-35 days. This signal is also seen in altimetric fields in the Atlantic Ocean. We characterize these signals as Rossby waves, and speculate that the trigger for their generation would be barotropic instability generated by the current shear in the Tropical Atlantic Ocean.

Aditionally, with the intent of analyzing the generation process of the PE, we developed Feature Models of the NBUC and Deep Western Boundary Current (DWBC), to be used as basis for developing the initial field for numerical model simulations in a dynamical process-study approach. The Feature Models, developed from observed velocity data, with temperature calculated through the thermal wind equation, and salinity from WOA (2013) climatology, successfully capture the main attributes of the features of interest, and thus are suitable for the investigation of the main characteristics of the flow in the Potiguar Bight.

Two numerical experiments were set up; (i) a NBUC-only experiment, with maximum depth of $1500 \mathrm{~m}$, and (ii) a NBUC-DWBC experiment, with a maximum depth of $5500 \mathrm{~m}$. The Potiguar Eddy was formed in both experiments, with maximum velocity, core depth and size consistent with synoptic observations. As a result, the PE can be generated by a velocity field containing only the NBUC; and the DWBC - induced vertical shear seems to play a part on the eddy's characteristics (vertical extent, maximum velocities, etc), since the PE had different formation processes in the two experiments.

Keywords: Mesoscale, Eddy, North Brazil Undercurrent. 


\section{Chapter 1}

\section{Introduction}

This dissertation analyzes the Potiguar Eddy, a subsurface anticyclone within the North Brazil Undercurrent domain, on the northeast coast of South America. In the following sections, we describe the main characteristics of the current field in the area, stressing the ones that might influence the Potiguar Eddy. In this Chapter we also state our goals and scientific hypothesis for the present work.

\subsection{Equatorial Current System}

The South Equatorial Current (SEC) crosses the Atlantic Ocean zonally westward, meridionally extending from about $20^{\circ} \mathrm{S}$ to $4^{\circ} \mathrm{N}$ (LUMPKIN and GARZOLI, 2005). Because of its meridional extent, the SEC is divided into three branches by Molinari (1982) and four branches by Stramma and Schott (1999). Here, we will use the division proposed by the latter authors (Figure 1.1):

- South South Equatorial Current (sSEC): The SSEC is the portion of the SEC which extends from about $8^{\circ} \mathrm{S}$ to $20^{\circ} \mathrm{S}$, located south of the South Equatorial Counter Current (SECC) (LUMPKIN and GARZOLI, 2005).

- Central South Equatorial Current (cSEC): The cSEC is the portion of the SEC located north of the SECC and south of the South Equatorial Undercurrent (SEUC), centered at about $4^{\circ} \mathrm{S}$, reaching $34 \pm 5 \mathrm{~cm} \cdot \mathrm{s}^{-1}$ velocities at $30^{\circ} \mathrm{W}$ (LUMPKIN and GARZOLI, 2005) with a transport of about 29 Sv (SILVEIRA et al., 1994). 
- Equatorial South Equatorial Current (eSEC): The eSEC is the portion of the SEC located north of the SEUC and south of the Equatorial Undercurrent (EUC), being located along about $1-2^{\circ} \mathrm{S}$ (SCHOTT et al., 2003).

- North South Equatorial Current (nSEC): The nSEC, the only branch of the SEC located on the northern hemisphere, flows north of the EUC and south of the North Equatorial Undercurrent (NEUC). Molinari (1982) does not distinguish between eSEC and nSEC. The nSEC has velocities of about $33 \pm 11 \mathrm{~cm} \cdot \mathrm{s}^{-1}$ at $2^{\circ} \mathrm{N}$ (LUMPKIN and GARZOLI, 2005).

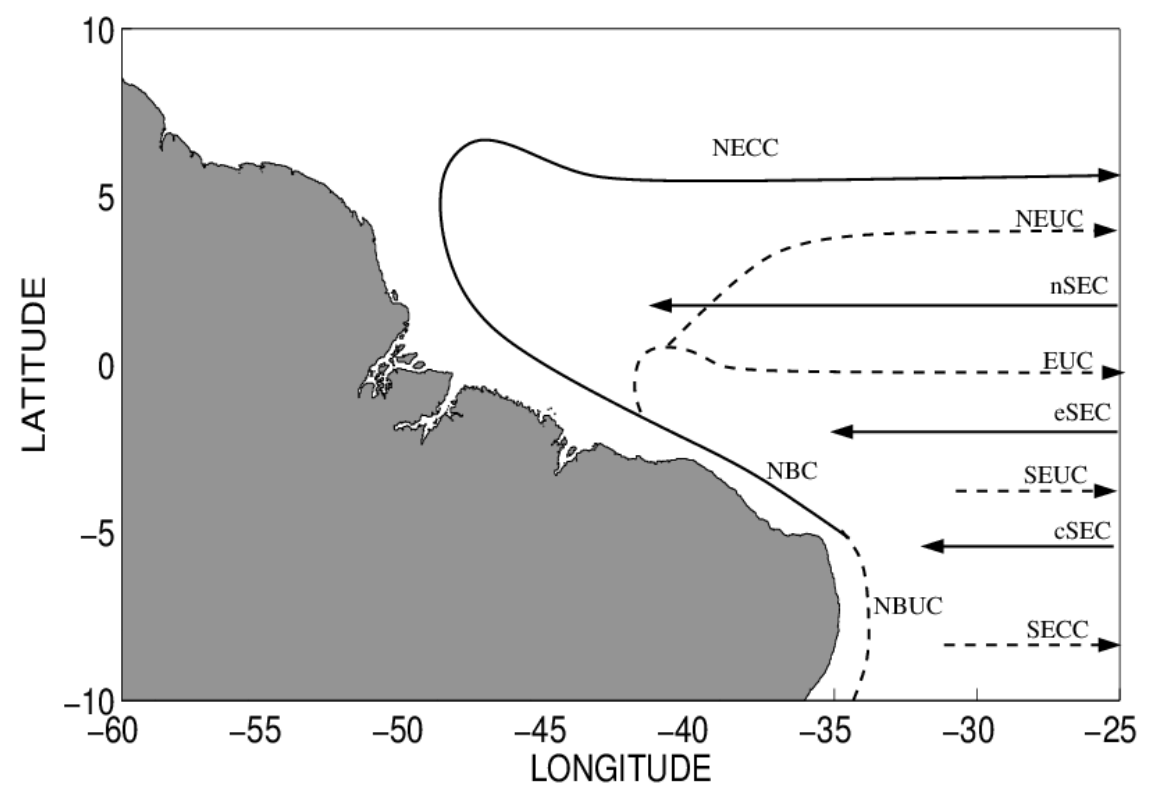

Figure 1.1: Schematic map of the currents in the upper Western Equatorial Atlantic Ocean. Solid lines represent surface-intensified currents, and dashed lines, subsurface currents. Shown are the South Equatorial Countercurrent (SECC), central, equatorial and north branches of the South Equatorial Current (cSEC, eSEC and nSEC, respectively), South Equatorial Undercurrent (SEUC), Equatorial Undercurrent (EUC), North Equatorial Undercurrent (NEUC), North Equatorial Countercurrent (NECC), and North Brazil Current (NBC). Based on Goes et al (2005), Stramma and Schott (1999) and Schott et al (1998).

The currents which separate the different branches of the SEC are mostly subsurface currents, and so the limits of most of the SEC branches are not always very clear 
at the surface. The nSEC and cSEC become clearly distinguishable, in the mean, only at about $30^{\circ} \mathrm{W}$, separated by an eastward velocity core of $6 \pm 12 \mathrm{~cm} \cdot \mathrm{s}^{-1}$ at $1^{\circ} \mathrm{S}$. However, this clear distinction does not happen with the other SEC branches. As a whole, the highest westward velocities in the SEC are at the cSEC core, at $4^{\circ} \mathrm{S}$, where they are about $34 \pm 5 \mathrm{~cm} . \mathrm{s}^{-1}$ at $30^{\circ} \mathrm{W}$, linearly decreasing to about $8 \mathrm{~cm} . \mathrm{s}^{-1}$ at $8^{\circ} \mathrm{S}$, remaining approximately at this value until $20^{\circ} \mathrm{S}$ (LUMPKIN and GARZOLI, 2005). The distinction between cSEC and eSEC is also not clear at the surface.

The variability of the SEC system is driven by i) resonant response to semiannual variations in equatorial wind forcing (PHILANDER and PACANOWSKI, 1980), and ii) annual variations in South Atlantic wind stress. The second process is important because it connects the southern hemisphere subtropical gyre to the equatorial gyre through the NBC. Both processes influence on the strength of the SEC branches (LUMPKIN and GARZOLI, 2005).

The largest values of seasonal variations occur in the nSEC, which strenghtens in boreal fall (Sep/Oct/Nov) and reverses in boreal spring (Mar/Abr/May). According to Lumpkin and Garzoli (2005), this mode corresponds to the equilibrium response to the annual variation of winds (PHILANDER and PACANOWSKI, 1980). Lumpkin and Garzoli (2005) point that specifically in the western tropics, the wind stress curl reverses in boreal spring, which forces thermocline depth changes consistent with the reversing NECC (GARZOLI and KATZ, 1983) and nSEC (KATZ, 1981). The nSEC also has high amplitudes of semiannual fluctuations (LUMPKIN and GARZOLI, 2005), which are a resonant response to the semiannual component of equatorial wind forcing in the eastern Atlantic (PHILANDER and PACANOWSKI, 1980). It is important to note that in the mean field, the nSEC feeds into the North Brazil Current (NBC) at $0-2^{\circ} \mathrm{N}$, so its reversal during boreal spring deprives the NBC of this input (LUMPKIN and GARZOLI, 2005).

\subsection{The Origins of the North Brazil Undercurrent}

The sSEC reaches the Brazillian coast at approximately $10^{\circ} \mathrm{S}$, according to $\mathrm{Pe}-$ terson and Stramma (1991), $12-20^{\circ} \mathrm{S}$, according to Stramma and Schott (1999), and ap- 
proximately $12-14^{\circ} \mathrm{S}$, on the mean, according to Lumpkin and Garzoli (2005). With the Ekman transport removed, these authors indicate that the sSEC bifurcates further south, at about $15-17^{\circ} \mathrm{S}$. At this bifurcation, the sSEC divides into a southern branch, which is called the Brazil Current (BC), and a northern branch, called the North Brazil Undercurrent (NBUC) (SILVEIRA et al., 1994).

The Rodrigues et al. (2007) numerical model results suggest that there is a seasonal variation of the position of the bifurcation, and that this variation is related to changes in the local wind stress curl due to annual north-south excursion the the Intertropical Convergence Zone (ITCZ). More specifically, their results show that as the SEC bifurcation latitude moves south (north), the NBUC transport increases (decreases) and the $\mathrm{BC}$ transport decreases (increases). The southernmost position of the bifurcation latitude, in the first $200 \mathrm{~m}$ of the water column, is reached in July $\left(\approx 17^{\circ} \mathrm{S}\right)$ and its northernmost location is reached in November $\left(\approx 13^{\circ} \mathrm{S}\right)$.

Even though the sSEC has surface expression, the Ekman drift in the region is southwestward, therefore the surface expression of the NBUC is weakened. The eastern coast of Brazil then has a subsurface-intensified boundary current, with its core located at approximately at 100-200 m depth (SILVEIRA et al., 1994).

\subsection{NBUC Characterization}

At $11^{\circ} \mathrm{S}$, the core of the NBUC is found at $200 \mathrm{~m}$ depth, with a transport of 12.3 $\mathrm{Sv}$ between the isopicnals $24.5 \mathrm{~kg} \cdot \mathrm{m}^{-3}(\approx 70 \mathrm{~m})$ and $26.8 \mathrm{~kg} \cdot \mathrm{m}^{-3}(\approx 250 \mathrm{~m})$ GOES et al., 2005). The NBUC surface-layer transport at this latitude is less than $2.5 \mathrm{~Sv}$ - evidence of its subsurface nature. From the surface down to about $1000 \mathrm{~m}$, Silveira et al. (1994) found at $10.5^{\circ} \mathrm{S}$ a total transport of $23.7 \mathrm{~Sv}$, with a $50 \mathrm{~cm} . \mathrm{s}^{-1}$ core somewhat shallower, at $150 \mathrm{~m}$ depth. The mean total NBUC transport at $11^{\circ} \mathrm{S}$ (from five realizations) is reported by Schott et al. (2005) as $25.4 \pm 7.4 \mathrm{~Sv}$ above $1100 \mathrm{~m}$.

From a 4-year-long transport time series at $11^{\circ} \mathrm{S}$, Schott et al. (2005) found a 2.5 Sv amplitude seasonal variation in the NBUC transport, with maximum northward transport in July. This corroborates the numerical results of Rodrigues et al. (2007), 
who relate the NBUC maximum transport in July to the southernmost position of the sSEC bifurcation. Variability of the NBUC at $11^{\circ} \mathrm{S}$ was also investigated by Veleda $e t$ al. (2012), who describes intraseasonal variability with periods of two-three weeks in the alongshore velocity component measurements, consistent with Coastally Trapped Wave theory.

There are no dramatic changes in the NBUC on its northward pathway. At about $5^{\circ} \mathrm{S}$, its core is still located at the subsurface, at about 100-150 m depth, with a transport of 19.9 Sv above $1000 \mathrm{~m}$ (SILVEIRA et al., 1994). At the same latitude, Schott et al. (2002) found a $25.0 \pm 4.4 \mathrm{~Sv}$ transport above $1100 \mathrm{~m}$, with only $2.7 \pm 1.8 \mathrm{~Sv}$ between the surface and the 24.5 isopicnal, and $13.4 \pm 2.7 \mathrm{~Sv}$ between 24.5 and 26.8 isopycnals, which is the density range that feeds the EUC (SCHOTT et al., 1998). It is noteworthy that Schott et al. (2002), from 5 realizations, did not find a seasonal signal at $5^{\circ} \mathrm{S}$ in the NBUC transport.

The water mass structure of the NBUC at $5^{\circ} \mathrm{S}$ is characterized by Tropical Water, Subtropical Underwater, South Atlantic Central Water and Antarctic Intermediate Water, with a transport of $26.5 \pm 3.7 \mathrm{~Sv}$ above $1100 \mathrm{~m}$ (SCHOTT et al., 2005), from 9 sections. At the same latitude, Goes et al. (2005) found a smaller (compared to their $11^{\circ} \mathrm{S}$ estimate) transport, of $12.6 \mathrm{~Sv}$, between the $\sigma_{0}=24.5 \mathrm{~kg} \cdot \mathrm{m}^{-3}$ and $\sigma_{0}=26.8 \mathrm{~kg} \cdot \mathrm{m}^{-3}$ isopicnals. However, it must be noted that these authors calculated the NBUC transport down to the $\sigma_{0}=26.8 \mathrm{~kg} \cdot \mathrm{m}^{-3}$ isopicnal, which at this region is located approximately at $700 \mathrm{~m}$ depth. Therefore, their total transport for the NBUC is calculated in a smaller portion of the water column than the calculations from other authors.

\subsection{The cSEC and its Influence on the NBUC}

As the cSEC approaches the equator, it begins to influence the transport, velocity and core depth of the NBUC. Therefore, it becomes important to know the characteristics of the cSEC in order to understand the effects it will have on the NBUC.

The westward cSEC flows zonally along about $4^{\circ} \mathrm{S}$ (LUMPKIN and GARZOLI, 2005 ) with a transport upper bound of $26 \mathrm{~Sv}$ according to Molinari (1982) and a $29 \mathrm{~Sv}$ 
transport indicated by Silveira et al. (1994) at the western part of the Atlantic, where it reaches the Brazillian coast. At $30^{\circ} \mathrm{W}$, this surface-intensified current has $34 \pm 5 \mathrm{~cm} . \mathrm{s}^{-1}$ velocities, and is separated from the nSEC by a mean eastward speed of $6 \pm 12 \mathrm{~cm} . \mathrm{s}^{-1}$ at $1^{\circ} \mathrm{S}$ (LUMPKIN and GARZOLI, 2005), even though it must be noted that these authors apparently do not differenciate the cSEC from the eSEC.

At $35^{\circ} \mathrm{W}$, Schott et al. (1995) found in March, 1994 a combined cSEC and eSEC transport of $18.6 \mathrm{~Sv}$, with a surface core of $0.4 \mathrm{~m} . \mathrm{s}^{-1}$ and a weaker subsurface core of 0.2 $\mathrm{m} . \mathrm{s}^{-1}$, extending from the surface to about $400 \mathrm{~m}$ depth. On the other hand, Schott $e t$ al. (2003) describe the mean (from 13 sections) transport associated with the cSEC and eSEC as much smaller, of only $7 \mathrm{~Sv}$ between 4 and $2^{\circ} \mathrm{S}$, and not clearly distinguishable from the NBC, which they consider to flow south of $4^{\circ} \mathrm{S}$. Even though there is not a clear distinction, the authors associate a $50 \mathrm{~cm} \cdot \mathrm{s}^{-1}$ surface core identified at $35^{\circ} \mathrm{W}$ to the cSEC. It is noteworthy that in the study of Schott et al. (2003) the SEUC was connected to the EUC, therefore limiting the vertical extent of the eSEC and cSEC, thus reducing its transport, which may be the cause for such a difference between the calculated transport from Schott et al. (2003) and from Schott et al. (1995). Both cSEC and eSEC extend deeper than the $\sigma_{0}=24.5 \mathrm{~kg} \cdot \mathrm{m}^{-3}$ isopicnal, as described by Goes et al. (2005) and Schott et al. (2003), and since the eSEC is considered to be the flow north of the SEUC and the cSEC is defined as the flow south of SEUC, once the SEUC has no surface expression, the combined mean flow is also over the SEUC, extending from about $2^{\circ} \mathrm{S}$ to $4^{\circ} \mathrm{S}$ (SCHOTT et al., 2003) (Figure 1.2).

Mesoscale activity has been reported upon the arrival of the cSEC on the western boundary. Silveira et al. (1994) found that, in May-July 1986, this current bifurcates at about $6-5^{\circ} \mathrm{S}$ into two branches at $31^{\circ} \mathrm{W}$. One of them (with a transport of about $14 \mathrm{~Sv}$ ) flows southwestward until $9.5^{\circ} \mathrm{S}$ and them makes a cyclonic turn and coalesces with the NBUC, already formed by the sSEC. The other branch of the cSEC (with a transport of about $15 \mathrm{~Sv}$ ) flows northwestward and coalesces with the NBUC north of $5^{\circ} \mathrm{S}$, where the NBUC had already been originated by the SSEC and fed by the other branch of the cSEC. However, only Silveira et al. (1994) identified this bifurcation, suggesting that it might be seasonal/occasional. The superposition of the cSEC and NBUC cores was also reported 
by, for example, Stramma et al. (1995), and the current originated by the superposition of these two cores is then called North Brazil Current (NBC) (SCHOTT et al., 1998).

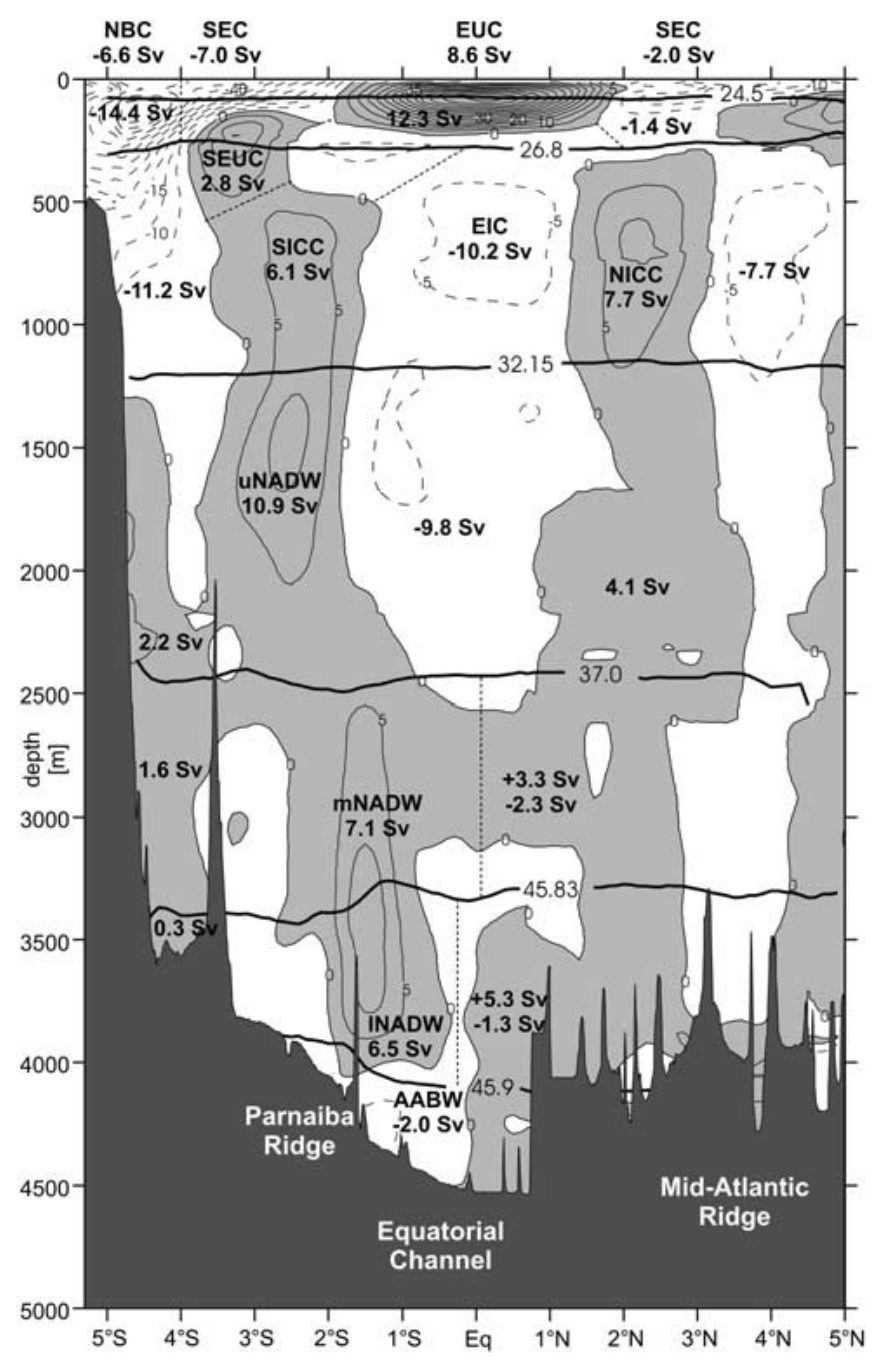

Figure 1.2: Mean $35^{\circ} \mathrm{W}$ velocity section from Schott et al (2003) (from 13 sections). Shown are the North Brazil Current (NBC), South Equatorial Current (SEC), South Equatorial Undercurrent (SEUC), South Intermediate Countercurrent (SICC), Equatorial Undercurrent (EUC), Equatorial intermediate Current (EIC), North Intermediate Countercurrent (NICC), upper, middle and lower North Atlantic Deep Water (uNADW, mNADW and INADW, respectively), and Antarctic Bottom Water (AABW). Positive values indicate eastward flow. 


\subsection{The NBUC North of $5^{\circ} \mathrm{S}$}

North of about $6-4^{\circ} \mathrm{S}$, the NBUC receives contribution from the cSEC (SILVEIRA et al., 1994; LUMPKIN and GARZOLI, 2005), which greatly increases the NBUC transport, also being capable of originating a double-core current system. This kind of structure was observed, for example, in March 1994 at $35^{\circ} \mathrm{W}$, by Schott et al. (1995), who found the NBUC/NBC system with a $0.6 \mathrm{~m} . \mathrm{s}^{-1}$ core at about $150 \mathrm{~m}$ depth and a surface core of about $0.3 \mathrm{~m} . \mathrm{s}^{-1}$. The total transport for the NBUC/NBC system in this realization was $26.2 \mathrm{~Sv}$. Transport increase due to the superposition of the cSEC and NBUC cores is large not only at the surface layer: Goes et al. (2005), for instance, reported an increase from $12.6 \mathrm{~Sv}$ at $5^{\circ} \mathrm{S}$ to almost $17 \mathrm{~Sv}$ at $35^{\circ} \mathrm{W}$ within the $\sigma_{0}=24.5$ - $26.8 \mathrm{~kg} \cdot \mathrm{m}^{-3}$ layer, implying that the cSEC extends deeper than the $\sigma_{0}=24.5 \mathrm{~kg} \cdot \mathrm{m}^{-3}$ isopicnal.

In the upper layer (surface- $\sigma_{0}=24.5 \mathrm{~kg} \cdot \mathrm{m}^{-3}$ ) at $35^{\circ} \mathrm{W}$, the boundary transport is also enhanced, increasing from less than $2.5 \mathrm{~Sv}$ to $12.3 \mathrm{~Sv}$ (GOES et al., 2005). This results in a contribution of about $14 \mathrm{~Sv}$ between the surface and the $\sigma_{0}=26.8 \mathrm{~kg} \cdot \mathrm{m}^{-3}$ isopicnal by the cSEC. In the study of Schott et al. (2003), due to the cSEC contribution, the NBC/NBUC system at $35^{\circ} \mathrm{W}$ transports $32.2 \mathrm{~Sv}$ above $1200 \mathrm{~m}$ depth. Summing the mean transport found by the same authors in the cSEC and eSEC (7 Sv) to the NBC/NBUC system transport, the mean northwestward transport at $35^{\circ} \mathrm{W}$ south of $2^{\circ} \mathrm{S}$ is $39.2 \mathrm{~Sv}$ above the $\sigma_{1}=32.15 \mathrm{~kg} . \mathrm{m}^{-3}$ isopycnal, with a $60 \mathrm{~cm} . \mathrm{s}^{-1}$ core at about $100 \mathrm{~m}$ depth (SCHOTT et al., 2003).

\subsection{Dissertation Hypothesis}

As mentioned on the previous sections, most of the information on the NBUC before its coalescence with the cSEC is found at approximately zonal sections at $11^{\circ} \mathrm{S}$ and $5^{\circ} \mathrm{S}$. Information on the horizontal synoptic structure of the NBUC, as well as its vertical structure, is scarse between those latitudes - the only NBUC description between $11^{\circ} \mathrm{S}$ and $5^{\circ} \mathrm{S}$ is by Silveira et al. (1994). In addition, the subsurface nature of the current prevents altimetry-based studies of the NBUC in this area. Further downstream, 
on the region of superposition of the cSEC and NBUC cores, the information is even more scarse. West of $35^{\circ} \mathrm{W}$, the next section in which the NBUC was repeatedly studied was $44^{\circ} \mathrm{W}$, where the NBUC and cSEC are already merged and are, on the mean, not distinguishable (SCHOTT et al., 1998). Between $35^{\circ} \mathrm{W}$ and $44^{\circ} \mathrm{W}$ the only study that addresses the horizontal structure of the NBUC is Goes et al. (2005).

This data scarcity leaves a knowledge gap on the three dimensional synoptic structure and time variability of the NBUC on the region between $35^{\circ} \mathrm{W}$ and $44^{\circ} \mathrm{W}$, i. e., between the latitudes where the cSEC reaches the western boundary and where these two currents are already merged. In this context, in this dissertation we describe the Potiguar Eddy (PE), a mesoscale anticyclonic eddy identified at the Potiguar Bight, centered at about $36.5^{\circ} \mathrm{W}, 4^{\circ} \mathrm{S}$. Considering the existence of this feature, we hypothesize that

The NBUC has important mesoscale activity in the Potiguar Bight region, and this activity, on the form of meandering, is associated with the interaction of the NBUC with the continental margin physiography and the Deep Western Boundary Current (DWBC).

To test this hypothesis, we describe the Potiguar Eddy based on synoptic hydrographic and current data, moored current data, and global numerical model simulation results. Besides describing the eddy through observational data, we also characterize it through a process-oriented study approach, carrying out simulations with the Regional Ocean Modeling System (ROMS).

\subsection{Objectives}

This dissertation aims to characterize the mesoscale feature referred here as Potiguar Eddy as well as investigate its formation, maintenance, and recurrence processes. To achieve this goal, we analyze hydrographic and current synoptic data, moored current data, altimetry data, and global numerical model outputs. Furthermore, for a better understanding of the feature, we turn to idealized numerical model simulations, using the process-study approach with the oceanic feature modeling technique. 
Specifically, the objectives of the dissertation research are:

- $\quad$ to three-dimensionally characterize the PE based on hydrographic and vesselmounted Acoustic Doppler Current Profiler data;

- $\quad$ to assess the dynamical regime of the PE based on in situ synoptic data;

- to analyze moored current data and altimetry data in terms of the PE persistence/recurrence and its intraseasonal variability;

- to understand the processes involved on the PE persistence/recurrence through longer time scales (semiannual and annual variabilities) by way of an analysis on global numerical model outputs;

- to address the importance of the vertical shear due to the interaction with the DWBC on the dynamics of the PE through idealized experiments, by applying a Feature Model technique in a primitive-equation numerical model.

In Chapter 2, we characterize synoptically the eddy and investigate its vertical structure, based on data from two oceanographic cruises. In Chapter 3 , the temporal variability is analyzed, using moored and altimetry data, as well as model results. In Chapter 4, we describe and analyze the results of numerical simulations carried out using the process-study approach. The summary and conclusions are presented in Chapter 5 , 


\section{Chapter 2}

\section{Characterization of the Potiguar Eddy}

In this chapter we characterize the PE based on synoptic data collected by two oceanographic cruises. These observations are, together with the ones described by Goes et al. (2005), the only data available to us on the region in which the NBUC subsurface core and the cSEC surface core are superposed but still distinguishable. In this chapter we analyze these observations using them as basis for investigating the spatial distribution of the ocean currents and the mesoscale activity in the region.

\subsection{Data set}

Two surveys of the PE region were carried out from RV Antares by the Brazilian Navy, during February $26^{\text {th }}$ - March 21 $1^{\text {st }}$, 2002 (ONEI cruise) and October $26^{\text {th }}$ December $20^{t h}, 2004$ (ONEII cruise). During both surveys, Conductivity-TemperatureDepth (CTD) data was acquired, as well as current data from a vessel-mounted Acoustic Doppler Current Profiler (VMADCP).

The VMADCP profiling of the near-surface layer was carried out by a $75 \mathrm{kHz}$ RD-Instruments system. The ADCP was configured for $8 \mathrm{~m}$ - depth cells and its depth range was about $450 \mathrm{~m}$ for ONEI and $300 \mathrm{~m}$ for ONEII, and the data were processed using the Common Ocean Data Access System (CODAS) software. The sampling grid differed between cruises; 8 transects were sampled during ONEI and 13 during ONEII (Figure 2.1). 

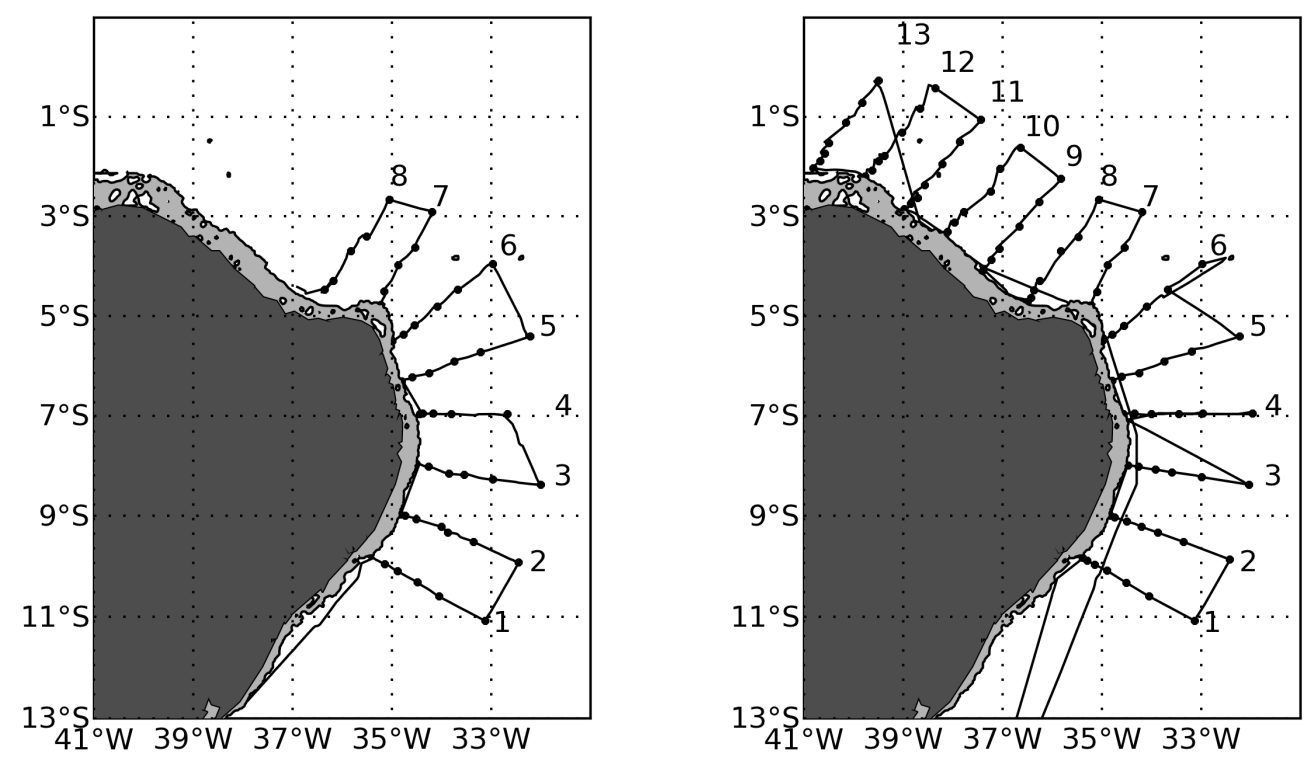

Figure 2.1: Trajectory of the vessel while acquiring ADCP data and location of CTD stations during ONEI (February $26^{\text {th }}$ - March $21^{\text {st }}$ 2002, left panel) and ONEII (October $26^{\text {th }}$ - December $20^{\text {th }} 2004$, right panel) cruises. Light gray areas indicate regions shallower than $60 \mathrm{~m}$.

For these VMADCP sections, due to instrument noise, objective analysis was performed on the velocity data, considering a correlation function of the form 2.1 .

$$
C(x, z)=\left(1-\epsilon^{2}\right) e^{\left(-\left(\frac{x}{L_{x}}\right)^{2}-\left(\frac{z}{L_{z}}\right)^{2}\right)}
$$

where $\epsilon$ is the data random error variance, and $L_{x}$ and $L_{z}$ are the correlation lengthscales in $\mathrm{x}$ (cross-shore) and z (vertical) directions, respectively (SILVEIRA et al., 1994).

Specifically for the case of the velocity sections, considering the anisotropy between the vertical and the horizontal cross-shore axes, the possibility of choosing different correlation legthscales for different axes is crucial. Here we use values of $100 \mathrm{~km}$ and 50 $\mathrm{m}$ on the $\mathrm{x}$ - and $\mathrm{z}$-axis, respectively. The squared variance of the error considered is 0.02 . We also use objective analysis to perform extrapolation between the first velocity profile acquired and the coast, applying a no-slip boundary condition at the bottom.

Besides the VMADCP data, hydrographic data were collected by a Sea Bird Electronics 9 plus CTD with a sampling frequency of $24 \mathrm{~Hz}$, temperature accuracy es- 
timated at $\pm 0.001{ }^{\circ} \mathrm{C}$, and salinity accuracy, at \pm 0.001 . During both cruises a series of CTD profiles were sampled at the locations indicated by the black dots in Figure 2.1. The CTD data were processed using the Sea Bird Electronics software. Horizontal distributions of temperature, salinity and potential density were obtained through objective mapping with an assumed isotropy of a correlation function of the same form as the one presented in Equation 2.1 with the y-coordinate substituting the z-coordinate.

Due to the depth reach of the equipment, the water column below $\approx 300-450 \mathrm{~m}$ was not sampled by the VMADCP. We then use the CTD data in order to estimate the velocities in a larger portion of the water column, using the geostrophic aproximation.

The geostrophic aproximation assumes that the flow is steady, friction is negligible, vertical velocities are negligible (i. e., hydrostatic approximation), and the ratio between the advective and coriolis acceleration (i. e., the Rossby number) is much smaller than one. These characteristics are typical of regions of open ocean, far from the surface and bottom boundary layers. This relation is mathematically expressed by Equation 2.2 ,

$$
u=-\frac{1}{f} \frac{\partial \Delta \Phi}{\partial y} ; v=\frac{1}{f} \frac{\partial \Delta \Phi}{\partial x}
$$

where $u$ is the cross-shore velocity; $v$ is the alongshore velocity; $f$ is the coriolis acceleration; and $\Delta \Phi$ is the geopotential anomaly inferred from hydrographic data.

Considering the limitations of the geostrophic approximation, mainly that the Rossby number should be smaller than one, and the proximity between the equator and the study region, we make an assessment of the validity of the geostrophic aproximation for this study through computations of the Rossby number from the observed data, prior to the computation of the geostrophic velocity sections. We also compare the calculated geostrophic velocities and the VMADCP velocities.

For the computation of the geostrophic velocities, we follow Stramma (1991) and Stramma et al. (2005) level of no motion of $\sigma_{1}=32.15 \mathrm{~kg} \cdot \mathrm{m}^{-3}$. The resulting geostrophic sections were then regridded using objective analysis (Equation 2.1), with correlation lengthscales on the $\mathrm{x}$ - and z-axes of $300 \mathrm{~km}$ and $70 \mathrm{~m}$, respectively, and error squared variance of 0.1 . After regridding, the geostrophic velocities were extrapolated up to the coast and a no-slip boundary condition was enforced. For this procedure, $80 \mathrm{~km}$ 
and $10 \mathrm{~m}$ lengthscales were used for the $\mathrm{x}$ - and $\mathrm{z}$-axis, respectively. The velocity sections, observed as well as geostrophic, allow the investigation of the vertical extent of the eddy.

In order to investigate the horizontal patterns of flow, the ADCP-derived streamfunction distribution was calculated for all levels in which ADCP data was acquired. For the mapping, we employ the so-called direct objective mapping, as described by Bretherton et al. (1976) and later successfully applied by Silveira et al. (2000) to the NBC retroflection region $\left(5^{\circ}-8^{\circ} \mathrm{N}\right)$. This technique uses the kinematic relationship between horizontal velocities and streamfunction to derive a correlation function for the latter quantity once the correlation function of the former quantities are known from the observations. We closely follow Silveira et al. (2000) by assuming an isotropic streamfunction correlation function with lengthscale of $125 \mathrm{~km}$ for both the $\mathrm{x}$ and $\mathrm{y}$ directions. The squared variance of the error considered was 0.2678 . The streamfunction mapping reveals mesoscale spatial patterns that aid the interpretation of the information from the velocity sections. 


\subsection{Results}

We start our analyses with the description of the horizontal distribution of the hydrographic variables collected during ONEI and ONEII cruises. Then we analyze the horizontal ADCP-derived streamfunction distribution for both cruises, at the near-surface and at the depth of the highest PE velocities, i. e., $\approx 150 \mathrm{~m}$. We then turn to the ADCP velocity sections to aid our understanding of the circulation in the area, specifically the Potiguar Bight. Considering the limited ADCP depth reach, in order to have a better understanding of the circulation on a larger portion of the water column, we apply the Classical Dynamic Method to obtain geostrophic velocities from the surface down to about 1500-1800 $\mathrm{m}$. That is done after an assessment of the dynamical regime of the PE is made, to assure that the geostrophic aproximation is reasonable in the area.

The near-surface temperature distribution for ONEI as well as for ONEII cruise (Figures 2.2 and 2.3, left panels) does not show a clear pattern that can be associated with the circulation in the area. During ONEI, the highest values of about $28.4{ }^{\circ} \mathrm{C}$ occur on the southern portion of the domain, around $8^{\circ} \mathrm{S}$. During ONEII the near-surface water is not as warm as during ONEI, presenting maximum values of about $27.5^{\circ} \mathrm{C}$ on the northern portion of the domain. At $144 \mathrm{~m}$ (Figures 2.2 and 2.3, right panels), the temperature fields present much greater gradients than at the near-surface. On both cruises, the highest temperatures are found on the southern portion of the sampling grid, and a patch of higher temperature values is seen along the coast on the NBUC domain, suggesting that these high temperature values are advected northward by the NBUC. The lowest temperature values are found, in both instances, on the northeastern portion of the domain. Also, during ONEI the temperature at the near-surface layer is higher, and at the $144 \mathrm{~m}$ level it is lower than during ONEII. Therefore, the water column had stronger stratification during ONEI (February-March).

The near-surface salinity fields for ONEI and ONEII (Figures 2.4 and 2.5, left panels) show the highest salinity values on the southern portion of the sampling grid, and a patch of relatively high salinity values along the coast, on the NBUC domain. The lowest salinity values, on the other hand, are located, on both instances, on the north/northeastern portion of the sampling grid for each cruise. It is interesting to notice that the near-surface 
salinity distribution for ONEI shows much larger gradients than during ONEII. On 144 $\mathrm{m}$ (Figures 2.4 and 2.5, right panels), the gradients do not differ as much between the cruises; the salinity values during ONEI and ONEII are approximately within the same range. As at the near-surface, the higest values are located on the southern portion of the sampling grid as well as close to the coast, on the NBUC domain. The highest gradients are found on the offshore side of the NBUC, between $5^{\circ} \mathrm{S}$ and $10^{\circ} \mathrm{S}$.
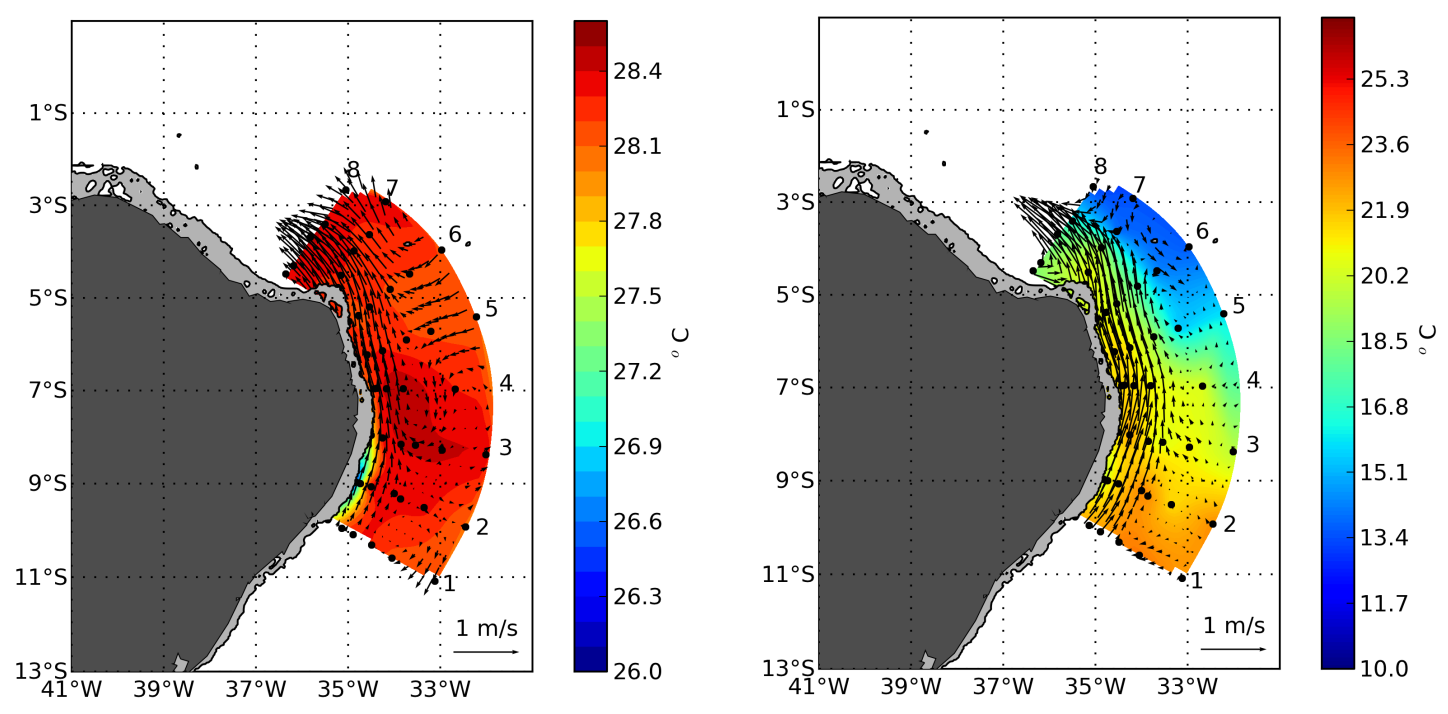

Figure 2.2: Temperature and ADCP velocity vectors at $32 \mathrm{~m}$ (left panel) and $144 \mathrm{~m}$ (right panel) during ONEI. Light gray areas indicate regions shallower than $60 \mathrm{~m}$.
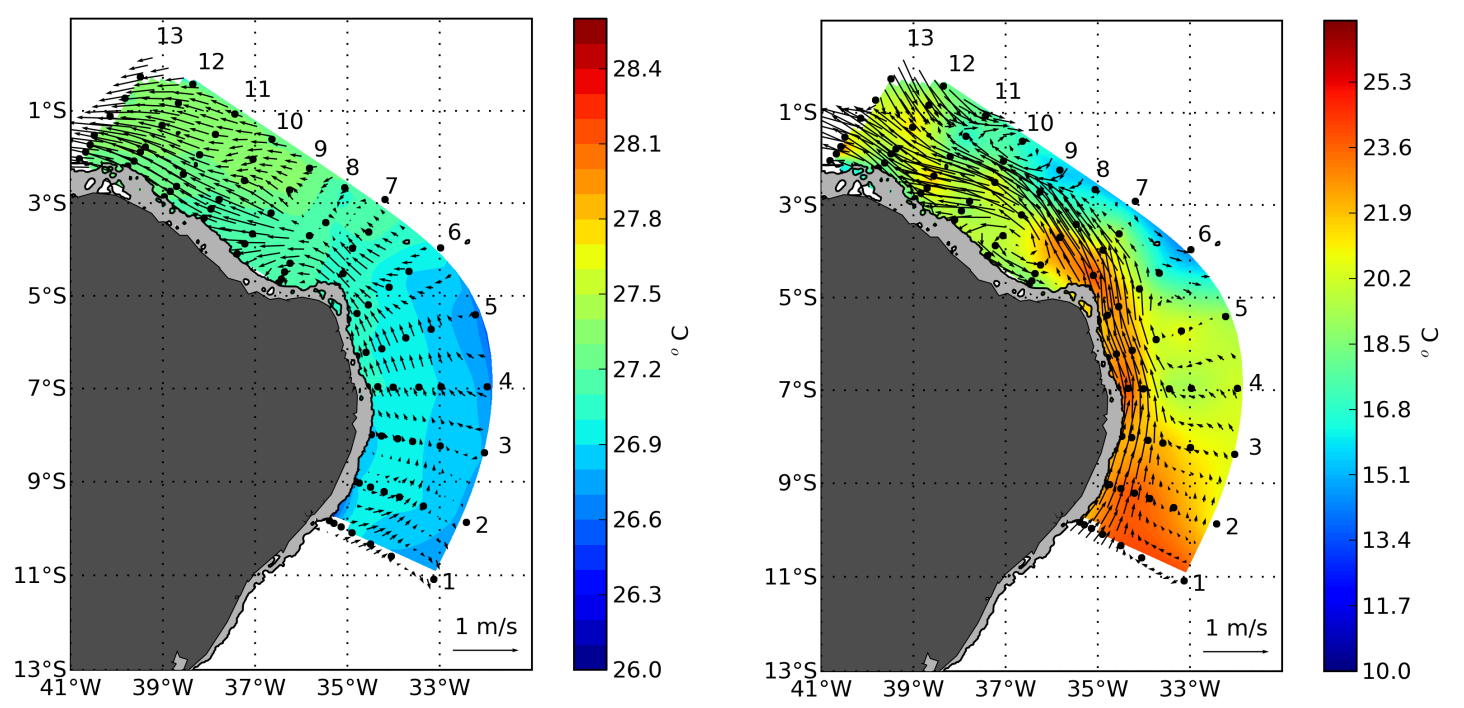

Figure 2.3: Temperature and ADCP velocity vectors at $32 \mathrm{~m}$ (left panel) and $144 \mathrm{~m}$ (right panel) during ONEII. Light gray areas indicate regions shallower than $60 \mathrm{~m}$. 

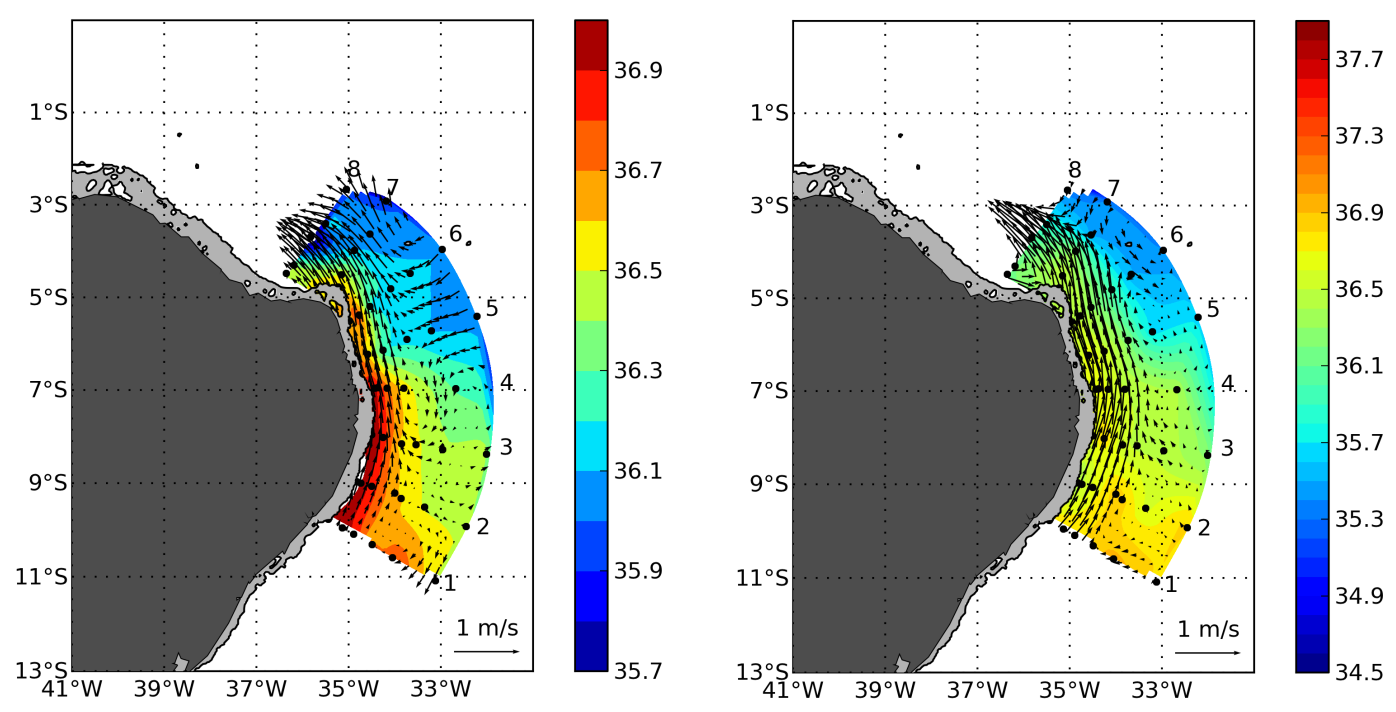

Figure 2.4: Salinity and ADCP velocity vectors at $32 \mathrm{~m}$ (left panel) and $144 \mathrm{~m}$ (right panel) during ONEI. Light gray areas indicate regions shallower than $60 \mathrm{~m}$.
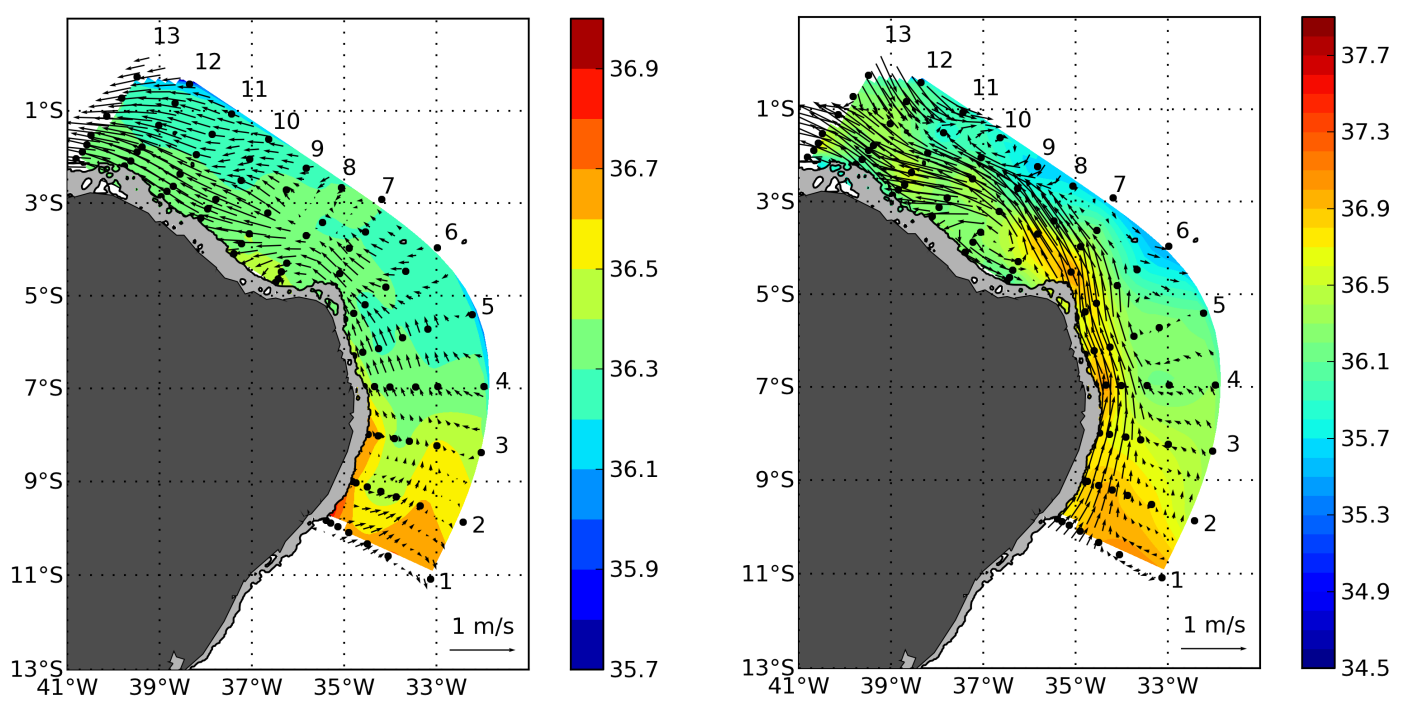

Figure 2.5: Salinity and ADCP velocity vectors at $32 \mathrm{~m}$ (left panel) and $144 \mathrm{~m}$ (right panel) during ONEII. Light gray areas indicate regions shallower than $60 \mathrm{~m}$. 
The potential density near-surface distribution (Figures 2.6 and 2.7, left panels) is quite different between the ONEI and ONEII cruises. During ONEI, larger gradients are found, since the potential density presents a much wider range of values when compared to ONEII. In general, for both cruises the higher potential density values occured along the coast and close to the southern portion of the domain, while the lowest values are present on the northeastern portion of the sampling grid. At $144 \mathrm{~m}$ depth (Figures 2.6 and 2.7, right panels), the distributions for both cruises are more alike; the lowest potential density values are located on the southern portion of the sampling grid and they follow the path of the NBUC northward, as the sSEC low density waters are transported by the NBUC. The highest potential density values are located on the same area where the lower temperature and salinity values occur, i. e., the northeast corner, around $5^{\circ} \mathrm{S}-3^{\circ} \mathrm{S}$.

Therefore, from the hydrografic fields for both cruises, we can see that the sSEC signature (high temperature, high salinity, low potential density) is transported northward along the coast by the NBUC. Also, the subsurface nature of the NBUC caused these signatures not to be very distinguishable, or not visible at all, at the near-surface. It is also noteworthy that the Potiguar eddy, in spite of being present in the area, has a subtile signature on the temperature, salinity of potential density fields relative to the NBUC but contrasts importantly with the lower-density surface-intensified inpinging cSEC.
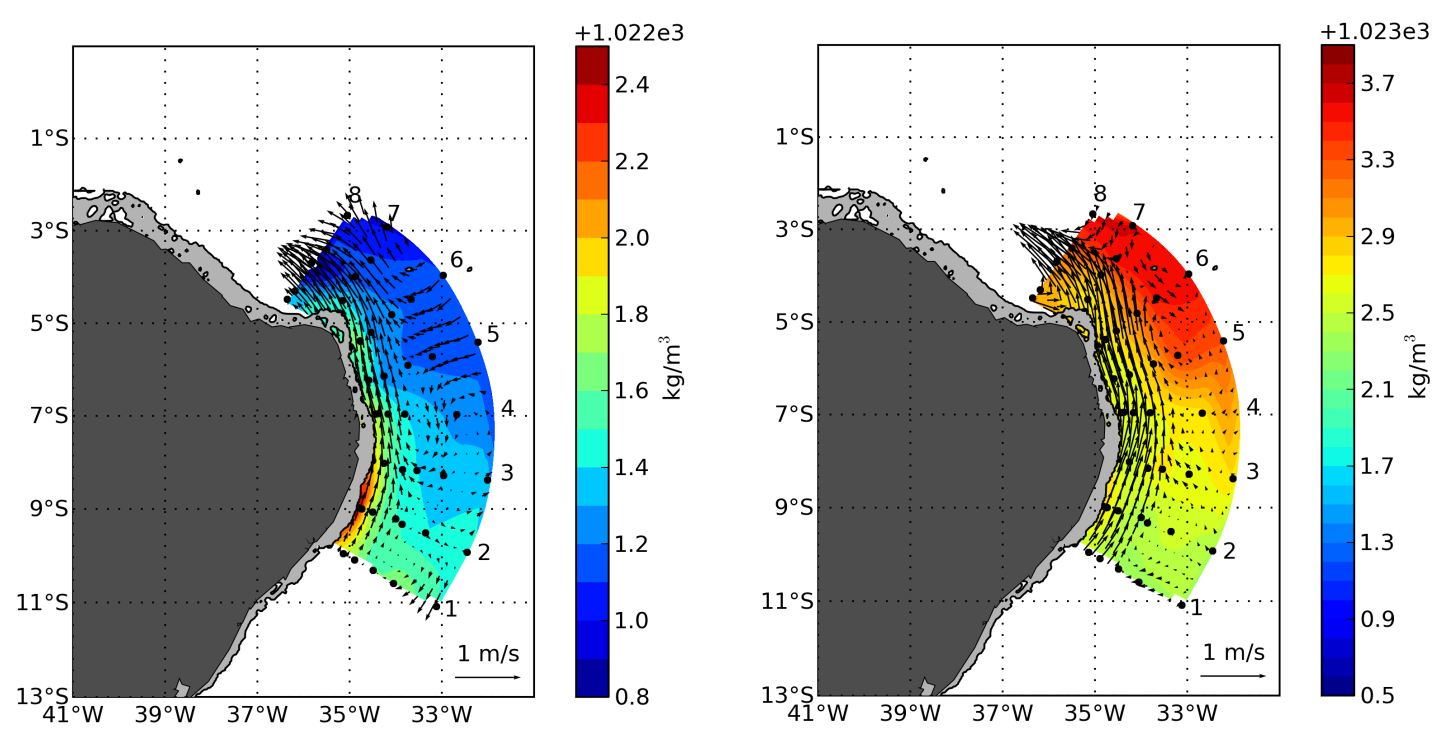

Figure 2.6: Potential density and ADCP velocity vectors at $32 \mathrm{~m}$ (left panel) and $144 \mathrm{~m}$ (right panel) during ONEI. Light gray areas indicate regions shallower than $60 \mathrm{~m}$. 

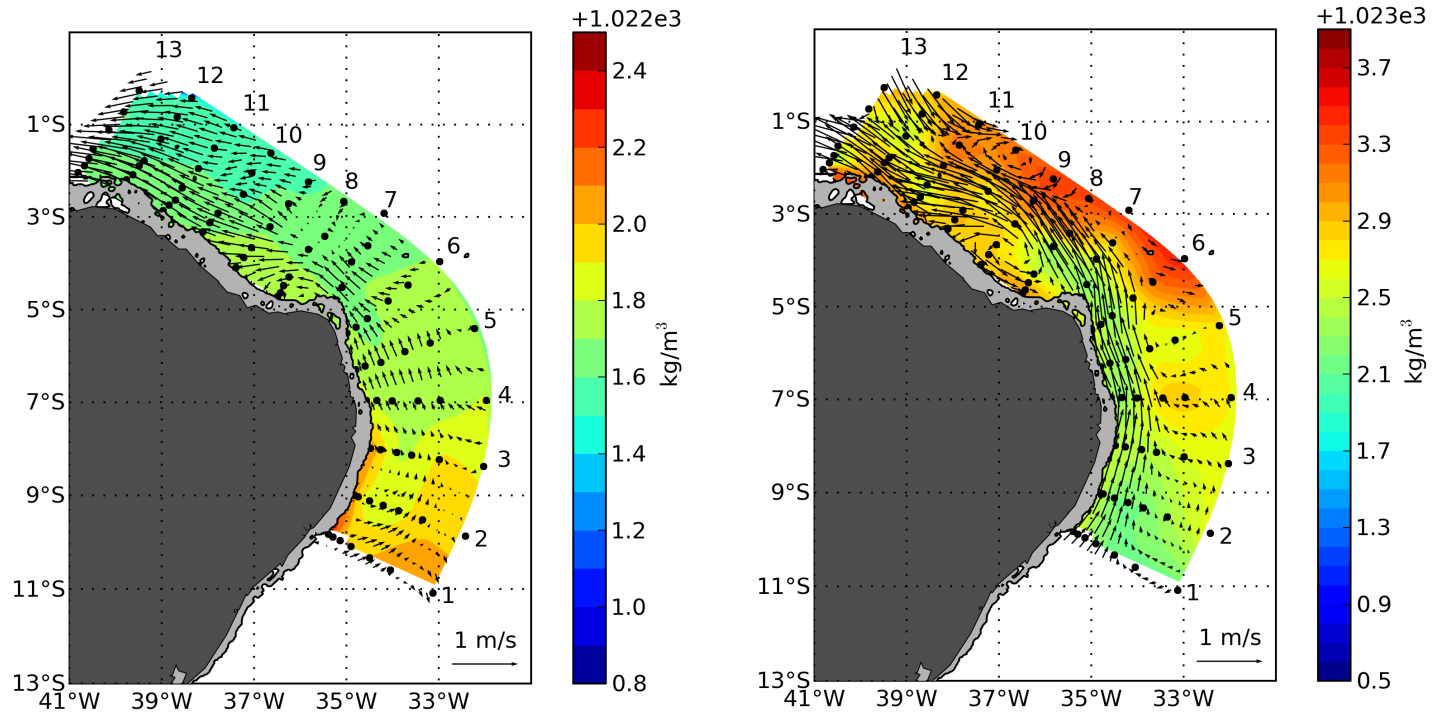

Figure 2.7: Potential density and ADCP velocity vectors at $32 \mathrm{~m}$ (left panel) and $144 \mathrm{~m}$ (right panel) during ONEII. Light gray areas indicate regions shallower than $60 \mathrm{~m}$.

After analyzing the hydrographic properties, we turn to the horizontal distributions of the ADCP-derived streamfunction. The near-surface streamfunction distribution for both cruises (Figures 2.8 and 2.9, left panels) depict the cSEC impinging on the northeastern tip of South America. The expression of the NBUC is either very weak or absent, due to the subsurface nature of its core. Suggestions of a recirculation, especially on the northern part of the domain, which might be associated with the retroflection that originates the EUC, are identified. Also, a cyclonic turn of the cSEC, in agreement with the one observed on the study of Silveira et al. (1994), is seen during ONEI (Figure 2.8, left panel). Other than that, suggestions of a few weaker recirculations on the domain are identified.

At $\approx 150 \mathrm{~m}$ (Figures 2.8 and 2.9, right panels), the streamfuncion distribution changes dramatically. The path of the NBUC, following the coast of Brazil in its path northward, is clearly identified in both instances. Also, the PE, as an anticyclonic recirculation confined between the coast and the NBUC, is observed during ONEII, and suggestions of its existence are seen on the distribution for the ONEI period. This ellipseshaped eddy is centered at approximately $4^{\circ} \mathrm{S}, 36^{\circ} 30^{\prime} \mathrm{W}$, with major axis parallel to the coast. We estimate from the streamfunction maps the minor and major axis of the PE to be $136 \mathrm{~km}$ and $330 \mathrm{~km}$, respectively. To perform this calculation we considered the 
outermost closed streamline, with a value of $-4.10^{4} \mathrm{~m}^{2} \mathrm{~s}^{-1}$, as the limit of the eddy.
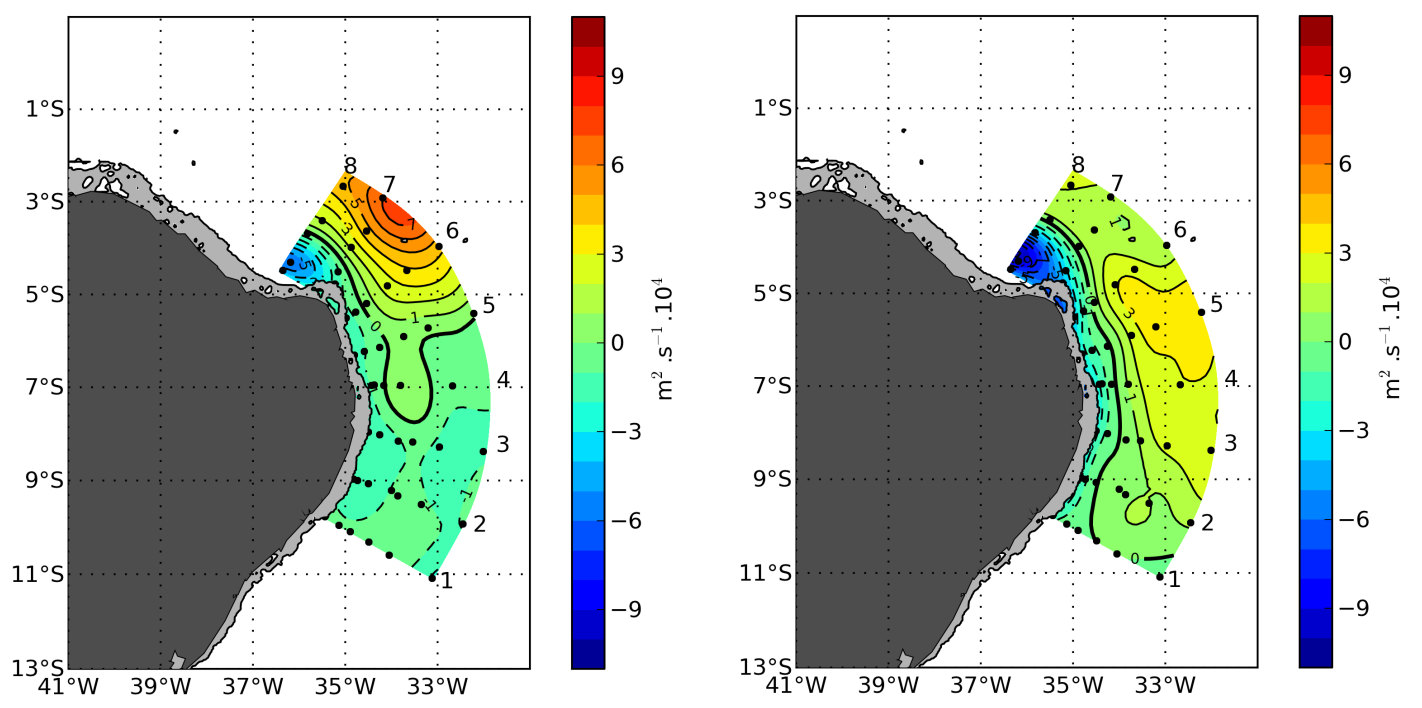

Figure 2.8: ADCP-derived streamfunction distribution during ONEI (February - March $2002)$ at $32 \mathrm{~m}$ ( $\approx$ surface, upper panel) and $144 \mathrm{~m}(\approx$ depth of the PE core, lower panel) depth.
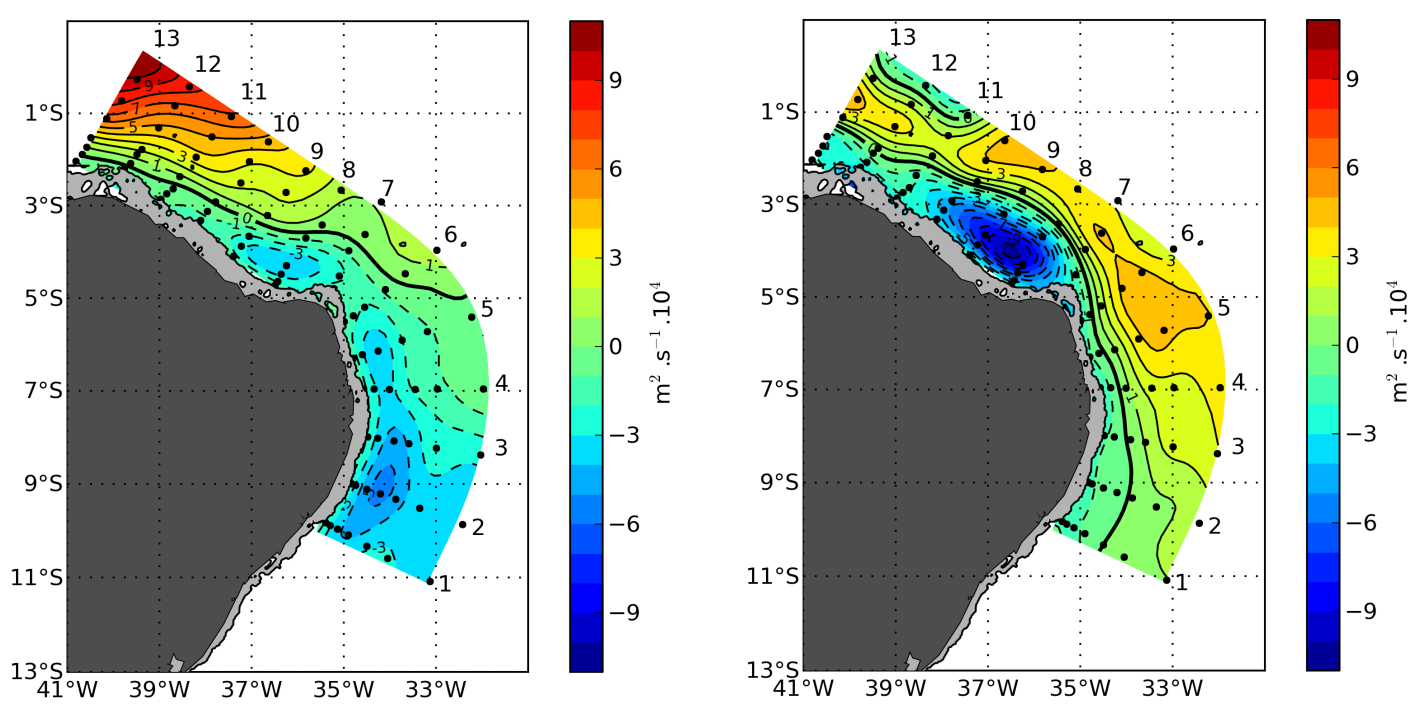

Figure 2.9: ADCP-derived streamfunction distribution during ONEII (October - December 2004) at $32 \mathrm{~m}$ ( $\approx$ surface, upper panel) and $144 \mathrm{~m}$ ( $\approx$ depth of the PE core, lower panel) depth. 


\subsubsection{VMADCP Vertical Sections}

After analyzing the horizontal circulation patterns, we turn to ADCP-acquired velocity sections in order to characterize three-dimensionally the flow on the study area. On the velocity sections from ONEI (Figures 2.10 2.12), the NBUC is clearly identified, with intense velocities of about $1.1 \mathrm{~m} . \mathrm{s}^{-1}$ at the subsurface. The depth of the NBUC core varies between $250 \mathrm{~m}$ on section 1 and $100 \mathrm{~m}$ on section 8 , with a general tendency of shoaling on the downstream direction, as expected (SILVEIRA et al., 1994; SCHOTT et al., 1998). Even though the NBUC signature is very clear at the nearshore portion of the sections, the flow on the offshore portion does not present a clear pattern, specially for the sections 1-5 (Figures 2.10 2.11). The flow on the eastern part of these sections is much weaker than on the western part, and there is no clear correspondence between the flow on the eastern part of different sections. Section 2, in particular (Figure 2.10, middle panel), shows a structure that may be interpreted as an anticyclonic eddy, with a core beyond the depth reach of the ADCP and similar velocity magnitudes in both positive and negative velocity cores. It is likely, by the latitude of this feature, that it is part of a DWBC deep eddy as described by Dengler et al. (2004). However, there is no sign of this structure on sections 1 or 3 .

Further downstream, sections 6-8 (Figures 2.11-2.12) present a quite different pattern from the previous sections. Sections 6 and 7, which show the NBUC going around the Calcanhar Cape at the northeastern tip of Brazil, show a consistent $0.4 \mathrm{~m} . \mathrm{s}^{-1}$ southeastward/eastward velocity core at the offshore part of the section, at 200-250 m depth, which corresponds to the subpycnocline retroflection of the NBUC to form the SEUC. Section 8 is a unique section in the sense that the NBUC is detached from the coast. This is the only ONEI section in which there is actually an eastward flow near the coast instead of westward. The NBUC then, located at about $120 \mathrm{~km}$ from the coast, spreads over a much larger horizontal area then on previous sections. Also, its core is considerably closer to the surface than on previous sections, as well as stronger, with velocities of about $1.3 \mathrm{~m} . \mathrm{s}^{-1}$. The shoaling of the core and the intensification of the current are both due to the presence, in this region, of the central branch of the South Equatorial Current. Also noteworthy is the downstream strenghtening of the surface expression of the NBUC: 
on section 1 (Figure 2.10, top panel) the NBUC surface velocities are about $0.2 \mathrm{~m} . \mathrm{s}^{-1}$ in contrast to section 7 , where the surface velocities reach about $1 \mathrm{~m} . \mathrm{s}^{-1}$, decreasing to about $0.6 \mathrm{~m} . \mathrm{s}^{-1}$ on section 8 . Table 2.1 presents the transports for the NBUC and PE for all the transects.
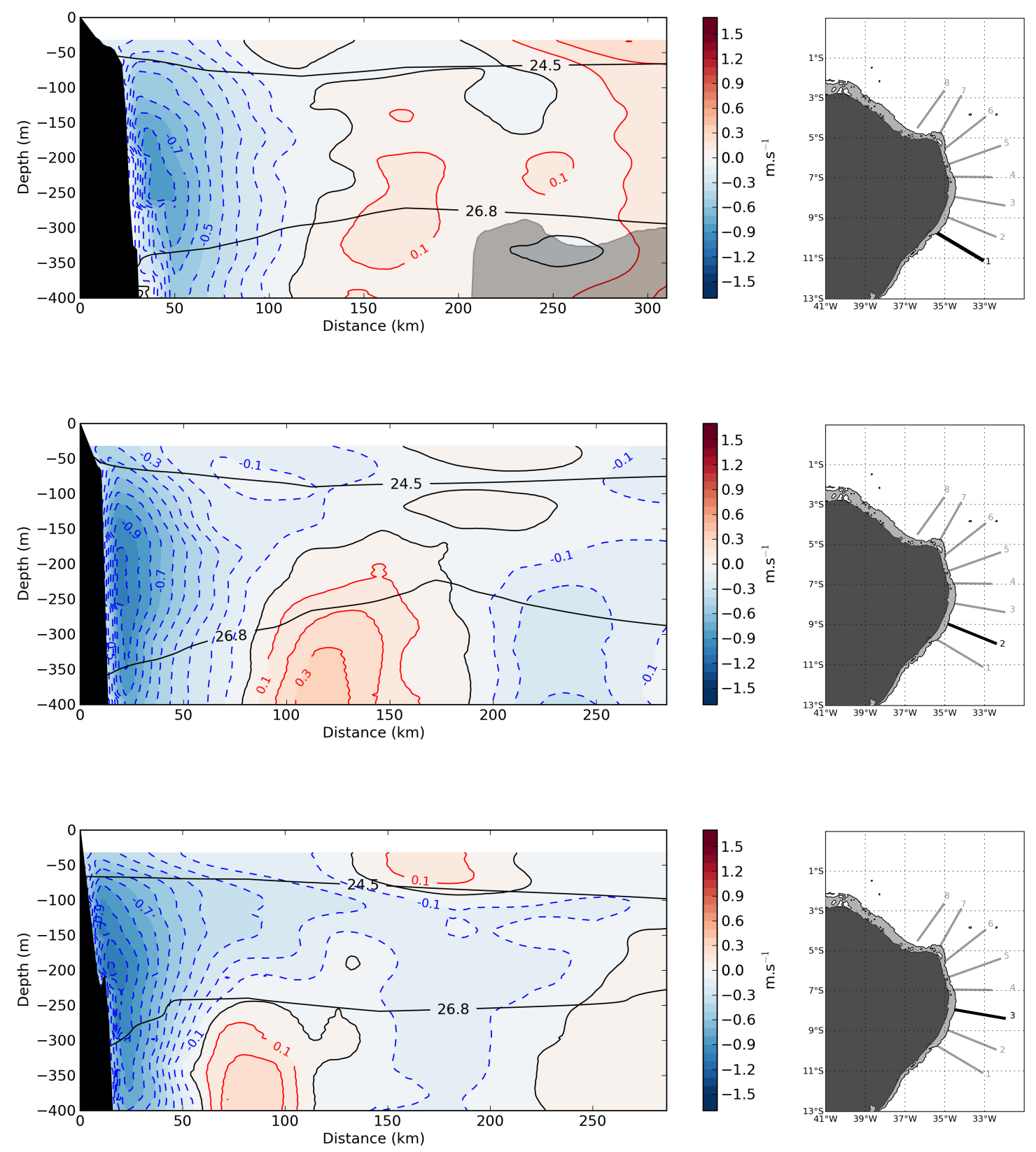

Figure 2.10: ADCP velocity sections 1 (top panel), 2 (middle panel) and 3 (bottom panel) from ONEI cruise (February - March 2002). Values are in $\mathrm{m} . \mathrm{s}^{-1}$. Dashed velocities are northward. The $\sigma_{0}=24.5 \mathrm{~kg} \cdot \mathrm{m}^{-3}$ and $\sigma_{0}=26.8 \mathrm{~kg} \cdot \mathrm{m}^{-3}$ isopycnals are plotted. Shaded areas indicate regions where the percent good from the ADCP data was lower than 50 . 

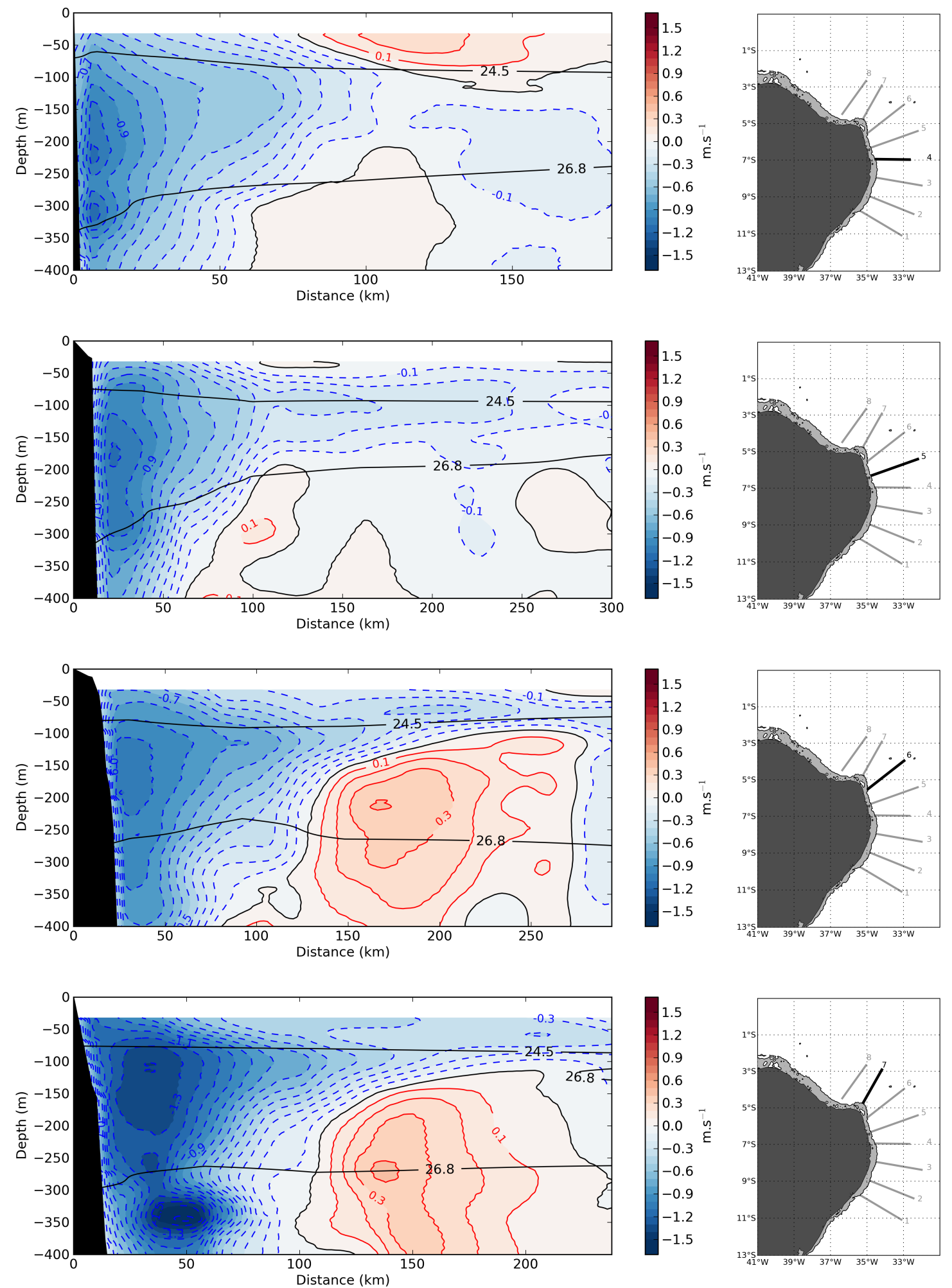

Figure 2.11: ADCP velocity sections 4 (top panel), 5 (second panel), 6 (third panel) and 7

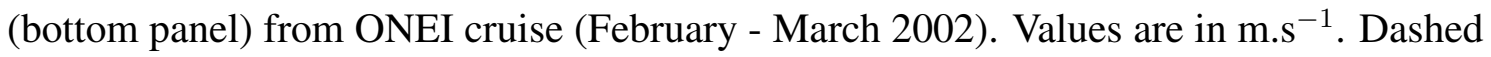
velocities are northward. The $\sigma_{0}=24.5 \mathrm{~kg} \cdot \mathrm{m}^{-3}$ and $\sigma_{0}=26.8 \mathrm{~kg} \cdot \mathrm{m}^{-3}$ isopycnals are plotted. Shaded areas indicate regions where the percent good from the ADCP data was lower than 50. 

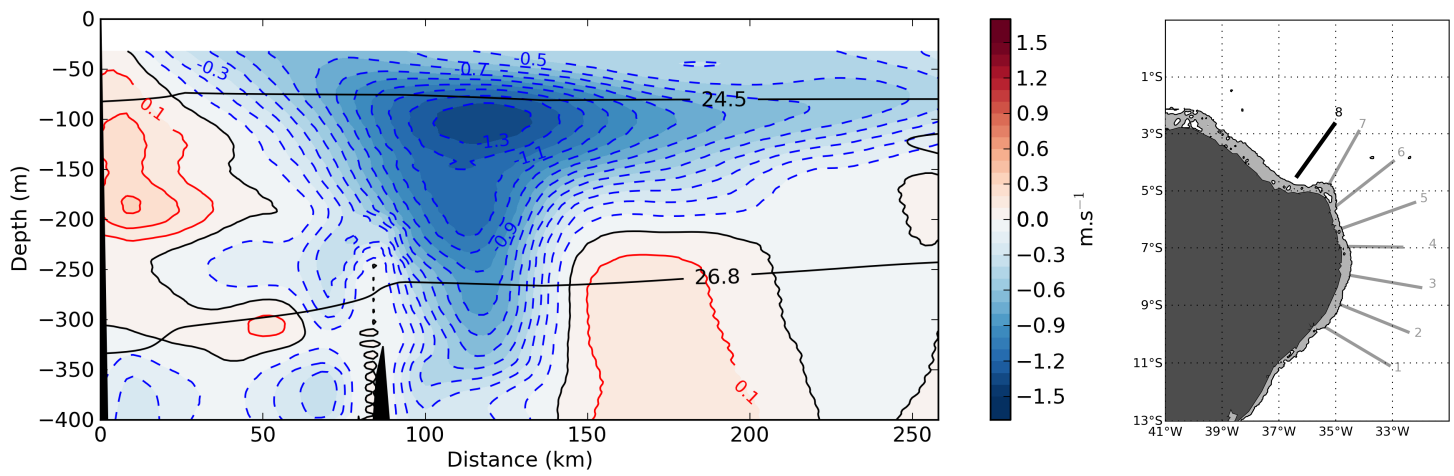

Figure 2.12: ADCP velocity section 8 from ONEI cruise (February - March 2002). Values are in $\mathrm{m} . \mathrm{s}^{-1}$. Dashed velocities are northwestward. The $\sigma_{0}=24.5 \mathrm{~kg} . \mathrm{m}^{-3}$ and $\sigma_{0}=26.8$ $\mathrm{kg} . \mathrm{m}^{-3}$ isopycnals are plotted. Shaded areas indicate regions where the percent good from the ADCP data was lower than 50 .
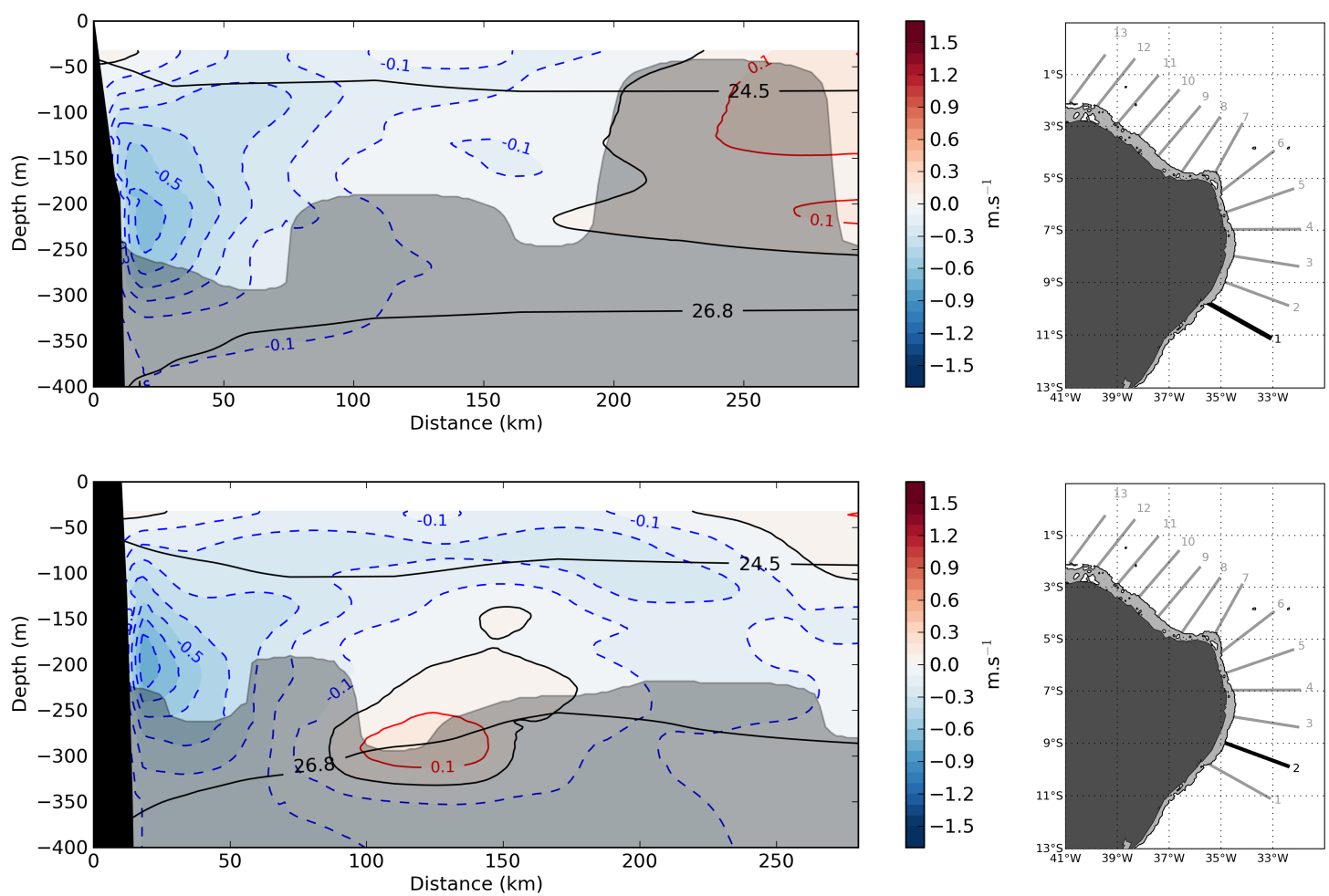

Figure 2.13: ADCP velocity sections 1 (top panel) and 2 (bottom panel) from ONEII

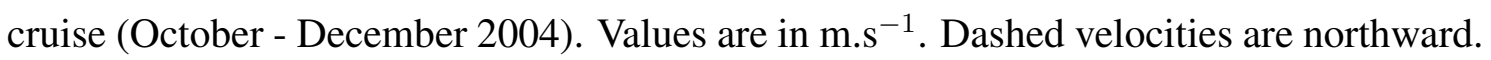
The $\sigma_{0}=24.5 \mathrm{~kg} \cdot \mathrm{m}^{-3}$ and $\sigma_{0}=26.8 \mathrm{~kg} \cdot \mathrm{m}^{-3}$ isopycnals are plotted. Shaded areas indicate regions where the percent good from the ADCP data was lower than 50. 
Table 2.1: Transports from VMADCP transects for cruises ONEI and ONEII. Only the areas with percent good higher than 50 were computed.

\begin{tabular}{|c|c|c|}
\hline Transect/cruise & NBUC transport (Sv) & PE transport $(\mathrm{Sv})$ \\
\hline 1/ONEI & 18.06 & - \\
\hline 2/ONEI & 21.71 & - \\
\hline 3/ONEI & 22.00 & - \\
\hline 4/ONEI & 18.25 & - \\
\hline 5/ONEI & 28.30 & - \\
\hline 6/ONEI & 34.50 & - \\
\hline 7/ONEI & 33.20 & - \\
\hline 8/ONEI & 29.50 & 1.16 \\
\hline 1/ONEII & 8.61 & - \\
\hline 2/ONEII & 10.36 & - \\
\hline 3/ONEII & 7.35 & - \\
\hline 4/ONEII & 15.87 & - \\
\hline 5/ONEII & 16.94 & - \\
\hline 6/ONEII & 15.45 & - \\
\hline 7/ONEII & 16.99 & - \\
\hline 8/ONEII & 7.16 & 2.17 \\
\hline 9/ONEII & 15.93 & 1.70 \\
\hline 10/ONEII & 19.19 & - \\
\hline 11/ONEII & 26.71 & - \\
\hline 12/ONEII & 22.80 & - \\
\hline 13/ONEII & 18.42 & - \\
\hline
\end{tabular}


During the ONEII cruise, the depth reach of $\approx 300 \mathrm{~m}$ of the ADCP equipment was considerably shallower than during ONEI (450 m). As a consequence, inferences about the NBUC vertical structure could not be made for the isopycnal interior of $\sigma_{0}=$ $24.5-26.8 \mathrm{~kg} \cdot \mathrm{m}^{-3}$. The NBUC during ONEII (Figures 2.13 2.17) has roughly the same strength as during the ONEI cruise, with the core velocity ranging between $0.7 \mathrm{~m} . \mathrm{s}^{-1}$ and $1.2 \mathrm{~m} . \mathrm{s}^{-1}$. As done for the sections from ONEI cruise, for ONEII cruise we will separate the sections for analysis purposes.

Over sections 1-5 (Figures 2.13-2.15), the NBUC is attached to the coast, with its core at aproximately $200 \mathrm{~m}$ depth, with similar magnitudes to the ones during ONEI $\left(\approx 0.6-1 \mathrm{~m} \cdot \mathrm{s}^{-1}\right)$. The eastern part of the sections presented velocities even weaker than those during ONEI, and a flow pattern is not identifiable.
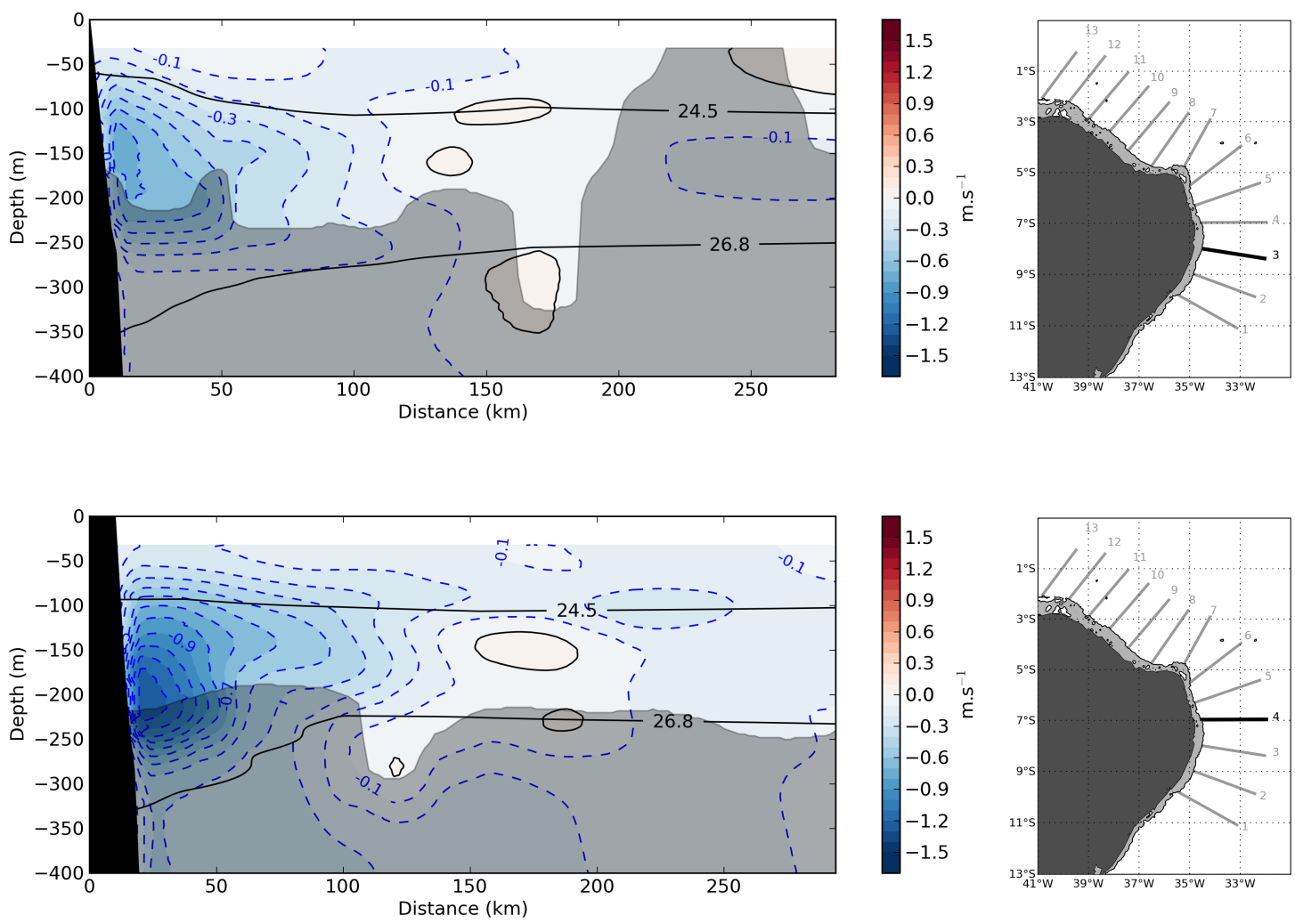

Figure 2.14: ADCP velocity sections 3 (top panel) and 4 (bottom panel) from ONEII

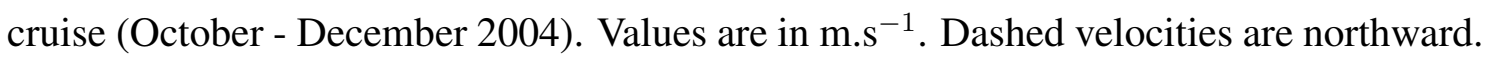
The $\sigma_{0}=24.5 \mathrm{~kg} \cdot \mathrm{m}^{-3}$ and $\sigma_{0}=26.8 \mathrm{~kg} \cdot \mathrm{m}^{-3}$ isopycnals are plotted. Shaded areas indicate regions where the percent good from the ADCP data was lower than 50 . 

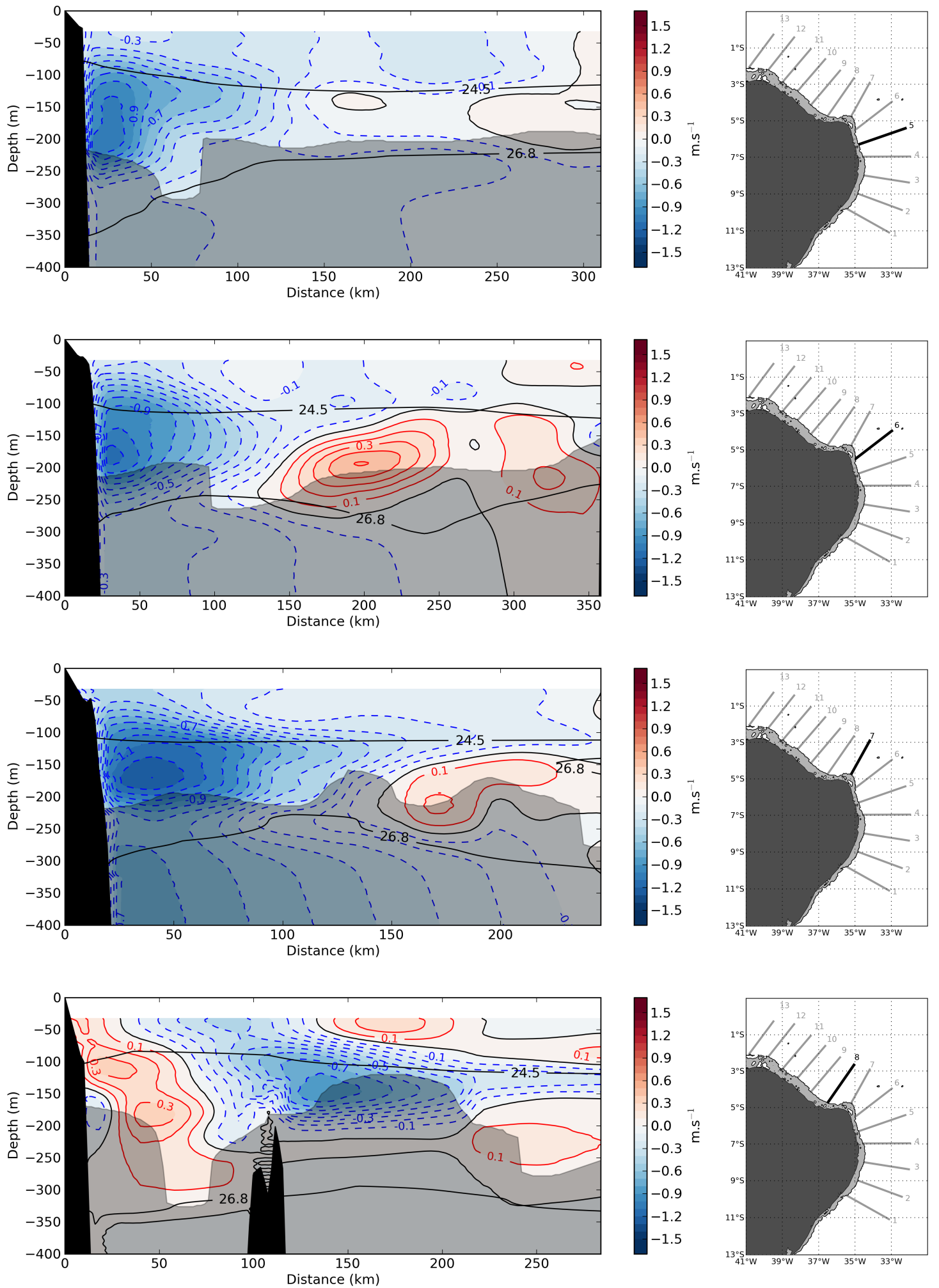

Figure 2.15: ADCP velocity sections 5 (top panel), 6 (second panel), 7 (third panel), and 8 (bottom panel) from ONEII cruise (October - December 2004). Values are in $\mathrm{m} . \mathrm{s}^{-1}$. Dashed velocities are northward. The $\sigma_{0}=24.5 \mathrm{~kg} \cdot \mathrm{m}^{-3}$ and $\sigma_{0}=26.8 \mathrm{~kg} \cdot \mathrm{m}^{-3}$ isopycnals are plotted. Shaded areas indicate regions where the percent good from the ADCP data was lower than 50 . 
On sections 6 and 7 (Figure 2.15), the NBUC has a stronger core than on previous sections, presenting velocities of about 1.1-1.2 m.s $\mathrm{s}^{-1}$. This suggests that, since section 6 is located at about $5^{\circ} \mathrm{S}$, the contribution from the cSEC is responsible for the NBUC intensification. However, no significant change on the depth of the core can be identified; on the other hand, the NBUC surface expression $\left(0.4 \mathrm{~m} . \mathrm{s}^{-1}\right)$ becomes stronger when compared to upstream sections $\left(\approx 0.2 \mathrm{~m} . \mathrm{s}^{-1}\right)$. On the eastern portion of the sections, the east/southeastward core associated to the SEUC formation is observed, stronger $(0.5$ m.s ${ }^{-1}$ ) on section 6 . On both sections 6 and 7 this core is present at about $200 \mathrm{~m}$ depth.

The fact that the NBUC suffers dramatic changes as it passes Cape Calcanhar is noticeable when comparing sections 8-10 (Figures 2.15-2.17) with upstream sections. Sections 8-10 are on the domain of the Potiguar Eddy, therefore their main characteristic is that the NBUC is detached from the coast and there is an eastward/southeastward velocity core close to the continental slope, associated with the nearshore lobe of the Eddy. The eastward flow observed has maximum velocities of about $0.4-0.6 \mathrm{~m} . \mathrm{s}^{-1}$, at about $170 \mathrm{~m}$ depth, with the exception of section 8 , in which it has a second core that reaches the surface. As mentioned, on these sections the NBUC is detached from the continental slope, being located at about $150 \mathrm{~km}$ from the coast on sections 8 and 9 , and closer $(\approx 50$ $\mathrm{km})$ to the coast on section 10 .
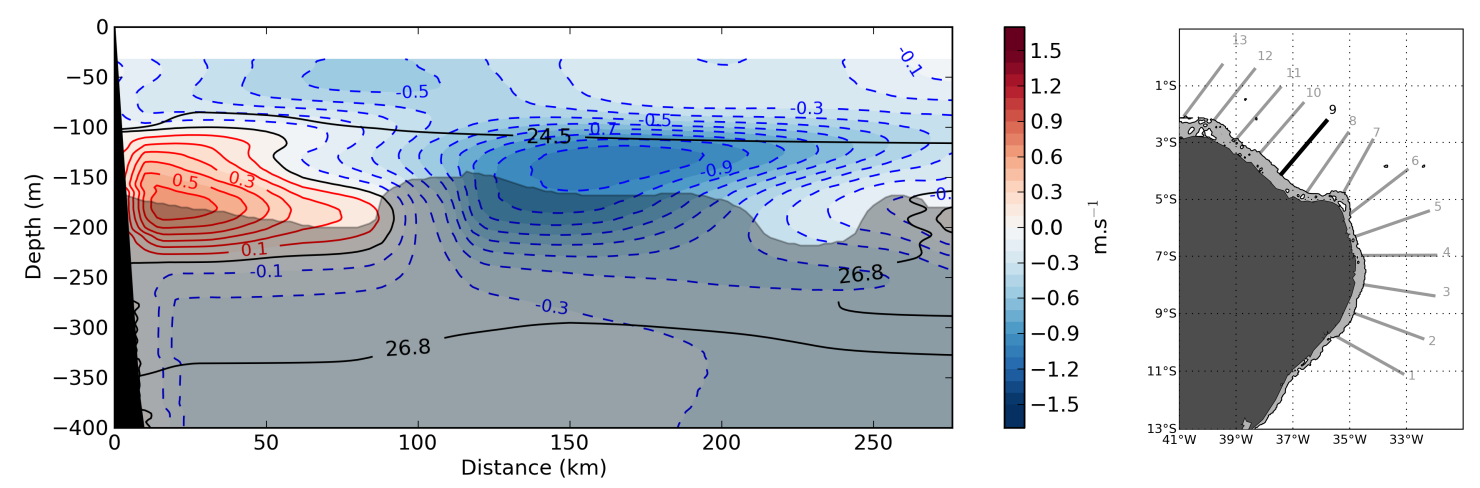

Figure 2.16: ADCP velocity section 9 from ONEII cruise (October - December 2004). Values are in m.s ${ }^{-1}$. Dashed velocities are northwestward. The $\sigma_{0}=24.5 \mathrm{~kg} . \mathrm{m}^{-3}$ and $\sigma_{0}$ $=26.8 \mathrm{~kg} \cdot \mathrm{m}^{-3}$ isopycnals are plotted. Shaded areas indicate regions where the percent good from the ADCP data was lower than 50. 

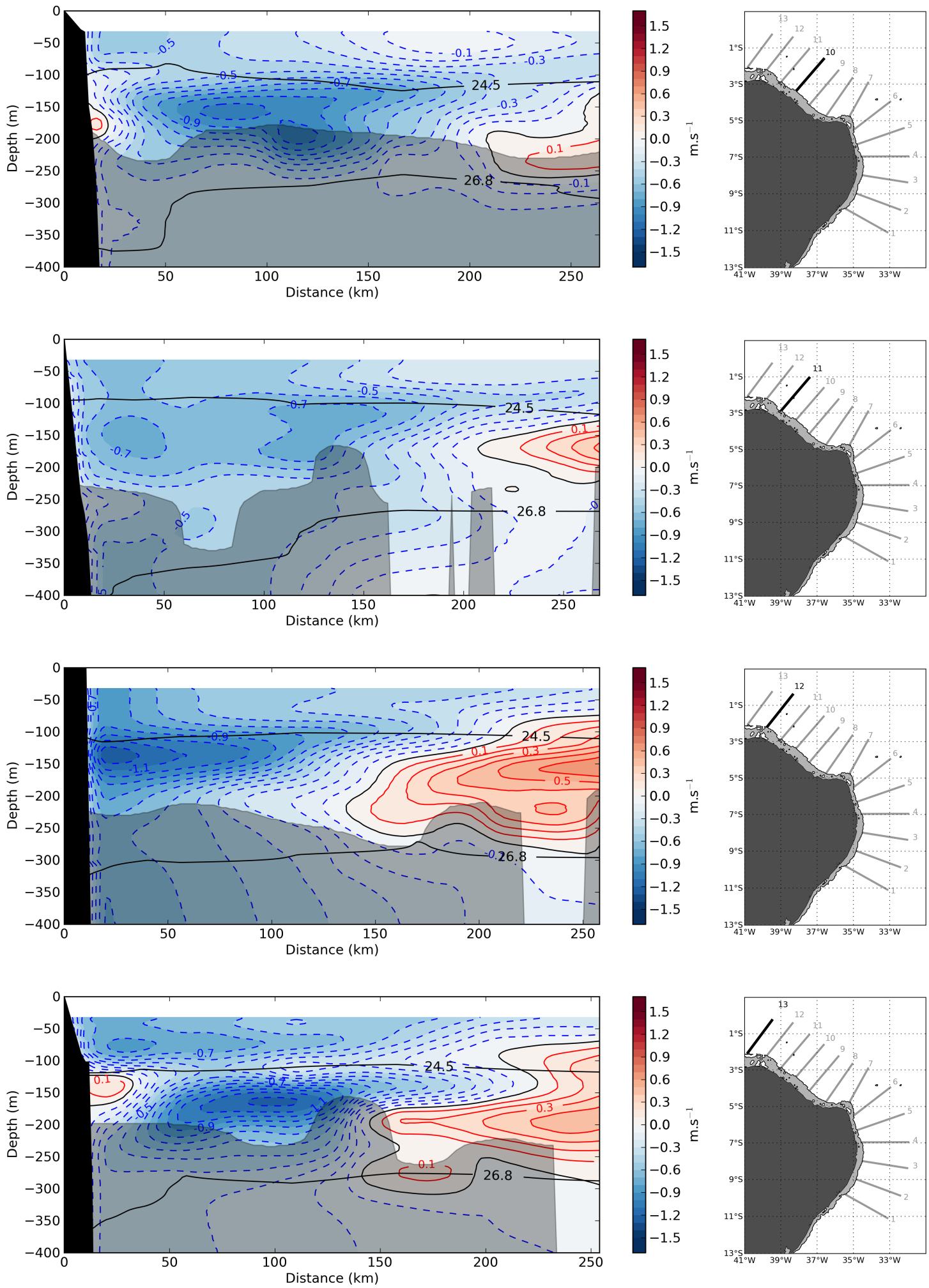

Figure 2.17: ADCP velocity sections 10 (top panel), 11 (second panel), 12 (third panel), and 13 (bottom panel) from ONEII cruise (October - December 2004). Values are in $\mathrm{m} . \mathrm{s}^{-1}$. Dashed velocities are northwestward. The $\sigma_{0}=24.5 \mathrm{~kg} \cdot \mathrm{m}^{-3}$ and $\sigma_{0}=26.8 \mathrm{~kg} \cdot \mathrm{m}^{-3}$ isopycnals are plotted. Shaded areas indicate regions where the percent good from the ADCP data was lower than 50. 
On sections 11-13 (Figures 2.17), the NBUC goes back to being attached to the slope, but with a larger horizontal extent, reaching up to about $200 \mathrm{~km}$ from the coast. Another noticeable change on the NBUC is the increasingly higher velocity at the surface, which culminate on section 13 (approximately at $40^{\circ} \mathrm{W}$ ) in which two cores are observed: a subsurface one, associated to the NBUC, and a surface one, associated with the cSEC and eSEC. This surface northwestward expression can reach about $0.8 \mathrm{~m} . \mathrm{s}^{-1}$ on the portion closest to the coast. However, no significant change in depth is seen on the subsurface core, which is still found at about 120-150 m depth. Table 2.1 presents the transports for the NBUC and PE for all the transects.

\subsubsection{The Rossby and Burger Numbers}

Even though the streamfunction maps and the velocity sections help us characterize the NBUC, the finite ADCP reach limits the description of the vertical extent of the currents as well as of the PE. In order to estimate the velocities on a larger part of the water column for investigation of the PE vertical structure and water mass transport, we use the classical dynamic method. However, due to the proximity to the equator, we first make an assessment of the validity of the geostrophic aproximation for the Potiguar Bight. As part of this assessment, we calculate the Rossby number of the PE by getting the mean magnitude of the velocity on a ring of the Potiguar eddy with mean width of $70 \mathrm{~km}$, using the $-4 \times 10^{4} \mathrm{~m}^{2} \mathrm{~s}^{-1}$ streamline as outer limit. Then, we divide by the value of the Coriolis parameter on the area multiplied by the mean distance between the correspondent streamline and the eddy core, i. e., its radius (Equation 2.3). The values used on the Rossby number calculation are presented on Table 2.2 .

$$
R o=\frac{U}{f_{o} R}
$$

where $U$ is the mean velocity magnitude between two closed streamlines; $f_{o}$ is the Coriolis parameter at the eddy center; and $R$ is the mean radius of the Potiguar Eddy.

Figure 2.18 shows the area used for the calculation of the Rossby number on the assessment of the validity of the geostrophic aproximation for the Potiguar Bight. As a result, we got a mean Rossby number of $\approx 0.4$ for the eddy core depth and of $\approx 0.22$ 
if averaged over the eddy thickness of $250 \mathrm{~m}$ (i.e., averaged over $H$, which is the mean thickness between the $24.5-26.8 \mathrm{~kg} \cdot \mathrm{m}^{-3}$ isopycnal interval).

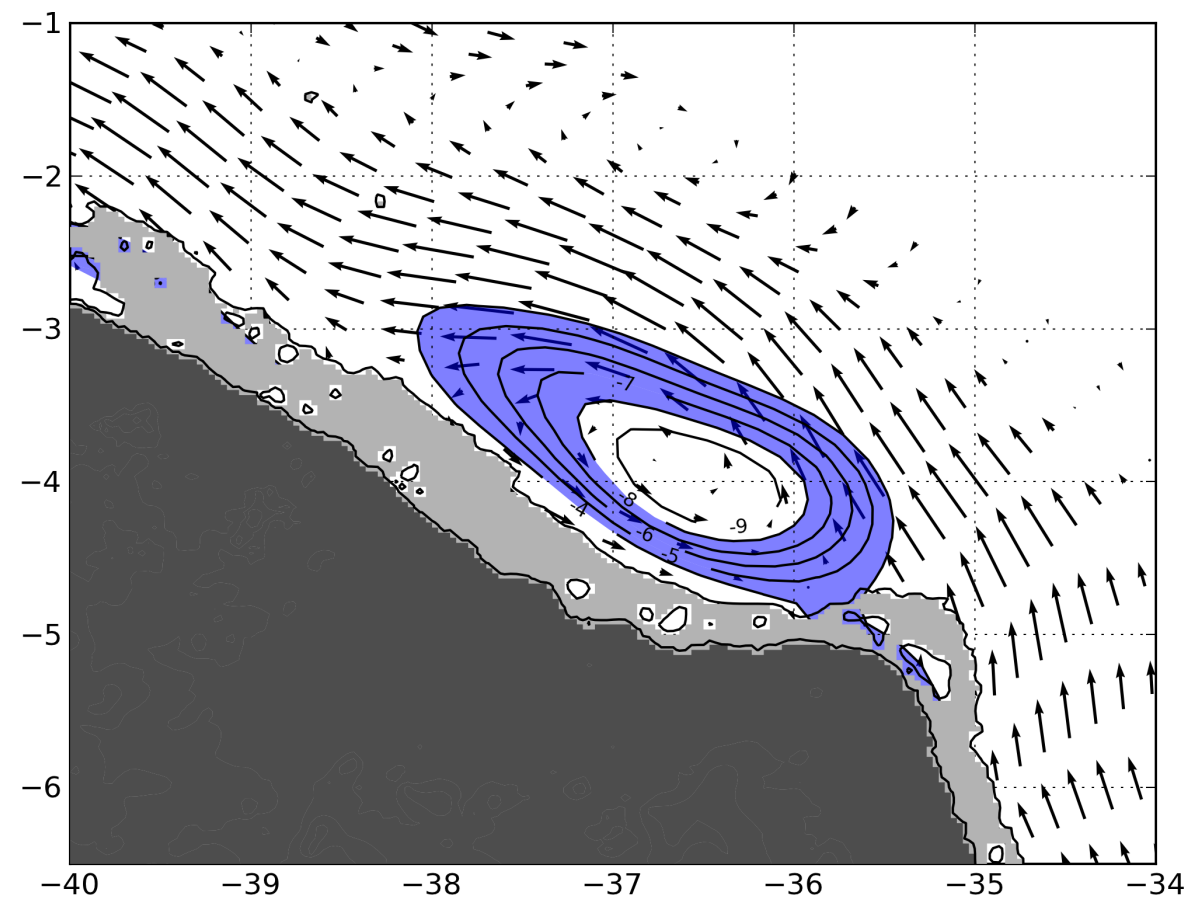

Figure 2.18: Map with the ADCP-derived velocity vectors at $150 \mathrm{~m}$ for ONEII cruise (October - December 2004). The area used for the Rossby number calculation is in blue.

Besides the Rossby number, in order to evaluate the role of stratification on the maintainance of the PE, the Burger number was calculated, according to Equation 2.4 . with the values presented on Table 2.2. The Burger number was calculated with information from three hydrographic sections that were sampled within the eddy (sections 8,9 and 10, Figure 2.1, right panel) during ONEII. The mean Burger number for the PE sampled during ONEII is approximately 1 . Therefore, we conclude that the stratification is as important as the horizontal velocity shear on the maintainance of the PE, characterizing the $\mathrm{PE}$ as a typical mesoscale structure of the tropical-equatorial region.

$$
B u=\sqrt{\frac{g \frac{\Delta \rho}{\bar{\rho}} H}{f_{o}^{2} R^{2}}}
$$

where $g$ is the gravitational acceleration, $\Delta \rho$ is the potential density difference, $\bar{\rho}$ is the 
mean density, $H$ is the thickness of the water column into consideration, $f_{o}$ is the local Coriolis parameter, and $R$ is the mean radius of the eddy.

Table 2.2: Scales used for the estimation of the Rossby and Burger numbers.

\begin{tabular}{cc}
\hline Parameter & Value \\
\hline $\mathrm{U}$ & $0.47 \mathrm{~m} \cdot \mathrm{s}^{-1}$ \\
$f_{o}$ & $1.02 .10^{-5} \mathrm{~s}^{-1}$ \\
$\mathrm{~L}$ & $236 \mathrm{~km}$ \\
$\mathrm{~g}$ & $9.81 \mathrm{~m} \cdot \mathrm{s}^{-2}$ \\
$\Delta \rho$ & $26.8-24.5 \mathrm{~kg} \cdot \mathrm{m}^{-3}$ \\
$\bar{\rho}$ & $1027.07 \mathrm{~kg} \cdot \mathrm{m}^{-3}$ \\
$H$ & $250 \mathrm{~m}$ \\
\hline
\end{tabular}

\subsubsection{Geostrophic Fields in the PE Region}

As the magnitude of the $H$-averaged Rossby number indicates, there is reasonable agreement between the geostrophic (considering the isopycnal $\sigma_{1}=32.15 \mathrm{~kg} . \mathrm{m}^{-3}$ as reference) and ADCP velocity (Figures 2.19 and 2.20 despite the near-equatorial location of the study area. The general pattern from the ADCP sections is well represented in the geostrophic velocities, even though the geostrophic NBUC is weaker and closer to the shore in both sections. The weaker NBUC reflects in smaller transports in geostrophic sections when compared to the ADCP data. In ONEI Section 8, the geostrophic NBUC transports $18.56 \mathrm{~Sv}$, in comparison to 26.39 from ADCP data. The geostrophic eddy, on the other hand, is stronger than the one shown in ADCP data, transporting 1.74 Sv, compared to $0.92 \mathrm{~Sv}$. On ONEII Section 9, the geostrophic NBUC transports 22.49 Sv in contrast to 26.91 shown in ADCP data. The geostrophic eddy in this instance is somewhat weaker than shown in ADCP data, transporting about 1.61 Sv compared to 2.37 Sv from ADCP data. All these transport values were calculated between the surface and $300 \mathrm{~m}$ depth, in order to compare the geostrophic and ADCP velocity fields. We consider the agreement reasonable, so we analyze the geostrophic velocities down to $1500 \mathrm{~m}$ (ONEI) and $1800 \mathrm{~m}$ (ONEII), beyond the ADCP reach. 

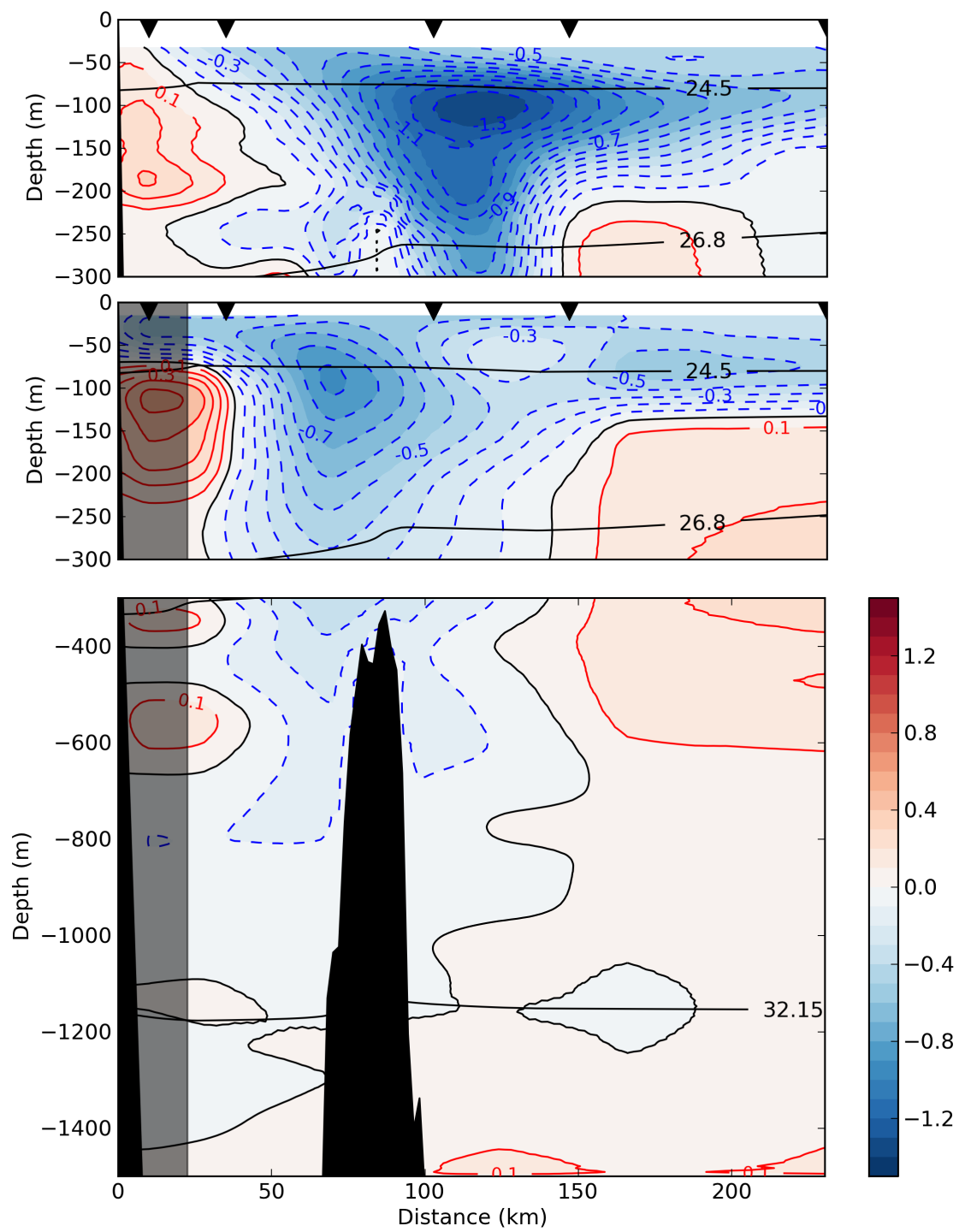

Figure 2.19: Comparison between the geostrophic velocity referenced to the $\sigma_{1}=32.15$ $\mathrm{kg} . \mathrm{m}^{-3}$ isopycnal (middle and bottom panels) and ADCP velocity (top panel) for transect 8 from ONEI (February - March 2002). Blue areas indicate west/northwestward velocities, red areas indicate east/southeast velocities. The shaded area on the top panel indicates areas with percent good lower than 50. The shaded area on the middle and bottom panels indicates the portion of the plot which is generated by extrapolation. Inverted triangles indicate the location of oceanographic stations. The isopycnals $\sigma_{\theta}=24.5 \mathrm{~kg} . \mathrm{m}^{-3}$ and $\sigma_{\theta}=26.8 \mathrm{~kg} \cdot \mathrm{m}^{-3}$ are also shown. 


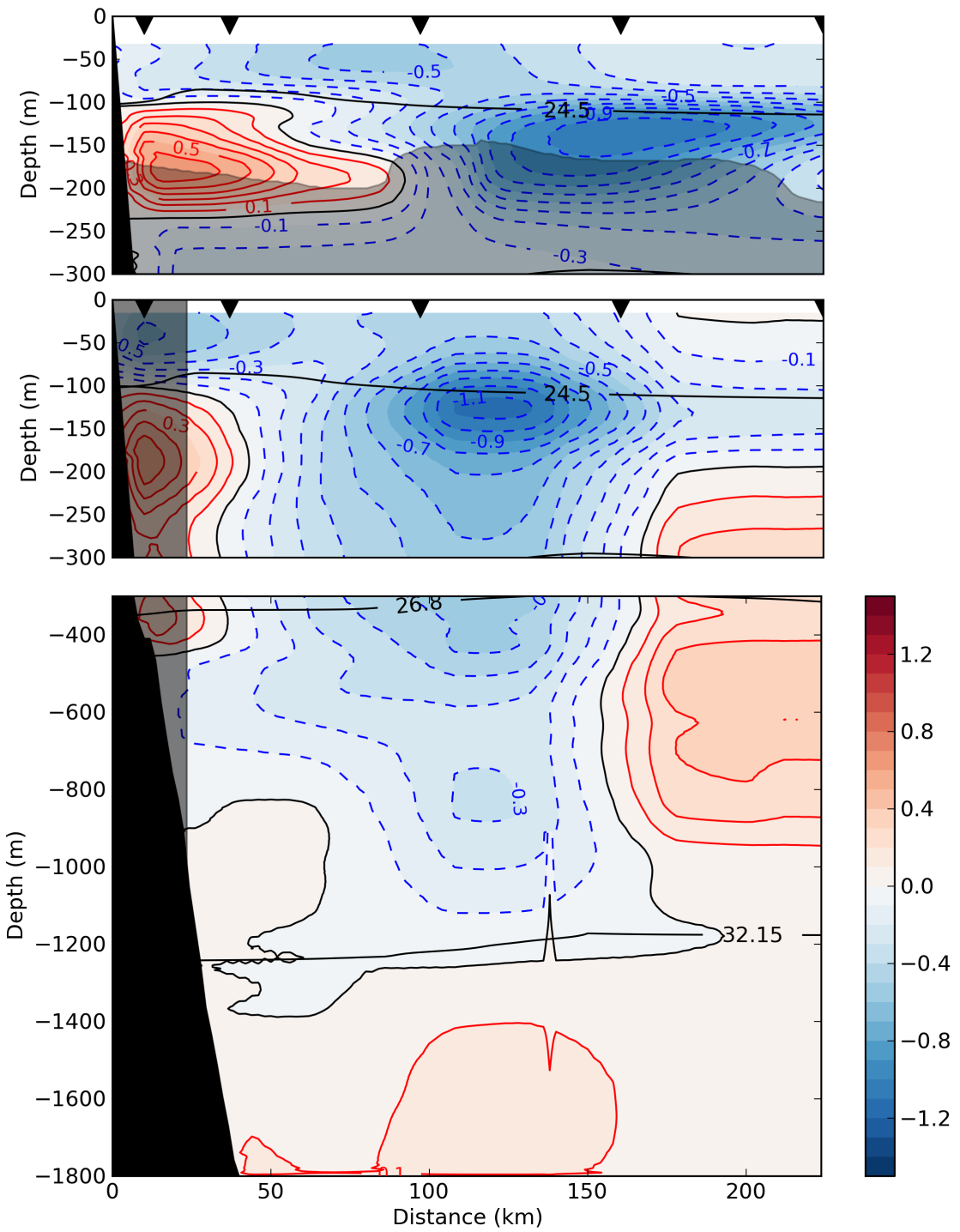

Figure 2.20: Comparison between the geostrophic velocity referenced to the $\sigma_{1}=32.15$ $\mathrm{kg} . \mathrm{m}^{-3}$ isopycnal (middle and bottom panels) and ADCP velocity (top panel) for transect 9 from ONEII (October - December 2004). Blue areas indicate west/northwestward velocities, red areas indicate east/southeast velocities. The shaded area on the top panel indicates areas with percent good lower than 50. The shaded area on the middle and bottom panels indicates the portion of the plot which is generated by extrapolation. Inverted triangles indicate the location of oceanographic stations. The isopycnals $\sigma_{\theta}=24.5 \mathrm{~kg} . \mathrm{m}^{-3}$ and $\sigma_{\theta}=26.8 \mathrm{~kg} \cdot \mathrm{m}^{-3}$ are also shown. 
The geostrophic velocity sections (Figures 2.19 and 2.20, middle and bottom panels) show the NBUC reaching 800 and $1100 \mathrm{~m}$ in ONEI and ONEII, respectively, considering the $0.1 \mathrm{~m} . \mathrm{s}^{-1}$ isotach as the limit of the current. In both sections the NBUC transports Tropical Water (TW), South Atlantic Central Water (SACW) and Antarctic Intermediate Water (AIA). The NBUC transport varies between sections: on ONEI it is 24.78 Sv (7.5 Sv AT, 10.35 Sv SACW, 6.95 Sv AIA) and during ONEII it increases to 43.35 Sv (7.8 Sv AT, 15.06 Sv SACW, 20.47 Sv AIA). So the large difference in transport is mostly due to an increase of the transport in the AIA layer during ONEII. The difference between the transport calculated from ADCP velocities (between the surface and $300 \mathrm{~m}$, therefore not accounting for any transport in the AIA range) between both cruises is not nearly as large; only about $0.5 \mathrm{~Sv}$.

In both sections the eddy has no surface signature, with the velocity transition from the northwestward surface flow to the southeastward subsurface flow at about 80$100 \mathrm{~m}$. The eddy is confined between the coast and $40 \mathrm{~km}$ off the coast, and in both geostrophic sections it appears with two cores; one closer to the surface, at about 100-200 $\mathrm{m}$, and another at about $350 \mathrm{~m}$. In addition, on the ONEI geostrophic velocity section 8 a possible third core of the eddy can be identified at approximately $550 \mathrm{~m}$. The transport of the eddy is $1.97 \mathrm{~Sv}$ and $2.07 \mathrm{~Sv}$ during ONEI and ONEII, respectively, mostly made of SACW (approximately 1.7 Sv) with a smaller amount of water in the AIA layer (approximately $0.7 \mathrm{~Sv}$ ). 


\subsection{Discussion}

The Western Equatorial Atlantic has been a region of great interest of the oceanographic community due to its importance in the Interhemispheric heat and mass transport. With the intent of investigating the role of this region on the Conveyor belt, most studies focus either on the northeast coast of South America, or in an equatorial section along 44 ${ }^{\circ} \mathrm{W}$ (SILVEIRA et al., 1994; STRAMMA et al., 1995; SCHOTT et al., 1995; FISCHER and SCHOTT, 1997; SCHOTT et al., 1998; SCHOTT et al., 2002; SCHOTT et al., 2003; SCHOTT et al., 2005; GOES et al., 2005; RICHARDSON and FRATANTONI, 1999). The flow south of the equator, specifically, was mostly investigated with repeated zonal sections at $10^{\circ} \mathrm{S}$ and $5^{\circ} \mathrm{S}$, and a meridional section at $35^{\circ} \mathrm{W}$, preventing the detailed analysis of mesoscale horizontal structures in this region. The only study that focuses on mesoscale features between $5^{\circ}$ and $10^{\circ} \mathrm{S}$ is the study of Silveira et al. (1994), in which the fine sampling grid allowed the authors to identify the previously unknown subsurface character of the NBC in its formation area, as well as other mesoscale features such as the retroflection to generate the SEUC. With a finer sampling grid than most of the previous studies in the region, in this dissertation we were able to identify the changes on the NBUC regime that take place as this current flows equatorward.

The analysis of the data-set between $11^{\circ} \mathrm{S}$ and $6^{\circ} \mathrm{S}$ showed the NBUC with its core at approximately $200 \mathrm{~m}$, presenting no shoaling in the downstream direction. During ONEI cruise the core was slightly $(\approx 50 \mathrm{~m})$ deeper and the near-surface velocities stronger, yielding a larger transport of the NBUC on this realization. This seems to be related to the seasonal variation of the winds over the Equatorial Atlantic. With weaker winds during February, the Ekman transport during ONEI was weaker, allowing for the near-surface northward velocities to be stronger. In both cruises, the NBUC core was attached to the continental slope. Our results corroborate previous studies (SILVEIRA et al., 1994; GOES et al., 2005; STRAMMA et al., 1995; SCHOTT et al., 2002; SCHOTT et al., 2005). Also, the near-surface ADCP-derived streamfunction maps for this region for the ONEI cruise (February-March, 2002), show a bifurcation of the cSEC, with one branch going south and then making a cyclonic turn to feed into the NBUC; this is very similar to the observed by Silveira et al. (1994), whose data acquisition months (May- 
July) were similar to the ONEI cruise (February-March). The presence of this cyclonic turn in ONEI cruise and during Silveira et al. (1994) s cruise may indicate a seasonality of this feature. During ONEII cruise, which took place in October-December, this cyclonic turn of the cSEC was not identified.

Between $6^{\circ}$ and $4^{\circ} \mathrm{S}$, we identified significant changes in the NBUC regime, as it receives large contribution from the cSEC (SILVEIRA et al., 1994; LUMPKIN and GARZOLI, 2005), increasing its transport. Another difference between the flow in this region and the upstream NBUC is the flow in its opposite direction, with a core of $\approx$ $0.4 \mathrm{~m} \cdot \mathrm{s}^{-1}$ at $200-250 \mathrm{~m}$ depth, at approximately $160 \mathrm{~km}$ off the coast. The analysis of streamfunction and velocity maps for both cruises at $144 \mathrm{~m}$ indicate that this flow corresponds to the SEUC, being fed into by a retroflection of the NBUC, as also indicated by Silveira et al. (1994) and Stramma et al. (1995).

North of $4^{\circ} \mathrm{S}$, one of the main studies on synoptical horizontal distribution of ocean currents is from Goes et al. (2005). These authors use ADCP, $\mathrm{CTDO}_{2}$, and XBT data to analyze the source waters of the currents in the region and identify their pathways close to the Equator. They also calculate the streamfunction distribution for the flow in the area between $35^{\circ} \mathrm{W}$ and $44^{\circ} \mathrm{W}$, but were not able to describe in detail the circulation in the region of the Potiguar Bight due to the lack of data in this area. The finer resolution of the sampling grid of the data-set analyzed in this dissertation allowed a more thorough investigation of the mesoscale structures on the northeastern coast of South America, specially in the region between $36^{\circ} \mathrm{W}$ and $37^{\circ} \mathrm{W}$, where we found that the NBUC presents a particular and previously undescribed behavior.

This region, as we found in this dissertation, is unique in the sense that the NBUC is not attached to the coast, but located at about $150 \mathrm{~km}$ from it. The NBUC core in these sections has strong velocities of about $0.8-1.3 \mathrm{~m} \cdot \mathrm{s}^{-1}$, at $100-150 \mathrm{~m}$ depth, with a nearsurface $(32 \mathrm{~m})$ signature of $0.4-0.6 \mathrm{~m} . \mathrm{s}^{-1}$. Attached to the coast is a 0.3-0.6 m.s $\mathrm{s}^{-1}$ core of southeastward velocities, at approximately 150-200 m depth, which, after analysis of streamfunction maps, we found to be a recirculation of the NBUC, which we named Potiguar Eddy (PE). This feature had not been described by any of the previous studies in the area; specifically, the study from Goes et al. (2005) lacked enough data to analyze in 
detail the ocean currents in this region.

The PE is an elliptical shaped eddy, with major and minor axes of approximately 330 and $130 \mathrm{~km}$, with a subsurface signature. It is centered at about $36^{\circ} \mathrm{W}, 4^{\circ} \mathrm{S}$, and extends from $100 \mathrm{~m}$ to $400 \mathrm{~m}$, with maximum velocities of $0.6 \mathrm{~m} \cdot \mathrm{s}^{-1}$, recirculating about 2 $\mathrm{Sv}$ of the water from the NBUC. The subsurface nature of this feature is not something unprecedent in the Western Equatorial Atlantic. Subsurface-intensified rings with no surface signature have been reported to pinch off the NBC retroflection, further north of our study area, and translate northwestward (GARRAFFO et al., 2003). Johns et al. (2003), specifically, report a NBC retroflection ring with characteristics that resemble the PE. Their "ring 1 " was identified at $\approx 8^{\circ} \mathrm{N}$ with maximum velocities at approximately $150 \mathrm{~m}$, extending vertically from 50-100 m to about $400 \mathrm{~m}$. This eddy, as the PE, was assymetric, with a stronger and deeper-reaching nortwestward velocities lobe when compared to the southeastward velocities one, with both lobes with velocities comparable to the ones present in the PE. This feature has $\mathrm{a} \approx 200 \mathrm{~km}$ diameter, which also makes it comparable to the PE, even though their process of generation clearly differ. As the PE, Johns et al. (2003) s ring 1 had no signature in altimetry data. The lack of altimetry signature is probably one of the main reasons why subsurface-intensified NBC rings as well as the PE remained undetected for so long. After the estimation of its Rossby and Burger numbers, we reach the conclusion that, as expected, this is a typical mesoscale feature of the Western Equatorial Atlantic, with reasonable correspondence between geostrophic velocities within the eddy and global numerical model outputs due to a dominant geostrophic balance. As a matter of fact, the upper-bound Rossby number value of about 0.4 is comparable with the 0.36 estimated by Silveira et al. (2000) for the NBC retroflection deep eddies at $5^{\circ} \mathrm{N}$. These authors used quasi-geostrophic theory to investigate the anticiclone dynamics. Moreover, if the PE depth-average Rossby number is considered, the value of 0.22 is very typical from the supbtropical western boundary currents at temperate latitudes. As examples, the Brazil Current semi-permanent anticiclones off the Eastern Brazilian continental margin, presented by Soutelino et al. (2013) at $15^{\circ} \mathrm{S}-20^{\circ} \mathrm{S}$ have Ro of about 0.20 .

Further downstream, between $38^{\circ} \mathrm{W}$ and $41^{\circ} \mathrm{W}$, the southeastward flow from PE is not detected close to the coast; instead, the NBUC is again attached to the continental 
slope. The surface expression of the NBUC, in this case caused by the contribution from the cSEC, increases, reaching $0.7 \mathrm{~m} \cdot \mathrm{s}^{-1}$ at $41^{\circ} \mathrm{W}$. The NBUC on these sections occupy a much larger portion of the water column, with a width of about $200 \mathrm{~km}$ compared to aproximately $100 \mathrm{~km}$ on the previous transects. There is not a clear surface core; the NBUC core is still located at about $150 \mathrm{~m}$ depth. Only in $41^{\circ} \mathrm{W}$ there seems to be a surface core being formed, which is in agreement with Schott et al. (1998), who indicate that the NBUC/cSEC turns into the surface-intensified NBC only at $44^{\circ} \mathrm{W}$.

Aditionally, at about $1^{\circ} \mathrm{S}$, between $37^{\circ} \mathrm{W}-39^{\circ} \mathrm{W}$, a flow in the opposite direction of the NBUC is identified. This flow increases in velocity northwestward, reaching maximum velocities of $0.6 \mathrm{~m} . \mathrm{s}^{-1}$ at about $39^{\circ} \mathrm{W}$. The analysis of streamfunction maps indicate that this flow corresponds to the retroflected thermocline portion of the NBUC to form the Equatorial undercurrent, corroborating the study of Goes et al. (2005); Schott et al. (1998); Urbano et al. (2008).

This chapter presented the characteristics and changes of the NBUC along its path equatorward, and some features associated with this current, such as the retroflections to feed into the EUC and SEUC. The NBUC main characteristics, such as transport, core depth, and width are in agreement with previous studies, as well as the location, transport and depth of the two mentioned retroflections. Here we stress the identification of the Potiguar Eddy, due to the fact that it had not been yet described in the scientific literature. On this chapter we were only able to provide evidence of its existence from two oceanographic cruises; on the next, we will adress its permanence/recurrence and temporal variability. 


\section{Chapter 3}

\section{Temporal Variability}

After characterizing the eddy, a few questions remain unanswered. We can estimate the transport and the water masses transported by the PE observed in oceanographic cruises, but is that feature permanent in the Potiguar Bight? The evidence of its existence in both cruises suggests so, but the analyses of current meter time series are necessary for making definitive statements. In this section we use moored and altimetry data, as well as numerical model outputs, in order to investigate whether the PE is stationary or recurrent, as well as address the intraseasonal variability that the PE may present.

\subsection{Data sets}

\subsubsection{Mooring Data}

Data from two moorings, hereafter Potiguar Basin 1 (PBM1) and Potiguar Basin 2 (PBM2), from PETRÓLEO BRASILEIRO S.A., were analyzed in terms of the vertical structure of the Potiguar Eddy as well as its time-dependent behavior. The two moorings were deployed on the continental slope of the Potiguar Bight, and the detailed information about period of data acquisition, sampling frequency, instruments used, and other details are presented on the following paragraphs.

The PBM1 mooring had upward-looking 75kHz Teledyne RD-Instruments ADCP and Aquadopp instruments. It was deployed approximately over the $1000 \mathrm{~m}$ isobath at $4.2^{\circ} \mathrm{S}, 37.2^{\circ} \mathrm{W}$ (Figure 3.1), with ADCP data from the near-surface (44 m) down to 444 
m, with 10-meter cells. At 800 and 995 m, hourly currents were measured by Aquadopp current meters. All instruments were set to acquire velocity data hourly. This mooring was deployed on April 6th, 2008 and retrieved on April 12th, 2009, and had three campaigns for data recovery and redeployment. Due to instrument failure, the dataset could only be used until November 8th, 2008.

Mooring PBM2 also had upward-looking 75kHz Teledyne RD-Instruments ADCP and Aquadopp instruments, and was deployed close to mooring PBM1, approximately over the $2000 \mathrm{~m}$ isobath at $3.9^{\circ} \mathrm{S}, 37^{\circ} \mathrm{W}$ (Figure 3.1). Velocity data were acquired by an ADCP system from the near-surface $(35 \mathrm{~m})$ down to $365 \mathrm{~m}$, with 10-meter cells. Further downward, velocity data at 800, 1200, 1600, and $1995 \mathrm{~m}$ were acquired by Aquadopp current meters, with all instruments set to acquire velocity data hourly.

The PBM2 mooring was deployed and retrieved on the same dates as mooring PBM1 (April 6th, 2008 - April 12th, 2009), also with three campaigns for data recovery and redeployment. There was no instrument failure in PBM2, therefore the dataset could be used in its entire extent. The site of the deployment of both moorings is close to ONEII section 9, as shown on Figure 3.1. It is noteworthy that both moorings are located on the area that the ADCP sections indicate as the nearshore lobe of the PE, therefore the mooring-acquired velocities are southeastward over the vertical extent of the eddy.

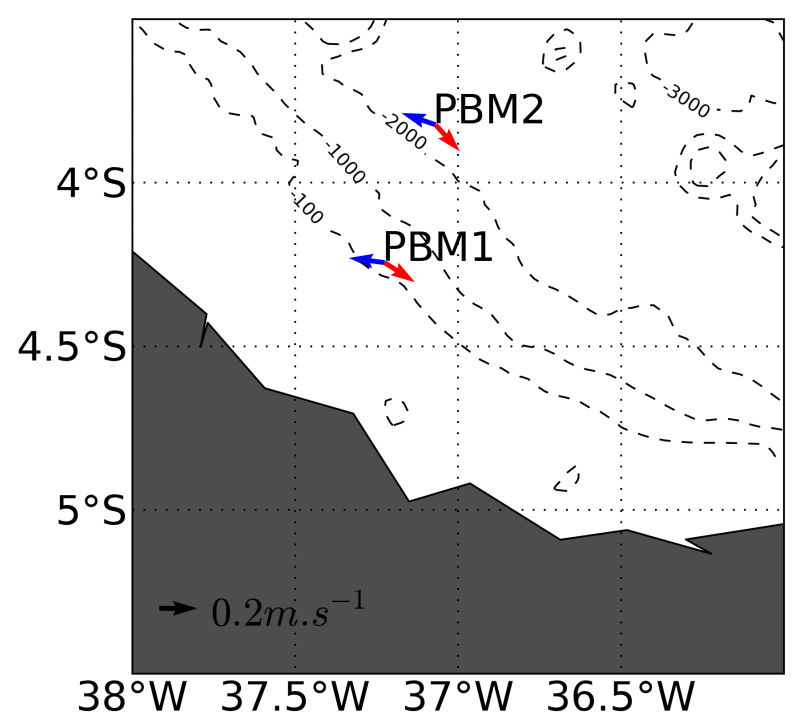

Figure 3.1: Location of the PBM1 and PBM2 moorings, with the mean velocity vectors for $44 \mathrm{~m}$ (blue) and $144 \mathrm{~m}$ (red). 


\subsubsection{Numerical Model Outputs}

Considering the coarse oceanographic cruise data and the small time span of the mooring data, we use the outputs of a global model to address the longer variability and persistence of the Potiguar Eddy. We analyze 8 years of results from a Hybrid Coordinate Ocean Model (HYCOM) assimilative run, carried out by the HYCOM Consortium with results available on the web (HYCOM, 2014). This run has a $1 / 12^{\circ}$ horizontal resolution, which translates to a $8 \mathrm{~km}$ spacing near the equator, and is configured vertically for 32 hybrid layers. The surface forcing is from the Navy Operational Global Atmospheric Prediction System (NOGAPS) including wind stress, wind speed, heat flux and precipitation.

The data assimilation scheme used is the Navy Coupled Ocean Data Assimilation (NCODA) system (CUMMINGS, 2005), which assimilates alongtrack satellite altimeter observations, satellite and in-situ Sea Surface Temperature, as well as temperature and salinity profiles from expendable bathythermographs (XBTs), ARGO floats and moored buoys. The downward projection of the surface information is made using Cooper and Haines (1996) scheme. A total of 8 years (Nov/2003-December/2011) of daily temperature, salinity, altimetry, zonal and meridional velocity model results were analyzed, on the Potiguar Bight $\left(35^{\circ} \mathrm{W}-38^{\circ} \mathrm{W} ; 6^{\circ} \mathrm{S}, 3^{\circ} \mathrm{S}\right.$, and on a zonal section at $4^{\circ} \mathrm{S}$.

\subsubsection{Altimetry Data}

In order to characterize the variability found in mooring velocities, we turn to satellite sea level anomaly data. The altimetry data that we use are merged dual-satellite anomalies referenced to the 1993-2012 period from the Archiving, Validation and Interpretation of Satellite Oceanographic Data (AVISO). The product that we used is level 4, delayed-time, with a 0.25 degree zonal and meridional resolution, part of project SSALTO/Duacs (AVISO, 2014). We use altimetry data over the $4^{\circ} \mathrm{S}$ latitude, over the entire Atlantic Ocean, between January 1st, 2003 and December 31st, 2009. The $4^{\circ} \mathrm{S}$ section was chosen in order to investigate processes that could be originated in the Atlantic Ocean, propagate westward, and reach the locations of the moorings, which are approximately at $4^{\circ} \mathrm{S}$. The time span was chosen to include the time-period of the HYCOM numerical model results, ONEII cruise synoptic data, and mooring data. 


\subsection{Observed Intraseasonal Variability}

\subsubsection{Current meter mooring mean patterns}

The velocity vectors of the mooring acquired data were rotated (65 degrees anticlockwise) into alongshore and crossshore components, conventioned that the southeastward velocities are positive. The rotated mean profiles for moorings PBM1 and PBM2 (Figures 3.2 and 3.3 , respectively) show the mean magnitude of the NBUC and the PE.

As can be seen in Figure 3.2, right panel, the PE is present on the southeastward mean moored velocity profile, extends from about $60 \mathrm{~m}$ to $264 \mathrm{~m}$ on PBM1, with its 0.46 $\mathrm{m} . \mathrm{s}^{-1}$ core located at $144 \mathrm{~m}$ depth. On PBM2 (Figure 3.3, right panel), further offshore, the PE is also identified on the mean profile, occupying a larger portion of the water column and extending from $100 \mathrm{~m}$ to $430 \mathrm{~m}$, with a deeper and weaker $0.32 \mathrm{~m} \cdot \mathrm{s}^{-1}$ core at $200 \mathrm{~m}$ depth. Below the PE, westward/northwestward mean velocities are observed, stronger on PBM1 $\left(\approx 0.2 \mathrm{~m} \cdot \mathrm{s}^{-1}\right)$ than on PBM2 $\left(\approx 0.15 \mathrm{~m} \cdot \mathrm{s}^{-1}\right)$. The (northwestward) mean surface flow, on the other hand, is stronger on PBM2 $\left(0.45 \mathrm{~m} . \mathrm{s}^{-1}\right)$ than on PBM1 $\left(0.2 \mathrm{~m} \cdot \mathrm{s}^{-1}\right)$.

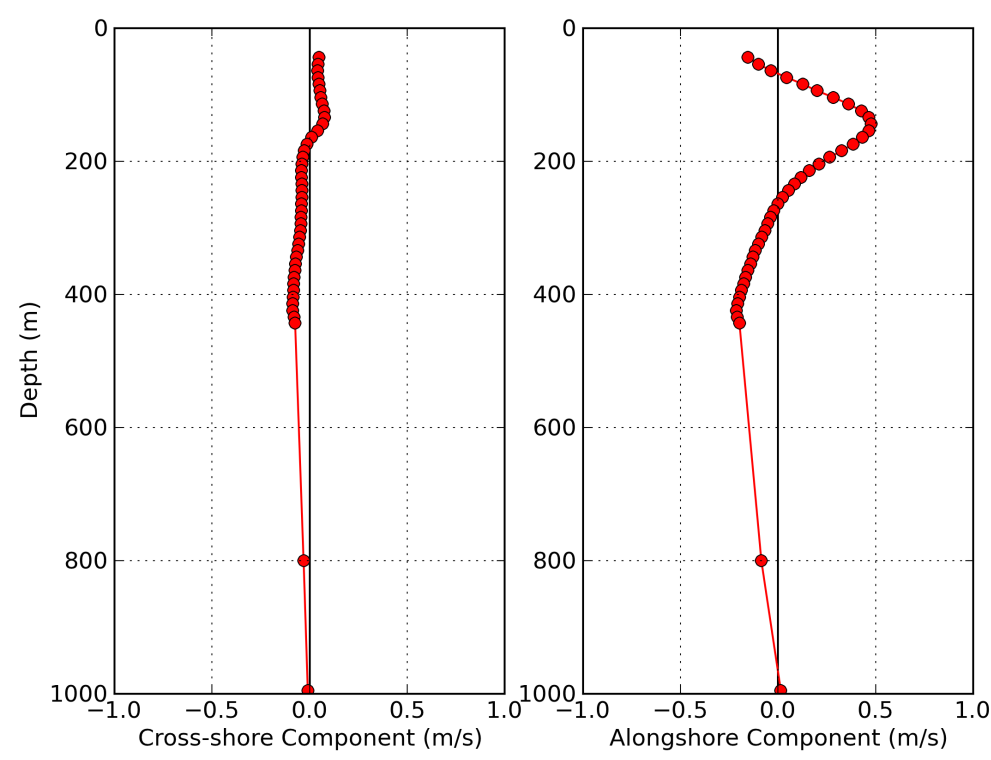

Figure 3.2: Mean cross-shore (left) and alongshore (right) profiles for mooring PBM1. Positive values of cross-shore (alongshore) velocity indicate northeastward (southeastward) flow. 


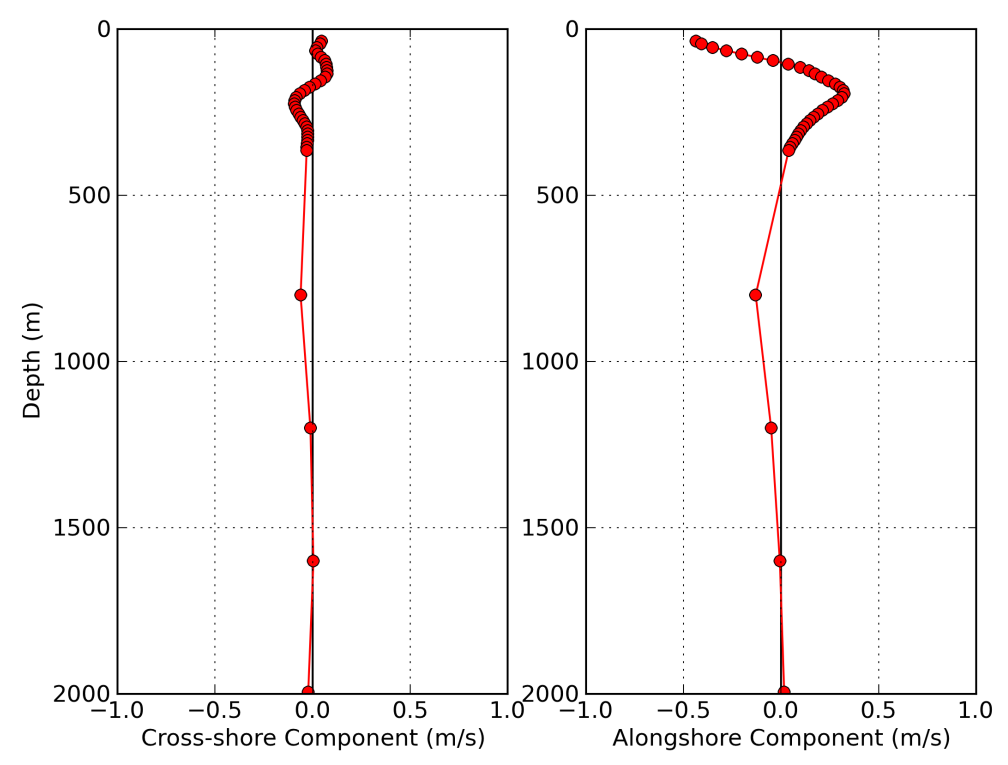

Figure 3.3: Mean cross-shore (left) and alongshore (right) profiles for mooring PBM2. Positive values of cross-shore (alongshore) velocity indicate northeastward (southeastward) flow.

Comparing the mean velocity profile of PBM1 (Figure 3.2) and ONEII section 9 (Figure 2.16, it is noticeable the resemblance between the mean profile from the mooring line and the nearshore portion of the ONEII velocity section. In both the velocity inversion associated with the upper limit of the eddy is at about 50-100 m, and in both the core of the PE is at about $150 \mathrm{~m}$ depth. The signature of the PE on the mean alongshore velocity profiles for both moorings strongly suggest that this is a permanent feature in the area.

\subsubsection{Current Meter Mooring Time Series Analysis}

In order to investigate the variability of the system, we performed Empirical Orthogonal Function (EOF) analysis on the alongshore velocity data of both moorings. After the EOF analysis of the data, we followed Preisendorfer (1988) and used Montecarlo simulations in order to assure which EOF modes are significant at the $95 \%$ confidence level.

For PBM1, we found four statistically significant modes of variability (Figure 3.4), explaining $60 \%, 16 \%, 8 \%$, and $5 \%$ of the variance of the original series. For PBM2 
data, on the other hand, 5 statistically significant modes were found (Figure 3.5), suggesting that more processes take place on mooring PBM2, therefore that the variability pattern is more complex at this location.

We focus on the two modes that have the highest explained variance percentage, i. e., the first and second EOF modes. Since the vertical structure for the first two modes of the moorings is similar, we describe them together.

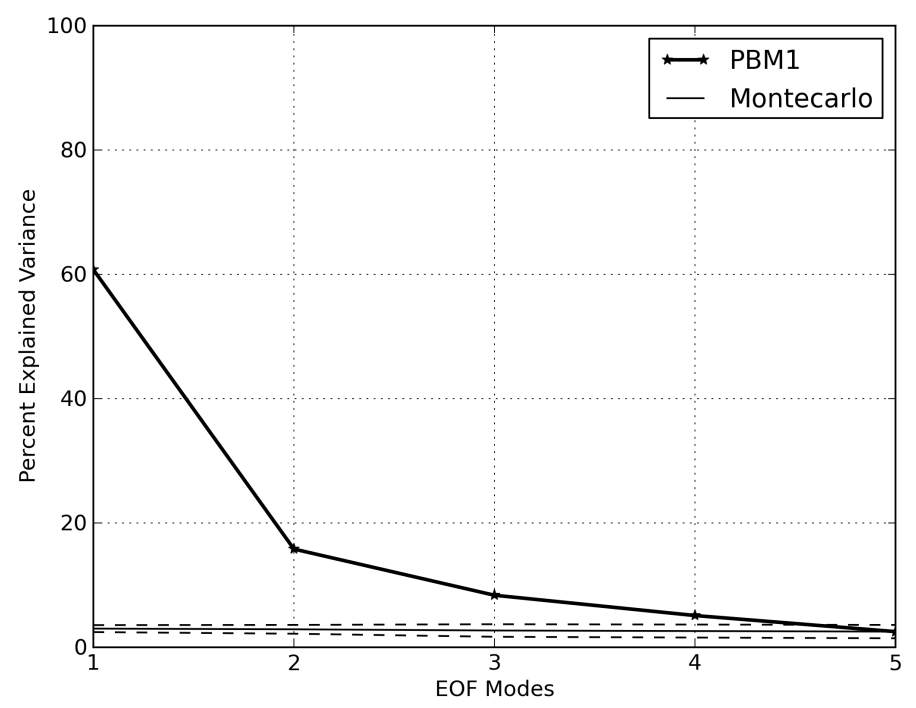

Figure 3.4: Explained variance of each statistical mode calculated from the observed PBM1 data and from a random time-series. The thick black line represents the explained variance for each statistical mode for the observed mooring; the thin black line represents the mean explained variance for the statistical modes of a random time-series (Montecarlo simulations). The dashed lines represent the interval of two standard deviations about the mean.

On the vertical structure of the first EOF for PBM1 (Figure 3.6), the highest amplitude is located at the part of the water column corresponding to the lower half of the eddy, with peak amplitude at about $270 \mathrm{~m}$ depth. On the remaining of the water column, the amplitude decreases considerably, reaching values very close to zero close to the surface and at the bottom.

The vertical structure of the first EOF for PBM2, explaining 37\% of the variance of the original time-series, is shown on Figure 3.7. It presents high values over the water 
column corresponding to the lower half of the mean PE (compare Figures 3.7 and 3.3 , right panel), with highest values at about $350 \mathrm{~m}$ depth, corroborating the information presented by the first EOF for PBM1.

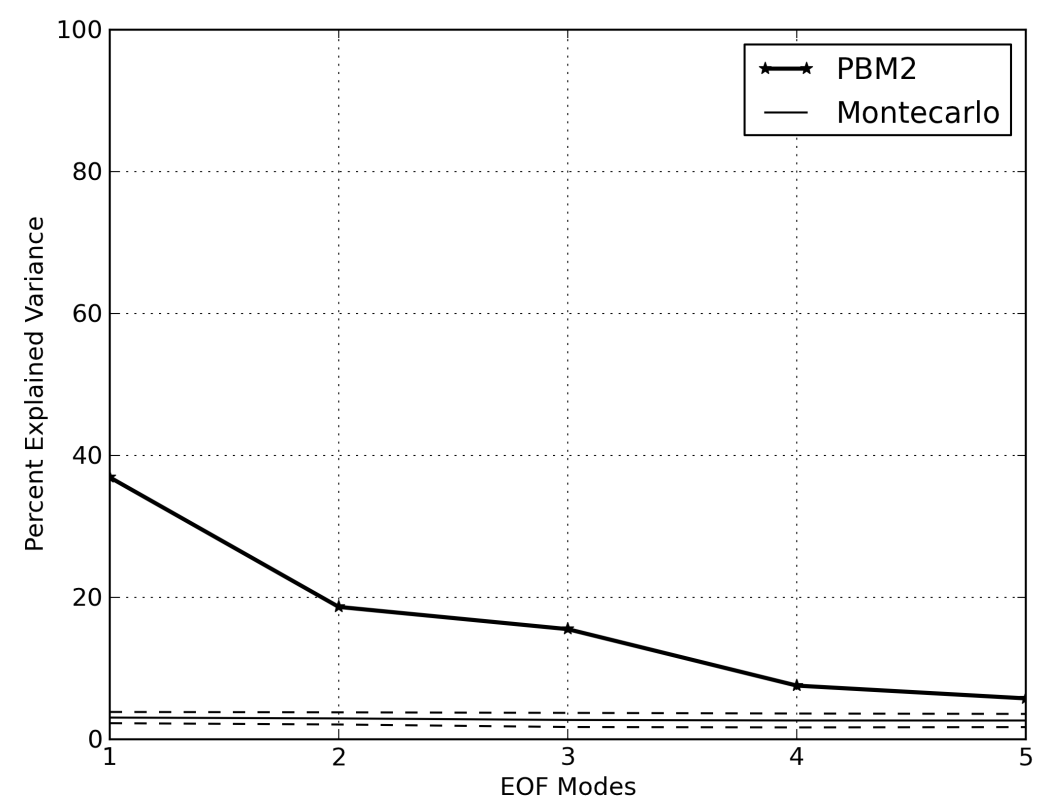

Figure 3.5: Explained variance of each statistical mode calculated from the observed PBM2 data and from a random time-series. The thick black line represents the explained variance for each statistical mode for the observed mooring; the thin black line represents the mean explained variance for the statistical modes of a random time-series (Montecarlo simulations). The dashed lines represent the interval of two standard deviations about the mean.

The vertical structure of the second EOF (Figure 3.8) for PBM1 has as main feature its peak amplitude approximately at the depth of the upper boundary of the eddy, with relatively high values between the near-surface layer and about $200 \mathrm{~m}$. The amplitude zero-crossing takes place at approximately $250 \mathrm{~m}$, close to the lower boundary of the mean PE. On the remaining of the water column the amplitude presents small values, virtually reaching zero at the bottom. 

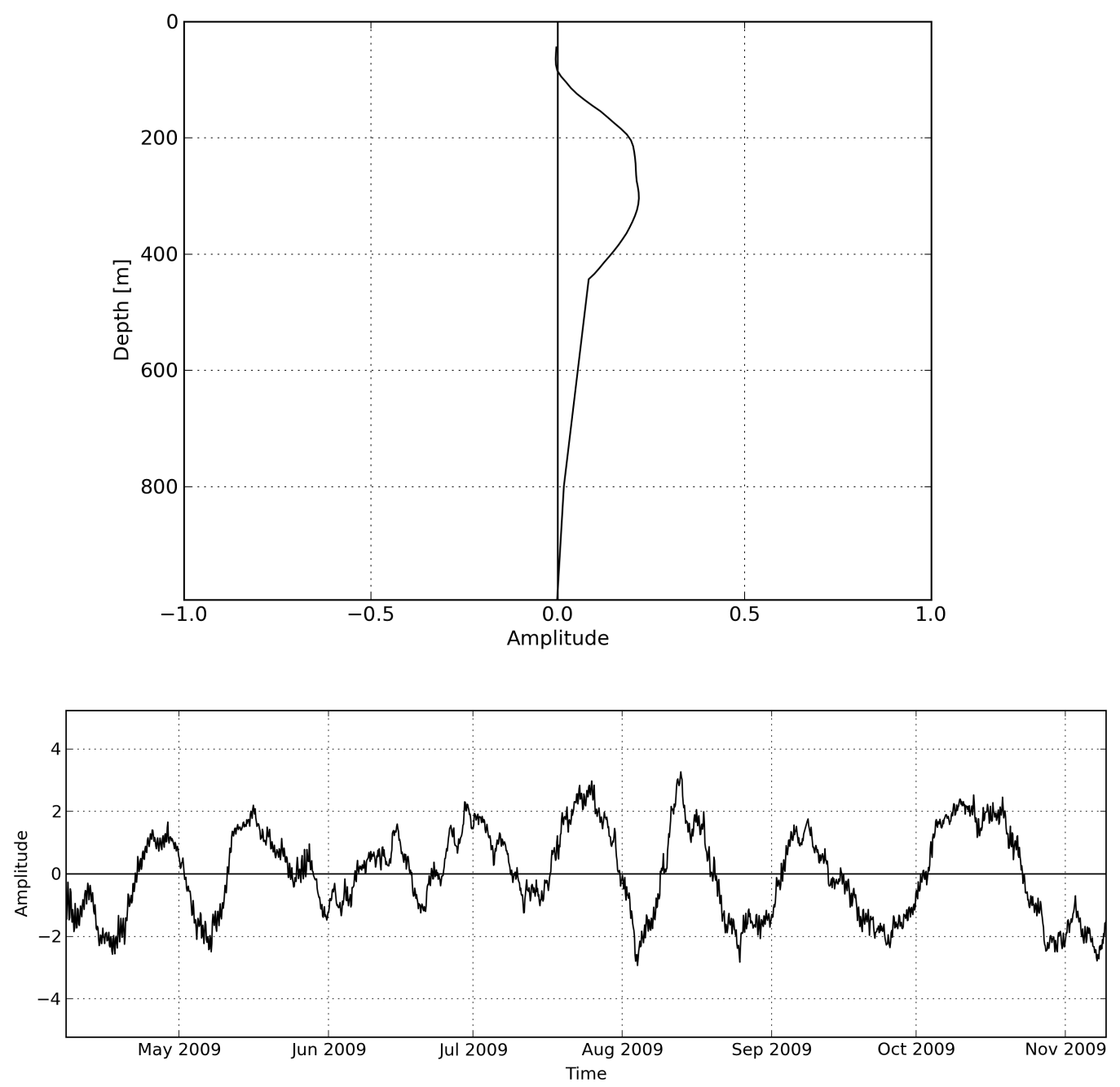

Figure 3.6: Vertical structure of the first EOF for mooring PBM1 (top panel) and amplitude time series for the first EOF mode for PBM1 (bottom panel).

Figure 3.9 shows the vertical structure of the second EOF for PBM2. This EOF explains $19 \%$ of the variance of the original data, with highest amplitude at about $100 \mathrm{~m}$, decreasing sharply and presenting low values on the remainder of the water column. The $100 \mathrm{~m}$ depth is roughly the depth of the first velocity inversion on the mean alongshore profile, i. e., the upper boundary of the PE. This also corroborates the information given by the EOF analysis of PBM1, in which the second EOF represents variability on the depth of the upper limit of the eddy. 

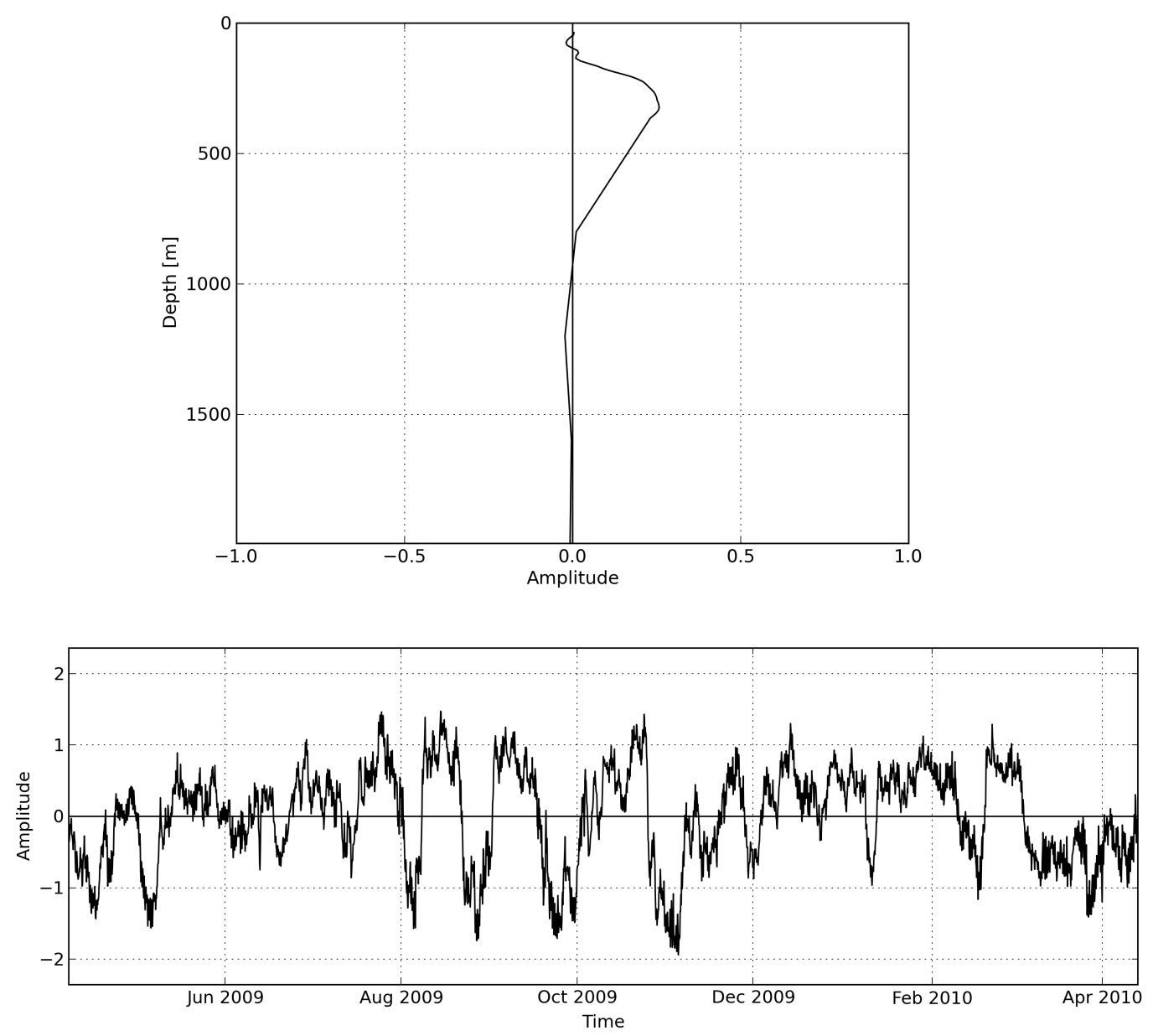

Figure 3.7: Vertical structure of the first EOF for mooring PBM2 (top panel) and amplitude time series for the first EOF mode for PBM2 (bottom panel).

The comparison between the mean alongshore velocity profile of both moorings (Figures 3.2 and 3.3 , right panels) and the vertical structure of the EOFs (Figures 3.6. 3.8 3.7 and 3.9 allows a better interpretation of these patterns of variability. The vertical structure of the first EOF, with highest amplitudes close to the lower boundary of the mean PE, indicates that the main pattern of variability (explaining 60\% and $37 \%$ of the variance of the time-series of PBM1 and PBM2, respectively) at the location of the moorings is associated with the increase/decrease of the vertical extent of the eddy, due to the variation on the depth of its lower boundary. The vertical structure of the second EOF, on the other hand, indicates that lower, but still important variability $(16 \%$ and $19 \%$ of the 
variance of the time-series of PBM1 and PBM2, respectively) is due to the variation of the depth of the upper boundary of the PE by upper layer processes, which also implicates in an increase/decrease of its vertical extent. In short, these two modes combined have an effect of increasing/decreasing of the PE vertical extent, mainly due to variations on its lower limit, with a smaller contribution from variations on its upper limit. Considering the subpycnoclinic nature of the eddy and that the first EOF mode explains a larger percentage of the variance of the original time-series for PBM1 as well as PBM2, here we will concentrate on the analysis of the first EOF mode, for both moorings.
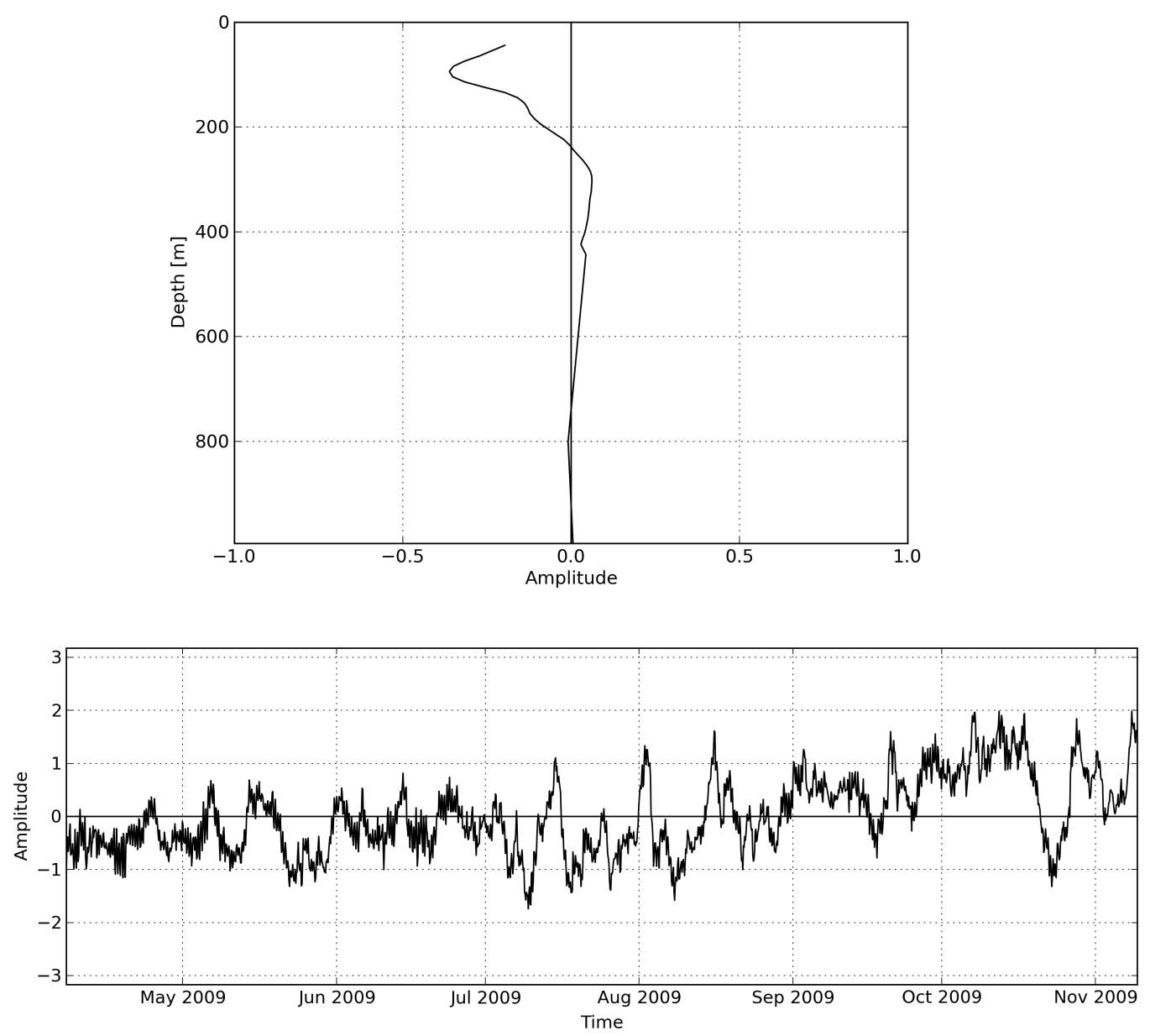

Figure 3.8: Vertical structure of the second EOF for mooring PBM1 (top panel) and amplitude time series for the second EOF mode for PBM1 (bottom panel). 

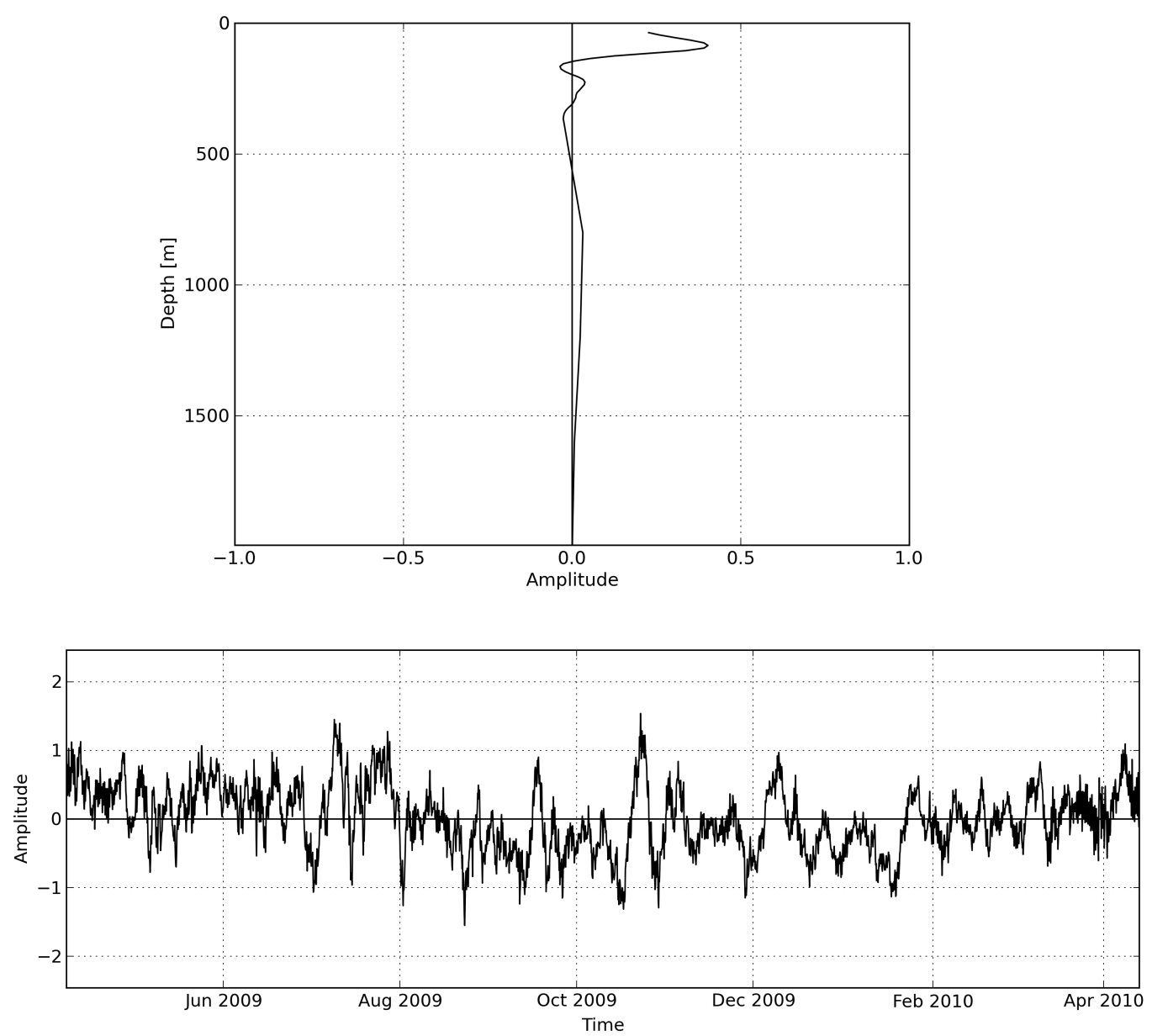

Figure 3.9: Vertical structure of the second EOF for mooring PBM2 (top panel) and amplitude time series for the second EOF mode for PBM2 (bottom panel).

To evaluate the periodicity of the identified variability, we performed wavelet analysis on the amplitude time-series of the first EOF mode for both moorings. Classical Fourier analysis was not performed due to the non-stationary character of the series, as shown in Figures 3.6 and 3.7, bottom panels). The resuls of the wavelet analysis are shown in Figures 3.10 and 3.11 for PBM1 and PBM2, respectively. Also, for comparison between the plots for PBM1 and PBM2, it must be stressed that the length of the time- series differ between the moorings (eight months for PBM1; one year for PBM2). After these considerations, the analysis of the plots show that the highest energy of the amplitude time series of the first EOF is concentrated at periods of 25-35 days, for both 
moorings, between July and December. For the remainder of the year, these oscilations are either absent or much weaker. Data from PBM1 presents these oscilations also on the period between May and August, weaker than during July-December. For both moorings, the period of the oscilation remains at about 25 days until the end of September, when it increases to about 35 days.

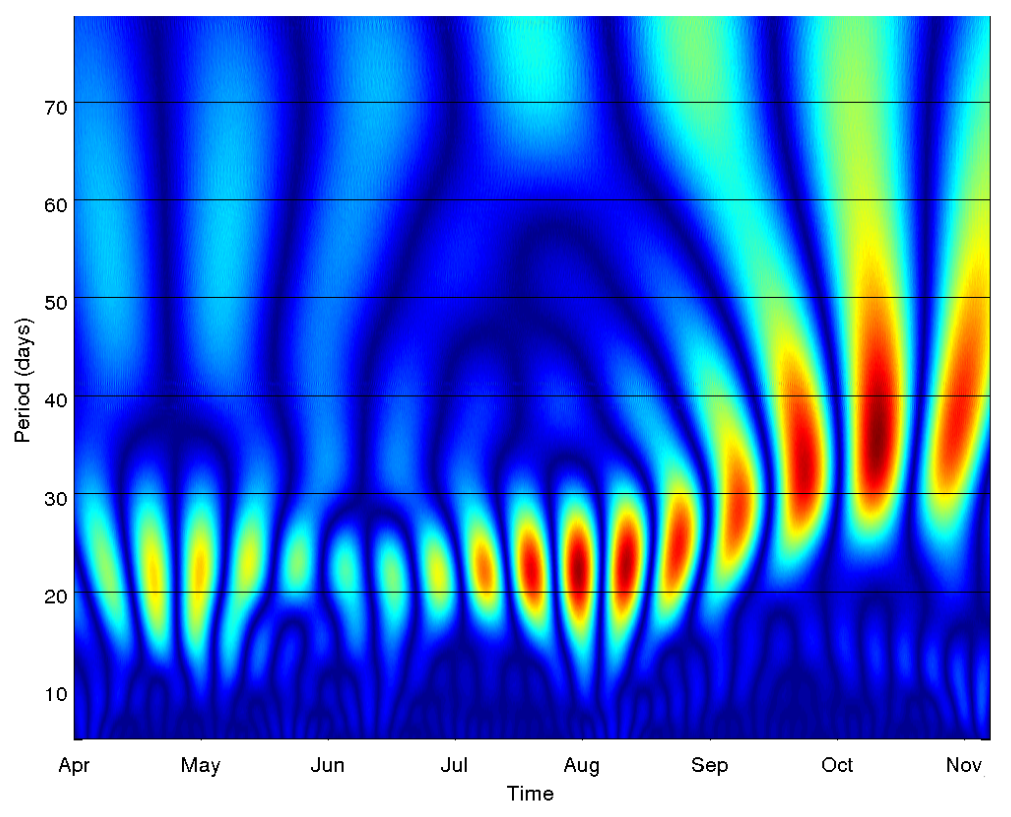

Figure 3.10: Wavelet analysis of the amplitude time-series for the first EOF for the alongshore velocity data for PBM1.

In order to better understand the EOF-derived variability found on the PE, we calculate the dynamical modes on the area of the moorings' deployment, following the procedure of Silveira et al. (2008). For the calculation, we use the ONEs cruises temperature and salinity profiles located closest to the location of deployment of the moorings, using a total of four profiles. The vertical structure of the dynamical modes for moorings PBM1 and PBM2 are shown on Figures 3.12 and 3.13, respectively.

After calculating the dynamical modes, in order to understand which ones play key roles on the variability of the system, we project the dynamical modes onto the EOF vertical structures. This enables us to characterize physically the variability experienced by the system. 


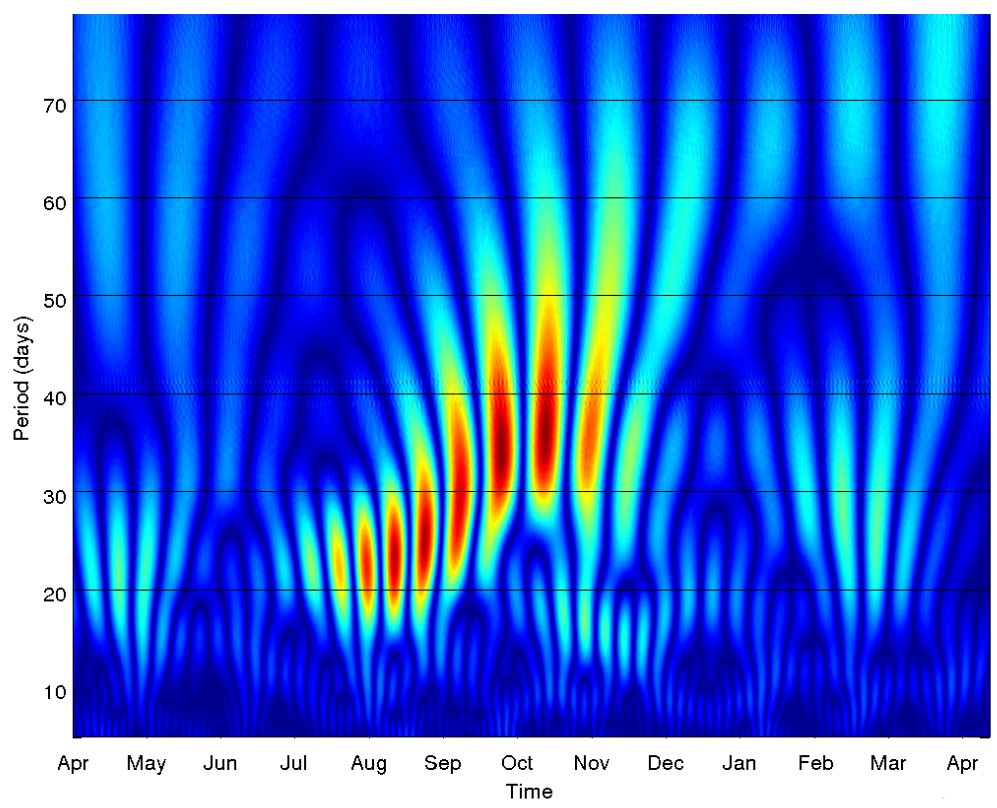

Figure 3.11: Wavelet analysis of the amplitude time-series for the first EOF for the alongshore velocity data for PBM2.

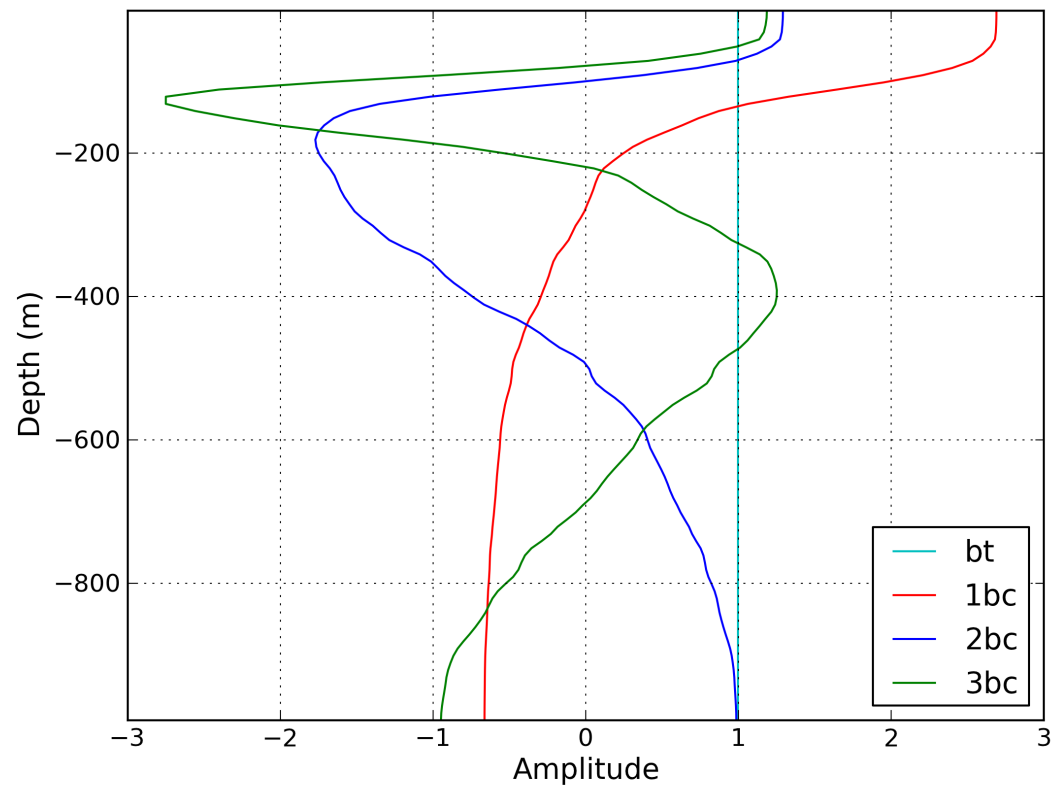

Figure 3.12: Vertical structure of the barotropic and first three baroclinic modes for mooring PBM1. 
The projection of the dynamical modes onto the first EOF for moorings PBM1 and PBM2 (Figures 3.14 and 3.15) suggests a predominance of the second baroclinic mode on their vertical structures. The barotropic and first baroclinic modes have little contribution; the resemblance with the vertical profile of the EOF just visibly increases when the second baroclinic mode is taken into account. Surely, with the addition of the third baroclinic mode, the similarity between the recomposed and the original EOF profile increases. Therefore, the variability presented by the PE is primarily a second baroclinic mode one.

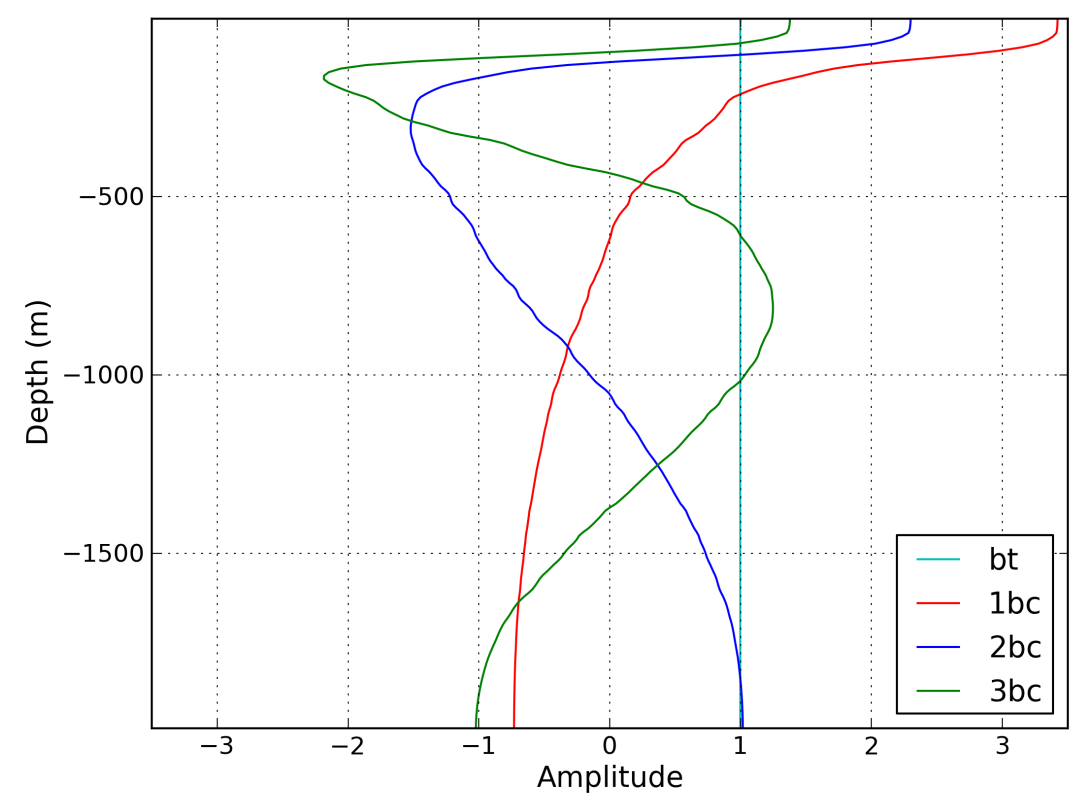

Figure 3.13: Vertical structure of the barotropic and first three baroclinic modes for mooring PBM2.

After identifying which dynamical mode plays the key role on the variability in the system, we turn to the linear wave theory in order to determine if the signal that reaches the Potiguar Eddy can be interpreted as a linear wave. We use the linear Rossby wave dispersion relationship (e.g., PEDLOSKY, 1986), considering no meridional propagation (meridional wavenumber equal to zero). If the signals in the EOF mode amplitudes are indeed from Rossby waves, they can just be generated eastward of the Potiguar Bight and then propagate westward. We thus choose a second-mode Rossby deformation radius $R_{d_{2}}$ 
for the Atlantic Ocean at $4^{\circ} \mathrm{S}, \approx 20^{\circ} \mathrm{W}$, of $206 \mathrm{~km}$. The depth considered was $3300 \mathrm{~m}$.

$$
\omega=\frac{-\beta k}{k^{2}+R_{d_{2}}^{-2}},
$$

where $\omega$ is the wave frequency, $\beta$ is the meridional gradient of planetary vorticity, $\mathrm{k}$ is the zonal wavenumber, and $\mathrm{R}_{d_{2}}$ is the second baroclinic Rossby deformation radius. We then plot the dispersion curve for such waves. The peak of the curve corresponds to 29-day waves. Hence, only waves longer than this period are associated to the linear Rossby waves. We thus take the value for the period of 35 days from the wavelet analysis of the amplitude time series of the first EOF mode. We then use the dispersion relation to obtain the two k values via Equation 3.1 corresponding to the 25-day and 35-day waves. As a result, we present the linear Rossby wave dispersion diagram in Figure 3.16, The wavelengths associated with these 35-day waves are shown in Table 3.1. We therefore conclude by inspection of Figure 3.16 that linear free second-mode Rossby waves can be used to approximate to the signal that dominates the first EOF mode amplitude time series of both moorings.

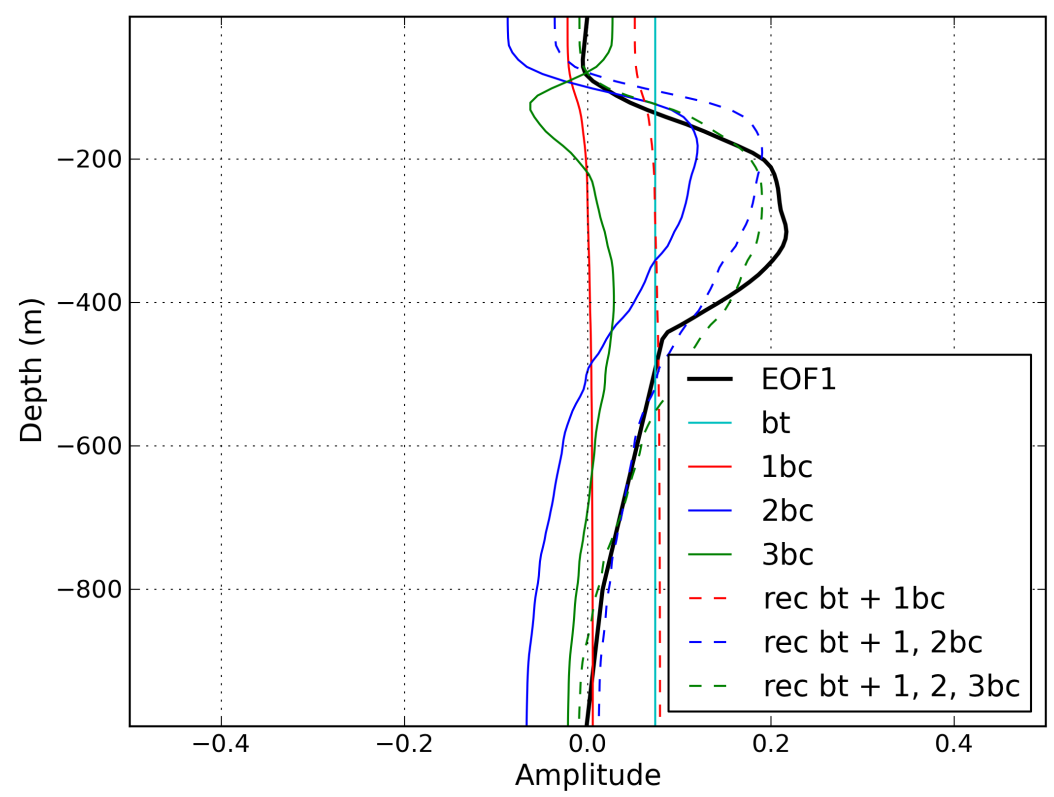

Figure 3.14: Projection of the dynamical modes onto the first EOF for mooring PBM1. 


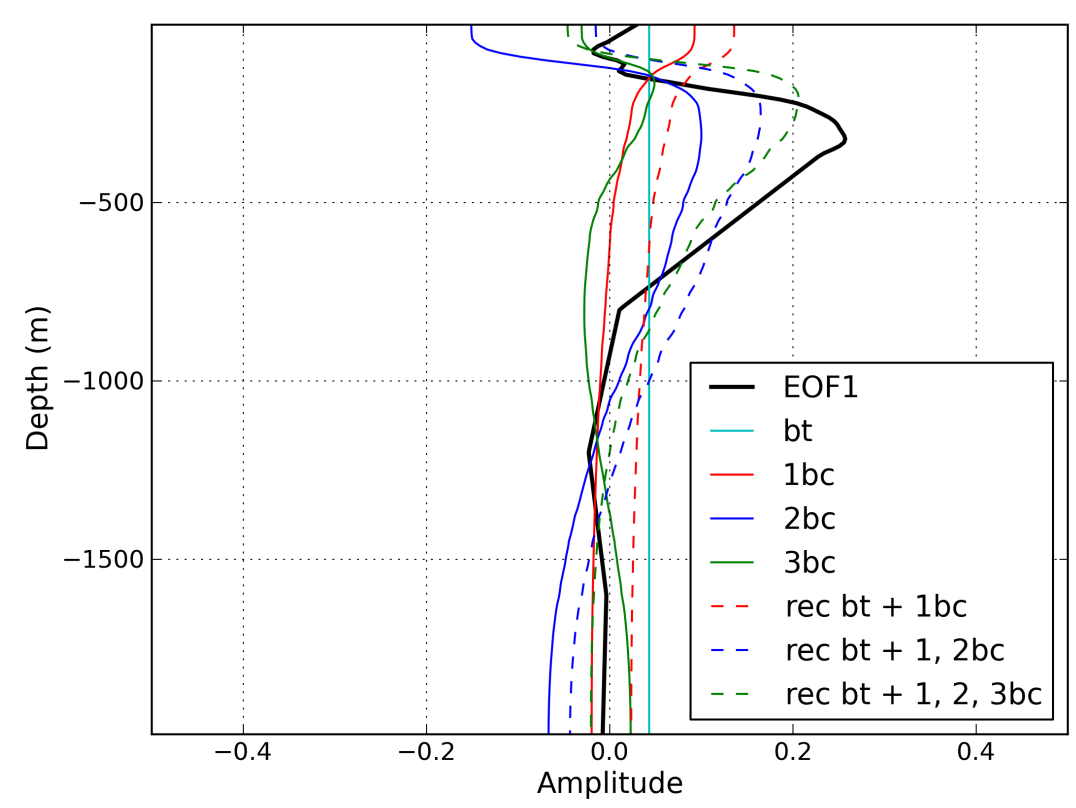

Figure 3.15: Projection of the dynamical modes onto the first EOF for mooring PBM2.

Table 3.1: Properties of the 35-day linear free second-mode Rossby waves in the Tropical Atlantic.

\begin{tabular}{cccc} 
Property name & Property symbol & Larger root & Smaller root \\
\hline zonal wavenumber & $k$ & $8.0 \times 10^{-3} \mathrm{~km}^{-1}$ & $9.9 \times 10^{-4} \mathrm{~km}^{-1}$ \\
wavelength & $\lambda$ & $790 \mathrm{~km}$ & $2118 \mathrm{~km}$ \\
phase velocity & $c_{p h}$ & $-0.37 \mathrm{~m} . \mathrm{s}^{-1}$ & $-0.98 \mathrm{~m} . \mathrm{s}^{-1}$ \\
\hline
\end{tabular}

The two roots of Equation 3.1 and listed in Table 3.1 are related to dispersive Rossby waves. The larger one is of a $790 \mathrm{~km}$ wave. Half wavelength corresponding to alternate cyclones and anticyclones are about $395 \mathrm{~km}$. The size of the Rossby vortical structures then approximately matches the PE major axis and is likely to either enhance or decrease its signal. The phase speed is about $0.37 \mathrm{~m} \cdot \mathrm{s}^{-1}$ in the westward direction while the group speed is in the eastward direction. The smaller root is associated with a $2118 \mathrm{~km}$ wave that propagates both phase and energy westward. The question posed now is which of these two affects the Potiguar Eddy.

We now turn to altimetry data in order to look for signals with similar periodicity and seek to find its wavelength. Here we use a finite impulse response (FIR) filter 
(POLITO and LIU, 2003) to investigate these oscillations. For this filter, we use a value as a first guess, and then through Radon transform the filter does some "fine tunning" and returns the filtered field and the periods and wavelengths contained in the data that are within a previously specified uncertainty range from the first guess.

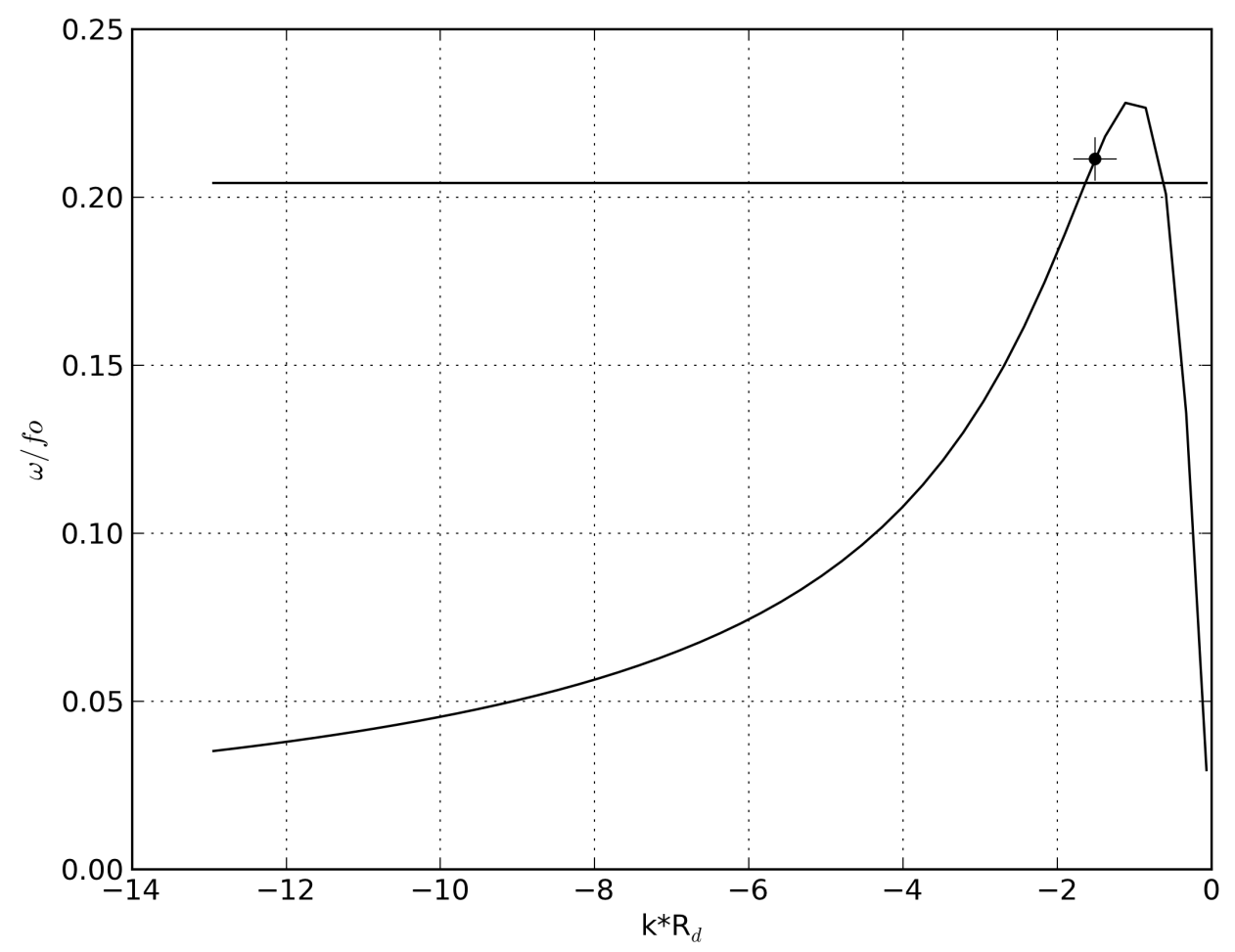

Figure 3.16: Dispersion relation for second-mode baroclinic Rossby Waves. The black bar denotes the frequency corresponding to the period of 35 days, as estimated from the currentmeter mooring time series. The black cross denotes the period of 33.8 days depicted from the altimeter data analysis.

The filtering of the altimetry data (Figure 3.17 ) reveals $\approx 34$-day signals west of $15^{\circ} \mathrm{W}$ in the Atlantic Ocean. As shown in Figure 3.17, these waves are not generated througout the year, but mostly during June-July, reaching the northeastern tip of South America during September-December. This information corroborates the findings from the wavelet analysis of the amplitude time series of the first EOF; both altmetry and amplitude time series present a very similar period of oscillation and seasonality on its intensity. Considering these similarities, we believe the 34-day signals to be clearly associated with 
the $\approx 35$-day oscillations found on the velocity data.

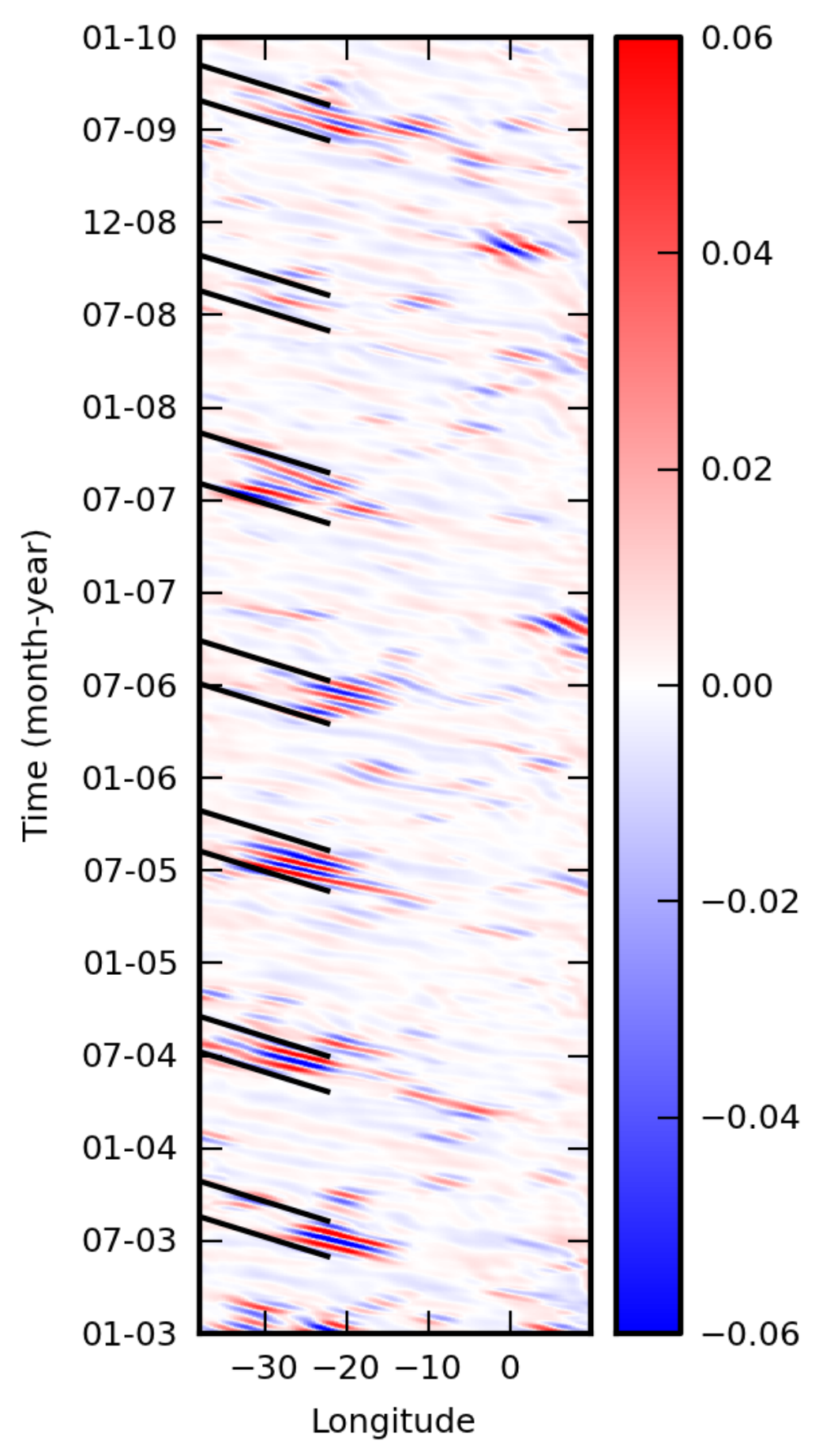

Figure 3.17: Time-Longitude diagram 33-day waves along $4^{\circ} \mathrm{S}$ from AVISO altimetric Sea Surface Height data (in meters). 
In summary, the comparison of the wavelength and frequency found by the FIR filter and the values from the linear wave theory show very good agreement. The theoretical wavelength for the 34-day period yielded a $790 \mathrm{~km}$ wavelength, very similar to the 811 $\mathrm{km}$ found by the FIR. The FIR-estimated phase speed of about $0.30 \mathrm{~m} . \mathrm{s}^{-1}$ is also similar to the 0.37 estimated theoretically. The fact that information from the linear wave theory, amplitude time series of EOF from velocity data, and altimetry converge is an indication that our results are robust, as the process under investigation indeed consists in Rossby Waves reaching the continental margin.

\subsection{Modeled Temporal Variability}

\subsubsection{Model Validation}

After characterizing the PE through mooring data, due to the short period of data acquisition (8 months for PBM1, one year for PBM2), we analyze 8 years (Nov/2003December/2011) of HYCOM model results in order to investigate annual and interannual variability associated with the PE. The HYCOM results, with its $1 / 12^{\circ}$ horizontal resolution, help on the characterization of the regional scenario in order to better understand the processes causing variability on the PE. We first perform a validation of the model results, to assure that they are a good tool for analyzing the kinematics and the dynamics on the Potiguar Bight region. Figure 3.18 shows the mean streamfunction map for model results, which pattern closely resembles the ONEII streamfunction map at $144 \mathrm{~m}$ (Figure 2.9, bottom panel), even though with lower magnitude (i. e., less shear). The clear signature of the PE in a 8-year mean streamfunction field, as well in a series of streamfunction snapshots over these 8-years (not shown), are an indication that the modeled eddy, as well as the observed eddy, is a permanent feature is the region. The PE on model results is, as on the ONEII data, confined within the Potiguar Bight, with a size comparable to the size of the PE depicted on ONEII data: major axis measures $\approx 330 \mathrm{~km}$; minor axis measures $93 \mathrm{~km}$.

In order to investigate if the modeled and observed PE are in the same dynamical regime, we use the same methodology as used for the obervational data: we calculate the 
Rossby number using the mean velocity magnitude in concentric streamlines of the eddy, on the mean streamfunction map at $\approx 150 \mathrm{~m}$ depth (Figure 3.19).

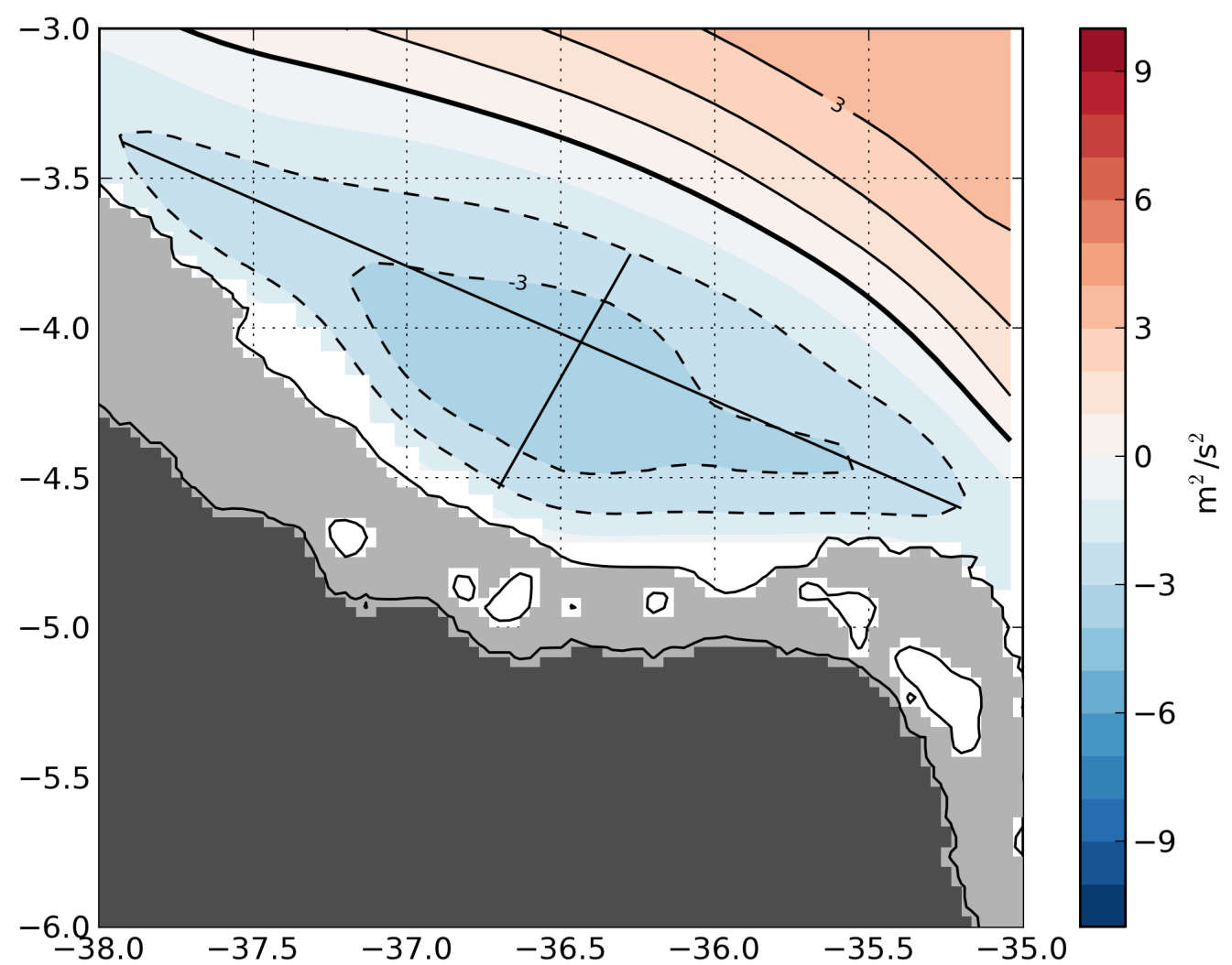

Figure 3.18: Mean (2003-2011) streamfunction map from HYCOM results at $150 \mathrm{~m}$ depth.

The first difference between Figure 3.19 and its counterpart from ONEII data (Figure 2.9) is the intensity; as noted earlier, the observed eddy is stronger than the modeled one. Also, the observed NBUC seems to detach more from the coast, resulting in a larger minor axis in observational data than in model results, therefore a more rounded shape of the PE in observational data. After calculating the Rossby number, we obtained a mean value of 0.35 , which suggests that the modeled eddy in fact is in a similar dynamical regime as the observed $\mathrm{PE}$. 
Another part of the validation is the mean cross-eddy section of the modeled PE (Figure 3.20). The mean cross eddy HYCOM velocity section shows a weaker NBUC than the geostrophic sections, but the flow pattern is realistic. The transport of the modeled $\mathrm{PE}$ is $1.3 \mathrm{~Sv}$, slightly lower than that indicated by the observational data, and the major and minor axis are in reasonable agreement, measuring 300 and $130 \mathrm{~km}$, respectively (Figure 3.18). Considering the similarity between the observed and modeled eddy concerning dynamical regime, size, transport and vertical extent, we turn to investigate the model results for variability of the PE of longer time scales.

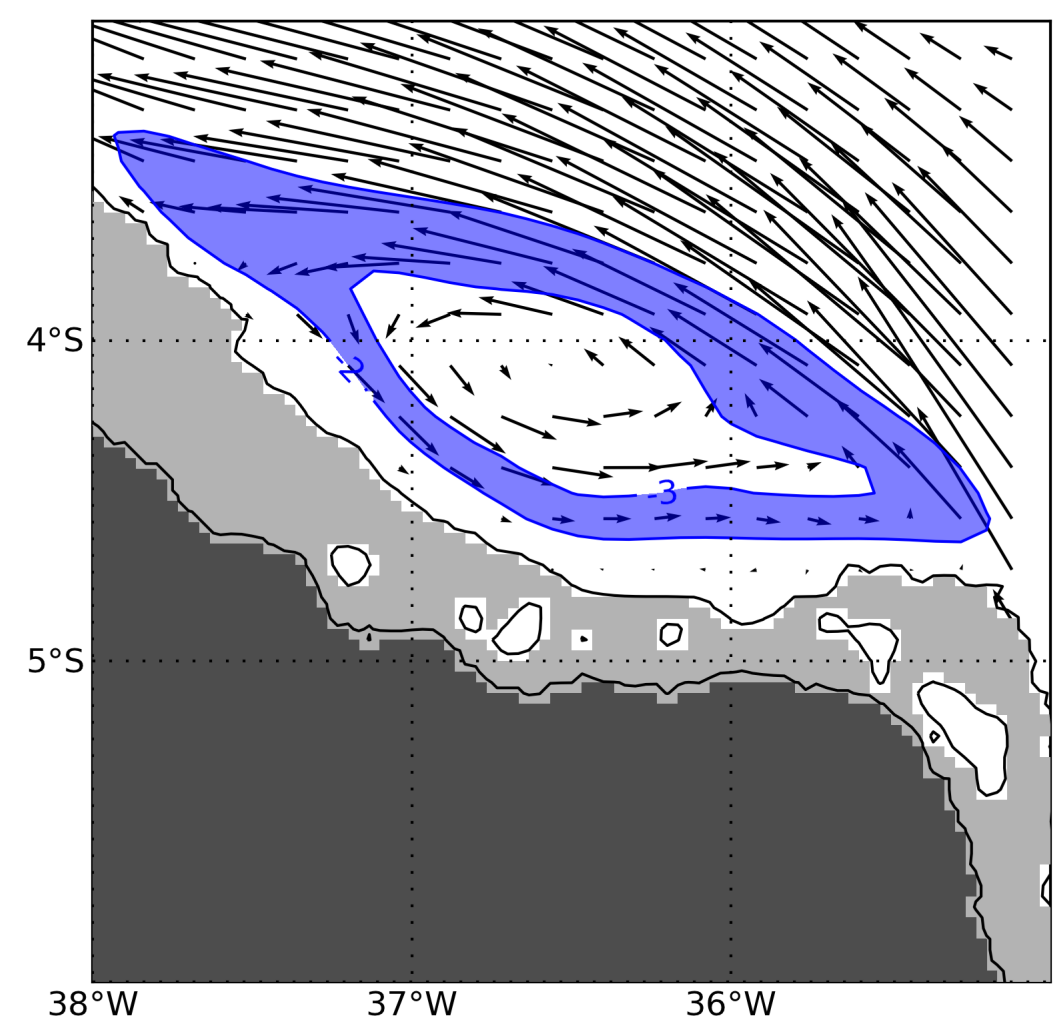

Figure 3.19: Map with the mean (2003-2011) velocity vectors at $150 \mathrm{~m}$ for HYCOM results. The area used on the calculation of the Rossby number is in blue. 


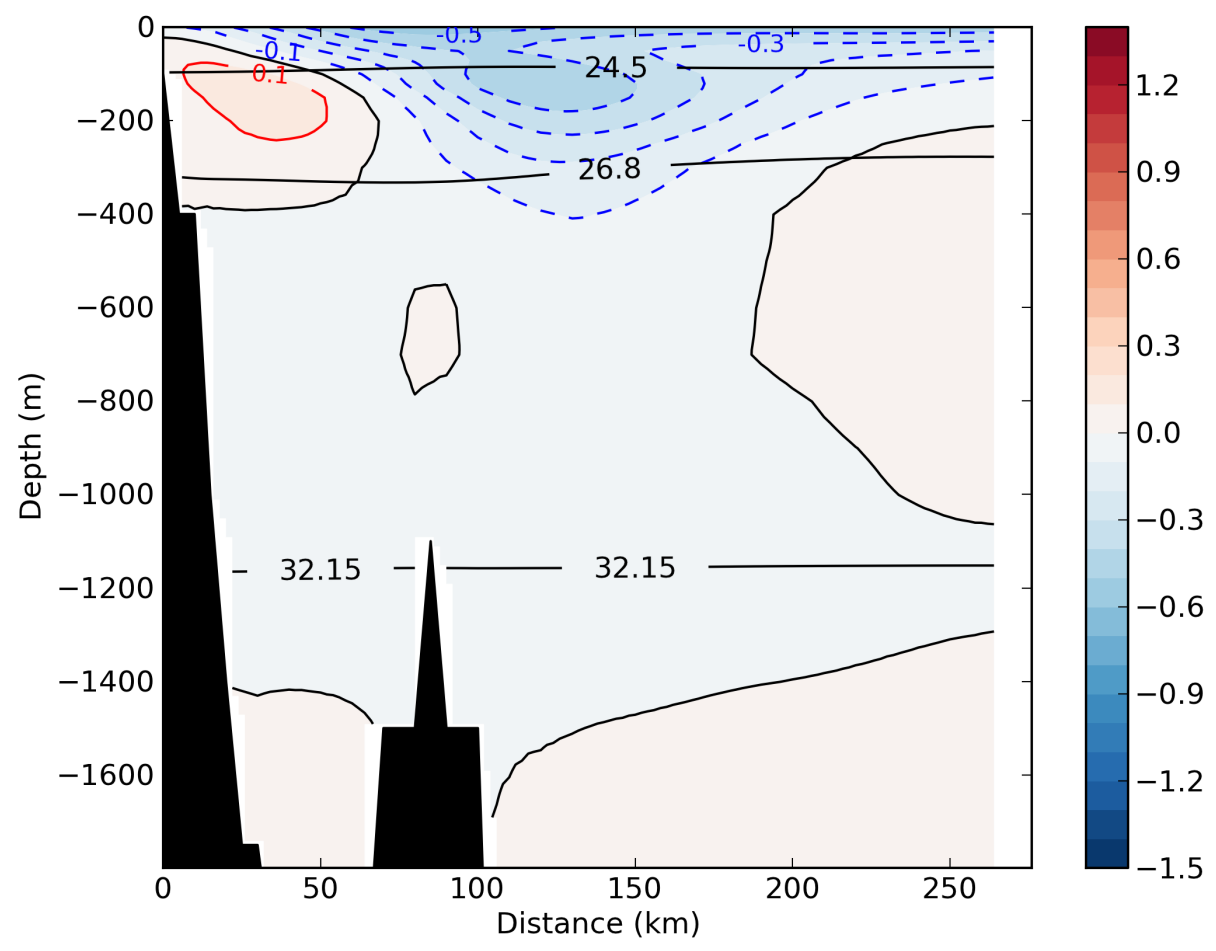

Figure 3.20: Mean (2003-2011) cross-eddy velocity section from HYCOM results. Dashed velocities are northwestward. The $\sigma_{0}=24.5 \mathrm{~kg} . \mathrm{m}^{-3}$ and $\sigma_{0}=26.8 \mathrm{~kg} \cdot \mathrm{m}^{-3}$ isopycnals are plotted.

\subsubsection{Analysis of the HYCOM Model Time Series}

In order to investigate the time-variability of the model eddy we consider two synthetic moorings, in the same location as the PBM1 amd PBM2 moorings. The mean rotated velocity profile for synthetic moorings PBM1 and PBM2 (Figures 3.21 and 3.22) provide more evidence that, on the mean, the PE is present on the model results, with its core at slightly less than $200 \mathrm{~m}$ depth. Also, we see that, in agreement with the observed eddy, the mean model PE does not have surface expression, presenting its upper boundary at about $100 \mathrm{~m}$ depth, in both synthetic moorings. Also, the mean vertical extent of the modeled eddy is about $250 \mathrm{~m}$, somewhat less than the observed PE. Another difference between the synthetic and the observed moored velocity data is the velocity magnitude. The modeled PE has at the depth of its core maximum (mean) velocities of about 0.2 $\mathrm{m} . \mathrm{s}^{-1}$, while the observed eddy has maximum velocities of about $0.4-0.5 \mathrm{~m} . \mathrm{s}^{-1}$. In spite of the small differences, the gereral agreement on the mean profile allows us to investigate 
the variability of the synthetic moooring velocity.

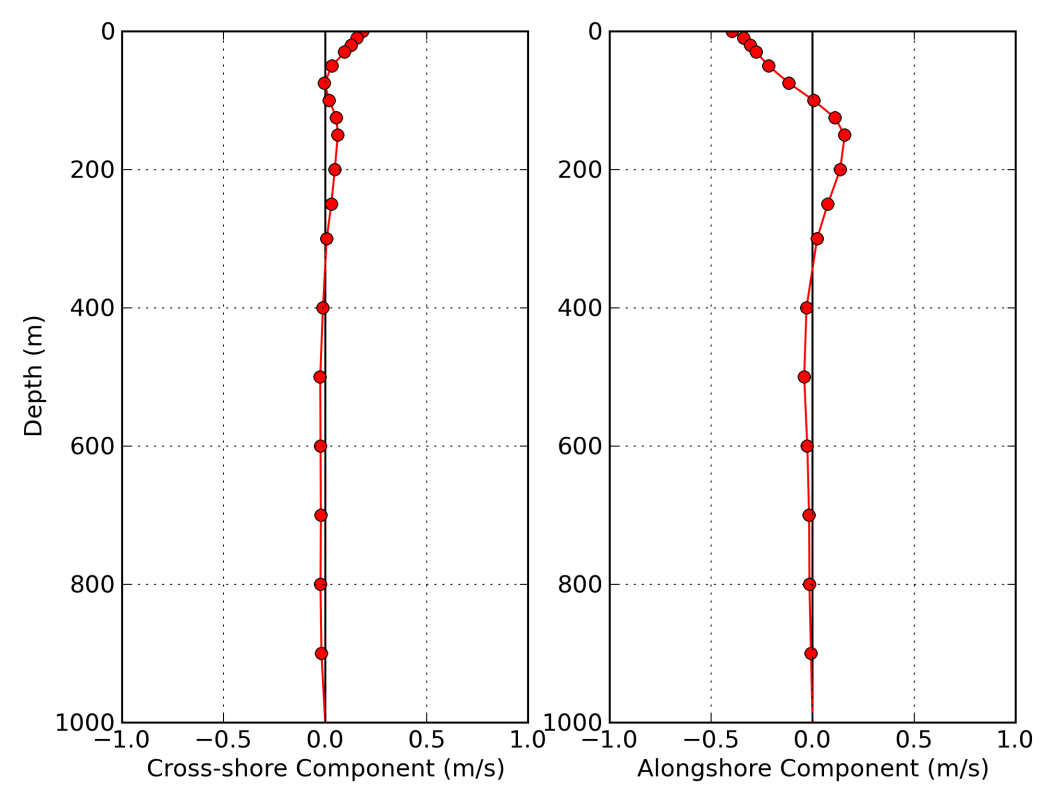

Figure 3.21: Mean cross-shore (left) and alongshore (right) profiles for PBM1 synthetic mooring. Positive values of cross-shore (alongshore) velocity indicate northeastward (southeastward) flow.

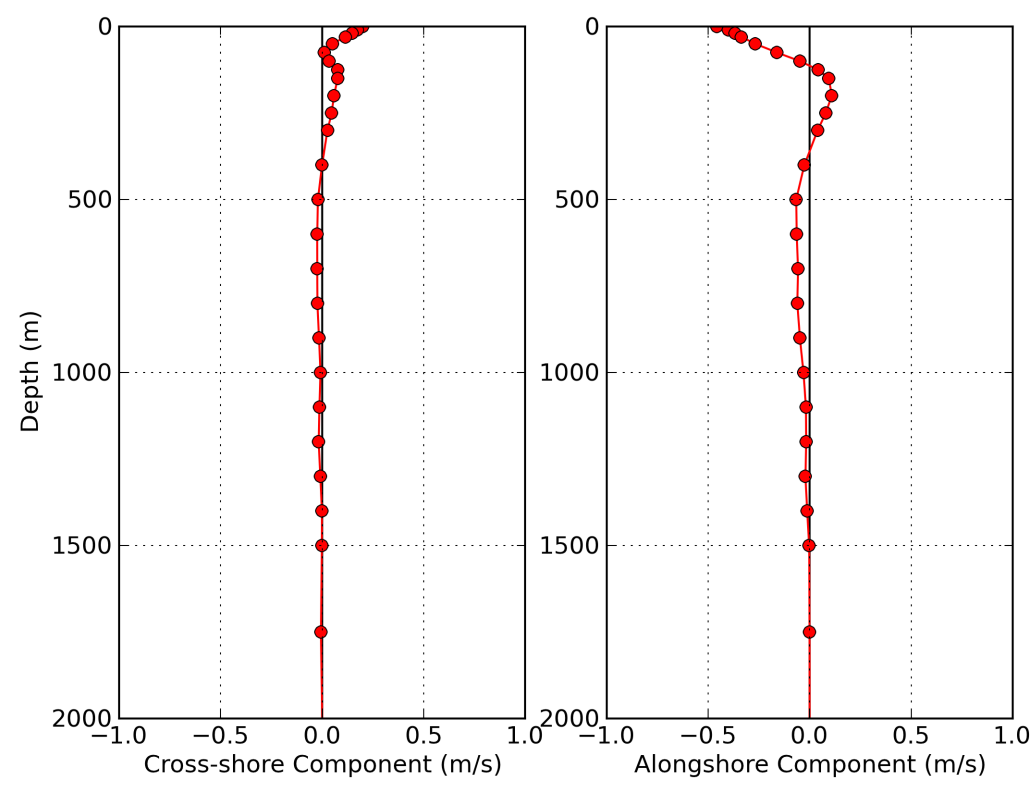

Figure 3.22: Mean cross-shore (left) and alongshore (right) profiles for PBM2 synthetic mooring. Positive values of cross-shore (alongshore) velocity indicate northeastward (southeastward) flow. 
An EOF analysis of the model-moored velocity time-series reveals three statistically significant modes at both PBM1 (Figure 3.23) and PBM2 (Figure 3.24). The vertical structure of the EOFs are very similar between both moorings. The vertical structure of the first EOF (Figures 3.25 and 3.26) has maximum amplitude at the surface, monotonically decreasing until about $200 \mathrm{~m}$, when it reaches zero and aproximately maintains this value throughout the rest of the water column. This structure is the same for both synthetic moorings; for the synthetic PBM1 it explains $53 \%$ of the time-series, and for synthetic mooring PBM2, it explains $49 \%$.

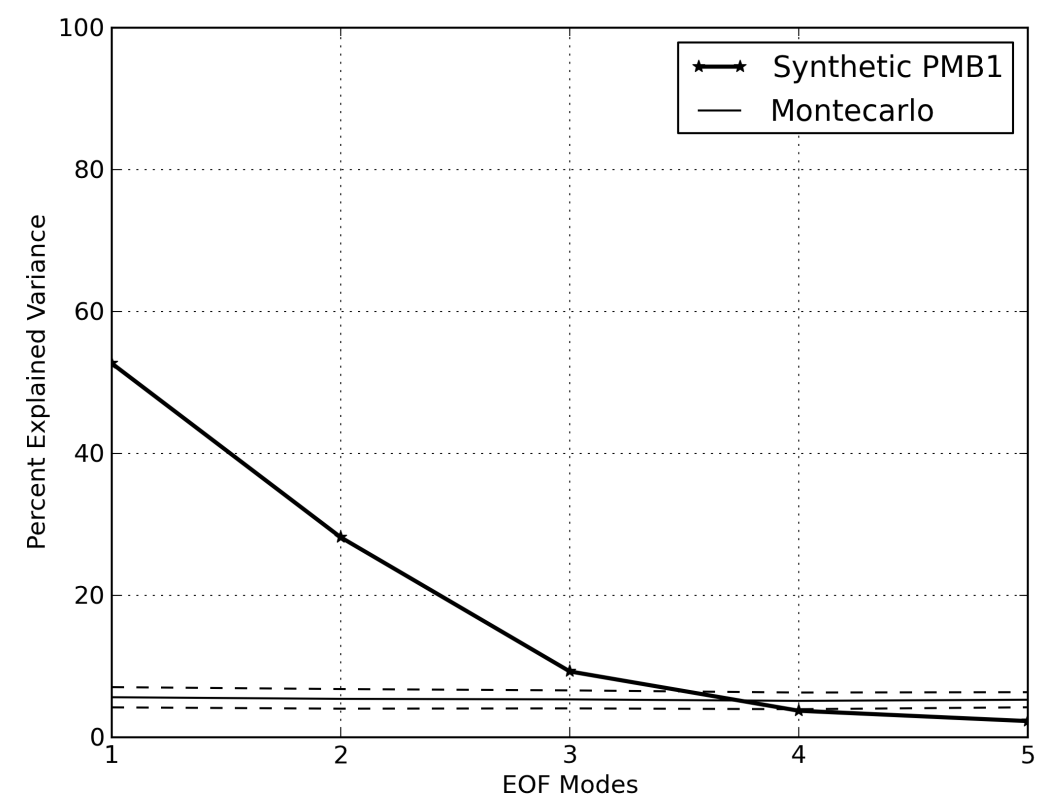

Figure 3.23: Explained variance of each statistical mode calculated from the synthetic PBM1 and from a random time-series. The thick black line represents the explained variance for each statistical mode for the observed mooring; the thin black line represents the mean explained variance for the statistical modes of a random time-series (Montecarlo simulations). The dashed lines represent the interval of two standard deviations about the mean.

The vertical structure of the second EOF of the synthetic moorings (Figures 3.27 and 3.28 is more similar to what we found on the observed data. It has greater amplitude between $100 \mathrm{~m}$ and 400-500 m depth, with maximum velocities at about $200 \mathrm{~m}$, which 
closely coincides with the depth of the modeled PE maximum velocities. This second EOF explains $28 \%$ and $27 \%$ of the variance of the series for the synthetic moorings PBM1 and PBM2, respectively.

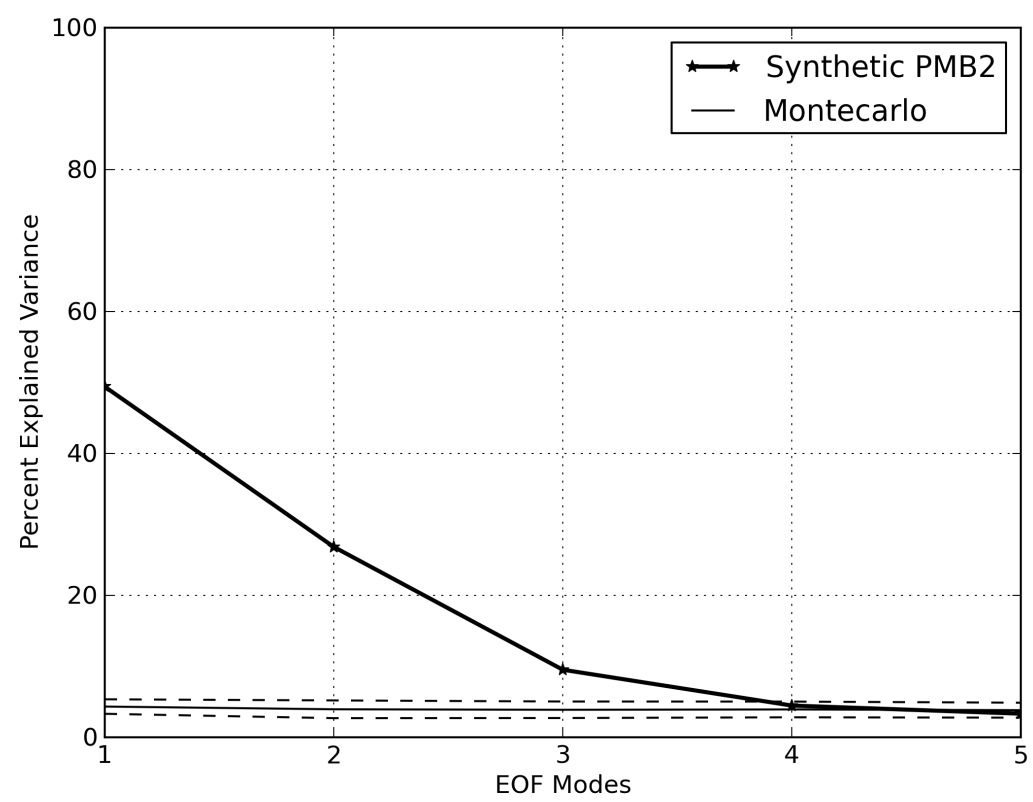

Figure 3.24: Explained variance of each statistical mode calculated from the synthetic PBM2 and from a random time-series. The thick black line represents the explained variance for each statistical mode for the observed mooring; the thin black line represents the mean explained variance for the statistical modes of a random time-series (Montecarlo simulations). The dashed lines represent the interval of two standard deviations about the mean.

The comparison between the statistical modes of the velocity time series from the observed and synthetic moorings reveals high correspondence between the first (second) EOF of the observed moorings and the second (first) EOF of the synthetic ones. The first EOF of the observed moorings, as previously stated, is associated with Rossby Waves propagating westward in the Equatorial Atlantic. The main period found for the first EOF for the observed moorings (25-35 days) is also found on the amplitude time series for the second EOF of the synthetic moorings, which strongly suggests that they are associated with the same process. The second EOF of the observed moorings is re- 
lated to upper-ocean processes, envolving the Ekman layer and the seasonal variability of the trade winds over the Tropical Atlantic. We believe that the first EOF from the model outputs is associated with this process, and probably has higher explained variance due to the time-limited observed mooring data which prevented from resolving the seasonal cycle in a 8-month or one-year long time series.

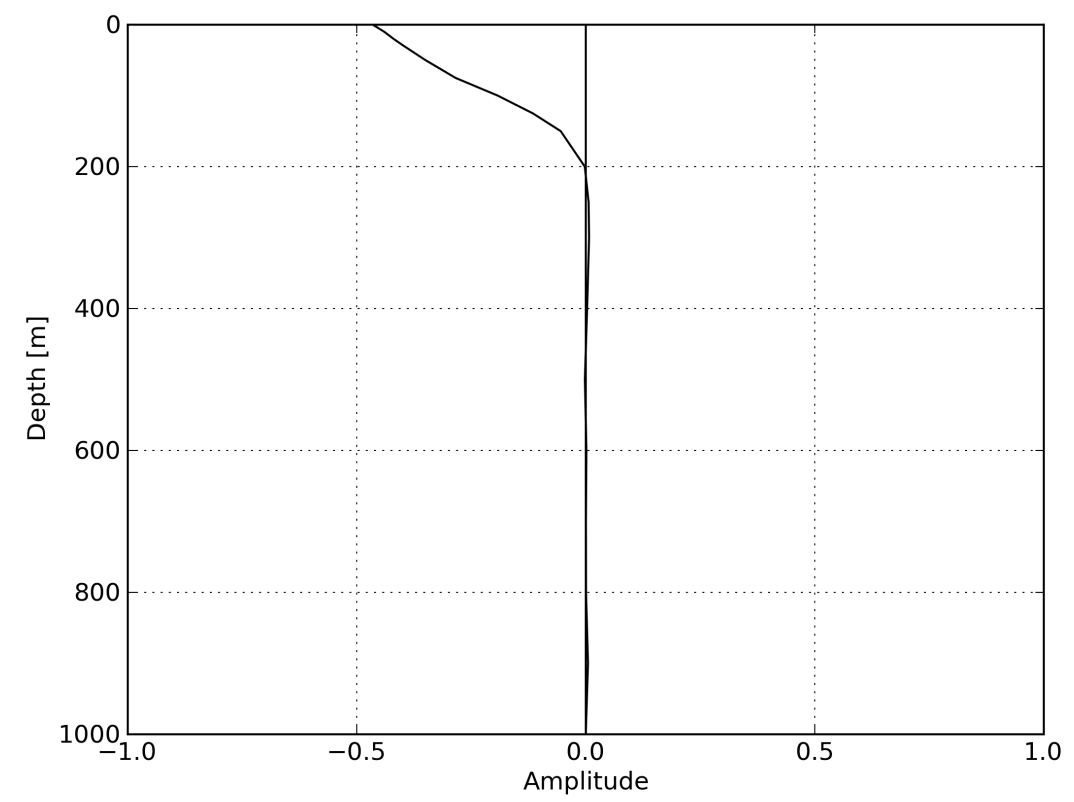

Figure 3.25: Vertical structure of the first EOF for synthetic mooring PBM1.

We also analyze the model results for lower-frequency variability. Figure 3.29 shows an annual and a semiannual wave fit on the amplitude time-series of the two EOFs for the synthetic mooring PBM1. The amplitude time series of the first EOF presents a larger annual signal than the second mode, which indicates that the first mode from the synthetic moorings is indeed related to upper ocean processes and therefore subject to the annual signal of the trade winds in the Atlantic. The same behavior is seen on the amplitude time series for synthetic mooring PBM2. 


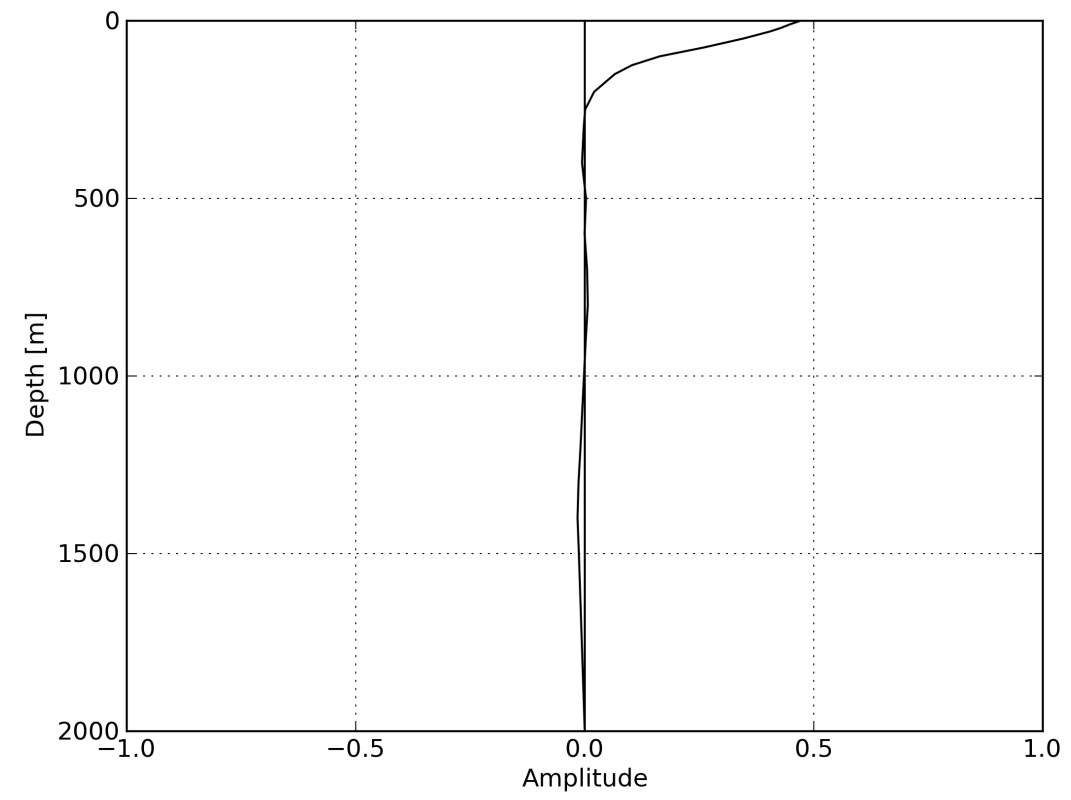

Figure 3.26: Vertical structure of the first EOF for synthetic mooring PBM2.

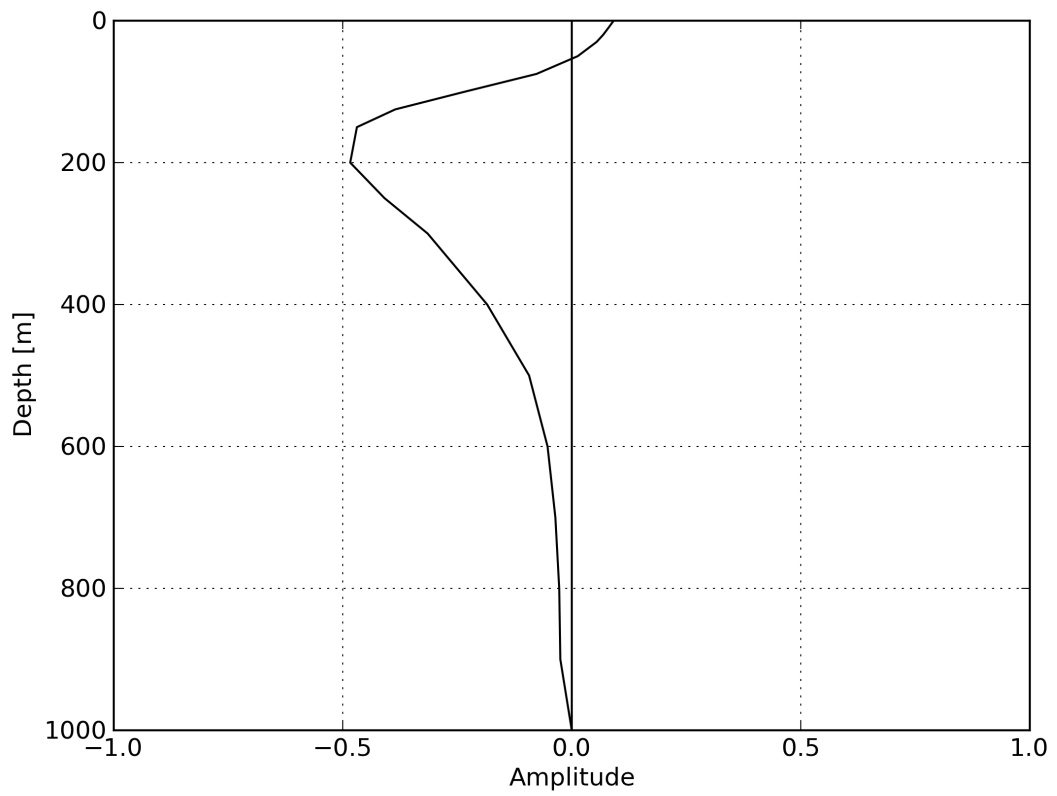

Figure 3.27: Vertical structure of the second EOF for synthetic mooring PBM1. 


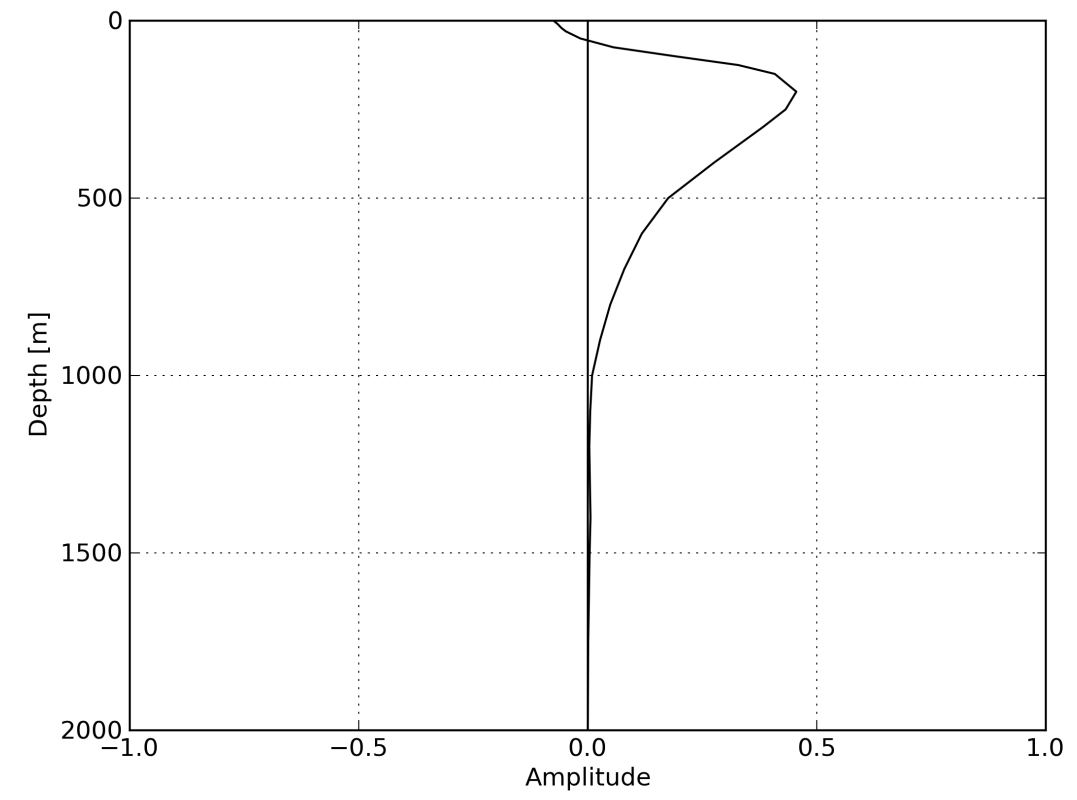

Figure 3.28: Vertical structure of the second EOF for synthetic mooring PBM2. 

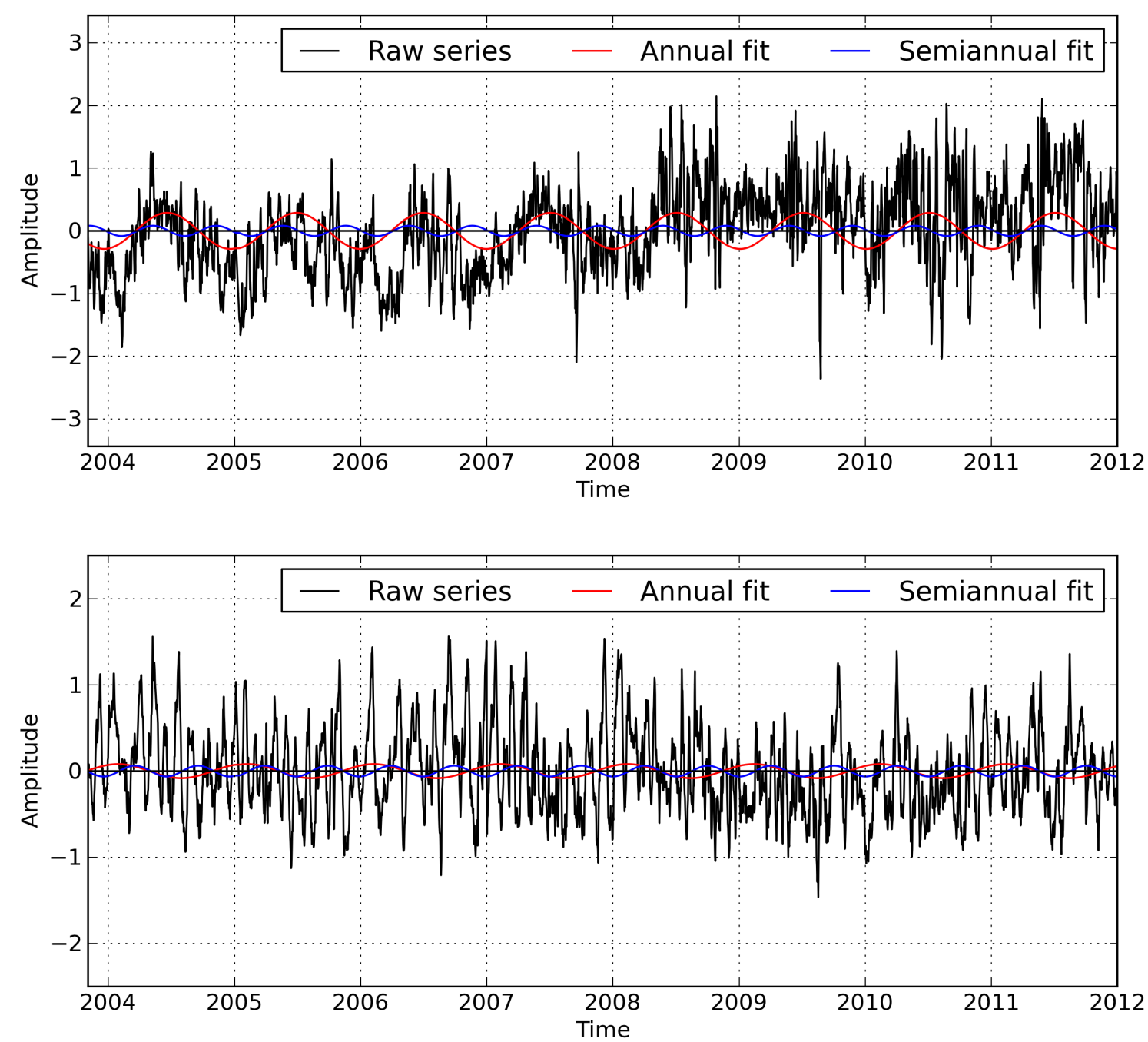

Figure 3.29: Fit of annual and semi-annual signals on the amplitude time series for the first (top panel) and second (bottom panel) EOF for synthetic mooring PBM1. 


\subsection{Discussion}

In this chapter we were able to address the PE stationarity and variability through the analysis of two (one 8-month long and another one-year long) time series of current meter moorings. The PE appears clearly in the mean profile of mooring velocity, with an about $250 \mathrm{~m}$ vertical extent (60-264 $\mathrm{m}$ in PBM1 and 100-430 $\mathrm{m}$ in PBM2), strongly suggesting that it is a permanent feature in the region. This is a subsurface frontal meander, with the mean current speeds at the surface on the opposite direction of that of its nearshore lobe. The PE southeastward velocity core is attached to the coast, as shown in the previous chapter, and extends offshore at least up to 50-100 km. The PE's highest velocities, on the mooring data, occur on the mooring line closer to the coast (PBM1), as was suggested by the synoptical velocity sections shown in chapter 2 .

Once the stationarity of the PE has been established, we turn to its temporal variability. The PE presents mainly two modes of variability, both affecting its vertical extent. The first mode is associated with the variation of the depth of the lower boundary of the PE, while the second mode, explaining less variance, is related to the variation of the upper limit of the eddy, and probably associated with upper-layer processes. In this dissertation, we focus on the first mode of variability.

This first mode of variability explains about $60 \%$ and $37 \%$ of the variance of the original series for PBM1 and PBM2, respectively. It has maximum amplitude close to the lower limit of the PE, being associated with the increase/decrease of the vertical extent, due to the variation on the depth of its lower boundary. Wavelet analysis of the EOF amplitude time-series reveal that most of the energy of this first mode is concentrated in periods of 25-35 days, with a modulation: the 25-day period is predominant during JulySeptember, while the 35-day period oscilation is prevalent during September-December. The vertical profile of this mode of variability is dominated by the second baroclinic mode, with maximum amplitude concentrated on the lower half of the eddy.

Knowing that there is a second-mode signal impinging variability on the PE, and with the urge to understand which phenomenon could cause such variability, we turned to altimetry data. Using the technique of Polito and Liu (2003) we were able to detect 34-day waves along a zonal section located at $4^{\circ} \mathrm{S}$. The filtered altimetry data indicate 
that these waves are generated west of $15^{\circ} \mathrm{W}$ mostly during the month of June. They then propagate westward and reach the Potiguar Bight during August-September.

Intraseasonal variability have been previously reported on the NBUC/cSEC and NBC system. At $4^{\circ} \mathrm{N}$, Johns et al. (1998) found two distinct modes of variability in current meter mooring data; a baroclinic deep-reaching 60-90 day mode and a surface trapped, 25-40 day mode. The 25-40 day mode is most energetic in May-June, related to the eddy shedding of the NBC retroflection. The 60-90 days mode, on the other hand, is present year-round, and is associated with the propagation of eddies, having a wave-like character. Further south, aproximately at the equator, Schott et al. (1993) found nearsurface currents dominated by $\approx 30$-day periodicity, with maximum energy occurring in May-July. At $11^{\circ} \mathrm{S}$, Veleda et al. (2012) report oscilations with a 14-21 day period, related to the lagged correlation structure between meridional wind stress and alongshore currents, consistent with Coastal Trapped Wave theory.

The period of the oscilations reported by Johns et al. (1998) and Schott et al. (1993) match the periods we found in the Potiguar Bight, but the processes envolved are clearly different. The 25-40 day mode from Johns et al. (1998) is strongly surface trapped, resembling the first baroclinic mode, as are the oscilations reported by Schott et al. (1993), Even though the periods are similar, these oscilations are dynamically different from the ones we identified in the Potiguar Bight.

From the dispersion relation, the oscilations we report here have a second-mode Rossby Wave behavior. This result does not disagree with the findings of Schott et al. (1993) and Johns et al. (1998), since they reported first-mode waves, instead of secondmode ones. After identifying the waves, we speculate their generation process.

Lumpkin and Garzoli (2005) study of drifter trajectories indicate that the maximum speeds in the cSEC occur in mid-July. Considering the modulation of the variability mode we that found (with most energy in this frequency band during July-December), we argue that these second-mode Rossby Waves are generated by barotropic instability in the Equatorial Current System, as the Tropical Instability waves reported by Schott et al. (1993).

After characterizing the intraseasonal variability, we turn to an analysis of the 
lower-frequency signals in the HYCOM global model results. The HYCOM outputs present neither significant annual nor interannual variability in the Potiguar Bight, as indicated by a number of studies on the NBUC (SCHOTT et al., 1998; JOHNS et al., 1990; JOHNS et al., 1998).

In this chapter we analyzed the variability of the PE through observational data, satellite altimetry and global numerical model results. On the following chapter we analyze the PE generation process within a process-study numerical model framework. 


\section{Chapter 4}

\section{Dynamical Process Studies}

Here we address the issue of the dynamics of the PE in terms of numerical experiments carried out using the Regional Ocean Modelling System (ROMS). To develop the initial fields for these simulations, we use the Feature-Oriented Regional Modeling System (FORMS) technique. Section 4.1 describes the development of Feature Models for NBUC and DWBC. In section 4.2 we present the numerical experiments set up carried out to address a set of science questions related to the eddy phenomenon. In section 4.3 we discuss the calibration and sensitivity of the numerical model to the choice of numerical parameters for establishing a realistic dynamic simulation. In section 4.4 we present the results of the analysis of numerical simulations.

\subsection{Development of Feature Models}

For the numerical experiments using ROMS, we applied the Feature-Oriented Regional Modeling System (FORMS) approach (GANGOPADHYAY et al., 1997; GANGOPADHYAY and ROBINSON, 2002; GANGOPADHYAY et al., 2003). This technique consists of empirically and analytically creating Feature Models to develop initial and boundary conditions for primitive equation numerical simulations. We applied this technique in a feature-oriented process study approach, in which one is able to build a conceptual scenario to reproduce and study the feature(s) of interest.

In this approach, an analytical formulation is developed for the synoptic features of interest, based on information from previous studies and observations. This analyt- 
ical formulation of the three-dimensional velocity and mass field (the Feature Model FM) is then used as initial field for process study numerical experiments, enabling the investigation of the dynamical processes taking place.

A main advantage of the feature-oriented process study approach is the possibility of filtering and/or enphasizing certain characteristics of the flow which, in spite of being realistic, may not be of fundamental importance for the process(es) of interest. For example, if one is studying a process which is dominated by barotropic instability, Feature Model parameters can be tuned to accentuate only the barotropic component of currents, even though the currents have a strong baroclinic component. This way, only the variables which are believed to play a crucial role on the process of interest will play dominant role in the simulations and can be studied dinamically. It must be stressed that, even though such process study Feature Models do not necessarily contain all the observed characteristics in nature, the FM does need to be based on the observed features and validated against actual data.

In the Potiguar Bight, the Potiguar Eddy is a recirculation of the NBUC waters; therefore, the first feature in the region that demands understanding is the NBUC. At deeper levels, on the other hand, the main feature of the circulation is the DWBC and, in spite of the fact that the PE only extends up to $400 \mathrm{~m}$ depth, this current might also play a role on the PE dynamics. The DWBC may influence the vertical shear to induce baroclinic instability and thus influence the generation of the PE. Additionally, the cSEC flows westward in the study domain to feed into the variability of these two dominant boundary currents in the region. With the knowledge of the main features that are present on the region and might influence the PE, we address the following questions using the FORMS technique and dynamical studies using ROMS, through the process study approach:

- Is the NBUC alone capable of generating the PE?

- How important is the vertical shear for the generation of the PE?

In order to address these questions, we use the information that we have from observations and past synthesis studies, of each of the main currents in the area, namely, the NBUC, the DWBC, and the cSEC, to develop individual Feature Models. These 
Feature Models are then used to set up the initial field for numerical simulations, and the results help understanding the role of each feature on the PE dynamics.

\subsubsection{NBUC Feature Model Formulation}

The NBUC FM is developed based on the observed data from ONEI (February March, 2002) and ONEII (October - December, 2004) cruises, as well as information from previous studies (SILVEIRA et al., 1994; SCHOTT et al., 2003; SCHOTT et al., 2005). We select the maximum speed, core depth, transport, horizontal and vertical extent from each source in order to develop the Feature Model, following earlier FM developments of BC, NBC (CALADO et al., 2008; SOUTELINO et al., 2013). Table 4.1 shows the values of these variables for each study, as well as the ones used for the NBUC Feature Model itself.

The values of the maximum speed, core depth, and western and eastern width of the current for the ONEI and ONEII cruises shown in Table 4.1 were estimated taking into account only sections 1-5 of each cruise, instead of all sections. This was done in order to extract and preserve the characteristics of the NBUC before the influence of the cSEC, i. e., south of $\approx 4^{\circ} \mathrm{S}$. This care was also taken for the estimated values for the studies of Silveira et al. (1994) and Schott et al. (2005), Caution was taken when considering the information from the study of Schott et al. (2003), since it is based on a mean meridional section at $35^{\circ} \mathrm{W}$, area in which the NBUC is under the strong influence of the cSEC. 


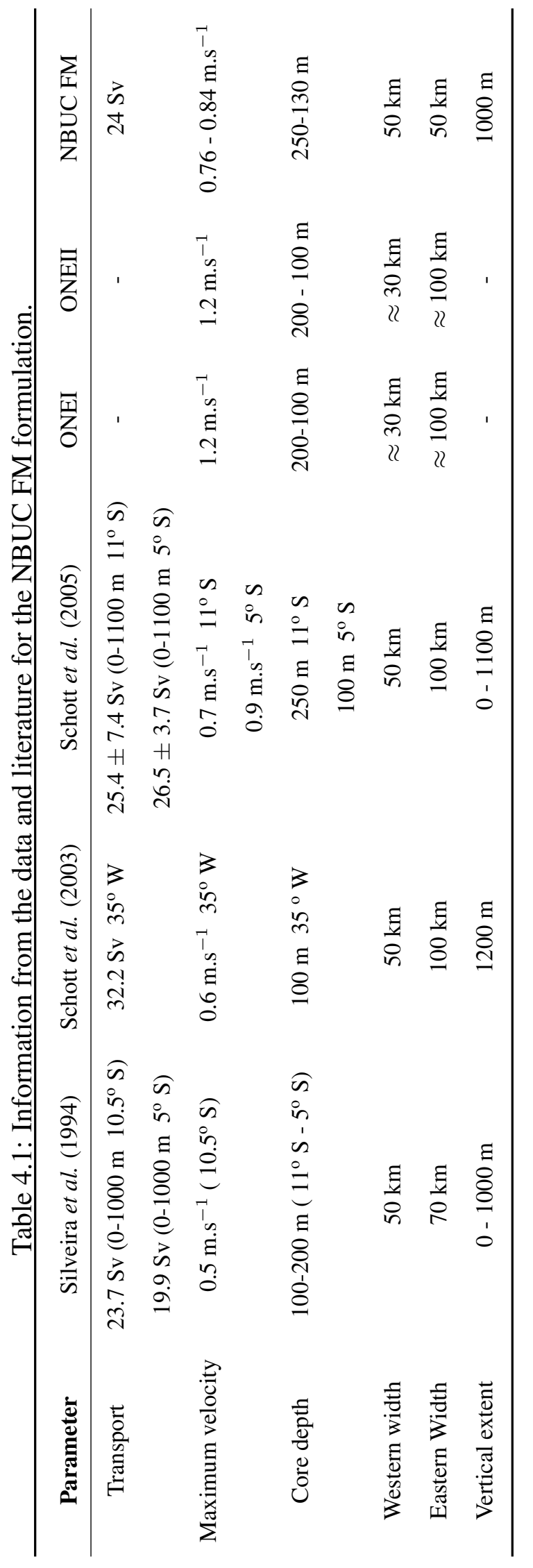


Based on the information from the data and previous studies, we developed an analytical function that represents the along-stream velocity structure of the NBUC (Equation 4.1). The orientation of the system is a natural coordinate frame of reference, in which $s$ is the along-stream axis, $n$ is the cross-stream axis, and $z$ is the vertical axis.

$$
\nu(s, n, z)=\nu_{\max }(s) \exp \left[-\left(\frac{\left(n-n_{c}\right)^{2}}{2 \delta_{n}^{2}}+\frac{\left(z-z_{c}(s)\right)^{2}}{2 \delta_{z}^{2}}\right)\right]
$$

where:

$\nu(s, n, z)$ is the velocity of the current, which varies in the along-stream (s), cross-stream (n), and vertical (z) axes;

$\nu_{\max }(s)$ is the maximum velocity of the current;

$n_{c}$ is the distance of the NBUC core from the coast;

$z_{c(s)}$ is the linear function for the NBUC core lifting;

$\delta_{n} / 2$ is the horizontal width of each side of the current:

for $n<n_{c}$ (onshore part of the current): $\delta_{n} / 2=50 \mathrm{~km}$;

for $n>n_{c}$ (offshore part of the current): $\delta_{n} / 2=50 \mathrm{~km}$;

$\delta_{z} / 2$ represents the upward/downward vertical extent of the current from the core:

$$
\begin{aligned}
& \text { for } z>z_{c}: \delta_{z} / 2=100 \mathrm{~m} ; \\
& \text { for } z<z_{c}: \delta_{z} / 2=360 \mathrm{~m} ;
\end{aligned}
$$

As previously stated, the formulation for the NBUC FM was based on information from the literature, as well as from ONEI and ONEII cruises. On Figures 4.1 and 4.2 , part of the analysis of the cruise data in order to develop the FM analytical formulation is exemplified. A simple best-fit is done on the data, to find parameters that matched with relevant information from the literature and cruises. Based on the vessel-mounted ADCP data from ONEII cruise, we calculated statistical fit to the curves, obtaining the values of the parameters for the analytical function in Equation 4.1, to be used as shape of the NBUC, vertically as well as horizontally. 

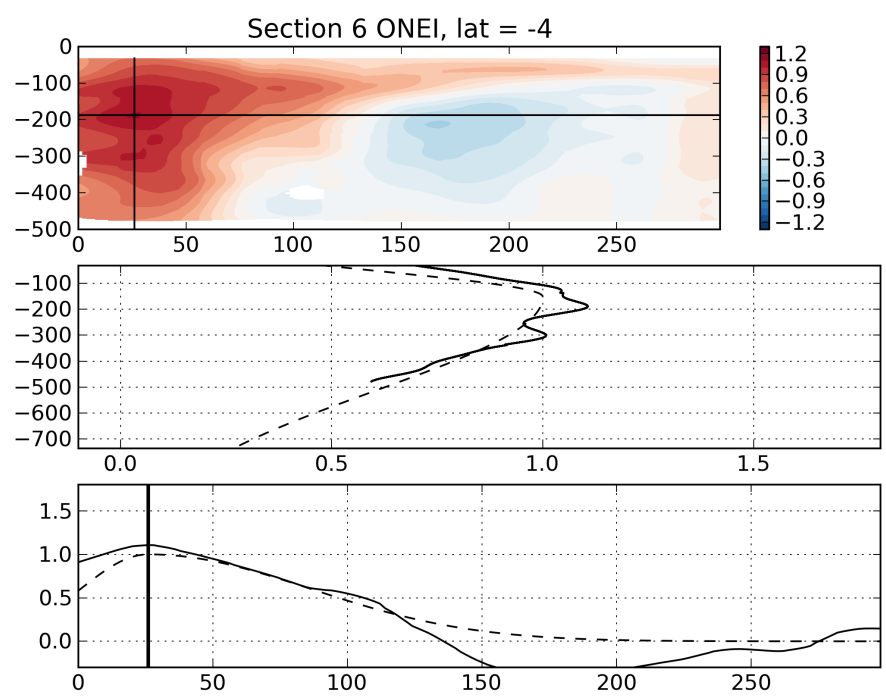

Figure 4.1: Feature Model Characteristics based on ONEI measurements. Upper panel: cross section velocity at section 6 of ONEI (Feb-Mar, 2002). Middle panel: observed (solid line) and FM (dashed line) velocity profile at the location indicated by the vertical black line on the upper panel. Lower panel: observed (solid line) and FM (dashed line) horizontal velocity distribution at the depth indicated by the horizontal black line on the upper panel. Positive velocities indicate northward flow.

According to the information from the literature and from ONEI and ONEII cruises, we set the parameters for the depth of the NBUC core $\left(z_{c}\right)$ to be $250 \mathrm{~m}$ at the southern (about $10^{\circ} \mathrm{S}$ ), and shoal up to $130 \mathrm{~m}$ at the northern boundary of the domain. Also, the maximum velocity of the $\operatorname{NBUC}(\nu(s, n, z))$ was set at about $0.8 \mathrm{~m} . \mathrm{s}^{-1}$, in order to yield a realistic transport of about $24.5 \mathrm{~Sv}$. The analytical function used for the NBUC FM was applied over various sections along the brazilian coast, as shown in Figure 4.3

As a result of the solution of the analytical velocity formulation for each transect, we have a current flowing along the coast, with the aforementioned characteristics which are specific to the NBUC. Figures 4.4 and 4.5 present the NBUC FM velocity through the southern and northern parts of the domain, respectively. The first characteristic to notice is the subsurface character of the NBUC core throughout the domain. Also, the modeled NBUC has $\mathrm{a} \approx 1000 \mathrm{~m}$ vertical extent $\left(\delta_{z}\right)$ on the southern portion of the domain; as the current flows northward, due to the shoaling of its core, its vertical extent is linearly 
reduced, reaching a minimum of about $850 \mathrm{~m}$. The horizontal width $\left(\delta_{n} / 2\right)$ used was constant over the domain, and the same for the western and eastern sides of the current. This fixed value was adopted even though realisticaly the width of the current is smaller on the onshore than on the offshore portion and varies along the currents' path due to contributions from different currents (Figures 4.1 and 4.2). This choice was based on two assumptions: (i) the difference of horizontal width between the onshore and offshore portions of the NBUC are not fundamental for the generation and maintenance of the PE, and (ii) the along-stream variation of the width of the current is due to contributions from other currents. Considering that in this work we develop an individual Feature Model for each current, it would be undesirable to insert on the NBUC FM characteristics which are due to the existence of other currents. The NBUC transport increases slightly in the along-stream direction, from $\approx 24.4 \mathrm{~Sv}$ at $11^{\circ} \mathrm{S}$ to $\approx 25 \mathrm{~Sv}$ at $2^{\circ} \mathrm{S}$.
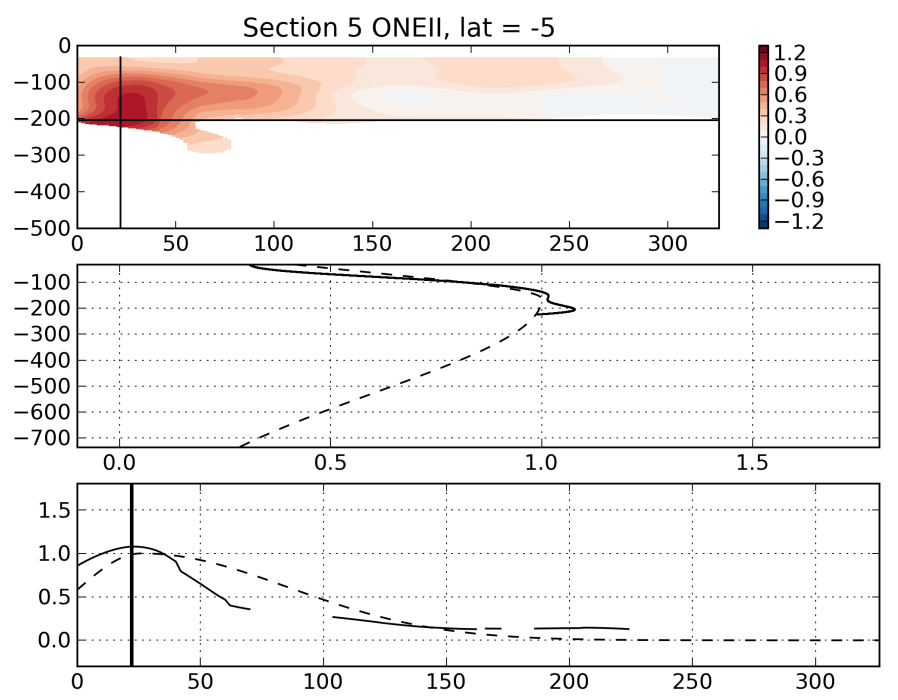

Figure 4.2: Feature Model Characteristics based on ONEII measurements. Upper panel: cross section velocity at section 5 of ONEII (Oct-Dec, 2004). Middle panel: observed (blue line) and FM (red line) velocity profile at the location indicated by the vertical black line on the upper panel. Lower panel: observed (solid line) and FM (dashed line) horizontal velocity distribution at the depth indicated by the horizontal black line on the upper panel. Positive velocities indicate northward flow. 


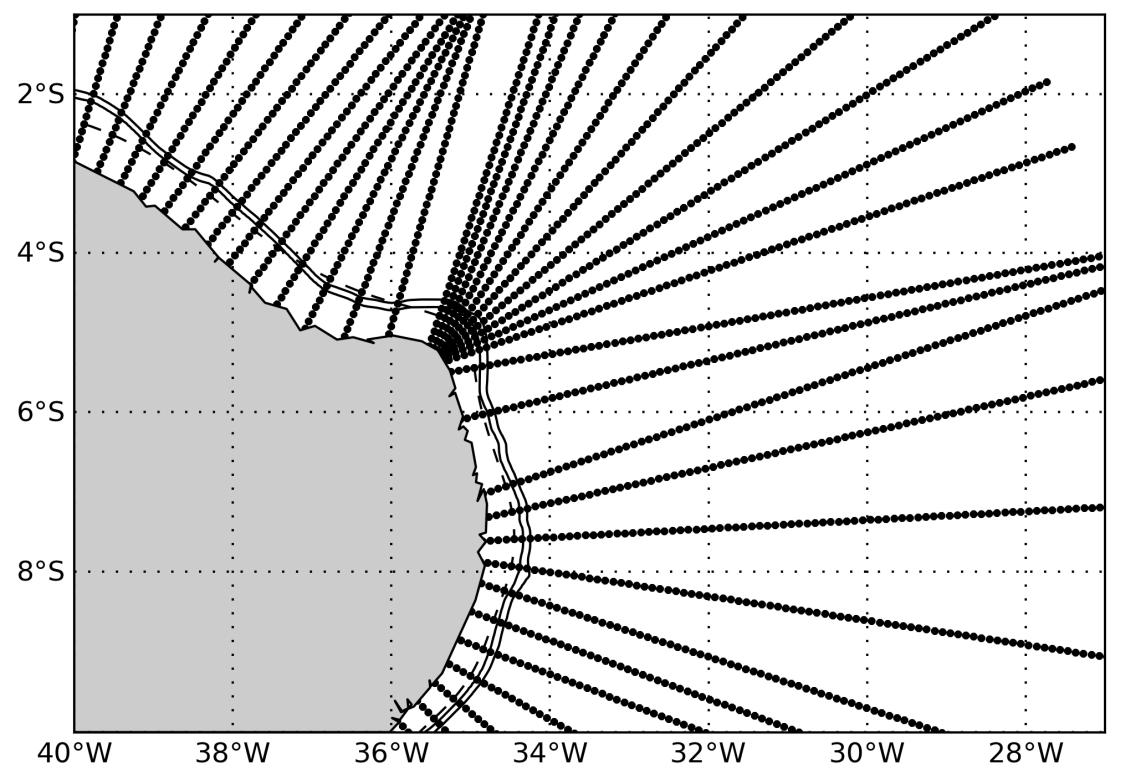

Figure 4.3: Sections in which the NBUC FM was calculated.

To develop the FM temperature field, we invert the thermal wind relation for each section of the FM. On this process, the thermal wind relation (Equation 4.2)

$$
f_{o} \frac{\partial v}{\partial z}=-\frac{g}{\bar{\rho}} \frac{\partial \rho}{\partial n}
$$

where:

$f_{o}$ is the Coriolis parameter;

$\bar{\rho}$ is the reference density;

$\rho$ is the density.

is integrated with respect to $\mathrm{x}$ to find density (Equation 4.3):

$$
\rho_{(s, n)}=\rho_{(0, z)}-\frac{f_{o} \bar{\rho}}{g} \int_{0}^{L} \frac{\partial v}{\partial z} d n
$$

where:

$\rho_{(s, n)}$ is the density;

$\rho_{(0, z)}$ is a mean density profile at the initial location of the transect;

$L$ is the length of the transect. 


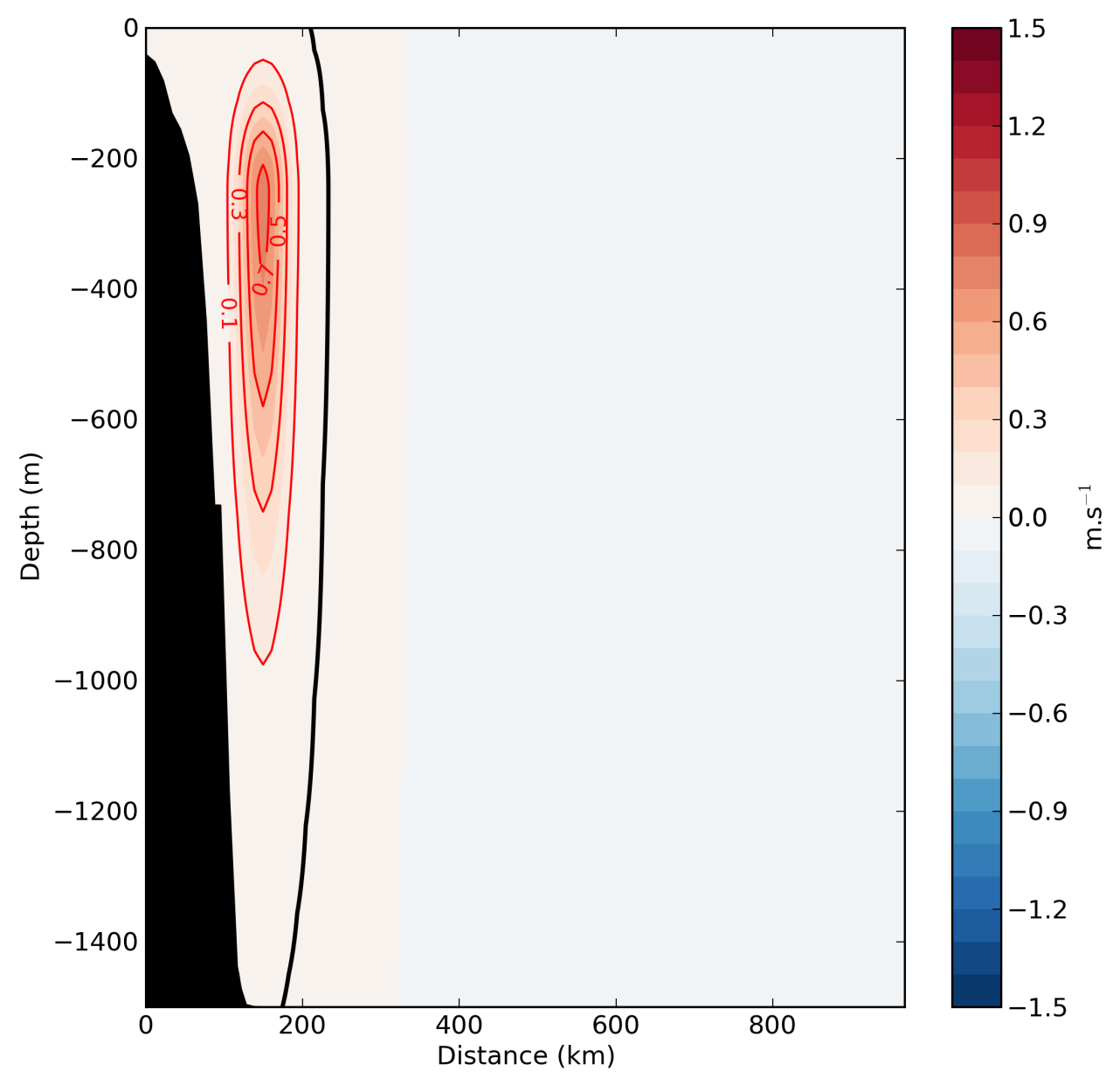

Figure 4.4: Velocity section 1 (southernmost) of the NBUC FM.

With the density values, we use a linearized equation of state following Soutelino et al. (2013) (Equation 4.4) to calculate the temperature field:

$$
T_{(s, n)}=\frac{\frac{-\rho}{\bar{\rho}}+1+\bar{\beta} S o_{(z)}}{\bar{\alpha}}
$$

where:

$T_{(s, n)}$ is the temperature;

$\bar{\beta}$ is the mean haline contraction coefficient;

$S o_{(z)}$ is a mean salinity profile computed from climatology;

$\bar{\alpha}$ is the mean thermal expansion coefficient. 


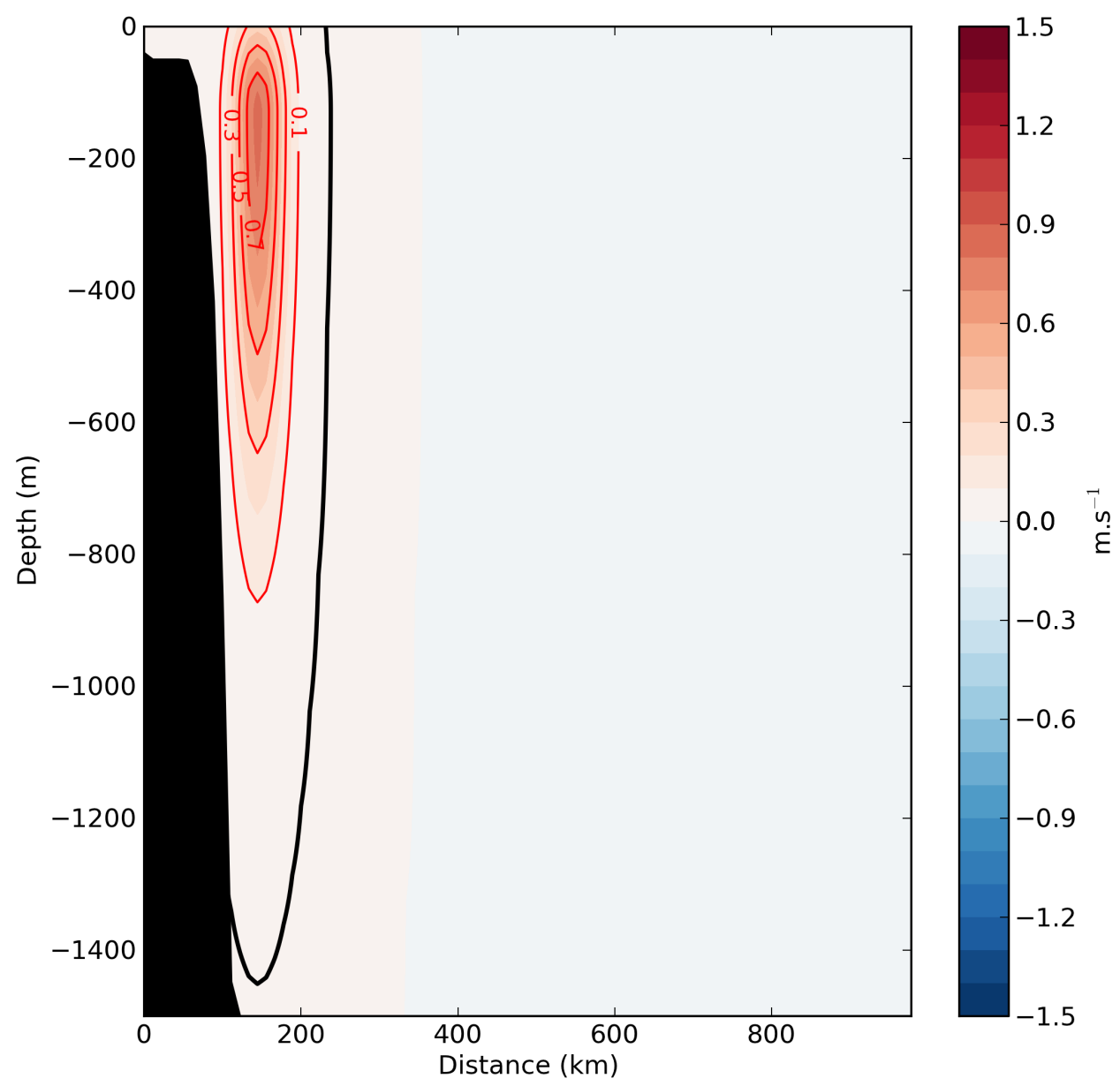

Figure 4.5: Velocity section 44 (northernmost) of the NBUC FM.

The near-equatorial salinity field has complications that were not captured by the feature model formulation; therefore, we use the climatological salinity field from WOA (2013). This process is described in detail in Section 4.3. After the FM velocity and temperature fields were developed, they were gridded to the domain $\left(40^{\circ} \mathrm{W}-26^{\circ} \mathrm{W}\right.$, $11^{\circ} \mathrm{S}-1^{\circ} \mathrm{S}$ ) by repeating the last (easternmost) values of temperature and velocity of each the FM transects up to the eastern edge of the domain. This procedure was not necessary for the salinity field, since the WOA salinity field spans the entire domain. 
The gridded FM temperature and salinity fields for the surface and $200 \mathrm{~m}$ are shown in Figures 4.6 and 4.7, respectively. The salinity field shows a larger spatial variability at both levels, since it is itself the WOA(2013) salinity field. The temperature field, on the other hand, has much less structures, with lower values confined close to the coast.

\subsubsection{DWBC Feature Model Formulation}

The DWBC FM was developed like that of the NBUC FM, but all the parameterrelated information (Table 4.2) was derived from previous studies only. That was necessary because the depth reach of the ADCP during ONEI and ONEII was much shallower than the upper layer of the DWBC $(\approx 1200 \mathrm{~m})$.

Table 4.2: Information from the literature for the DWBC FM formulation.

\begin{tabular}{ccccc}
\hline Parameter & Schott et al. (2003) & Schott et al. (2005) & DWBC FM \\
\hline Transport & $24.5 \mathrm{~Sv} 35^{\circ} \mathrm{W}$ & $25.5 \pm 8.3 \mathrm{~Sv} 5^{\circ} \mathrm{S}$ & $20 \mathrm{~Sv}$ \\
& & $35.5 \mathrm{~Sv} 11^{\circ} \mathrm{S}$ & \\
Maximum velocities & $10 \mathrm{~cm} \cdot \mathrm{s}^{-1}$ & $20-25 \mathrm{~cm} \cdot \mathrm{s}^{-1}$ & $0.25 \mathrm{~m} \cdot \mathrm{s}^{-1}$ \\
Core depth & $1500 \mathrm{~m}$ & $2000 \mathrm{~m}$ & $2000 \mathrm{~m}$ \\
Western width & $90 \mathrm{~km}$ & $50 \mathrm{~km}$ & $55 \mathrm{~km}$ \\
Eastern width & $90 \mathrm{~km}$ & $70 \mathrm{~km}$ & $55 \mathrm{~km}$ \\
Vertical extent & $1200-4000 \mathrm{~m}$ & $1200-3800 \mathrm{~m}$ & $1200-3500 \mathrm{~m}$ \\
\hline
\end{tabular}

The number of DWBC studies is clearly much smaller than studies about the NBUC, and that relates to the dificulties in sampling a deep current. Also, as the DWBC crosses the equator, its path is not very clear, as it may follow an eastward path as well as southward. Besides, some water mass transformations take place close to the equator. Primarily we used the two consecutive studies by Schott et al. (2003) and Schott et al. (2005) for DWBC FM development. Note that Schott et al. (2003) describes the DWBC in a mean sense at $35^{\circ} \mathrm{W}$ and Schott et al. (2005) describe a data-based synoptic characterization of the DWBC at $5^{\circ} \mathrm{S}$ and $11^{\circ} \mathrm{S}$. For implementing the synoptic DWBC FM, we thus chose Schott et al. (2005) mainly for extrating the parameters. See Figure 4.10 for observed depictions of DWBC from Schott et al. (2005). 
The adopted DWBC formulation is very similar to the NBUC formulation, with the main difference that the core depth does not vary along the path of the current. The formulation is the following (Equation 4.5):

$$
\nu(s, n, z)=\nu_{\max }(s) \exp \left[-\left(\frac{\left(n-n_{c}\right)^{2}}{2 \delta_{n}^{2}}+\frac{\left(z-z_{c}(s)\right)^{2}}{2 \delta_{z}^{2}}\right)\right],
$$

where $\nu_{\max }(s)$ is the maximum velocity of the current; $n_{c}$ is the distance of the DWBC core from the coast; $z_{c}$ is the core depth of the DWBC; $\delta_{n}^{2}$ represents the horizontal width on either side of the current at the depth of the core:

for $n<n_{c}$ (onshore part of the current): $\delta_{x} / 2=40 \mathrm{~km}$,

for $n>n_{c}$ (offshore part of the current): $\delta_{x} / 2=75 \mathrm{~km}$;

and $\delta_{z}$ represents the vertical width of the current from the core, which differs on the upper and lower part of the current:

$$
\begin{aligned}
& \text { for } z>z_{c}: \delta_{z} / 2=500 \mathrm{~m} \\
& \text { for } z<z_{c}: \delta_{z} / 2=800 \mathrm{~m}
\end{aligned}
$$

Based on the information from the literature (Schott et al. (2003) and Schott $e t$ al. (2005), the NBUC FM was chosen to have a $0.25 \mathrm{~m} \cdot \mathrm{s}^{-1}$ core $\left(\nu_{\max }\right)$ at $2000 \mathrm{~m}$ depth $\left(z_{c}\right)$, extending from 1200 to $3500 \mathrm{~m}$ and yielding a transport of about $20 \mathrm{~Sv}$ (Table 4.2). As done for the NBUC FM, the DWBC FM velocity formulation was solved for various sections along the coast, the same ones used for the NBUC (Figure 4.3). Also, considering that the PE is a feature within the depth range of the NBUC, we apply the DWBC together with the NBUC FM, since without the NBUC there would be no possibility of the PE to exist. To apply both FMs, we simply sum the NBUC FM and the DWBC FM.

The southernmost and northernmost sections of the combination of the DWBC and NBUC FMs (Figures 4.8 and 4.9, respectively), show the DWBC further offshore from the coast than the NBUC. Since the velocity and the vertical extent of the DWBC do not change along the current's path, the transport of the DWBC is constant througout the domain. The core is vertically located at $2000 \mathrm{~m}$ and the symetry of the current is visible through the fixed horizontal width, which is the same for both sides of the current.

Unfortunatly, the DWBC FM could not be validated against the ONEI or ONEII data, due to the depth reach of the ADCP equipment. Therefore, in Figure 4.10 we present 
Schott et al. (2005)'s sections at $5^{\circ} \mathrm{S}$ and $11^{\circ} \mathrm{S}$, to compare to the sections of our NBUC FM.

The comparison between the DWBC FM (Figures 4.8 and 4.9) and the mean observed DWBC (Figure 4.10) demonstrates that the parameters used for the development of the Feature Model were valid. The core velocity, $0.25 \mathrm{~m} . \mathrm{s}^{-1}$, is the same for the FM and the observations; the depth of the core, at approximately $2000 \mathrm{~m}$ depth, is coincident as well. The width of the current, somewhat over $100 \mathrm{~km}$, is also similar, yielding a similar transport for the feature model and the observed mean section at $5{ }^{\circ} \mathrm{S}$. The upper and lower limits of the current, $\approx 1200 \mathrm{~m}$ and $\approx 3500 \mathrm{~m}$, also match between model and observations.

As was done for the NBUC FM, the temperature was calculated through the inversion of the thermal wind relation (Equation 4.2), also with a mean T-S profile from the WOA (2013) climatology. Then the velocity and temperature fields were gridded to the domain $\left(40^{\circ} \mathrm{W}-26^{\circ} \mathrm{W}, 11^{\circ} \mathrm{S}-1^{\circ} \mathrm{S}\right)$ by repeating the last (easternmost) values of each of the FM transects up to the eastern edge of the domain. For the salinity field, the WOA (2013) salinity field, which spanned the entire domain, was used. Therefore, just interpolation to the bathymetry values was performed on the salinity values. 

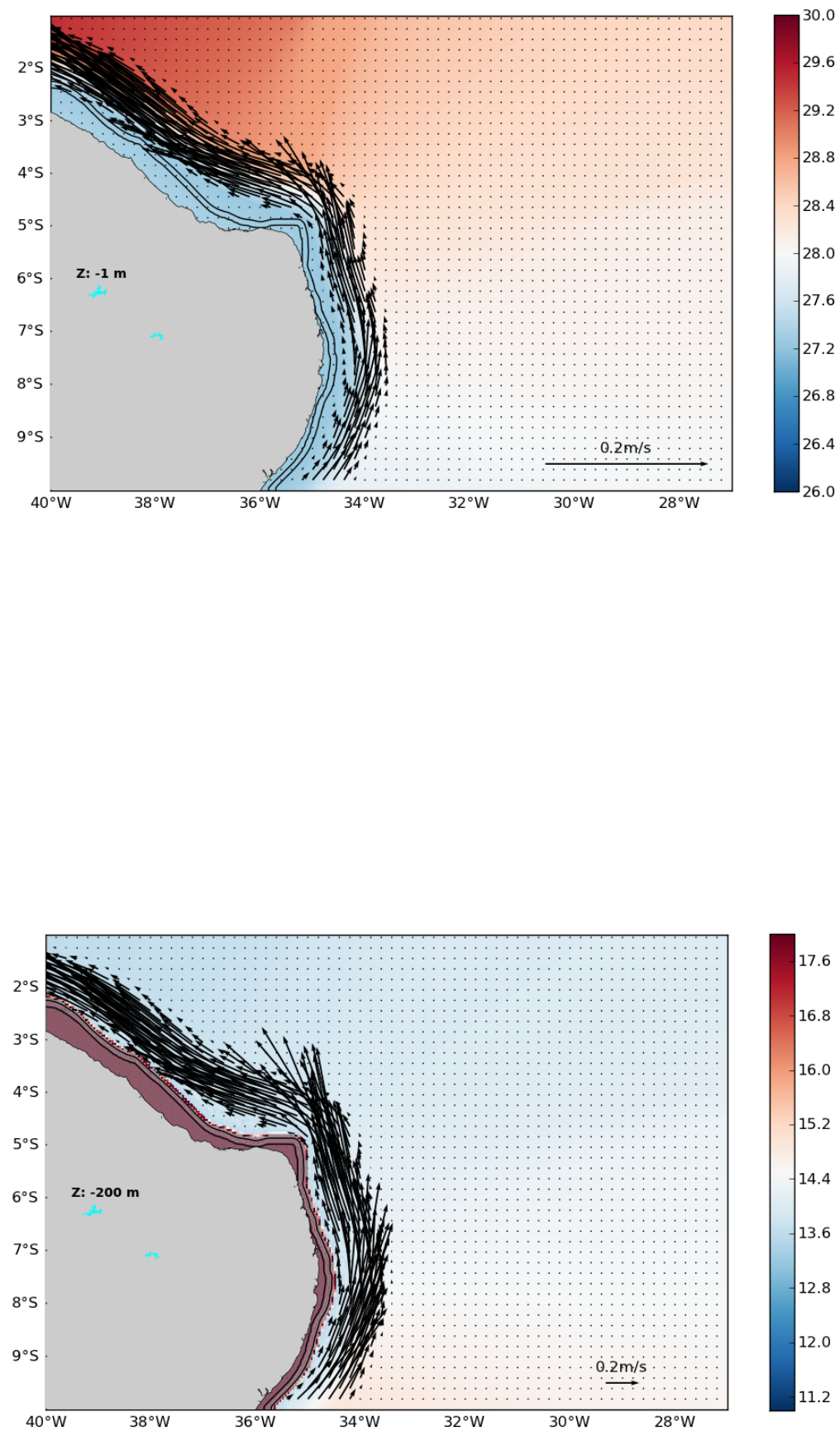

Figure 4.6: FM-derived potential temperature field of the NBUC FM for the entire domain at the surface (top panel) and $200 \mathrm{~m}$ (bottom panel). Superimposed are the FMderived velocity vectors for NBUC. 

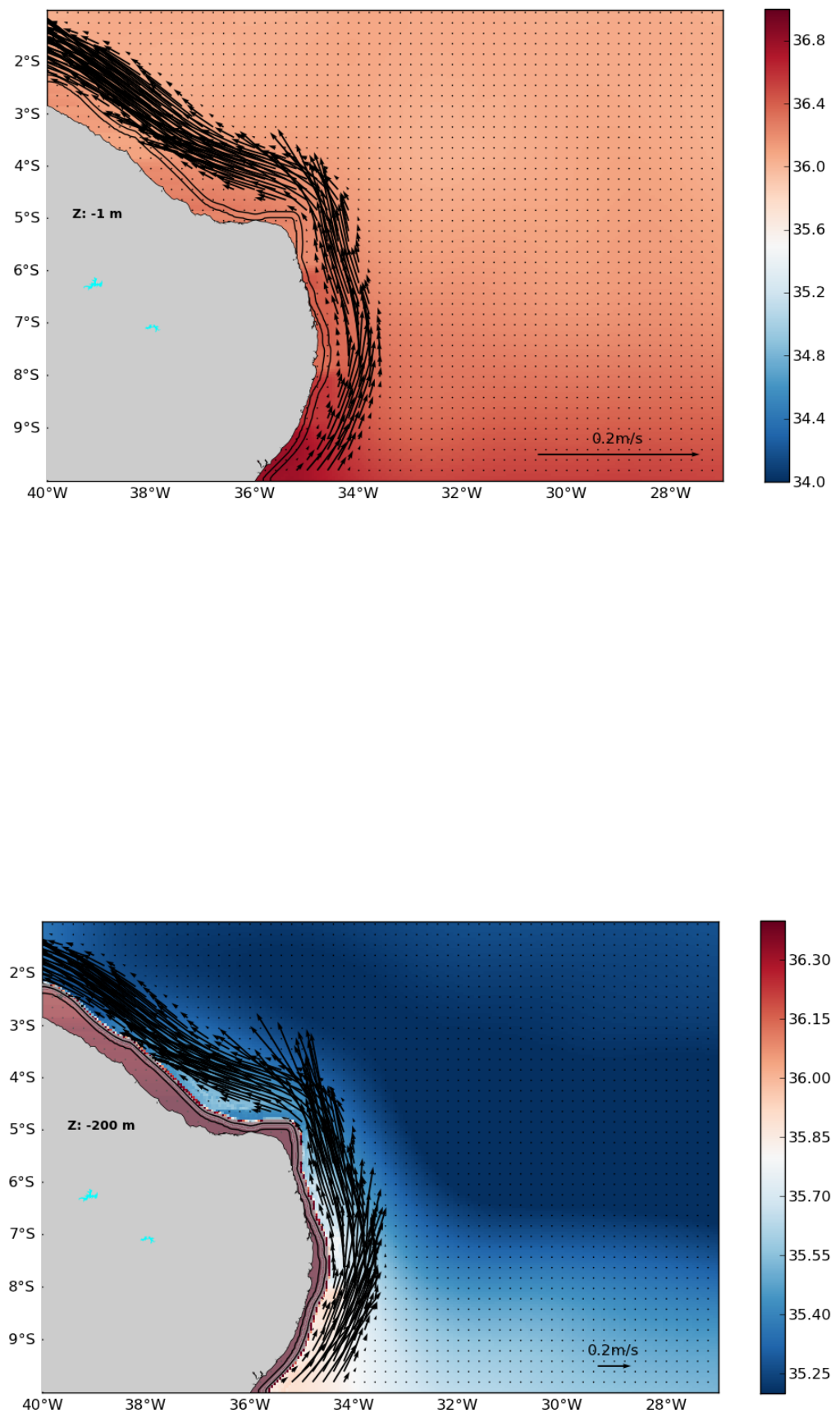

Figure 4.7: Salinity field of the NBUC FM for the entire domain at the surface (top panel) and $200 \mathrm{~m}$ (bottom) panel) (from WOA (2013)). 


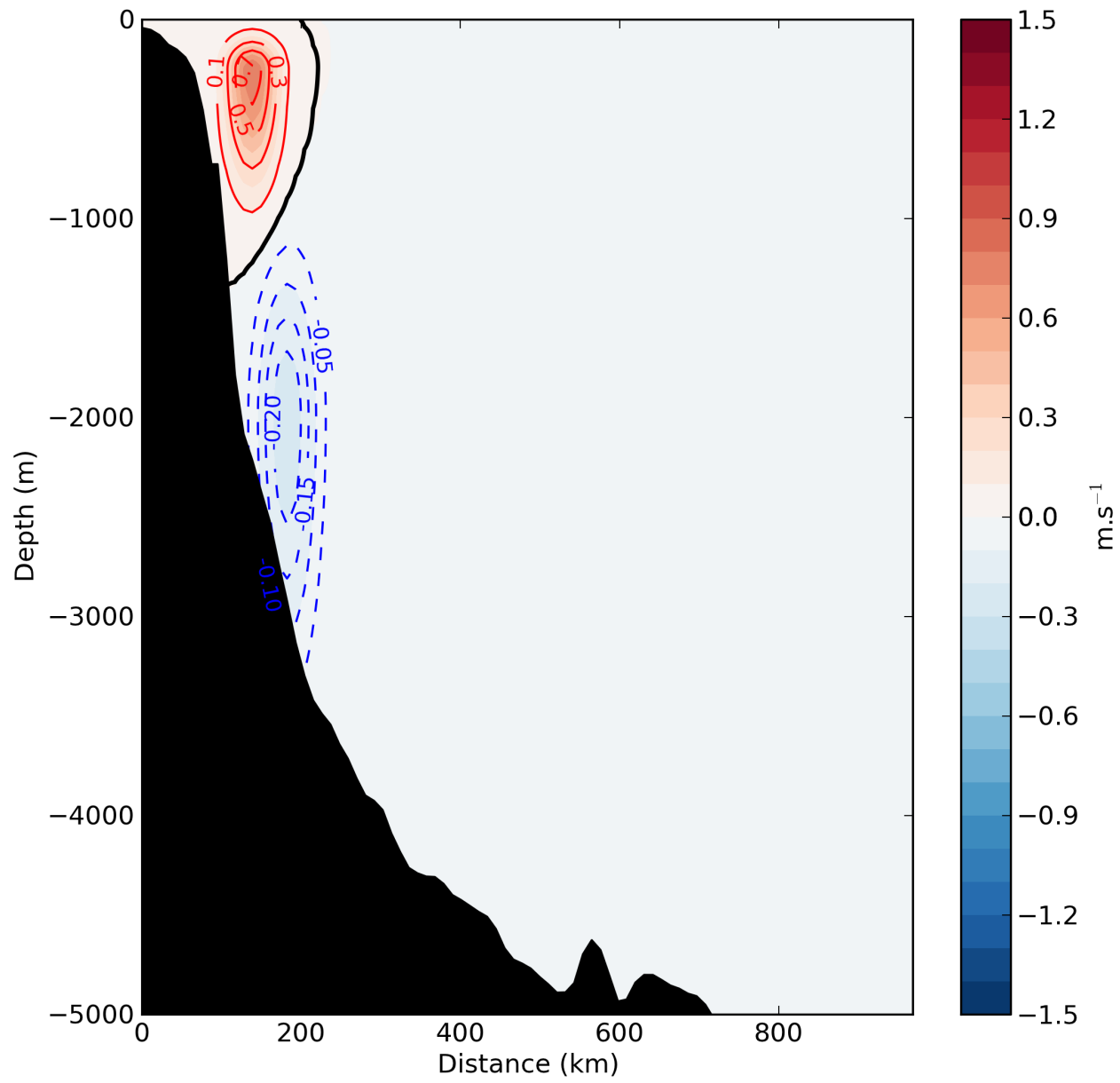

Figure 4.8: Velocity section 1 (southernmost) of the NBUC + DWBC FMs. 


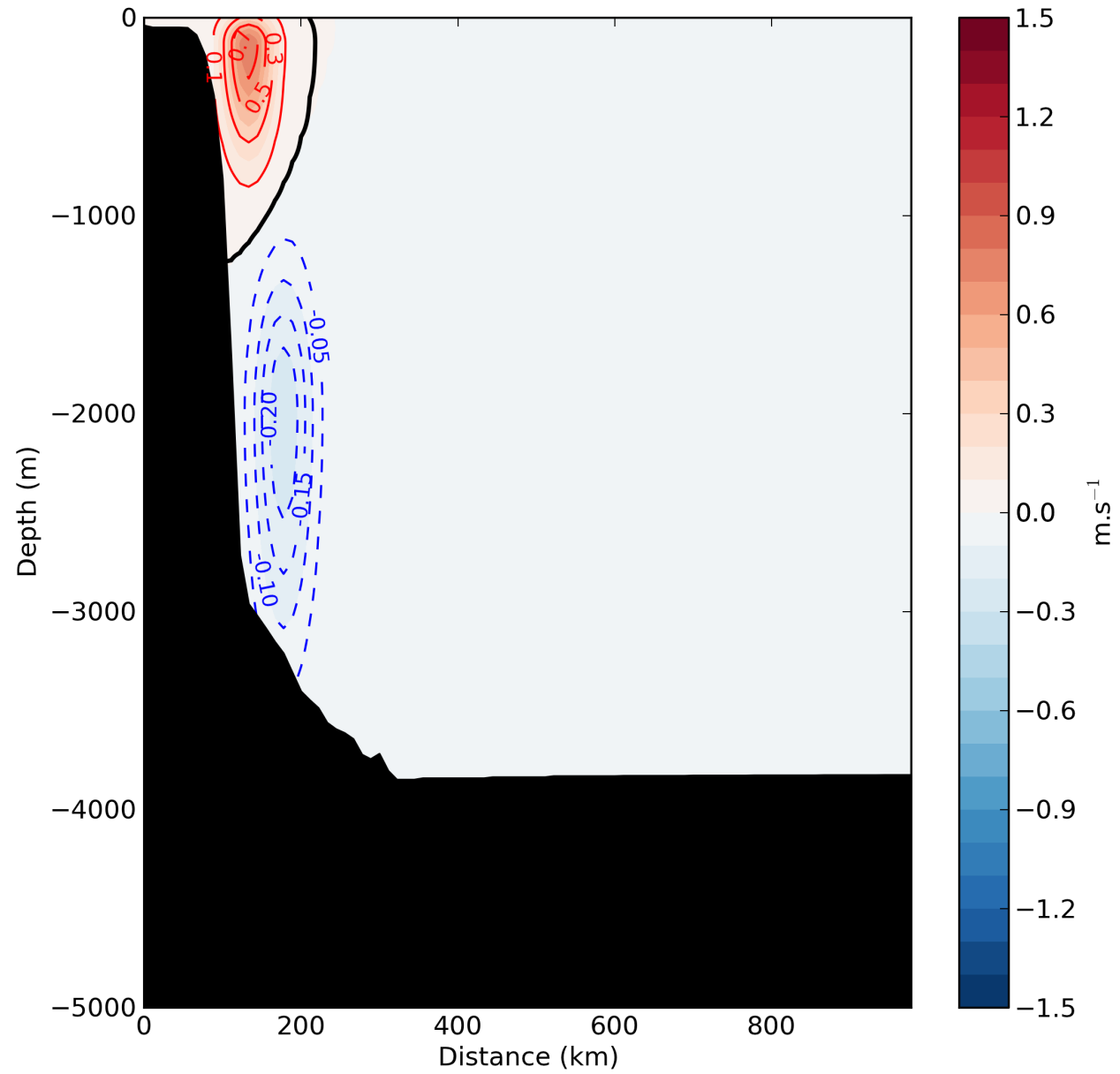

Figure 4.9: Velocity section 44 (northernmost) of the NBUC + DWBC FMs. 

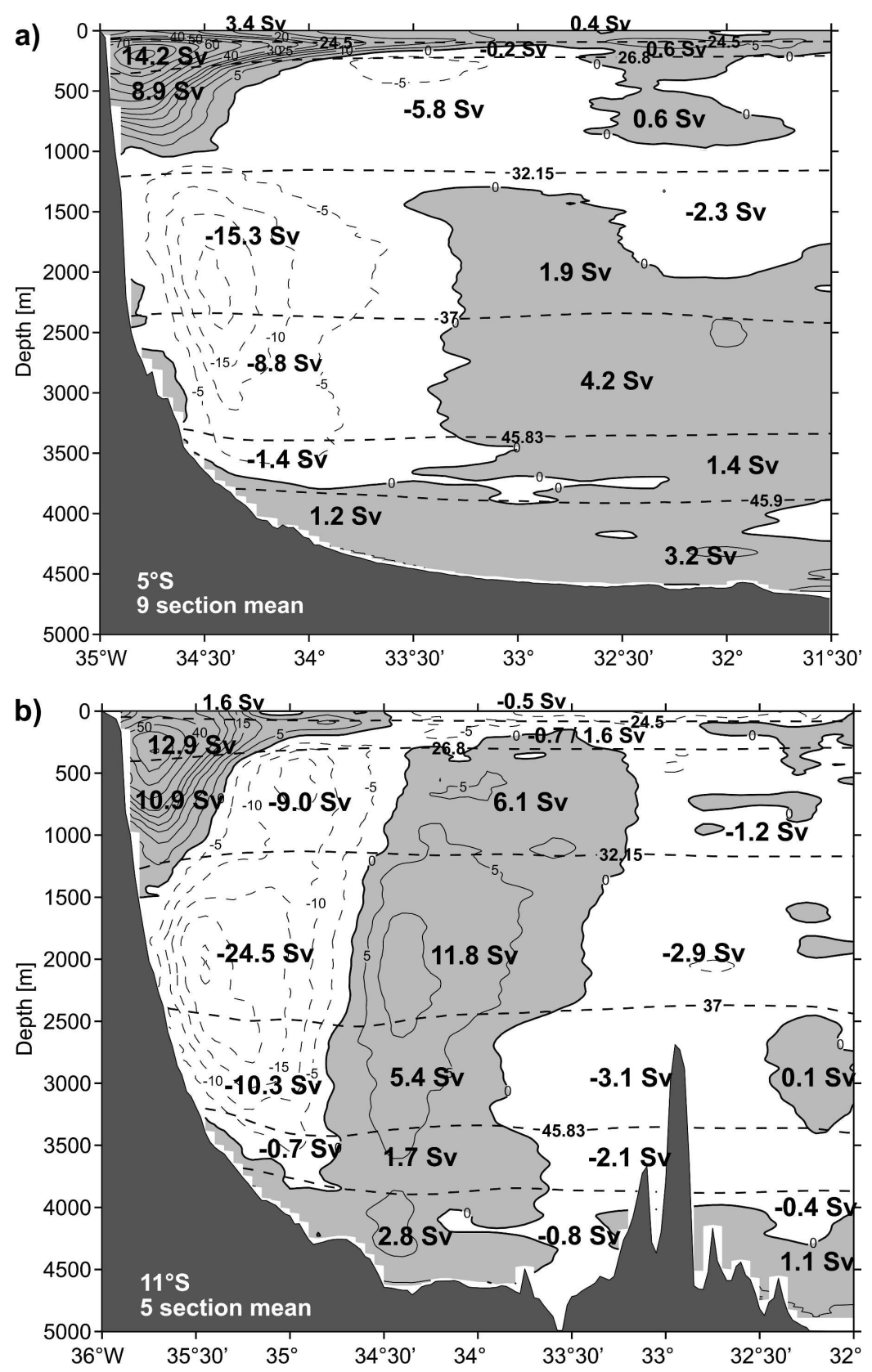

Figure 4.10: Upper panel: mean of 5 sections at $5^{\circ}$ S. Lower panel: mean of 9 sections at $11^{\circ} \mathrm{S}$. Image from Schott et al. (2005). 


\subsection{Numerical experiments set-up}

We address two dynamical questions with two numerical experiments. Each question was addressed with a particular combination of NBUC-DWBC feature model discussed in the previous section. We describe these in detail below.

\section{Question 1: Can the NBUC alone generate the PE?}

To address this question, we set up an experiment with an initial field composed by just the NBUC FM, with the topography truncated at $1500 \mathrm{~m}$ and no islands or seamounts offshore the continental slope, as well as no wind stress. The chosen domain is between $10^{\circ} \mathrm{S}$ and $1^{\circ} \mathrm{S} ; 27^{\circ} \mathrm{W}$ and $40^{\circ} \mathrm{W}$, with a $5-\mathrm{km}$ horizontal spaced grid and 30 sigma layers vertical resolution. In this set-up, the flow coming in from the south corresponds to $24.77 \mathrm{~Sv}$ and the flow going out on the western boundary is $25.13 \mathrm{~Sv}$, yielding an imbalance of $0.36 \mathrm{~Sv}$ (Figure 4.11). The difference in transport results from the increase in the NBUC core velocity.

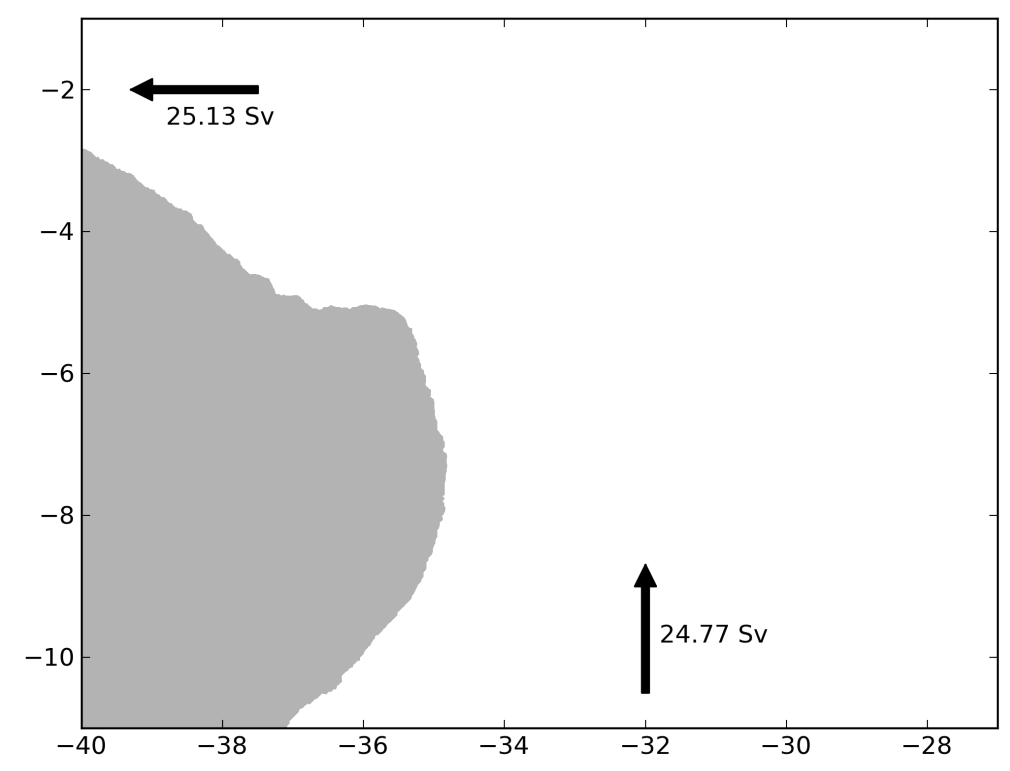

Figure 4.11: Transport values imposed on the edges of the domain for Experiment \# 1.

The boundary conditions were clamped on the southern and western boundaries (where there are inflow and outflow, respectively, on the initial field) and nudging on the eastern and northern boundaries. At these boundaries there is no inflow or outflow on the 
initial field, so the nudging was enforced in order to maintain this condition throughout the run. A 6-point sponge layer was imposed, with nudging time scales of 6 days 6 points away from the boundary, and 1 day at the boundary itself. This run was also set up with a free-slip condition, being called Experiment \# 1. Figure 4.11

Question 2: How important is the vertical shear on the generation of the PE?

To address this question, we set up an experiment with an initial field built with the composition of the NBUC and DWBC FMs. The horizontal limits of the domain and its horizontal resolution were the same as in Experiment \# 1, but on the vertical, the domain extended from the surface down to $5500 \mathrm{~m}$, with computations performed in 50 sigma layers. The boundary conditions enforced were the same as in Experiment \# 1, i. e., clamped on the southern and western boundaries, and nudging on the eastern and northern boundaries. This run was also set up with a free-slip condition and no wind stress, and was called Experiment \# 2. The schematics for the mass balance for this experiment is shown on Figure 4.12, demonstrating a total imbalance of about $0.85 \mathrm{~Sv}$, which we consider to be small enough not to cause mass-imbalance problems.

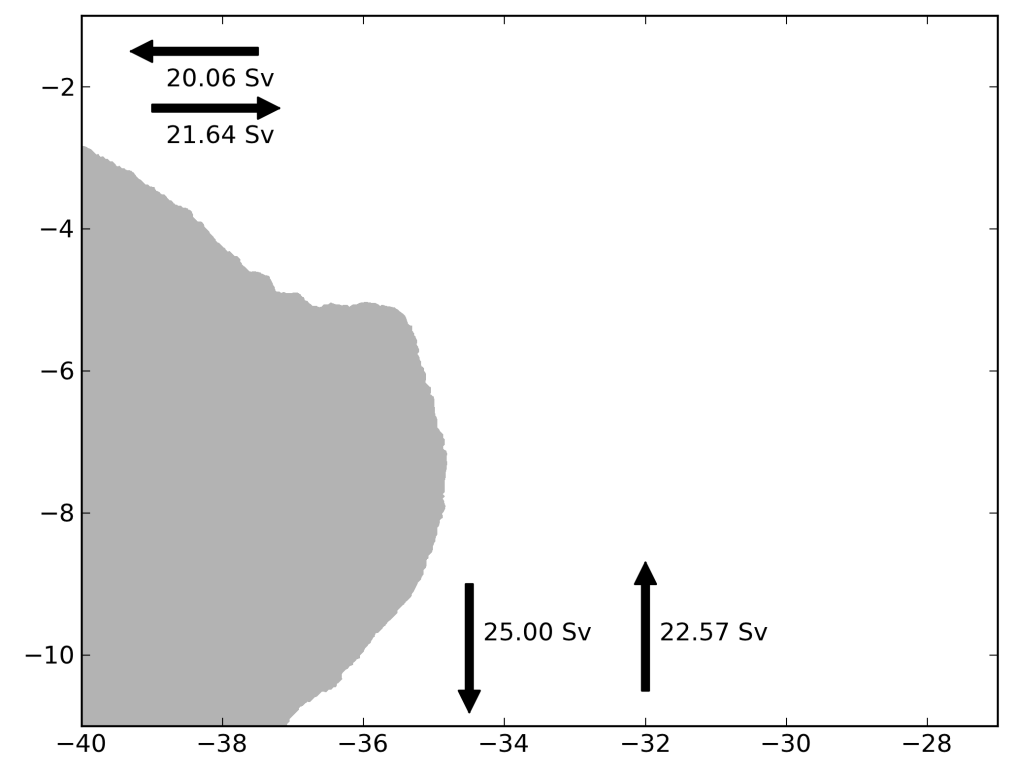

Figure 4.12: Transport values imposed on the edges of the domain for Experiment \# 2. 
These experiments are carried out with the Regional Ocean Modelling System (ROMS) (SHCHEPETKIN and MCWILLIAMS, 2005), which is a primitive- equation numerical model developed from the S-Coordinate Rutgers University Model. ROMS has stretched coordinates in the vertical and curvilinear coordinates on the horizontal, and uses an Arakawa-C grid. The domain, as cited on the previous sections, extended between $10^{\circ} \mathrm{S}$ and $1^{\circ} \mathrm{S} ; 27^{\circ} \mathrm{W}$ and $40^{\circ} \mathrm{W}$, with different discretizations on the vertical - 30 sigma levels for Experiments \#1 and 50 for Experiment \# 2. For Experiment \# 1 the batimetry was smoothed until the maximum topographic gradient was 0.2 , for Experiment \#2, we use a 0.15 gradient.

\subsection{Calibration of Numerical Model and Sensitivity studies for long-term simulations}

Generally, in a FORMS approach for synoptic ocean prediction, there are three distinct steps; (i) Validation, which is the physical validation of occurence and maintenance of realistic size and shape of the reproduced features; (ii) Calibration, which would be the changing and tuning parameter values to achieve validation, and (iii) Verification, which is realistically reproducing past observed events to verify that the prediction system has skill of forecasting as evidenced from hindcasts. In a process-study approach, the "verification" step is replaced by "investigation", over which we analyze the processes envolved on the features of interest.

In the previous sections we describe the development of the Feature Model and compare it with available data/information, thus completing step (i). After this step, we turn to the calibration phase, in which we develop a calibrated system to its dynamical equilibrium for investigating processes of interest with dynamical realizations. In step (ii), we configured a series of numerical simulations with the developed Feature Models, analyzing the requirements and the changes necessary for the dynamical equilibrium to be reached. In this sense, Tables 4.3 and 4.4 list all the sensitivity experiments that were carried out before the working set-up was achieved, with the boundary and initial conditions that are most suitable for our study. 


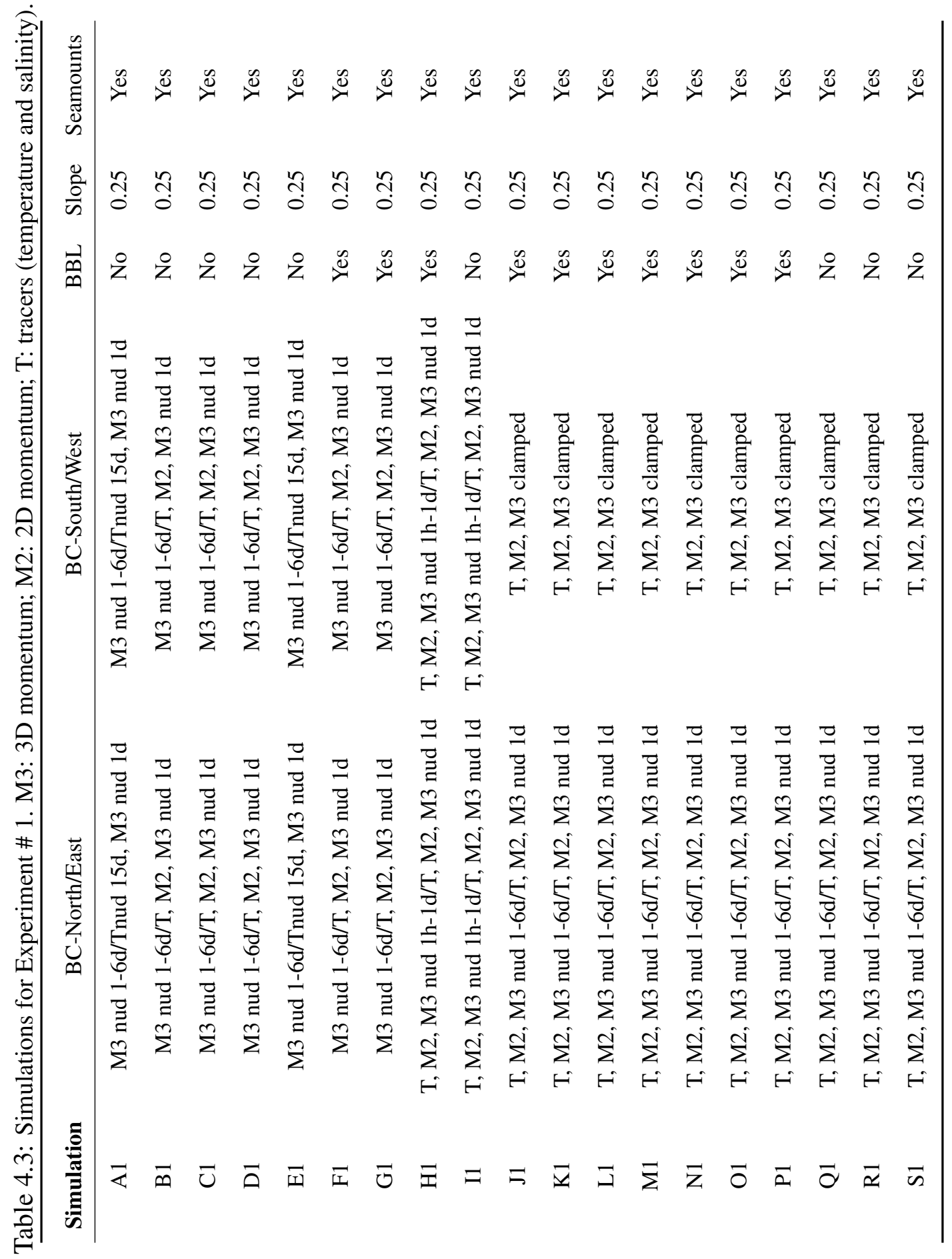




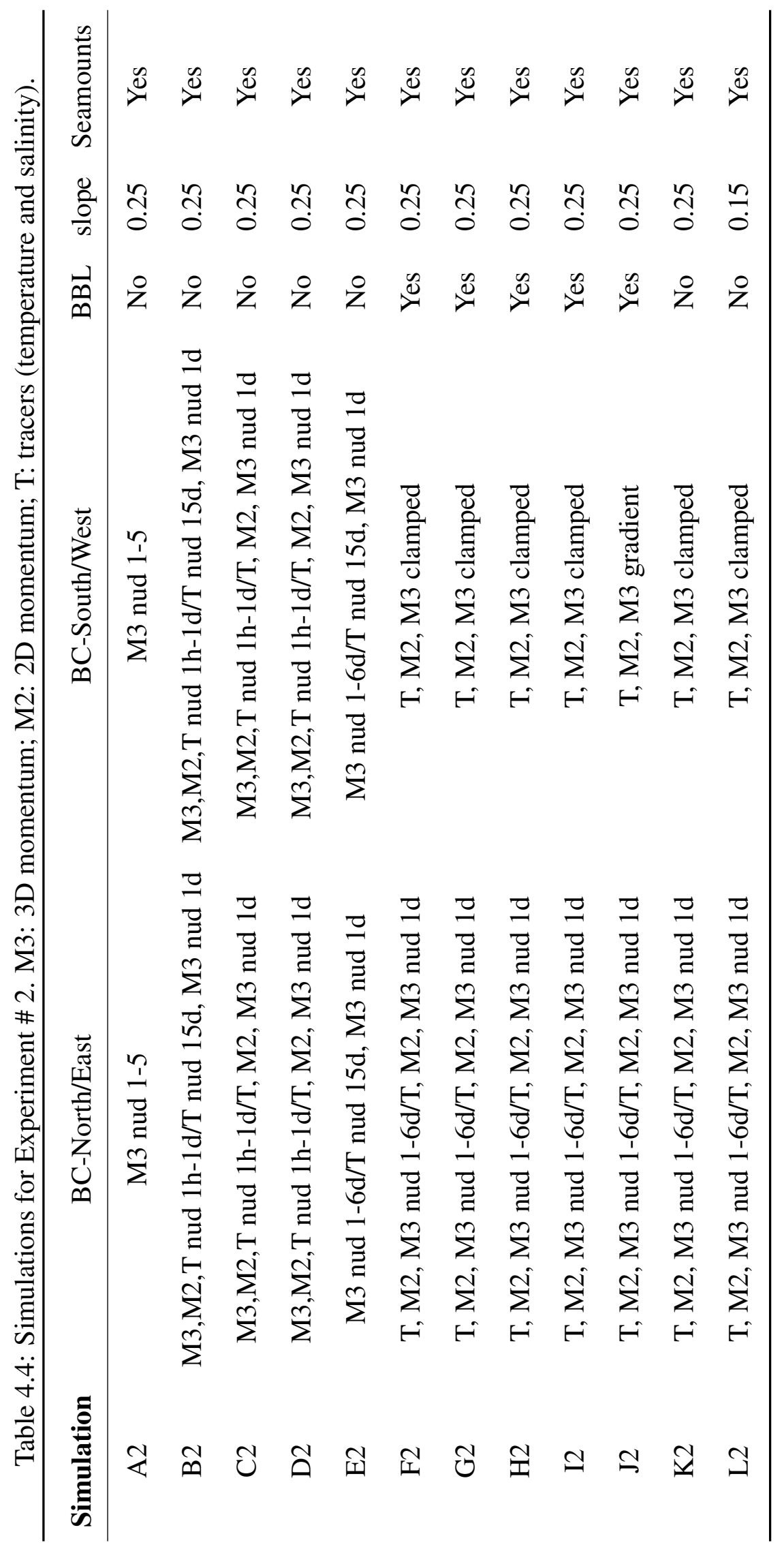


When developing the initial fields for the simulations, we considered a series of issues, including mainly: (a) salinity feature model derivation based on a single linear t-s relationship; (b) salinity feature model with two linear t-s relationships (one for the shelf and another for the deep ocean); (c) addition of a bottom boundary layer (BBL); (d) free-slip vs. no-slip; (e) use of salinity climatology from WOA 2009; (f) use of salinity climatology from WOA 2013; (g) maximum bottom slope allowed, and finally (h) seamounts vs. no-seamounts.

We found that both (a) and (b) resulted in multiple issues with generation of highsalinity regions and unrealistic salinities near the bottom. The enforced bottom boundary layer (with an exponential decay to zero velocity at the bottom from a specified depth) helped for a little while; but not for the long-term. We then used free-slip boundary condition, and no bottom boundary layer. The use of WOA2013 climatology finally helped the evolution of salinity near the western boundary (high-current) regions. However, at this time, we had issues with anomalous salinity concentrations around seamounts. So, in the final simulation for the $1500 \mathrm{~m}$ run (Experiment \#1), the WOA 2013 salinity field is used in a model domain without any seamounts. This simulation was stable and repetitive in its performance for over 500 days. For the Experiment \# 2, the seamounts were maintained, but the maximum model bathymetric slope alowed was reduced from 0.25 to 0.15. Similar long-term runs were carried out in parallel with the $5500 \mathrm{~m}$ set up and all of the sensitivity studies are listed in Table 4.4 .

\subsection{Model results}

Two experiments were conducted, with distinct vertical domain $(\mathrm{H}=1500 \mathrm{~m}$ and $\mathrm{H}=5500 \mathrm{~m}$ ) and small differences on the set-up, as indicated in section 4.2. On the following sections we describe the results of the model experiments \# 1 and \# 2 and compare them with information from observed data, focusing on the Potiguar Bight area. 


\subsubsection{Experiment \# 1 (NBUC only, $\mathrm{H}=1500 \mathrm{~m})$}

The kinetic energy in Experiment \# 1 stabilized after 100 days (Figure 4.13). This experiment was run for about 550 days, a time span within which the model seemed to have reached dynamical equilibrium.

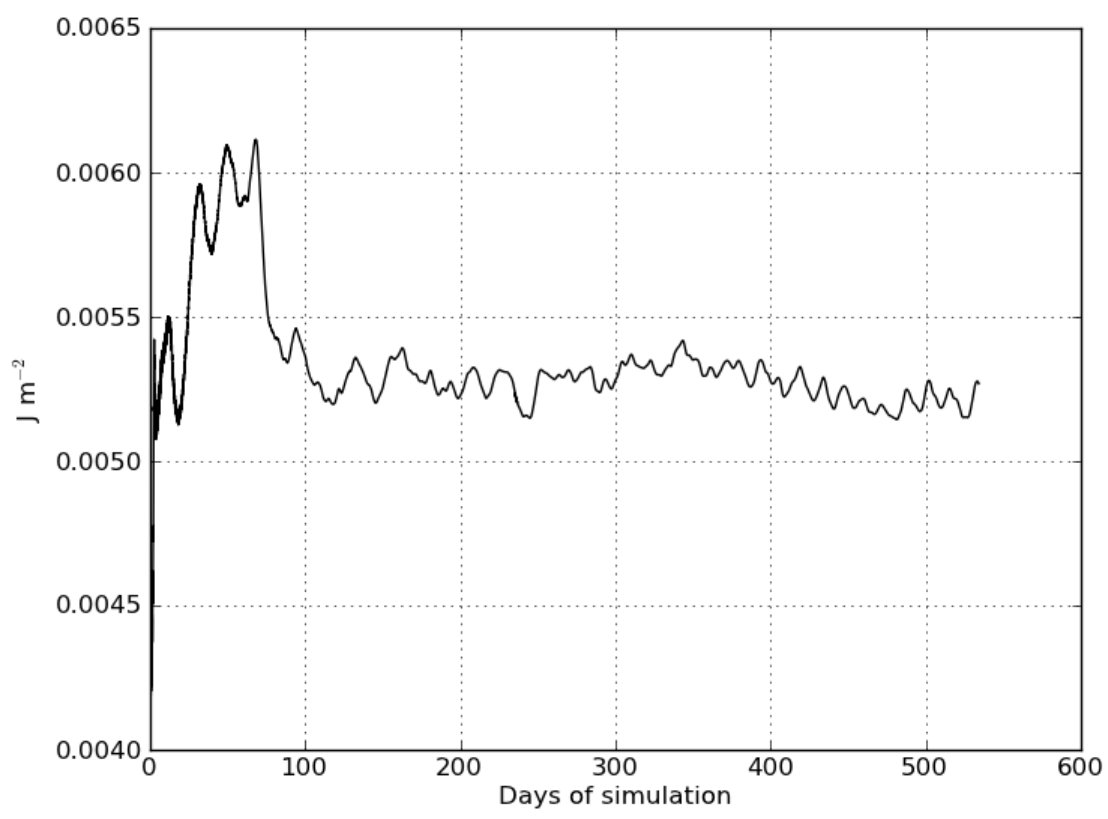

Figure 4.13: Time evolution of domain-averaged kinetic energy for Experiment \# 1. Note that the dynamical equilibrium of the simulation is reached after about 100 days.

In this experiment, the surface current field remained highly variable throughout the simulation, with the flow dominated by quasi-stationary and propagating eddies along the coast, specially on the northern part of the domain. A representative picture of the surface velocity field after the kinetic energy stabilization is given on Figure 4.14 .

At a depth of $200 \mathrm{~m}$, before the kinetic energy stabilization, the NBUC meanders close to the northeast tip of South America, generates dipoles in the Potiguar Basin area, and sheds eddies that move to the northwestern part of the domain, as shown on the sequence presented on Figure 4.15. Around day 100, the PE becomes a stationary eddy confined on the Potiguar Basin, and remains that way for the remainder of the run. The process of eddy generation, which happened before the onset of dynamical equilibrium was reached, can be followed in the $200 \mathrm{~m}$ horizontal velocity and temperature field in 
Figure 4.15 and on cross-eddy velocity and temperature sections in Figures 4.16 and 4.17 , respectively, and is described in the following paragraph.

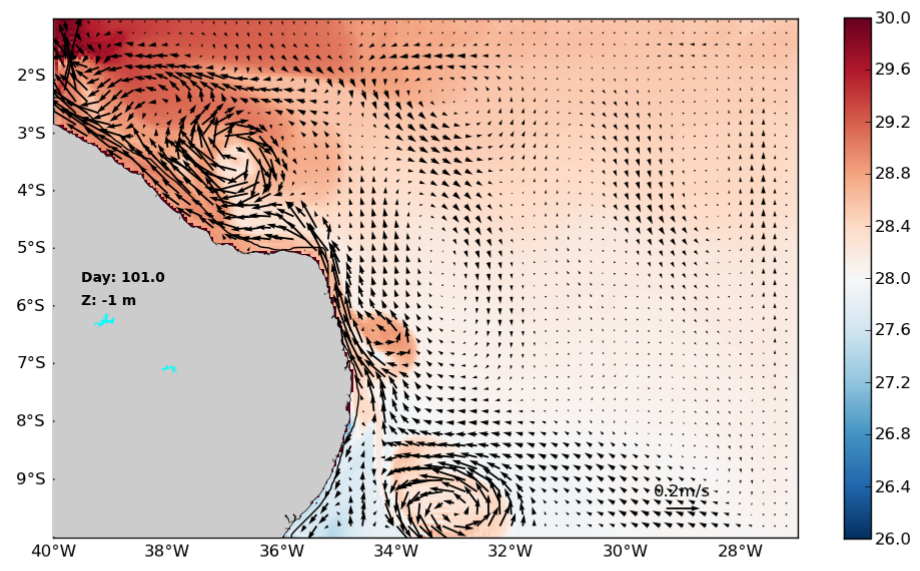

Figure 4.14: Velocity and temperature fields on day 101 at the surface for Experiment \# 1.

In the beginning of the run, during day one, the velocity field at $200 \mathrm{~m}$ shows the NBUC very similar to that of the initial field developed based on the Feature Model; no eddy is seen on the Potiguar Bight. On the following days, there are eddies formed in the region as part of a dipole structure with an anticyclone on the nearshore side of the current and a cyclone on the offshore side. The vertical velocity sections depict the perturbation on the velocity field with depth by the dipole structure as the eddy formation evolves. The temperature sections also show the perturbation on the isotherms caused by the instability of the field. On day 101 the field reaches a stable configuration, with the NBUC flowing northwestward along the coast and the stationary PE is confined to the Potiguar Bight. After this stable configuration is reached, the flow field does not change significantly over the integration period (up to day 500). Also, it should be stressed that the time required for the PE to become stationary coincides with the time required for the domain-averaged 
kinetic energy to stabilize (Figure 4.13).
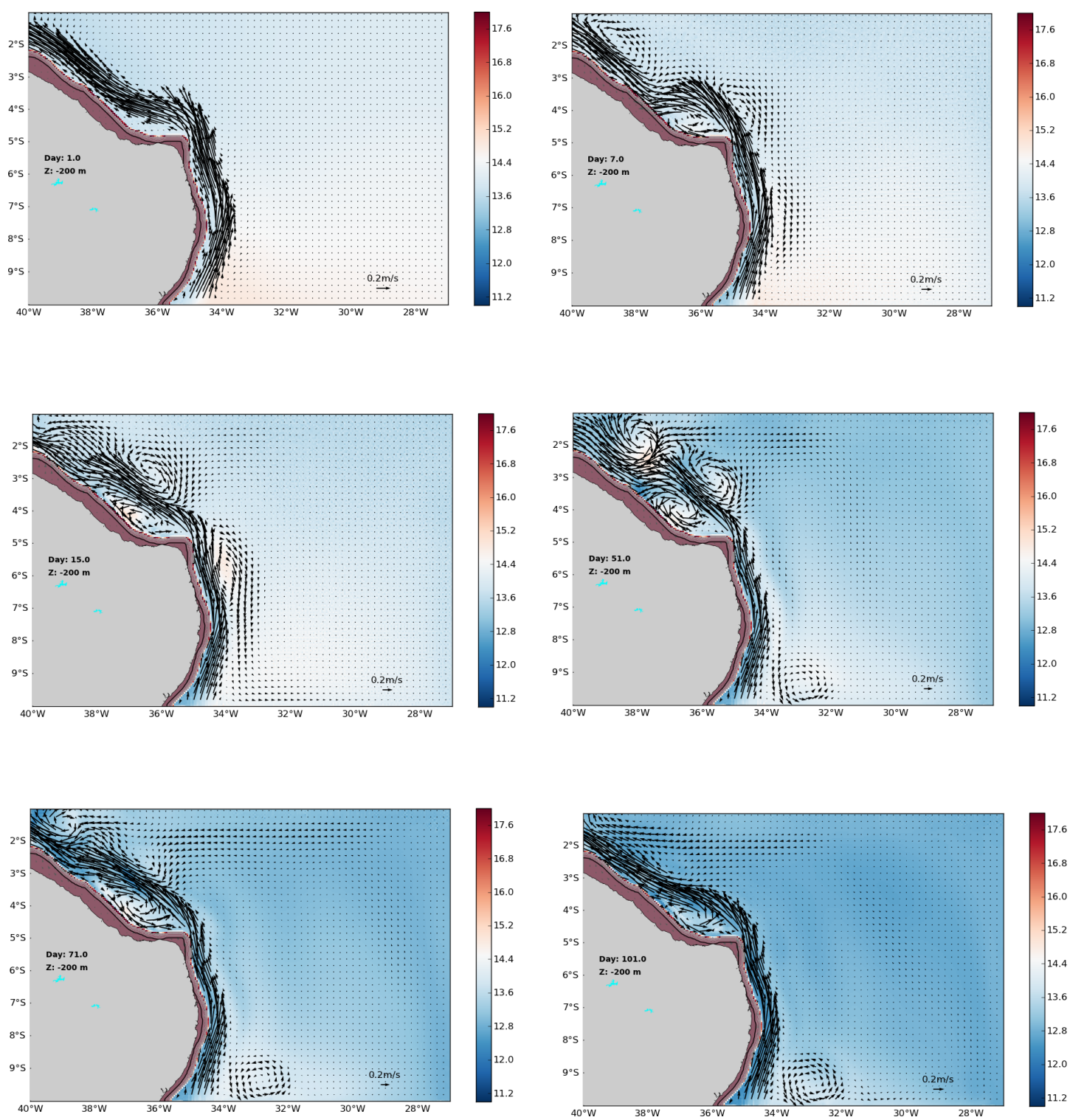

Figure 4.15: Evolution of the temperature and velocity fields at $200 \mathrm{~m}$ during Experiment \# 1 during days 1 (upper left), 7 (upper right), 15 (middle left), 51 (middle right), 71 (lower left), and 101 (lower right). 

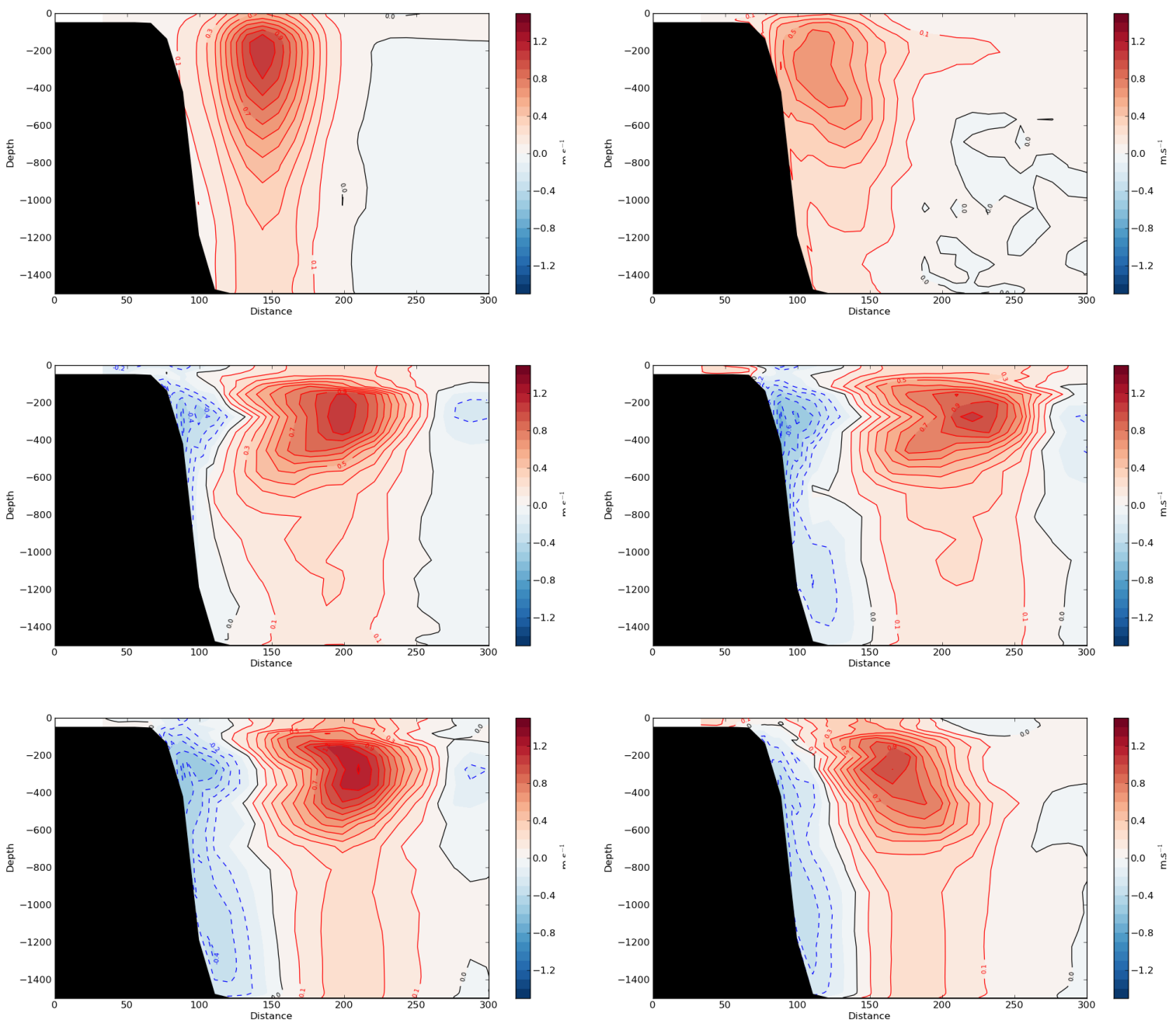

Figure 4.16: Evolution of the velocity field over a cross-eddy section during Experiment \# 1 during days 1 (upper left), 7 (upper right), 15 (middle left), 51 (middle right), 71 (lower left), and 101 (lower right).

As suggested by the mean cross-eddy section after the stabilization of the run (Figure 4.18), the modeled PE seems to have a very weak surface signature and a deepreaching structure. However, the sole analysis of the mean cross-eddy velocity section to infer the vertical extent of the eddy can be misleading. The horizontal temperature and velocity fields for day 101 for 500, 900 and $1000 \mathrm{~m}$ (Figures 4.19, 4.20 and 4.21, respectively), show that, even though there is a deep southeastward flow attached to the continental slope in the Potiguar Bight, this flow does not necessarily correspond to a part of the eddy. The PE is clearly seen on the $500 \mathrm{~m}$ field (Figure 4.19), but on the $900 \mathrm{~m}$ and 
$1000 \mathrm{~m}$ there is no eddy structure on the Potiguar Bight. The southeastward velocities are caused by a southward-flowing current along the coast, probably generated by the bathymetric constraints (1500 m maximum depth) imposed for this run. Therefore, caution must be exercized when delimiting the part of the water column over the influence of the eddy. Here, after analyzing horizontal velocity fields, we delimit the eddy as between 50 and $750 \mathrm{~m}$ for transport calculation.
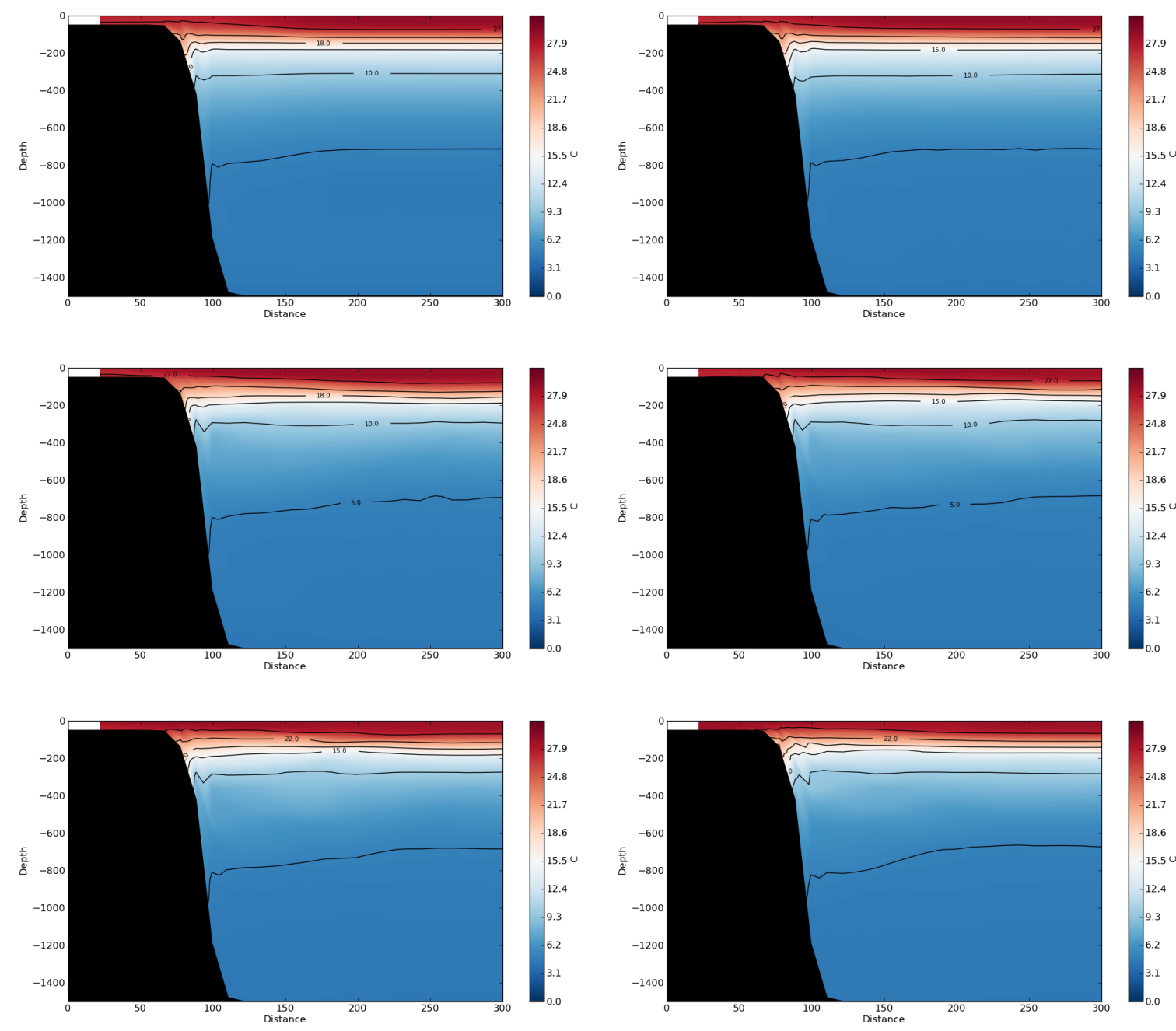

Figure 4.17: Evolution of the temperature field over a cross-eddy section during Experiment \# 1 during days 1 (upper left), 7 (upper right), 15 (middle left), 51 (middle right), 71 (lower left), and 101 (lower right).

The flow at $500 \mathrm{~m}$ presented on Figure 4.19 is representative of the flow at this depth after the run reaches stabilization. The field is similar to the $200 \mathrm{~m}$ field, with 
the Potiguar eddy clearly formed. On $1000 \mathrm{~m}$ (Figure 4.21), however, no PE is seen and a continuous southward current is identified along the coast, which is probably due to the continuity requirement from the bathymetric constraints imposed for this run, as previously stated. The mean modeled NBUC after the run reached dynamical equilibrium has a transport of $27 \mathrm{~Sv}$, comparable to the values indicated by Silveira et al. (1994); Schott et al. (2002), for example. Its path is also realistic, as well as its core depth and width.

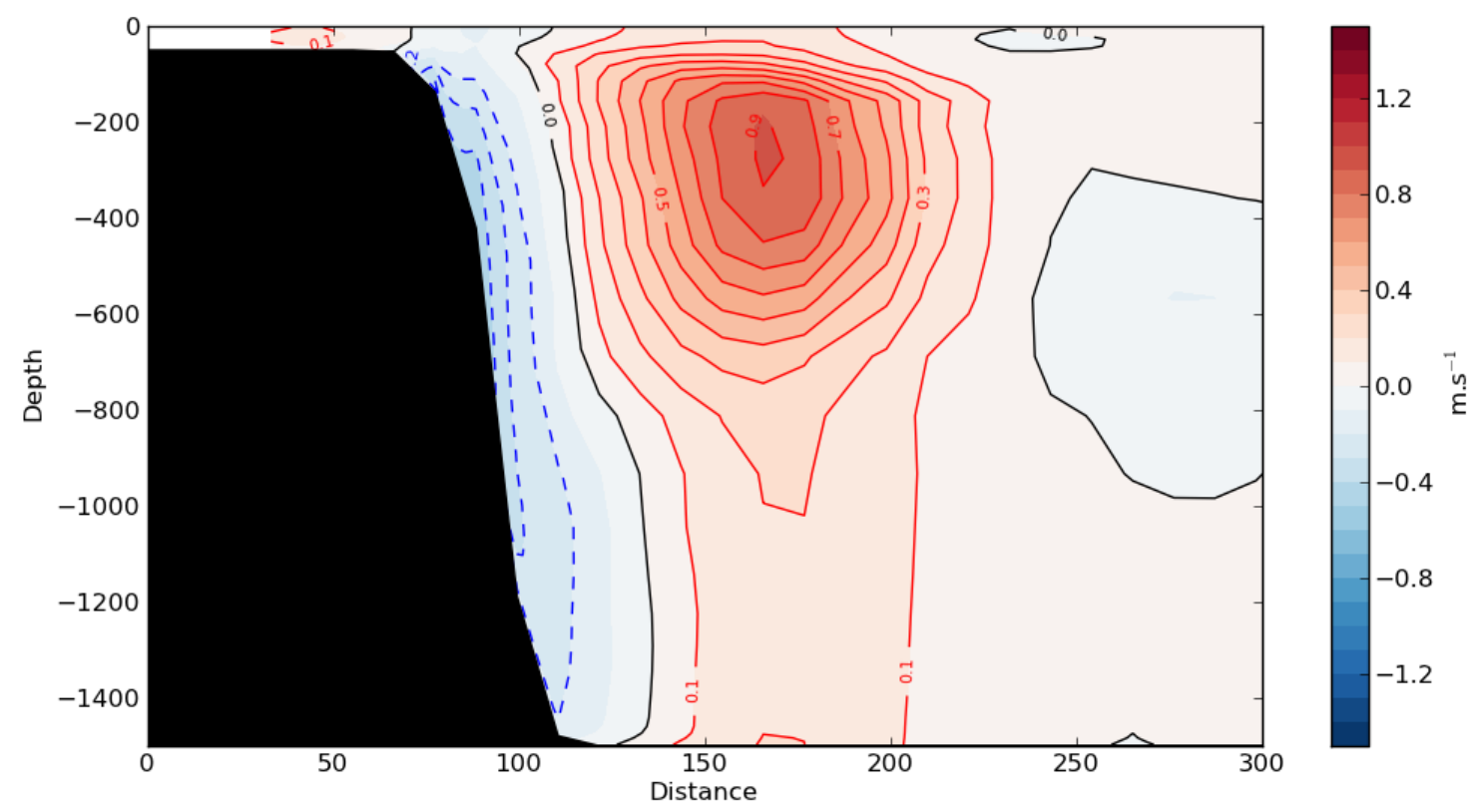

Figure 4.18: Mean cros-section for Experiment \# 1, over days 201-360.

In Experiment \# 1 we investigate whether or not the NBUC alone would be capable of generating the Potiguar Eddy. As a result of our analysis we reach the conclusion that the PE formation process does not require the presence of the DWBC, since its generation is observed in this NBUC-only configuration. On Figure 4.22 we analyze the formation of the PE at $200 \mathrm{~m}$ in the relative vorticity field. Figure 4.23 shows a cross-eddy relative vorticity profile at $200 \mathrm{~m}$ during the same days as Figure 4.22 , 


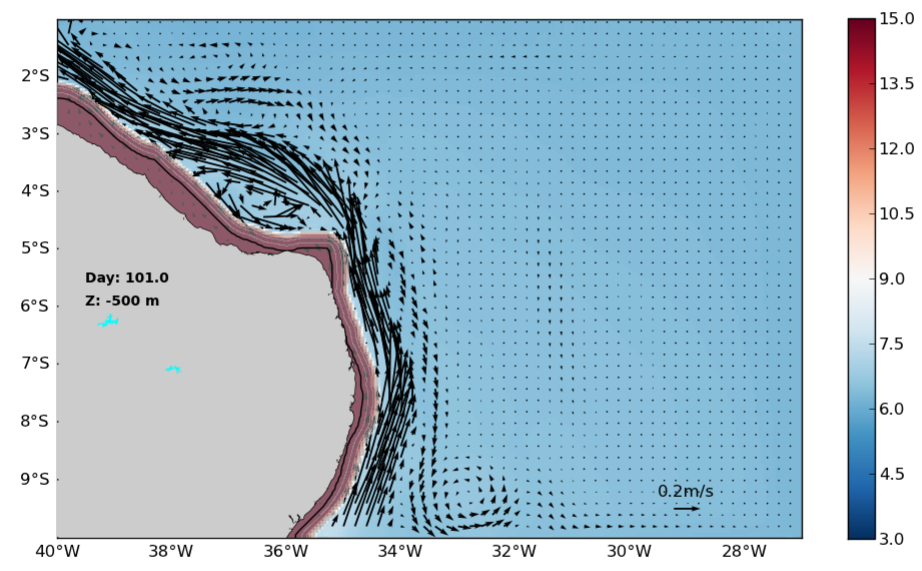

Figure 4.19: Velocity and temperature fields on day 101 at $500 \mathrm{~m}$ for Experiment \# 1.

The shear of the flow field on the Potiguar Bight during the process of eddy formation is revealed in the horizontal relative vorticity field at $200 \mathrm{~m}$ (Figure 4.22). On day 1 , only the patches of positive and negative relative vorticity associated with the NBUC are seen in the Potiguar Bight, following the topographic contours. On Figure 4.23 this is more evident, with the positive relative vorticity on the nearshore side of the current, the sign change (representing the location of the NBUC core), and the negative relative vorticity on the offshore side of the current.

On day 7 the field is already disturbed, as the NBUC starts to meander and flow further away from the coast. During days 15, 51 and 71 the NBUC does not follow the topography, flowing without much meandering further from the coast. The relative vorticity horizontal distribution close to the coast seems to be in a transient state, without a clear pattern close to the shore. On the cross-eddy profile, the slow development of a patch of negative relative vorticity close to the coast is more evident. 


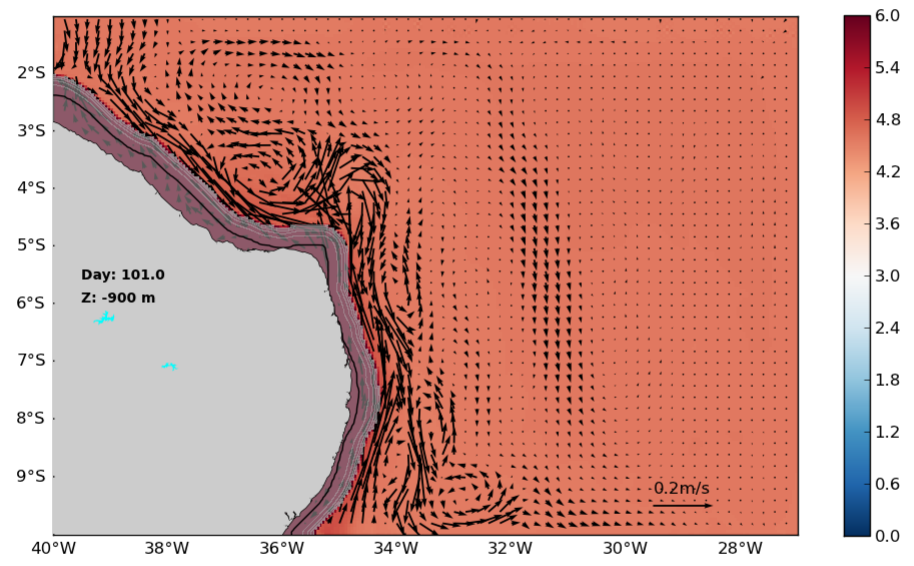

Figure 4.20: Velocity and temperature fields on day 101 at $900 \mathrm{~m}$ for Experiment \# 1.

Finally, on day 101, a steady state is reached, with the positive and negative patches representing the positive and negative relative vorticity areas on either side of the NBUC core, and a large area of positive relative vorticity over the Potiguar Bight on the horizontal distribution. On the cross-eddy profile (Figure 4.23, lower right panel), the signature of the now formed PE is seen as the profile presents a (i) negative (cyclonic) relative vorticity near the coast, followed by (ii) positive (anticyclonic) relative vorticity further offshore, which is followed by (iii) another patch of negative (cyclonic) relative vorticity. (i) represents the nearshore portion of the nearshore lobe of the PE, with (eastward) velocity increasing northward. After the peak velocities of the nearshore lobe of the PE are reached, the relative vorticity changes sign and becomes positive, (ii) associated with the (westward) velocity increase in the northern direction. At the location of the core of the NBUC, the relative vorticity changes sign again (iii), due to the (westward) velocity decrease in the northern direction. 


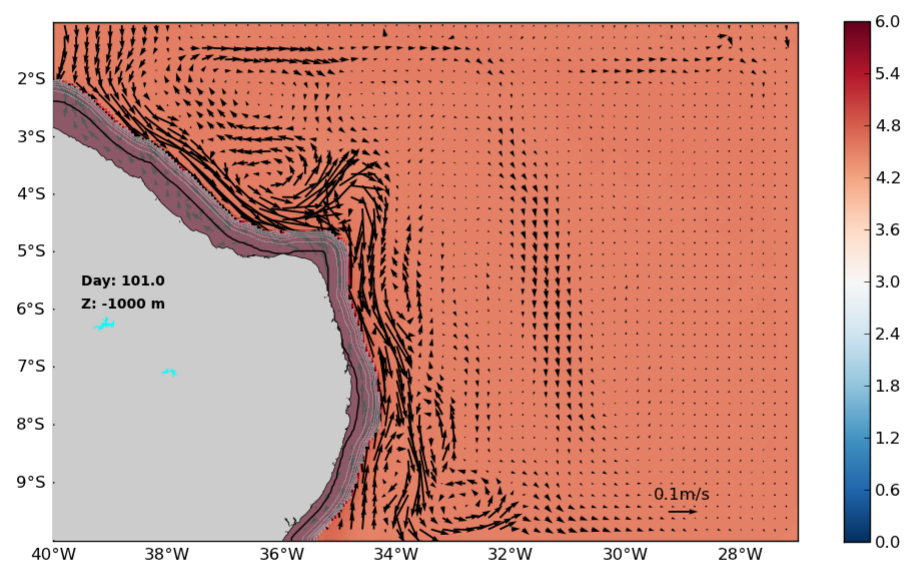

Figure 4.21: Velocity and temperature fields on day 101 at $1000 \mathrm{~m}$ for Experiment \# 1. 

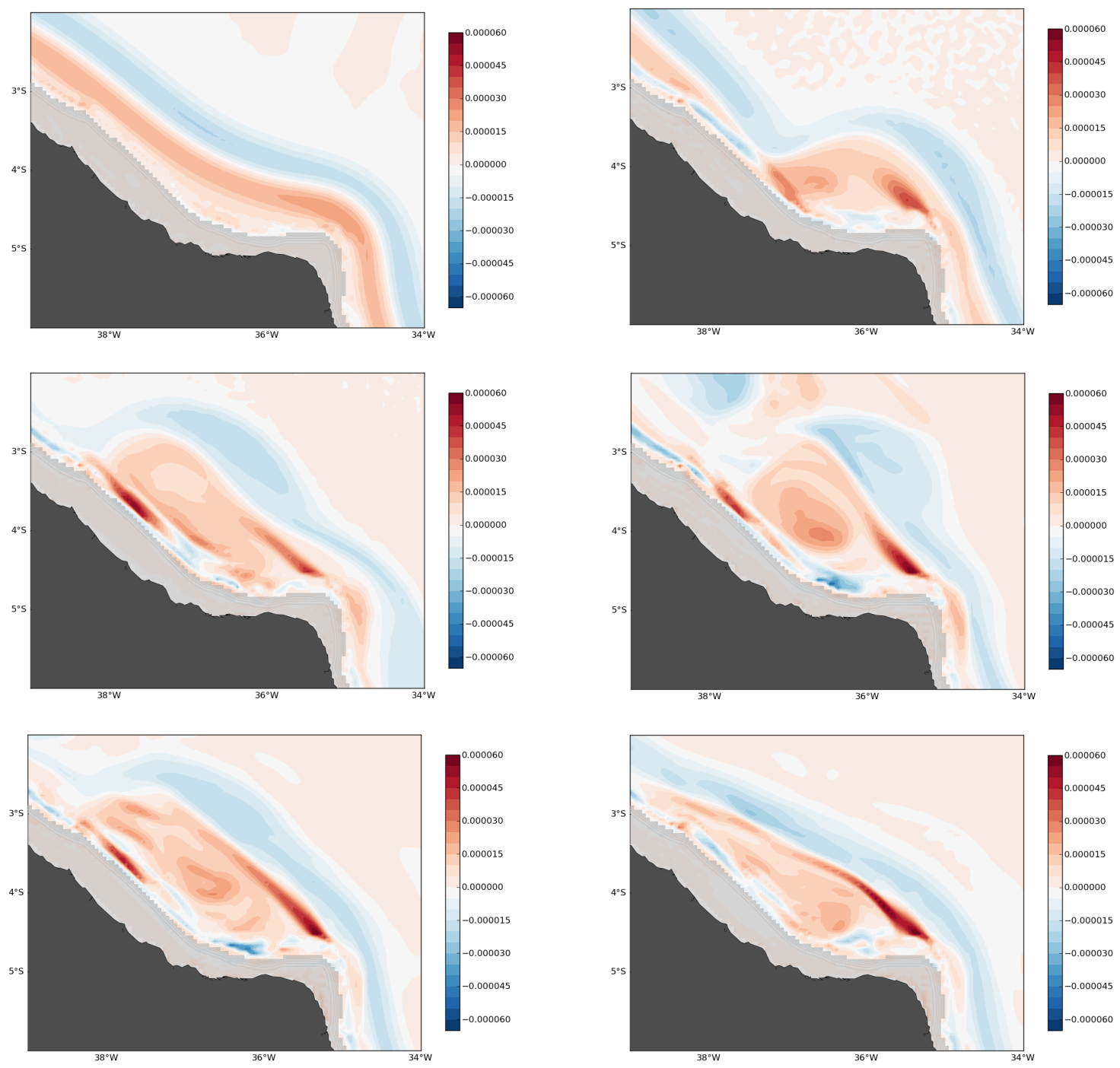

Figure 4.22: Evolution of the relative vorticity field at $200 \mathrm{~m}$ during Experiment \# 1 during days 1 (upper left), 7 (upper right), 15 (middle left), 51 (middle right), 71 (lower left), and 101 (lower right). 

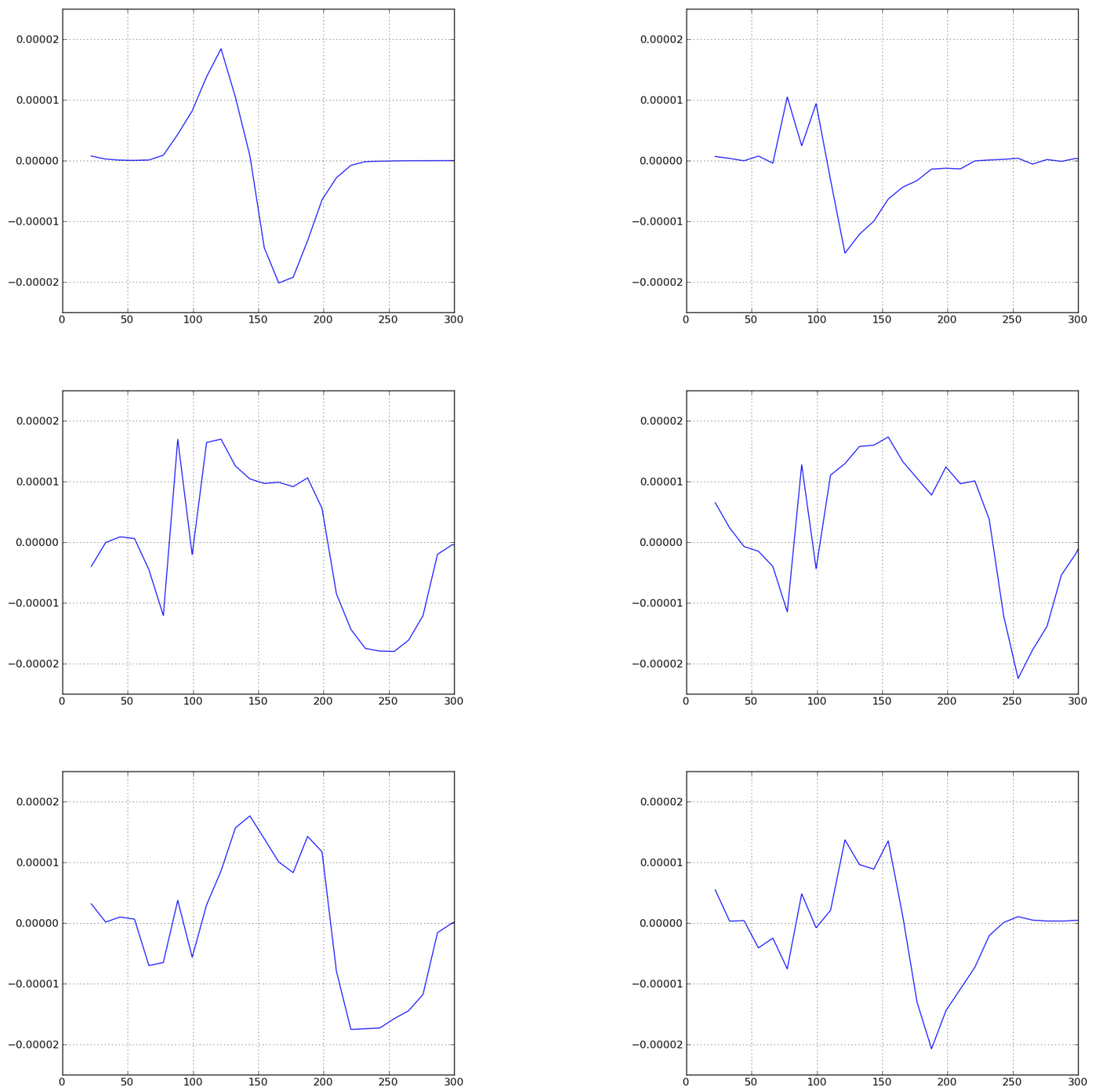

Figure 4.23: Evolution of the relative vorticity field at $200 \mathrm{~m}$ during Experiment \# 1 during days 1 (upper left), 7 (upper right), 15 (middle left), 51 (middle right), 71 (lower left), and 101 (lower right). 


\subsubsection{Experiment \# $2(\mathrm{NBUC}+\mathrm{DWBC}, \mathrm{H}=5500 \mathrm{~m})$}

Experiment \# 2 was run for 420 days, which corresponds to about 320 days after the stabilization of the domain-averaged kinetic energy, around day 100 ( Figure 4.24). Note that both Experiments \# 1 and \#2 took about 100 days to reach dynamical equilibrium and this is the same time-period for the PE to be established.

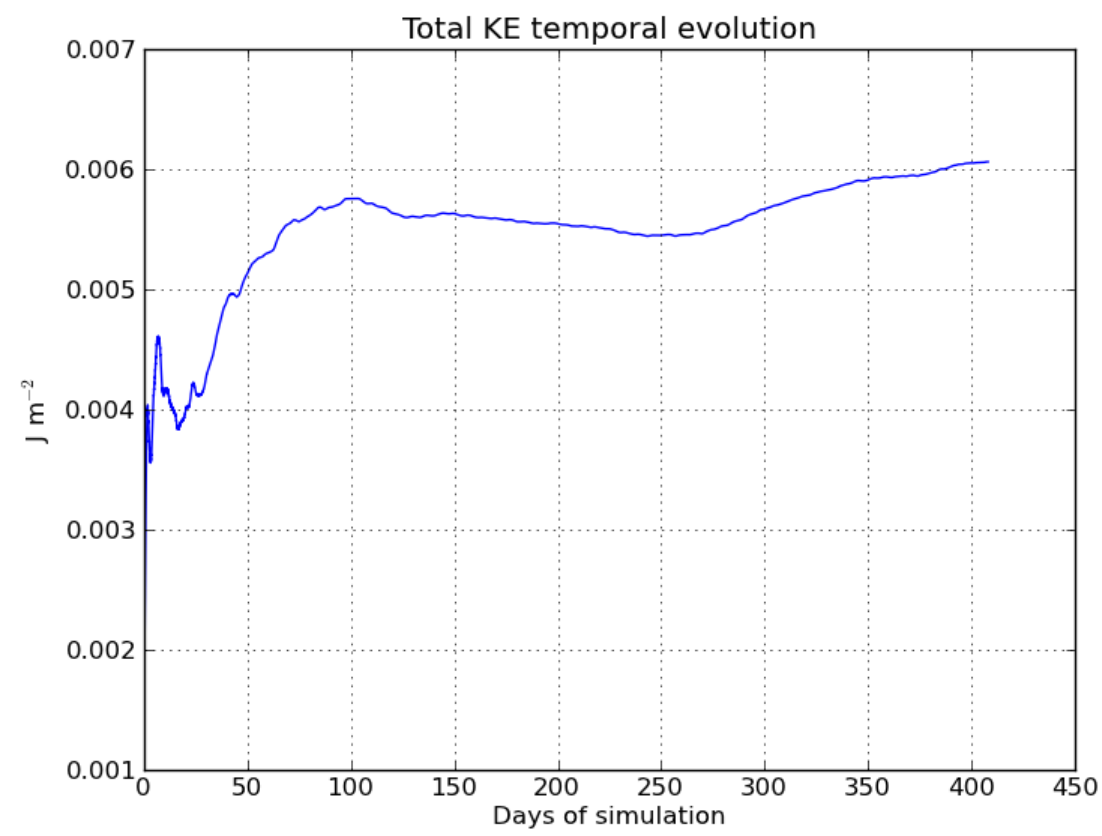

Figure 4.24: Time evolution of domain-averaged eddy kinetic energy for Experiment \# 2.

For this experiment, as done for Experiment \# 1, we explain in detail the generation of the modeled PE based on the $200 \mathrm{~m}$ horizontal velocity and temperature fields (Figure 4.25), cross-eddy velocity sections (Figure 4.26) and cross-eddy temperature sections (Figure 4.27) over the first days of the simulation.

On day 1 , the field is very similar to the initial field, since the flow has not yet had time to adjust. As days go by, the NBUC starts to flow further from the coast on the Potiguar Bight area, and on day 13 an eddy is formed in the region. However, it seems that the current takes a few more days to adjust to the bathymetry (Potiguar Bight), and therefore the nearshore eddy velocities oscillate in a strengthening and weakening cycle, until reaching an equilibrium around day 121. 

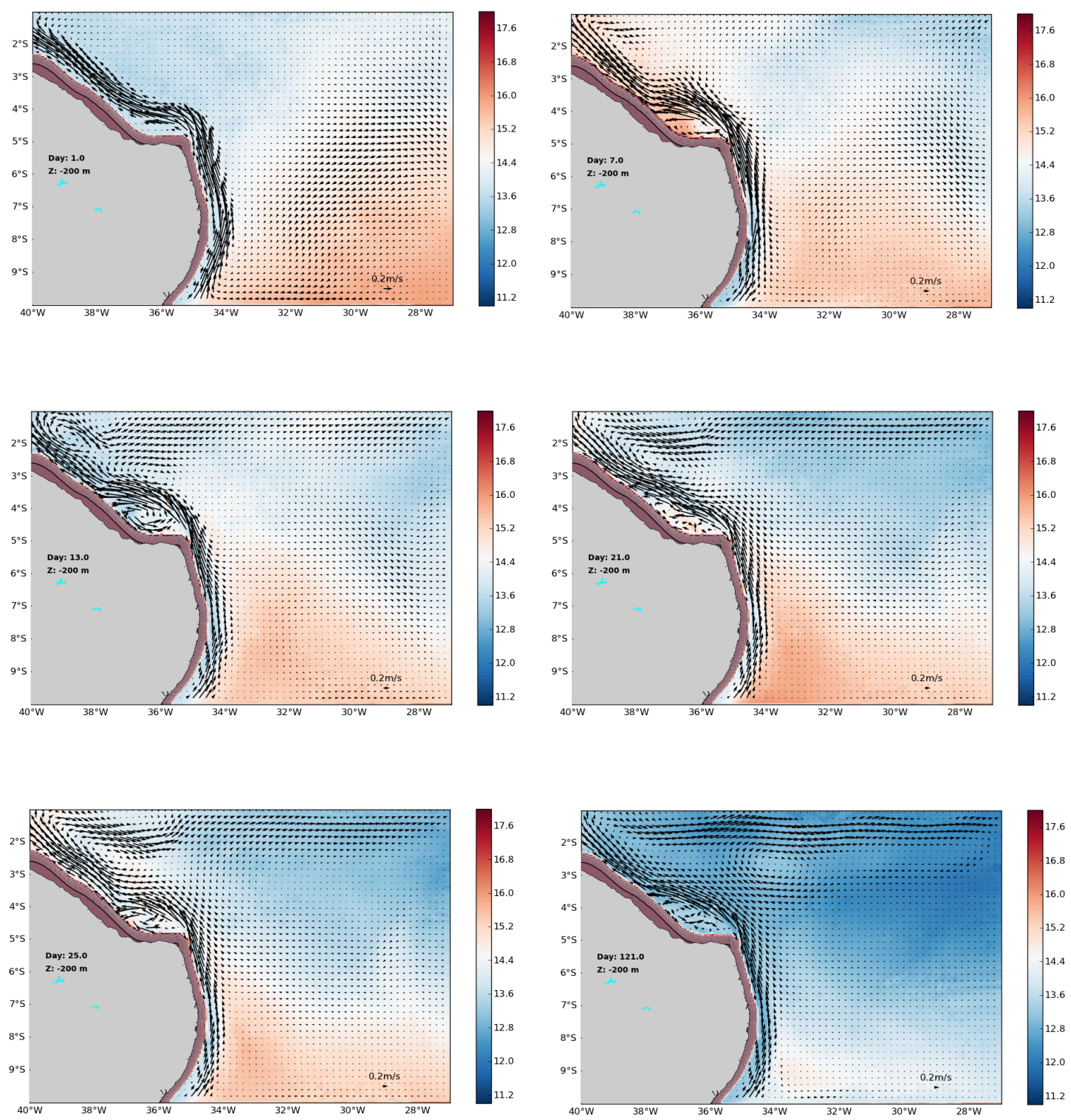

Figure 4.25: Evolution of the temperature and velocity fields at $200 \mathrm{~m}$ during Experiment \# 2 during days 1 (upper left), 7 (upper right), 13 (middle left), 21 (middle right), 25 (lower left), and 121 (lower right). 

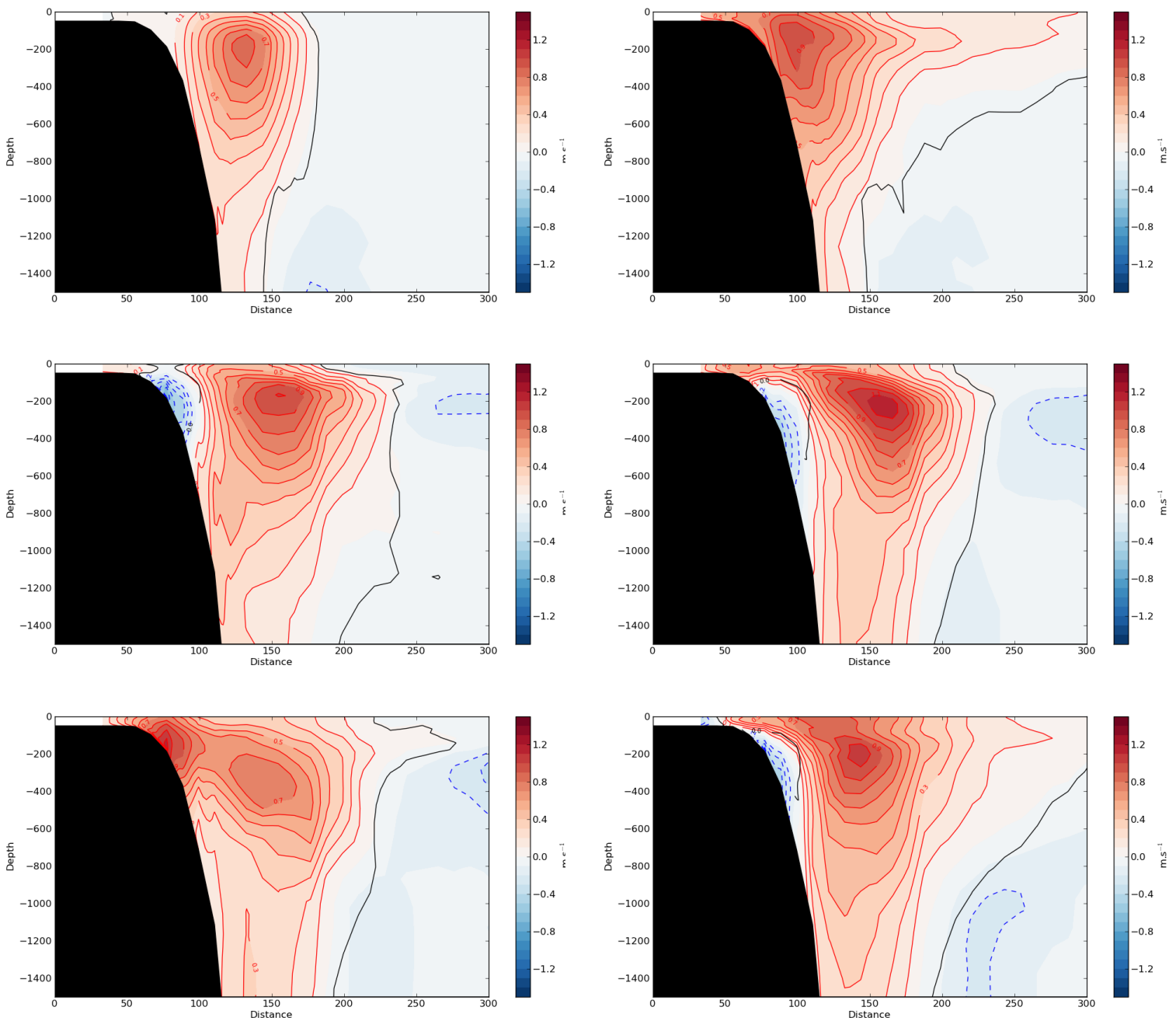

Figure 4.26: Evolution of the velocity field over a cross-eddy section during Experiment \# 2 during days 1 (upper left), 7 (upper right), 13 (middle left), 21 (middle right), 25 (lower left), and 121 (lower right). 
After the dynamical equilibrium is reached, the modeled NBUC offshore of the Potiguar Bight (Figure 4.28) presents realistic maximum velocities, but with a vertical extent, from the surface to $3000 \mathrm{~m}$, larger than indicated by observational studies. This larger vertical extent yields a transport of of about $50 \mathrm{~Sv}$, which is higher than most estimates in the literature. The DWBC, on the other hand, presents realistic velocities and transport, with a vertical extent matching the estimates from previous studies such as Schott et al. (2002).

The mean PE, after stabilization of the kinetic energy (Figure 4.28), has a core of $0.3 \mathrm{~m} . \mathrm{s}^{-1}$ at $250 \mathrm{~m}$, which is in agreement with the observations presented in chapters 2 and 3 . It extends from 50 to $550 \mathrm{~m}$, with major and minor axes measuring $300 \mathrm{~km}$ and $140 \mathrm{~km}$, respectively, which are also realistic according to the observations presented in the previous chapters.

On the first few days of the run, a retroflection on the first $500 \mathrm{~m}$ of the water column is developed. This retroflection remains present during the entire run, between the surface and $500 \mathrm{~m}$ depth, as shown in Figure 4.30. At the surface, besides the retroflection, the signature of the NBUC can be seen, northward of $6^{\circ} \mathrm{S}$. At $500 \mathrm{~m}$, the flow is very similar to the $200 \mathrm{~m}$ flow shown in Figure 4.25; the NBUC following its path northward along the coast, with a retroflection on the northwest corner of the domain, after which the current follows an eastward path paralel to the northern boundary. The flow after the retroflection occasionally is disturbed by wave-like signals, which can generate recirculations, as seen on Figure 4.30, lower panel and reported on observational data by Stramma et al. (2005).

The flow field at $1000 \mathrm{~m}$ (Figure 4.31, top panel) shows the NBUC flowing northward, with maximum velocities of about $0.2 \mathrm{~m} . \mathrm{s}^{-1}$. At the northwest corner, this current turns eastward and seems to permanently recirculate back into the NBUC at about $34^{\circ} \mathrm{W}$. On the rest of the domain there are no significant currents. At $2000 \mathrm{~m}$ (Figure 4.31, bottom panel), the DWBC signature is present, with a realistic path southward, velocity magnitudes and transport, in agreement with previous observational studies in the area (e. g., Schott et al. (2002)). 

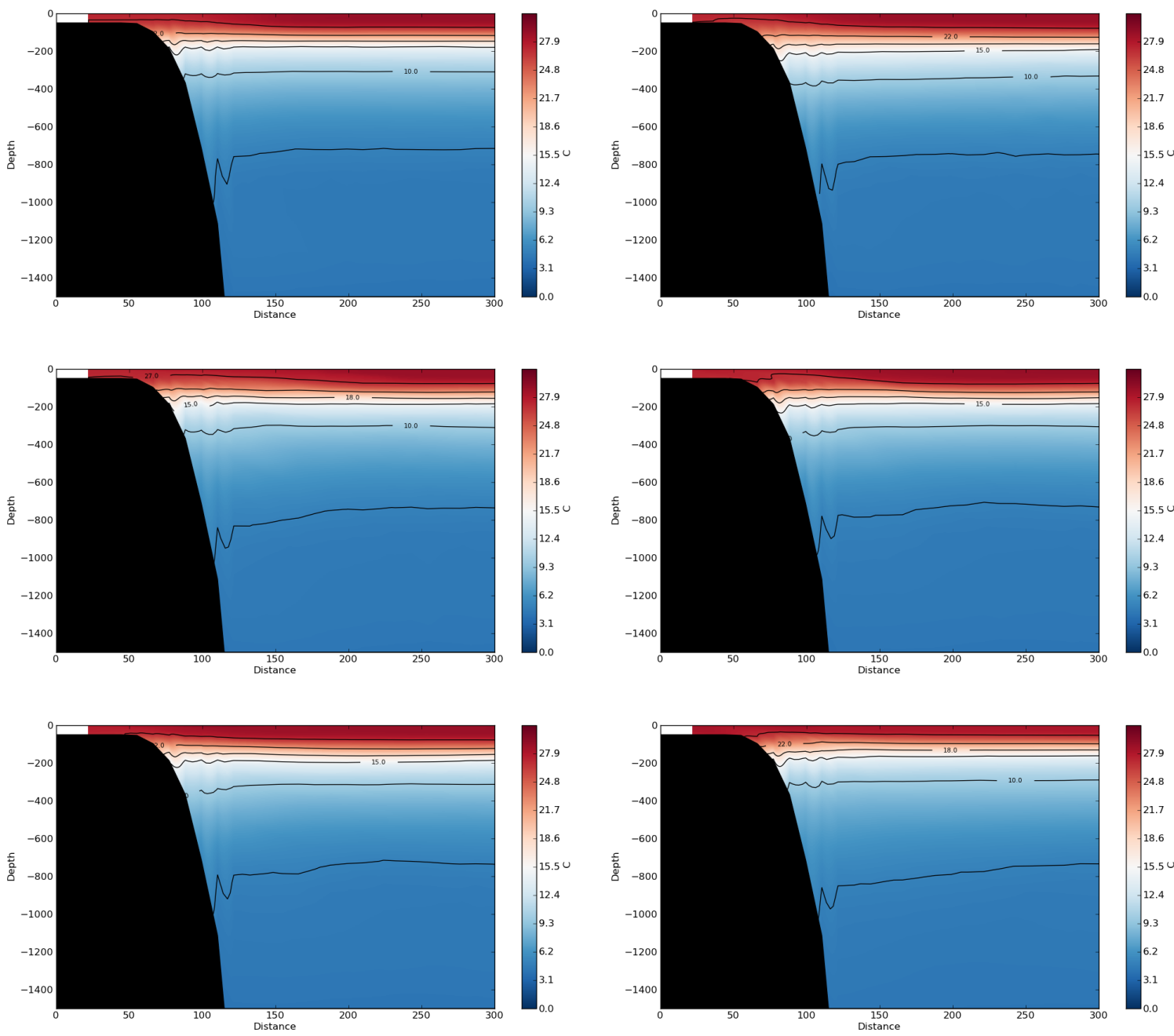

Figure 4.27: Evolution of the temperature field over a cross-eddy section during Experiment \# 2 during days 1 (upper left), 7 (upper right), 13 ( middle left), 21 (middle right), 25 (lower left), and 121 (lower right).

The relevance of the vertical shear on the PE generation and maintenance is investigated in this experiment. The analysis of Experiment \# 1 results show that the PE generation is independent of the presence of the DWBC. Now, we compare the results from both experiments to assess the influence of the vertical shear induced by the DWBC on the generation of the eddy. 


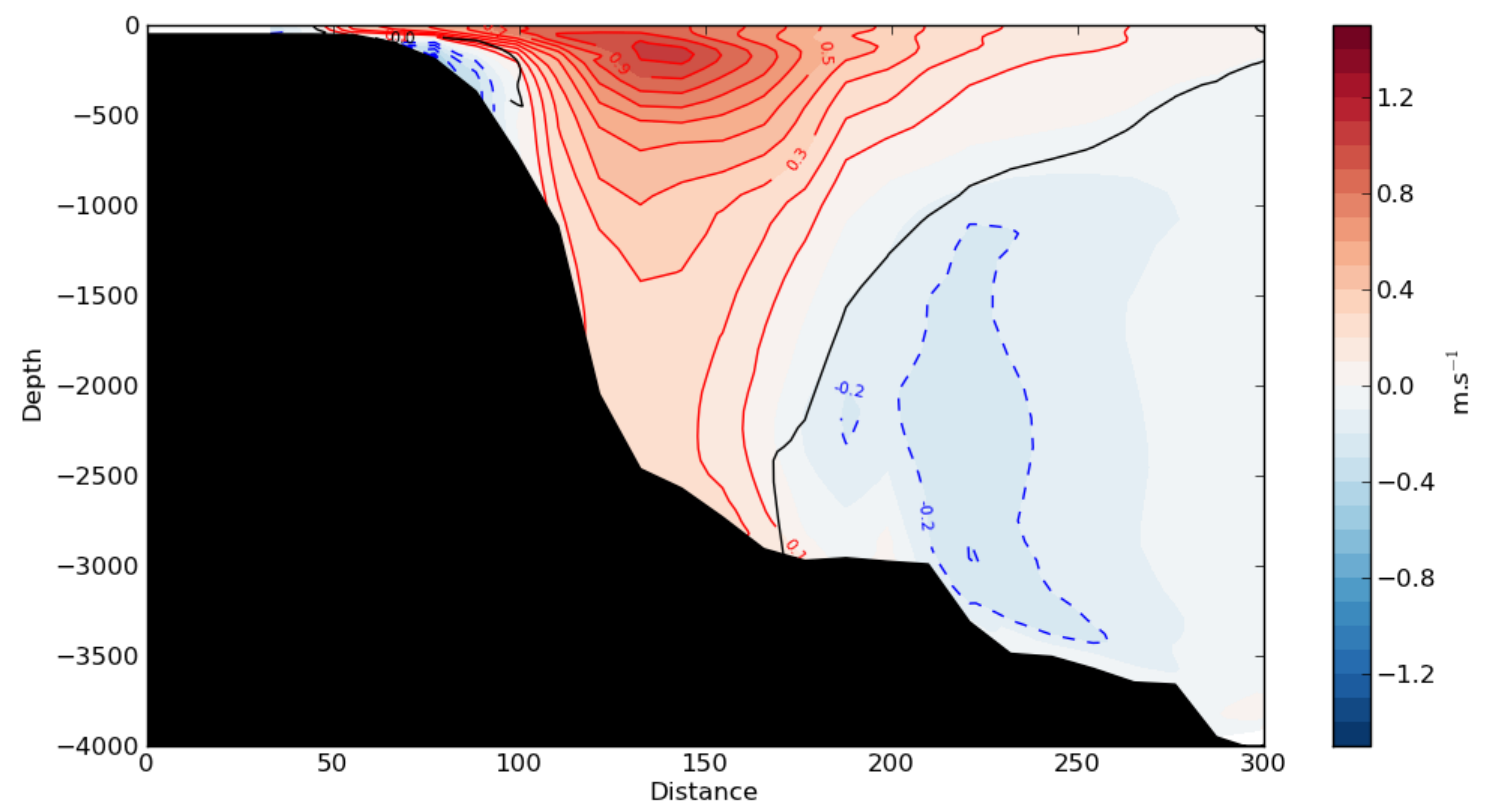

Figure 4.28: Mean cros-section for Experiment \# 2, over days 101-361.

We have seen from the detailed description of the eddy generation process in both simulations that the mechanism for the eddy formation differ between the Experiments. The horizontal evolution of the relative vorticity at $200 \mathrm{~m}$ (Figure 4.32) and the cross-eddy relative vorticity profile at the same depth (Figure 4.33) during the first days of Experiment \# 2 show the process of generation of the PE through a relative vorticity perspective. As during Experiment \# 1, on the first day of the run there is just the relative vorticity gradient associated with the NBUC itself, with the positive patch closest to the coast and the negative one, further away. The cross-eddy relative vorticity shows the same bahavior; a positive patch near the coast, a sign inversion at the location of the NBUC core, and a negative patch of relative vorticity further offshore. During the following few days, the field is disturbed, but not in the same way as in Experiment \# 1; no eddy-pinching is observed. The PE is formed by itself, without a dipole structure, on the Potiguar Bight, and no northwest propagation is seen. Once the eddy is formed, this feature becomes stationary in the area, with a cross-eddy relative vorticity profile similar to that of Experiment \# 1: a negative region close to the coast, representing the portion 


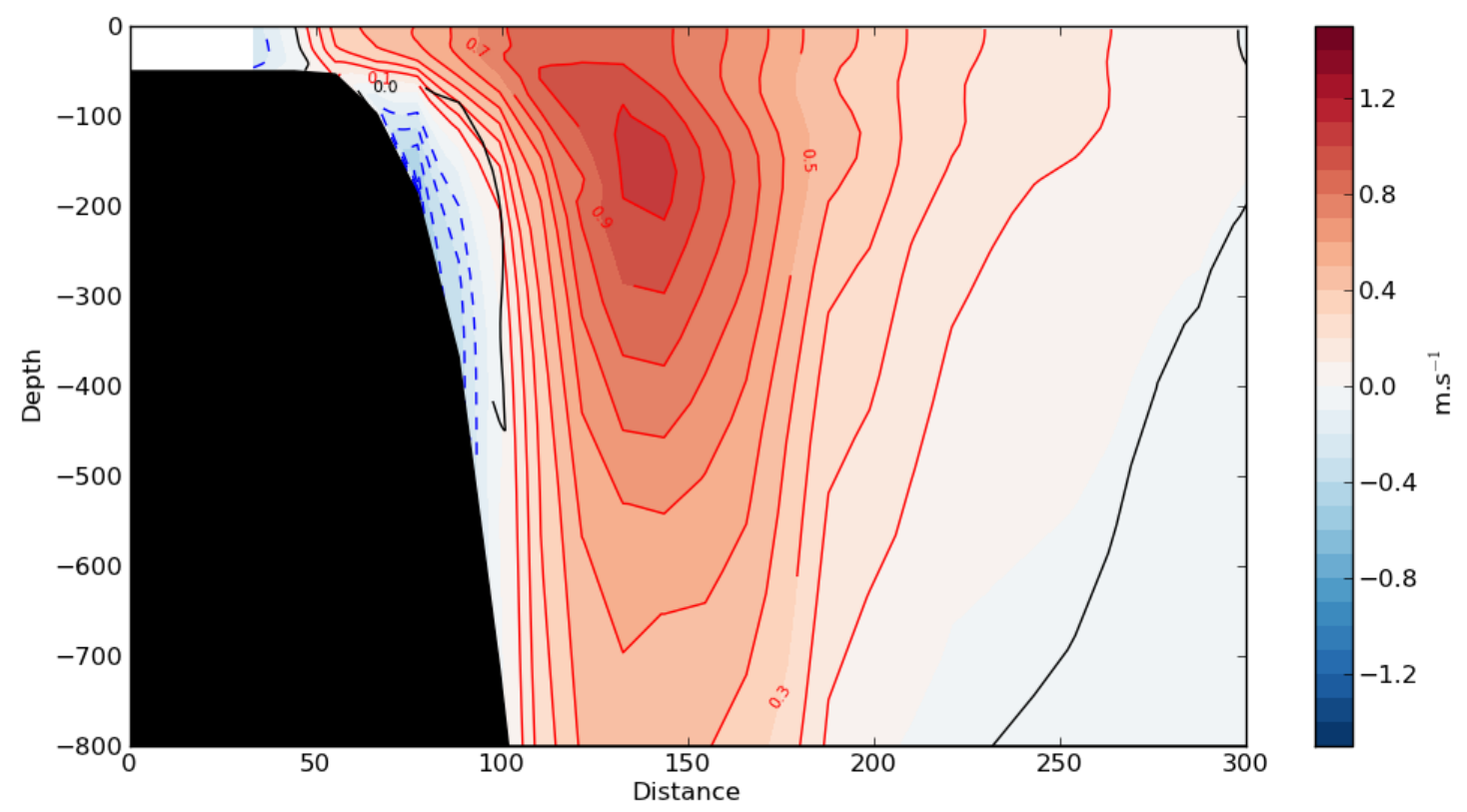

Figure 4.29: Mean cros-section for Experiment \# 2, over days 101-361 (Same as Figure 4.28, different axis).

closest to the shore of the nearshore PE lobe; a positive relative vorticity region due to the increase in (westward) velocities within the eddy, and, at the location of the NBUC core, a sign inversion, followed by a negative patch associated with the decreasing (westward) velocities in the northern direction. 

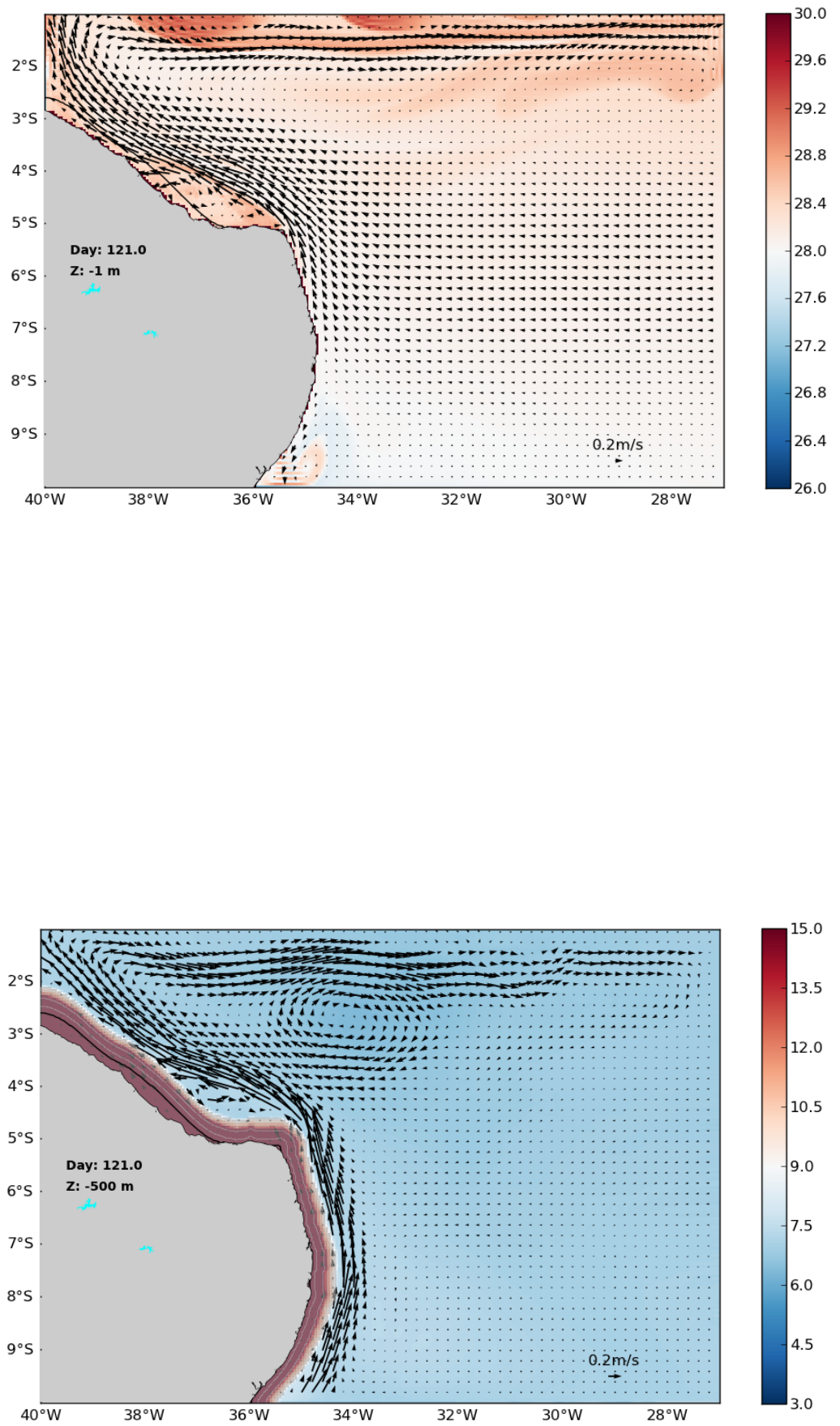

Figure 4.30: Velocity and temperature fields on day 121 at $1 \mathrm{~m}$ (top panel) and $500 \mathrm{~m}$ (bottom panel) for Experiment \# 2. 

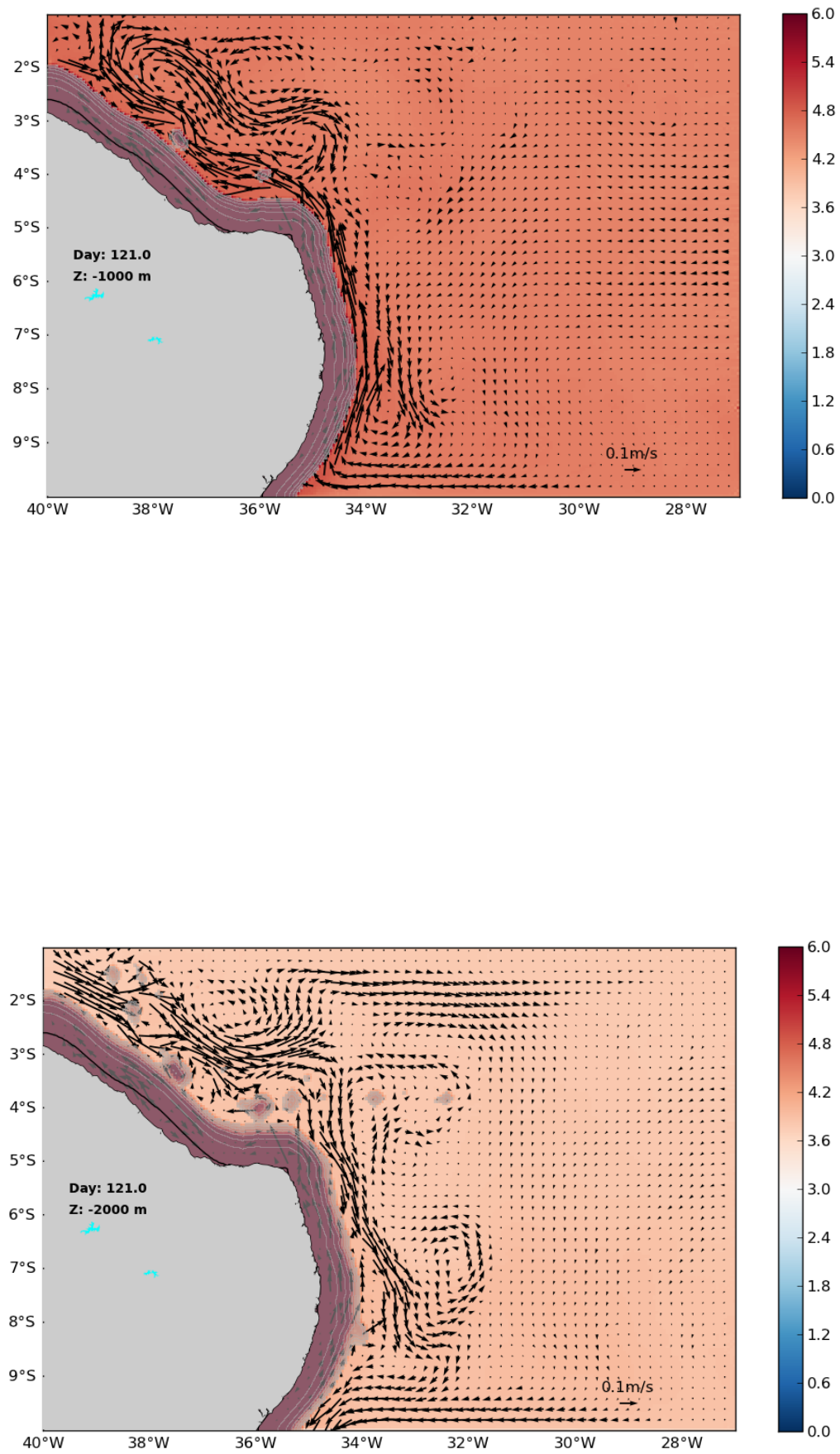

Figure 4.31: Velocity and temperature fields on day 121 at $1000 \mathrm{~m}$ (top panel) and 2000 m (bottom panel) for Experiment \# 2. 

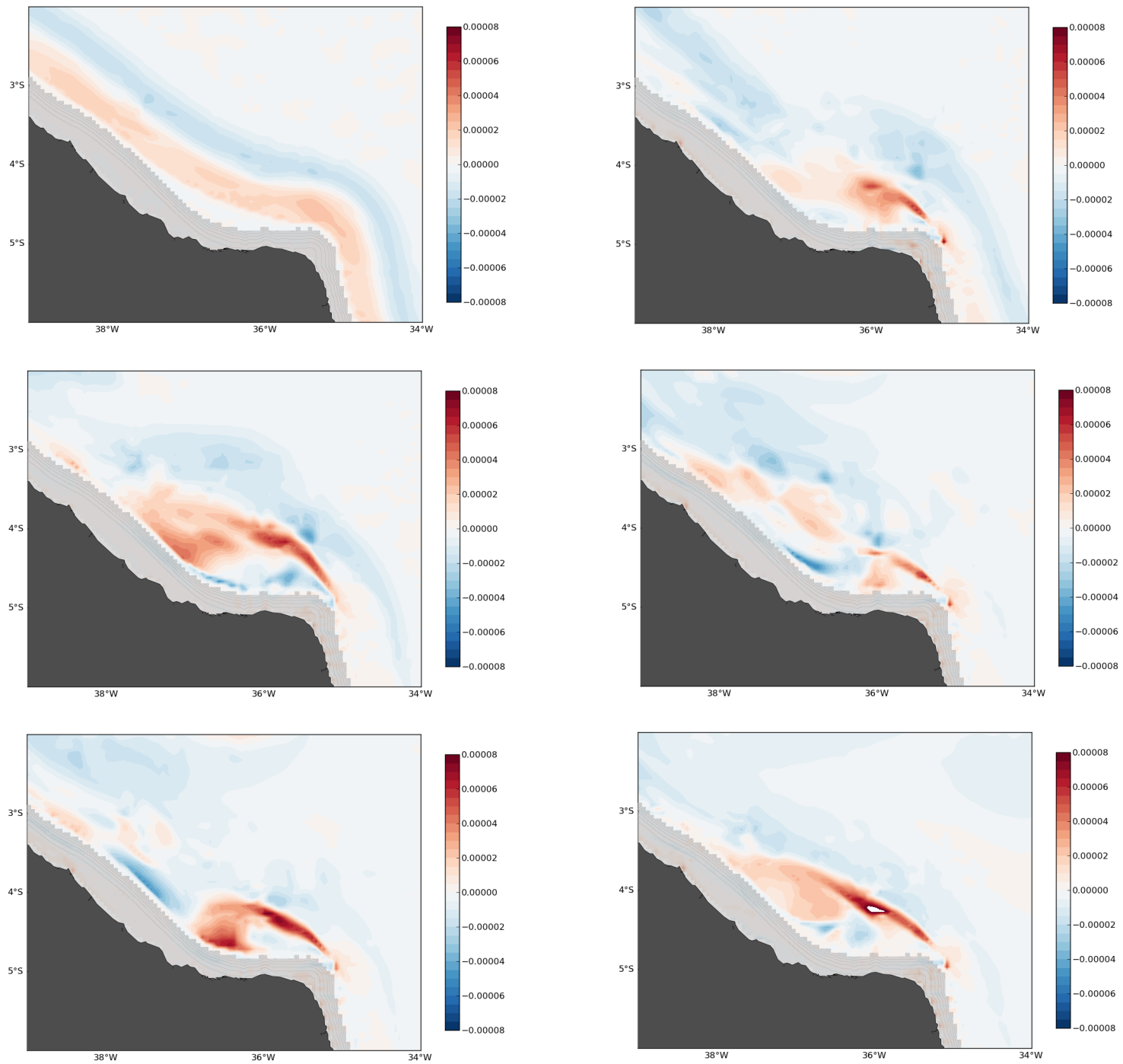

Figure 4.32: Evolution of the relative vorticity field at $200 \mathrm{~m}$ during Experiment \# 2 during days 1 (upper left), 7 (upper right), 13 (middle left), 21 (middle right), 25 (lower left), and 121 (lower right). 

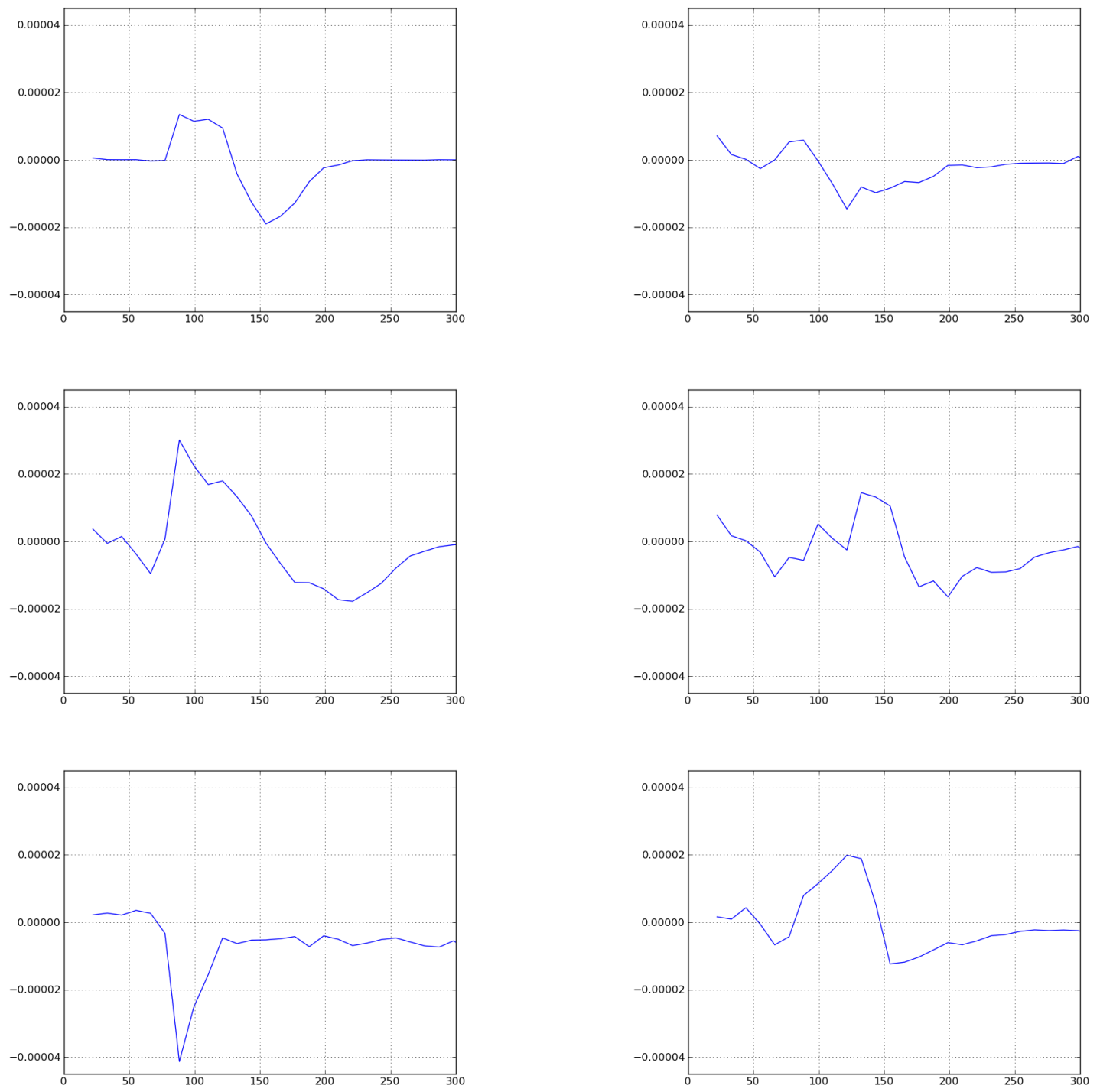

Figure 4.33: Evolution of the relative vorticity field at $200 \mathrm{~m}$ during Experiment \# 2 during days 1 (upper left), 7 (upper right), 13 (middle left), 21 (middle right), 25 (lower left), and 121 (lower right). 


\subsection{Discussion}

The Feature Oriented Regional Modeling System (FORMS) (GANGOPADHYAY and ROBINSON, 2002) is a useful tool that can be applied in a forecasting framework as well as in a process-study aproach. In this dissertation, we apply this methodology with the latter approach, in a similar fashion as Calado et al. (2008); Soutelino et al. (2013). We develop NBUC and DWBC Feature Models based on observational data and information from the scientific literature in order to develop an initial field as realistic as possible for our domain while filtering certain characteristics of the flow which, in spite of being realistic, are not of fundamental importance for the process(es) of interest. After that, we conducted experiments using the Regional Ocean Modeling System (ROMS), similarly to Soutelino et al. (2013).

Here we use the process-study approach to investigate the generation and maintenance of a frontal meander of the North Brazil Undercurrent off the northeastern tip of South America. The initial field for the numerical experiments was developed based on a number of observational studies in the area, as well as in situ data presented in the previous chapters. The developed Feature Models, for the NBUC as well as for the DWBC, seemed to successfully capture the main attributes of the features of interest, being suitable for a process-study assessment of the main characteristics of the flow in the Potiguar Bight.

After a long calibration procedure, stable configurations for the experiments were reached, yielding realistic mean current speeds and transports, as well as current width and location, according to extensive literature (e. g. Silveira et al. (1994); Schott et al. (2002)). Therefore, we regard the model results as realistic, considering the processstudy aproach here employed. The PE was formed in both experiments, with maximum velocity, core depth and size consistent with synoptic observations.

After the PE existence, stationarity and variability were adressed in the previous chapters, we move on to numerical simulations using the process-study aproach in order to examine the formation process of this feature. In this process-study approach we intended to answer two questions. The first one was if the NBUC alone could generate the PE. Our results from Experiment \# 1 show that the PE is successfully reproduced by the dynamical 
interaction between the parameterized NBUC and local topography. According to the results, there is no absolute necessity of the DWBC for the PE to be generated.

The other question we addressed on this study was about how important the vertical shear is on the generation of the PE, related to the existence of the DWBC. Our results from Experiment \# 1 indicate that the DWBC is not essential for the PE generation. However, the slight different characteristics of the eddy generated in each experiment suggest that the shear induced by the DWBC does modify the PE configuration in comparison to the NBUC-only set-up.

Based on the preliminary investigations of the model results presented here, we propose to address a few more scientific issues with the robust numerical set up established in this dissertation. These are identified below as four distinctively separate but linked issues. First, we would like to establish the dominant mechanism of instability for generation of the PE. From a first-order potential vorticity analysis (not presented) of Experiment \#1, it seems barotropic instability, where the pv changes sign across the current (CUSHMAN-ROISIN and BECKERS, 2011) might be the dominant mechanism. However, from Experiment \# 2, the set-up of potential vorticity shows a possible contribution towards modifying the strength and horizontal/vertical extent of the eddy from a baroclinic shear $(\mathrm{dv} / \mathrm{dz})$ perspective between NBUC and DWBC. It is further interesting to note the vertical extent of the simulated NBUC being deeper than observations. This could be an effect of over-smoothing of the topography, or other numerical set-up (mixing, resolution, missing flow structure?). We would also like to investigate the contribution of topographic beta in forming the eddy in a meander-eddy-topography related vorticity analysis, in evaluating and contributing each term of the vorticity balance equation of both of the experiments carried out so far.

Furthermore, the present set-up allows for changing the feature model parameters to modify the relative shear between NBUC and DWBC. Observational evidence from Dangler et al. (2004) suggests that the DWBC might break up into eddies south of $8^{\circ} \mathrm{S}$ when the DWBC is of weaker transport in some seasons. Preliminary evidence of eddy formation from the DWBC is noted from our simulations in Experiment \# 2 south of $8^{\circ} \mathrm{S}$ for a DWBC transport of $20 \mathrm{~Sv}$. We would like to carry out a third experiment with 
a DWBC transport of more than $25 \mathrm{~Sv}$ (also observed at times) to investigate this issue. 


\section{Chapter 5}

\section{Summary and Conclusions}

Over this study we were able to achieve the objectives set on Chapter 1, which were:

- $\quad$ to characterize three-dimensionally the PE based on hydrographic and vesselmounted Acoustic Doppler Current Profiler data

In this dissertation we analyzed in situ and altimetry data, as well as numerical model results, with the intent of describing the main characteristics of a subsurface frontal meander of the NBUC centered at about $4{ }^{\circ} \mathrm{S}, 36.5^{\circ} \mathrm{W}$, hereafter Potiguar Eddy (PE). The PE was first identified in synoptic cruises data, in VMADCP velocity fields. Here we show, from these fields, that this feature was observed during two cruises in different times of different years, suggesting a possibly stationary character. The synoptic data served to characterize spatially and vertically the PE, specially considering its subsurface character, which prevents the study of this feature through altimetric data. The Potiguar Eddy is an elliptically shaped eddy, with major and minor axes of approximately 330 and $130 \mathrm{~km}$, with a subsurface signature. It extends vertically from $100 \mathrm{~m}$ to $400 \mathrm{~m}$, with maximum velocities of $0.6 \mathrm{~m} . \mathrm{s}^{-1}$ and recirculating about $2 \mathrm{~Sv}$ of waters from the NBUC. As a frontal meander of the NBUC, the PE is assymetric, with a stronger and deeperreaching nortwestward (offshore) velocities lobe when compared to the southeastward (nearshore) velocities one. It must be stressed that, being a subsurface feature, there is no signature of the PE at surface near the shelf break; the surface velocity field is persistently northwestward throughout the year. 
- $\quad$ to assess the dynamical regime of the PE based on in situ synoptic data

After obtaining the general synoptic characteristics of the PE, we used the cruises data to make an assessment of the dynamical regime of this feature. A simple calculation of the Rossby and Burger numbers confirmed that the feature of interest is an anticyclone with typical mesoscale characteristics; estimated Rossby number $\approx 0.3$ and Burger number of $\approx 1$, comparable to that estimated by Silveira et al. (2000) for the NBC retroflection deep eddies at $5^{\circ} \mathrm{N}$. Due to the dominant geostrophic balance in the PE, we also found reasonable correspondence between geostrophic velocities within the eddy and global numerical model outputs.

- $\quad$ to analyze the PE persistence/recurrence and its intraseasonal variability through moored current data and altimetry data

After the synoptic description of the PE, we turn to the investigation of its variability and persistence. For that, we use currentmeter mooring data from two lines deployed in the Potiguar Bight, with an 8-month and a 12-month long time series, which confirmed the stationary character of the PE, with a slightly larger vertical extent than that seen on the VMADCP velocity sections.

An EOF analysis of the variability of the moored velocity data revealed two important statistical modes of variability (EOFs); the first with high amplitudes over most of the portion of the water column which corresponds to the PE, and the second, associated with upper-layer processes. The amplitude time series of the first mode of variability is found to have a distinct 25 to 35 day period of oscillation. In order to identify these oscillations, we project the dynamical modes onto the statistical ones, to find that the first EOF is related with the second baroclinic mode. We then hypothesize that second-mode baroclinic waves are reaching the Potiguar Bight and imposing variability of the vertical extent of the PE by deepening and shoaling its lower limit. With the assumption that these oscillations are due to westerward phase-propagating waves, we apply a finite-impulseresponse (FIR) filter to the altimetry data. The goal is to investigate the existence of signals with periods coincident with the ones we found on the EOF amplitude time series. The altimetry filtering revealed 34-day waves in the region, generated west of $15^{\circ} \mathrm{W}$ in 
the Atlantic and propagating westward along $4^{\circ} \mathrm{S}$. These waves are generated during the month of June and reach the Potiguar Bight during September-December, corroborating the high energy patches during these months found in the wavelet analysis conducted on the amplitude time series of the first EOF. In order to further investigate the physical nature this variability, we calculate the wave number from the dispersion equation for second-mode baroclinic Rossby waves. As a result, we obtain the confirmation that the 35-day variability seen on the EOF amplitude time-series is associated with linear free planetary Rossby waves about $800 \mathrm{~km}$ in length, and probably generated by barotropic instability caused by the shear between different zonal currents in the Equatorial Current system.

- To understand the processes involved on the PE persistence/recurrence through longer time scales (semiannual and annual variabilities) via performing analysis of global numerical model outputs

The limited duration of the currentmenter mooring velocity time series prevented the investigation of longer-period variability. Considering that we had found reasonable agreement between the synoptically-observed PE and global numerical model outputs, we analyze the model outputs for lower-frequency variability. We found that the second (first) numerical model statistical mode is associated with the first (second) EOF mode from the observed mooring data. Fitting an annual signal to the amplitude time series, we find that the surface-trapped mode (first EOF mode for model outputs, second EOF mode for observed mooring data) has a strong component of annual period, confirming our suspicions that the surface-trapped mode would be related to upper layer processes and consequently to the trade winds annual cycle over the Atlantic. On the other hand, the second EOF mode is associated with the deep structure variability, and therefore more closely affecting the PE. For this second mode, the annual harmonic amplitude is virtually negligle compared to the intraseasonal variability due to the planetary Rossby waves.

- To address the importance of the vertical shear due to the interaction with the DWBC on the dynamics of the PE through idealized experiments, applying a Feature Model technique in a primitive-equation numerical model. 
In order to develop insight into the PE generation, we apply the Feature Oriented Regional Modeling System (FORMS) (GANGOPADHYAY and ROBINSON, 2002) technique within a process-study framework. The Feature Models for the NBUC and DWBC were defined based on a number of observational studies in the region. The developed Feature Models seemed to successfully capture the main attributes of the features of interest, being suitable for a process-study assessment of the main characteristics of the flow in the Potiguar Bight.

We set up two experiments, i. e., a NBUC-only set up, with a maximum depth of $1500 \mathrm{~m}$, and a NBUC+DWBC set up, with a maximum depth of $5500 \mathrm{~m}$, in order to investigate if (i) the PE would be generated in a velocity field which contained only the NBUC, and (ii) which is the influence, if any, of the NBUC-DWBC shear for the generation and maintenance of the eddy. After a long calibration procedure, stable configurations for the experiments were reached, yielding realistic mean current speeds and transports, as well as current width and location, according to extensive literature (e. g. Silveira et al. (1994); Schott et al. (2002)). Therefore, we regard the model results as realistic, considering the process-study aproach here employed. The Potiguar Eddy was formed in both experiments, with maximum velocity, core depth and size consistent with synoptic observations. As a result, we conclude that the PE can be generated in a velocity field containing only the NBUC; and the DWBC - induced shear seems to play a part on the eddy's caracteristics (vertical extent, maximum velocities, etc), since the PE had a different formation processes in each experiment. 


\section{References}

AVISO. Archiving, Validation and Interpretation of Satellite Oceanographic Data. 2014. Available from Internet: <www.aviso.oceanobs.com $>$.

BRETHERTON, F. P.; RUSS, E. D.; FANDRY, C. B. A. A technique for objective analysis and design of oceanographic experiments applied to mode-73. v. 23, n. 7, p. $559-582,1976$.

CALADO, L.; GANGOPADHYAY, a.; SILVEIRA, I. C. a. da. Feature-oriented regional modeling and simulations (FORMS) for the western South Atlantic: Southeastern Brazil region. Ocean Modelling, p. 48-64, 2008.

COOPER, M.; HAINES, K. Altimetric assimilation with water property conservation. Journal of Geophysical Research, v. 101, p. 1059-1078, 1996.

CUMMINGS, J. A. Operational multivariate ocean data assimilation. Quarterly Journal of Meteorological Society, v. 131, p. 3583-3604, 2005.

CUSHMAN-ROISIN, B.; BECKERS, J. Introduction to Geophysical Fluid Dynamics: Physical and Numerical Aspects. [S.1.]: Elsevier, 2011.

DENGLER, M.; SCHOTT, F.; EDEN, C.; BRANDT, P.; FISCHER, J.; ZANTOPP, R. Break-up of the Atlantic deep western boundary current into eddies at $8^{\circ} \mathrm{S}$. Nature, v. 432, p. 1018-1020, 2004.

FISCHER, J.; SCHOTT, F. Seasonal transport variability of the Deep Western Boundary Current in the equatorial Atlantic. Journal of Geophysical Research, v. 102, p. 27751-27769, 1997.

GANGOPADHYAY, A.; ROBINSON, A. Feature-oriented reginal modelling of oceanic fronts. Dynamics of Atmosphere and Oceans, v. 36, p. 201-232, 2002. 
GANGOPADHYAY, A.; ROBINSON, A.; ARANGO, H. Circulation and dynamics of the Western North Atlantic. I: Multiscale feature models. Journal of Atmospheric and Oceanic Technology, v. 14, p. 1314-1332, 1997.

GANGOPADHYAY, A.; ROBINSON, A. R.; HALEY, P. J.; LESLIE, W. J.; LOZANO, C. J.; BISAGNI, J. J.; YU, Z. Feature Oriented Regional Modeling and Simulation (FORMS) in the Gulf of Maine and Georges Bank. Continental Shelf Research, v. 23, p. 317-353, 2003.

GARRAFFO, Z. D.; JOHNS, W. E.; CHASSIGNET, E. P.; GONI, G. J. North Brazil Current rings and transport of southern waters in a high resolution numerical simulation of the North Atlantic. In: JOCHUM, M.; MALANOTTE-RIZZOLI, P. (Ed.). Interhemispheric Water Exchange. [S.1.]: Elsevier Oceanographic Series, 2003. v. 68.

GARZOLI, S. L.; KATZ, E. J. The Forced Annual Reversal of the Atlantic North Equatorial Countercurrent. Journal of Physical Oceanography, v. 13, p. 2082-2090, 1983.

GOES, M.; MOLINARI, R.; SILVEIRA, I. da; WAINER, I. Retroflections of the North Brazil Current during February 2002. Deep Sea Research Part I: Oceanographic Research Papers, v. 52, n. 4, p. 647-667, abr. 2005. ISSN 09670637. Available from Internet: <http://linkinghub.elsevier.com/retrieve/pii/S0967063704002365>.

HYCOM. HYCOM Global 1/12 Simulation. 2014. Available from Internet: $<$ https://hycom.org/dataserver/glb-analysis $>$.

JOHNS, W. E.; LEE, T. N.; BEARDSLEY, R. C.; CANDELA, J.; LIMEBURNER, R.; CASTRO, B. Annual cycle and variability of the North Brazil Current. Journal of Physical Oceanography, v. 28, p. 103-128, 1998.

JOHNS, W. E.; LEE, T. N.; SCHOTT, F. A.; ZANTOPP, R. J.; EVANS, R. H. The North Brazil Current retroflection: seasonal structure and eddy variability. Journal of Geophysical Research, v. 95, p. 22103-22120, 1990.

JOHNS, W. E.; ZANTOPP, R. J.; GONI, G. J. Cross-gyre transport by North Brazil Current rings. In: JOCHUM, M.; MALANOTTE-RIZZOLI, P. (Ed.). Interhemispheric Water Exchange. [S.1.]: Elsevier Oceanographic Series, 2003. v. 68. 
KATZ, E. J. Dynamic Topography of the Sea Surface in the Equatorial Atlantic. Journal of Marine Research, v. 43, p. 267-288, 1981.

LUMPKIN, R.; GARZOLI, S. L. Near-surface circulation in the Tropical Atlantic Ocean. Deep Sea Research Part I: Oceanographic Research Papers, v. 52, n. 3, p. 495-518, mar. 2005. ISSN 09670637. Available from Internet: $<$ http://linkinghub.elsevier.com/retrieve/pii/S0967063704001694>.

MOLINARI, R. L. Observations of eastward currents in the tropical South Atlantic Ocean: 1978-1980. Journal of Geophysical Research, v. 87, p. 9707-9714, 1982.

PETERSON, R. G.; STRAMMA, L. Upper-level Circulation in the South Atlantic Ocean. Progress in Oceanography, v. 26, p. 1-73, 1991.

PHILANDER, S. G. H.; PACANOWSKI, R. C. The generation of equatorial currents. Journal of Geophysical Research, v. 85, n. C2, p. 1123, 1980. ISSN 0148-0227. Available from Internet: $<$ http://www.agu.org/pubs/crossref/1980/JC085iC02p01123.shtml > .

POLITO, P. S.; LIU, W. T. Global Characterization of Rossby Waves in Several Spectral Bands. Journal of Geophysical Research, v. 108, n. C1, p. 3373, 2003. ISSN 0148-0227. Available from Internet: $<$ http://www.agu.org/pubs/crossref/2003/2002JC001684.shtml >.

PREISENDORFER, R. W. Principal Component Analysis in Meteorology and Oceanography. [S.1.]: Elsevier, 1988. (Developments in Atmospheric Sciences).

RICHARDSON, P. L.; FRATANTONI, D. M. Float trajectories in the deep western boundary current and deep equatorial jets of the tropical Atlantic. Deep Sea Research Part II: Topical Studies in Oceanography, v. 46, n. 1-2, p. 305-333, jan. 1999. ISSN 09670645. Available from Internet: $<$ http://linkinghub.elsevier.com/retrieve/pii/S0967064598001003>.

RODRIGUES, R. R.; ROTHSTEIN, L. M.; WIMBUSH, M. Seasonal Variability of the South Equatorial Current Bifurcation in the Atlantic Ocean: A Numerical Study. Journal of Physical Oceanography, v. 37, n. 1, p. 16-30, jan. 2007. ISSN 0022-3670. Available from Internet: <http://journals.ametsoc.org/doi/abs/10.1175/JPO2983.1>. 
SCHOTT, F.; FISCHER, J.; REPPIN, J.; SEND, U. On mean and seasonal currents and transports at the western boundary of the equatorial Atlantic. Journal of Geophysical Research, v. 98, n. C8, p. 14353, 1993. ISSN 0148-0227. Available from Internet: <http://www.agu.org/pubs/crossref/1993/93JC01287.shtml >.

SCHOTT, F. a.; BRANDT, P.; HAMANN, M.; FISCHER, J.; STRAMMA, L. On the boundary flow off Brazil at $5-10^{\circ} \mathrm{S}$ and its connection to the interior tropical Atlantic. Geophysical Research Letters, v. 29, n. 17, p. 1840, 2002. ISSN 0094-8276. Available from Internet: <http://www.agu.org/pubs/crossref/2002/2002GL014786.shtml>.

SCHOTT, F. a.; DENGLER, M.; BRANDT, P.; AFFLER, K.; FISCHER, J.; BOURLES, B.; GORIOU, Y.; MOLINARI, R. L.; RHEIN, M. The zonal currents and transports at $35^{\circ} \mathrm{W}$ in the tropical Atlantic. Geophysical Research Letters, v. 30, n. 7, p. 1349, 2003. ISSN 0094-8276. Available from Internet: $<$ http://www.agu.org/pubs/crossref/2003/2002GL016849.shtml $>$.

SCHOTT, F. a.; DENGLER, M.; ZANTOPP, R. J.; STRAMMA, L.; FISCHER, J.; BRANDT, P. The Shallow and Deep Western Boundary Circulation of the South Atlantic at $5^{\circ}-11^{\circ}$ S. Journal of Physical Oceanography, v. 35, p. 2031-2053, 2005.

SCHOTT, F. A.; FISCHER, J.; STRAMMA, L. Transports and pathways of the upper-layer circulation in the western tropical Atlantic. Journal of Physical Oceanography, v. 28, p. 1904-1928, 1998.

SCHOTT, F. A.; STRAMMA, L.; FISCHER, J. The warm water inflow into the western tropical Atlantic boundary regime, spring 1994 waters of the equatorial circulation. Journal of Geophyscal Research, v. 100, p. 24745-24760, 1995.

SHCHEPETKIN, A.; MCWILLIAMS, J. The regional ocean modelling system (roms): a split-explicit, free-surface, topography-following-coordinate ocean model. Ocean Modelling, v. 9, p. 347-404, 2005.

SILVEIRA, I. C. A. da; BROWN, W. S.; FLIERL, G. R. Dynamics of the North Brazil Current retroflection region from the Western Tropical Atlantic Experiment observations. Journal of Geophysical Research, v. 105, p. 28559-28583, 2000. 
SILVEIRA, I. C. A. da; LIMA, J. A. M.; SCHMIDT, A. C. K.; CECCOPIERI, W.; SARTORI, A.; FRANSCISCO, C. P. F.; FONTES, R. F. C. Is the meander growth in the Brazil Current system off Southeast Brazil due to baroclinic instability? Dynamics of Atmospheres and Oceans, v. 45, n. 3-4, p. 187-207, ago. 2008. ISSN 03770265. Available from Internet: <http://linkinghub.elsevier.com/retrieve/pii/S037702650800033X >.

SILVEIRA, I. C. A. da; MIRANDA, L. B.; BROWN, W. S. On the origins of the North Brazil Current. Journal of Geophysical Research, v. 99, p. 22501-22512, 1994.

SOUTELINO, R. G.; GANGOPADHYAY, A.; SILVEIRA, I. C. A. The roles of vertical shear and topography on the eddy formation near the site of origin of the Brazil Current. Continental Shelf Research, v. 70, p. 46-60, 2013.

STRAMMA, L. Geostrophic transport of the south equatorial current in the atlantic. Journal of Marine Research, v. 49(2), p. 281-294, 1991.

STRAMMA, L.; FISCHER, J.; REPPIN, J. The North Brazil Undercurrent. Deep Sea Research Part I: Oceanographic Research Papers, v. 42, n. 5, p. 773-795, maio 1995. ISSN 09670637. Available from Internet: $<$ http://linkinghub.elsevier.com/retrieve/pii/096706379500014W $>$.

STRAMMA, L.; RHEIN, M.; BRANDT, P.; DENGLER, M.; BöNING, C.; WALTER, M. Upper ocean circulation in the western tropical Atlantic in Boreal fall 2000. Deep-sea Research I, v. 52, p. 221-240, 2005.

STRAMMA, L.; SCHOTT, F. A. The mean flow field of the tropical Atlantic Ocean. Deep-sea Research II, v. 46, p. 279-303, 1999.

URBANO, D. F.; ALMEIDA, R. A. F. de; NOBRE, P. Equatorial Undercurrent and North Equatorial Countercurrent at $38^{\circ} \mathrm{W}$ : A new perspective from direct velocity data. Journal of Geophysical Research, v. 113, p. C04041, 2008.

VELEDA, D.; ARAUJO, M.; ZANTOPP, R.; MONTAGNE, R. Intraseasonal variability of the North Brazil Undercurrent forced by remote winds. Journal of Geophysical Research, v. 117, n. C11, p. C11024, nov. 2012. ISSN 0148-0227. Available from Internet: < http://www.agu.org/pubs/crossref/2012/2012JC008392.shtml>. 
WOA. World Ocean Atlas 2013. 2013. Available from Internet: $<$ http://www.nodc.noaa.gov/OC5/woa13> 